\title{
$\frac{((x))}{\log }$
}

INSTITUTO DE PESQUISAS ENERGÉTICAS E NUCLEARES

Autarquia associada à Universidade de São Paulo

\section{REDUÇÃO DAS EMISSÕES DE GASES DE EFEITO ESTUFA LISTADOS NO PROTOCOLO DE QUIOTO PELO APROVEITAMENTO DO GÁS GERADO EM ATERROS SANITÁRIOS UTILIZANDO CÉLULAS A COMBUSTÍVEL DE ÓXIDO SÓLIDO}

Estudo de caso do aterro municipal de Santo André - S.P. - Brasil

ALEXANDRE GELLERT PARIS

Dissertação apresentada como parte dos requisitos para a obtenção do Grau de Mestre em Ciências na Área de Tecnologia Nuclear - Materiais.

Orientadora:

$\mathrm{Dr}^{\mathrm{a}}$. Emília Satoshi Miyamaru Seo

SÃO PAULO 
INSTITUTO DE PESQUISAS ENERGÉTICAS E NUCLEARES

Autarquia associada à Universidade de São Paulo

\begin{abstract}
REDUÇÃO DAS EMISSÕES DE GASES DE EFEITO ESTUFA LISTADOS NO PROTOCOLO DE QUIOTO PELO APROVEITAMENTO DO GÁS GERADO EM ATERROS SANITÁRIOS UTILIZANDO CÉLULAS A COMBUSTÍVEL DE ÓXIDO SÓLIDO
\end{abstract}

Estudo de caso do aterro municipal de Santo André - S.P. - Brasil

\title{
ALEXANDRE GELLERT PARIS
}

Dissertação apresentada como parte dos requisitos para a obtenção do Grau de Mestre em Ciências na Área de Tecnologia Nuclear - Materiais.

Orientadora:

$\mathrm{Dr}^{\mathrm{a}}$. Emília Satoshi Miyamaru Seo

Nome da Linha de Pesquisa: Células a Combustível 


\section{DEDICATÓRIA}

À minha família, meus pais Miriam e Ricardo e meu irmão Guga, meus avós.

À Juliana. 


\section{AGRADECIMENTOS}

Agradeço à minha orientadora, professora Emília Seo, pela dedicação e por acreditar na importância técnica e científica deste trabalho, e principalmente por acreditar meu potencial como aluno e profissional.

Aos professores das disciplinas de pós-graduação da USP José Goldemberg, Oswaldo Lucon, Fernando Amaral de Almeida Prado Junior, Marcos Antônio Saidel, Wagner dos Santos Oliveira, Marcelo Linardi, Jose Mestnik Filho, Afonso Rodrigues de Aquino, Alberto Todo, Gaianê Sabundjian, Iraci Martinez e Ricardo Leal.

Aos colegas do Ipen, Rubens Chiba, Reinaldo A. Vargas, Ranieri A. Rodrigues, Marco Andreoli, Antonio Carlos Silva, Luiz F. Setz, Paulo Bernardi, Caterina Velleca Bernardi, Amanda Yamamura, Aretha Sanchez, Cristiane Manetti, Raquel Monteiro e Ivan Santos.

Toda a equipe de sustentabilidade da PricewaterhouseCoopers, Rogério Gollo, Ernesto Cavasin, Ricardo Zibas, Luzia Hirata, Carlos Alberto, Carlos Rossin, Ana Campelli, Marcelo Freire, Thiago Teixeira, Caio Tucunduva, Leonardo Costa, Dominic Schmal, Joyce Fernandes, Karina Anhe, Fernando Abreu, Daniela Ariolli, Luciana Miura, Tatiana Campos, Ana Lia Touso, Thomas Poineaud e Maria Zampieri.

À Luiz Gylvan Meira Filho, Paulo Vanca, Marco Antonio Fujihara e Carlos Henrique Delpupo.

Ao SEMASA (Serviço Municipal de Saneamento Ambiental de Santo André), especialmente Pedro Henrique Milani diretor do Departamento de Resíduos Sólidos (DRS), Eliene Moraes e Fernado Arlei Cruseiro. 
"e a vida é vivida em detalhes inimagináveis e alcançáveis como naves e aves que sobrevoam e se debatem numa gaiola atmosférica” K.RAM.K cara feia pra espantar maus espíritos Santo André, 1997 


\title{
REDUÇÃO DAS EMISSÕES DE GASES DE EFEITO ESTUFA LISTADOS NO PROTOCOLO DE QUIOTO PELO APROVEITAMENTO DO GÁS GERADO EM ATERROS SANITÁRIOS UTILIZANDO CÉLULAS A COMBUSTÍVEL DE ÓXIDO SÓLIDO
}

\author{
ALEXANDRE GELLERT PARIS
}

\begin{abstract}
RESUMO
Nos últimos anos, o Protocolo de Quioto é um assunto que vem sendo bastante discutido, inicialmente, em um nicho restrito, principalmente os acadêmicos e profissionais ligados à área de mudanças climáticas. Com sua entrada em vigor, em fevereiro de 2005, o assunto rompeu as fronteiras iniciais e ganhou espaço na mídia, de forma que hoje é comum assistir as reportagens sobre o mesmo nos meios de comunicação de massa. Dada a ampla divulgação do tema, o presente trabalho pretende discutir a utilização de um mecanismo de flexibilização previsto nesse protocolo, para contribuir na viabilização do aproveitamento do gás gerado em aterros sanitários utilizando células a combustível de óxido sólido. Dentre os três mecanismos apresentados no Protocolo de Quioto, o mecanismo de desenvolvimento limpo (MDL) disposto pelo artigo 12, é o único que pode ser implementado por países que não estão listados no anexo I, caso do Brasil. Por outro lado, a questão da gestão de resíduos sólidos no Brasil é extremamente deficitária. Apesar de ser ilegal, a maioria dos resíduos é destinada para "lixões", degradando tanto o meio ambiente natural como as comunidades próximas e conseqüentemente, emitindo gases de efeito estufa (GEE), que estão cada vez mais desregulando o sistema climático global. A remediação ambiental dessas áreas contaminadas por esses lixões e construção de aterros sanitários para substituí-los, entendendo o aterro sanitário como um bioreator, e a utilização do biogás para a geração de energia pode contribuir para melhorar o quadro em que nos encontramos. A utilização da tecnologia alternativa inovadora de células a combustível de óxido sólido (SOFC - Solid Oxide Fuel Cell) ao invés de uma convencional trará ganhos tanto ambientais como em eficiência energética. Dentre as várias barreiras para uma maior utilização das células a combustível, o custo é apontado como a principal. Neste contexto, a SOFC é a que possui o maior custo dentro de todas as tecnologias de células a combustível, e neste sentido, a utilização do MDL pode contribuir para sua viabilização. Foram elaborados cenários para as potências instaladas de $250 \mathrm{~kW}, 500 \mathrm{~kW}, 1.000 \mathrm{~kW}, 5.000 \mathrm{~kW}$ e $10.000 \mathrm{~kW}$ utilizando o biogás do Aterro Municipal de Santo André. Os cálculos foram realizados de acordo com as duas modulações de cálculo da ACM0002 para o fator de emissão, sendo ex ante e ex post. Comparando os custos para a instalação das potências estudadas com os cálculos de reduções de emissões, que constituem uma potencial receita, os custos se apresentam superiores; entretanto, outras receitas advindas da venda da energia e receitas da disposição dos resíduos sólidos devem ser levados em consideração na tomada de decisão de investimento em projetos dessa natureza.
\end{abstract}




\title{
REDUCTION OF GREENHOUSE GASES EMISSIONS LISTED IN THE KYOTO PROTOCOL BY THE UTILIZATION OF LANDFILL GAS USING SOLID OXIDE FUEL CELLS
}

\begin{abstract}
ALEXANDRE GELLERT PARIS
ABSTRACT

In the last few years, the Kyoto Protocol had been a subject very debated, at first, in a restricted niche, manly academics and professionals related to the area of climate changes. On $16^{\text {th }}$ February 2005 the Kyoto Protocol entered into force and with this a lot of publicity all over the world, so today is common to hear about it at the mass communications medias. The extension of the subject is broad, this work discuss the utilization of one the Kyoto's flexibility mechanisms, to contribute to financing the use of the landfill gas in the solid oxide fuel cells. Among the three mechanisms presented in the Kyoto Protocol, the clean development mechanism (CDM) in article 12 , is the only one that can be implemented by non-Annex I countries, the case of Brazil. In other hand, the issue of solid waste in Brazil is critical. Even being illegal, most of the solid waste goes to uncontrolled areas in open air places "lixões", causing degradation of the environment and the communities around this areas, and also emission of green house gases (GHG), deregulating the global climate system. Decontaminate this areas and the construction of landfills to replace than, considering the landfill as a bioreactor, and the utilization of the biogas to generate power can improve nowadays picture that we are facing. The utilization of an innovative alternative technology as the solid oxide fuel cell (SOFC) instead the conventional technologies will be more efficient and environmentally better. Among other barriers the cost is pointed as the biggest. In this context, the SOFC is the most expensive fuel cell, so the utilization of CDM can contribute to finance the application of this technology. Scenarios were made of $250 \mathrm{~kW}, 500 \mathrm{~kW}, 1,000 \mathrm{~kW}, 5,000 \mathrm{~kW}$ and 10,000 kW of installed power using biogas from the Municipal Landfill of Santo André. The calculations of the emission factor were done ex ante and ex post according to ACM0002. Comparing the costs of the installed power studied and the calculation of the emission reduction, a potential income, the costs are superior, however, other incomes from the selling of energy and the disposal of solid waste most be taken into account in the process of decision of this type of projects.
\end{abstract}




\section{SUMÁRIO}

Página

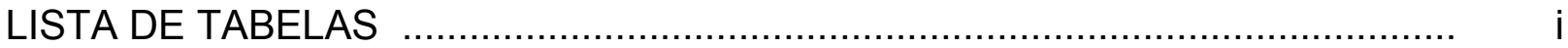

LISTA DE FIGURAS ................................................................................. iii

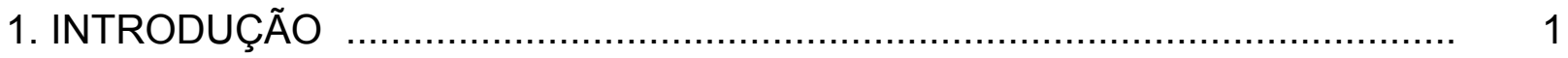

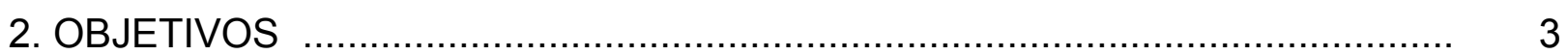

3. FUNDAMENTAÇÃO TEÓRICA …................................................................. 4

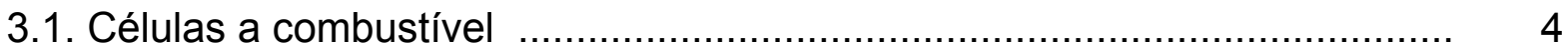

3.1.1. Célula a combustível de óxido sólido …………………………......... 7

3.1.2. O Hidrogênio ........................................................................ 10

3.1.3. Geração de energia distribuída ........................................................... 13

3.1.4. Células a combustível a biocombustíveis ........................................ 16

3.2. Mudanças climáticas ........................................................................ 20

3.2.1. Painel Intergovernamental sobre Mudança do Clima ........................ 25

3.2.2. Convenção-Quadro das Nações Unidas sobre Mudança do Clima (CQNUMC)

3.2.3 Protocolo de Quioto ……………………….............................. 33

3.2.4. Mecanismo de Desenvolvimento Limpo (MDL) .............................. 34

3.2.5. Projetos de MDL em aterros sanitários .............................................. 37

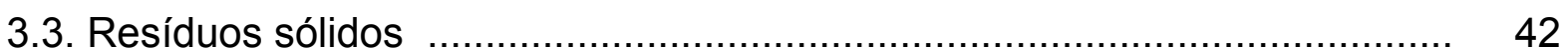

3.3.1. Disposição de resíduos sólidos no Brasil ........................................ 42

3.3.2. Aterros sanitários ……….................................................... 43

3.3.3. Gás de aterro sanitário ………………………......................... 44

3.3.4. Produção de energia elétrica e térmica ............................................. 44

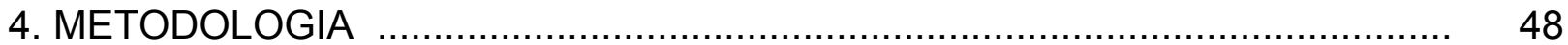

4.1. Sobre o município de Santo André - região delimitada para o estudo de caso

4.2. Aterro sanitário municipal - objeto do estudo de caso

4.3. ACM0001 - Metodologia consolidada de linha de base e monitoramentos para atividades de projetos com gas de aterro 
4.4. ACM0002 - Metodologia consolidada de linha de base para geração de

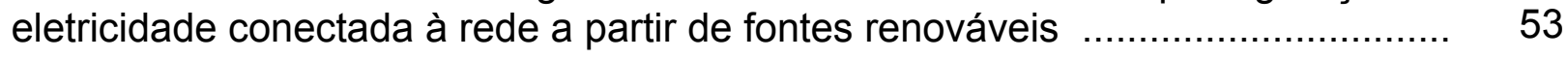

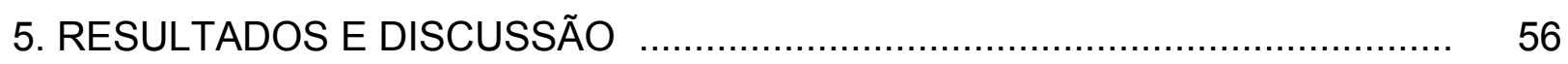

5.1. Estimativas de Reduções Certificadas de Emissão (RCEs) .................. 56

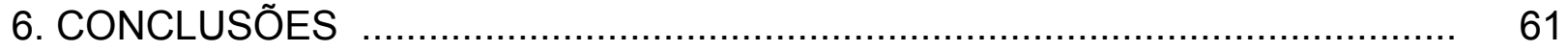

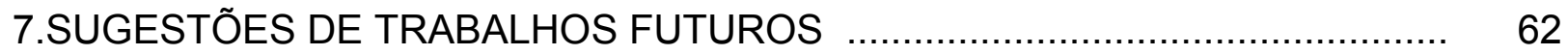

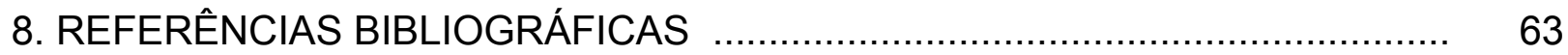

ANEXO A - ACM0001 - Metodologia consolidada de linha de base para atividades de projetos com gás de aterro ........................................................

ANEXO B - ACM0002 - Metodologia consolidada de linha de base para a geração de eletricidade conectada à rede a partir de fontes renováveis

ANEXO C - Tool to determine methane emissions avoided from dumping waste

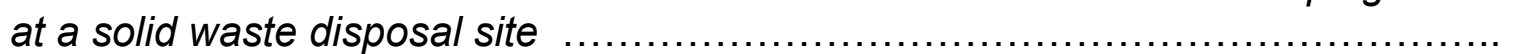

APÊNDICE A - Memória de cálculo para as emissões reduzidas do aterro sanitário de Santo André através da destruição do metano

APÊNDICE B - Memória de cálculo para as emissões reduzidas do aterro sanitário de Santo André pelo deslocamento do despacho 


\section{LISTA DE TABELAS}

TABELA 1 Principais tipos de Células a Combustível .................................. 5

TABELA 2 SOFCs testadas pela Siemens-Westinghouse …....................... 8

TABELA 3 Processos, insumos químicos e energéticos para produção de hidrogênio no Brasil

TABELA 4 Projetos brasileiros com células a combustível para geração estacionária

TABELA 5

Adequação das células a combustível para combustíveis de origem de biomassa

TABELA 6 Impactos de compostos gasosos comuns nos quatros tipos de células a combustível

TABELA 7 Pontos de atenção nos diferentes tipos de células a combustível

Expressões utilizadas para indicar a probabilidade avaliada, com

TABELA 8 base na opinião de especialistas, de uma conseqüência ou resultado, para os relatórios do IPCC

TABELA 9 Possíveis impactos decorrentes das mudanças climáticas ......... 28

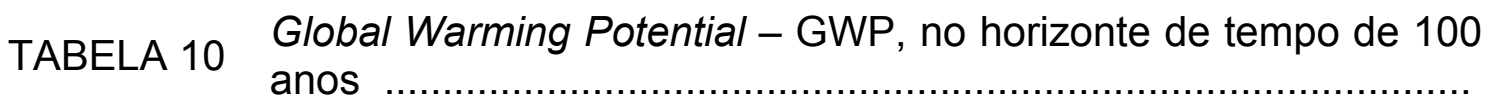

TABELA 11 Lista das COPs e MOPs ………….................................... 33

TABELA 12 Comissão Interministerial de Mudança Global do Clima (CIMGC) 36

TABELA 13 Distribuição das atividades de projeto no Brasil por tipo de projeto

TABELA 14 Histórico da metodologia ACM0001 ........................................ 52

TABELA 15 Histórico da metodologia ACM0002 .......................................... 53

TABELA 16 Fatores de emissão do SIN por submercado .............................. 54

TABELA 17 Fatores de emissão de paises da América do Sul ....................... 54

TABELA 18 Fatores de emissão para a modulação ex ante ................................. 55 
TABELA 19 Estimativa das emissões de GEE do aterro sanitário de Santo André através da destruição do metano

Reduções de emissão do aterro sanitário de Santo André pelo

TABELA 20 deslocamento do despacho no cenário de utilização de SOFC de $250 \mathrm{~kW}$

Reduções de emissão do aterro sanitário de Santo André pelo

TABELA 21 deslocamento do despacho no cenário de utilização de SOFC de $500 \mathrm{~kW}$

Reduções de emissão do aterro sanitário de Santo André pelo

TABELA 22 deslocamento do despacho no cenário de utilização de SOFC de $1.000 \mathrm{~kW}$

Reduções de emissão do aterro sanitário de Santo André pelo

TABELA 23 deslocamento do despacho no cenário de utilização de SOFC de $5.000 \mathrm{~kW}$

Reduções de emissão do aterro sanitário de Santo André pelo

TABELA 24 deslocamento do despacho no cenário de utilização de SOFC de $10.000 \mathrm{~kW}$

TABELA 25 Custos das SOFC nos cenários desenvolvidos 


\section{LISTA DE FIGURAS}

$\begin{array}{lllll}\text { FIGURA } 1 & \text { Esquema simplificado de uma célula a combustível tipo SOFC } & \ldots & 7\end{array}$

FIGURA 2 Exemplos de SOFC de configuração geométrica planar $\ldots \ldots \ldots \ldots \ldots . . . . .9$

FIGURA 3 Protótipos de SOFC tubular da Siemens-Westinghouse $\ldots \ldots \ldots \ldots \ldots . . . . . .9$

FIGURA 4 Mudanças na densidade de corrente em uma SOFC com uma

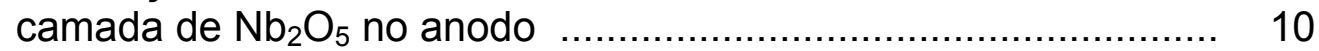

FIGURA 5 Produção mundial de hidrogênio …......................................... 11

FIGURA 6 Sistema centralizado e Geração distribuída $\quad$............................... 14

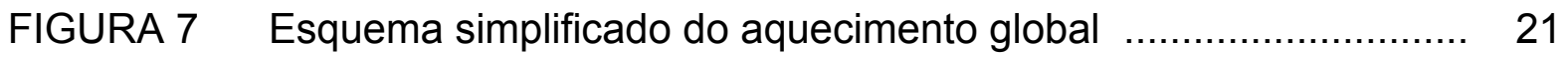

FIGURA 8 Mudanças nos gases de efeito estufa a partir de dados de testemunho de gelo e dados modernos .................................... 22

FIGURA 9 Médias de vários modelos e faixas avaliadas para o aquecimento

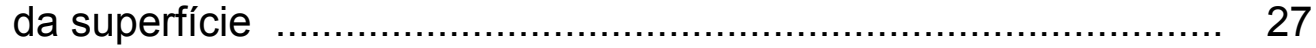

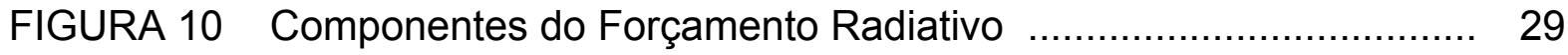

FIGURA 11 Plano de Monitoramento da ACM0001 f.................................. 40

FIGURA 12 Disposição final de resíduos por municípios no Brasil $\ldots \ldots \ldots \ldots \ldots \ldots . . . . . . . .43$

FIGURA 13 Produção de energia a partir de amostras de biogás à $30 \mathrm{ml} / \mathrm{min}$.. 45

FIGURA 14 Produção de energia em SOFC utilizando diferentes gases $\ldots . . . . .46$

FIGURA 15 Produção de energia em SOFC utilizando diferentes gases, com melhoria na performance ao se acrescentar ar ........................ 46

FIGURA 16 Localização da Central de Tratamento e Destinação Final de Resíduos Sólidos - CTDFR - Município de Santo André, SP ..... 50

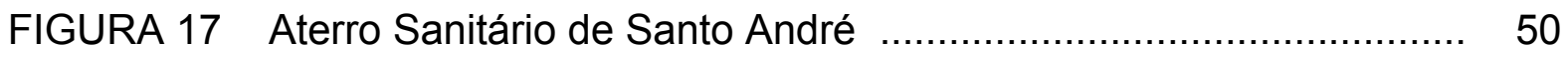

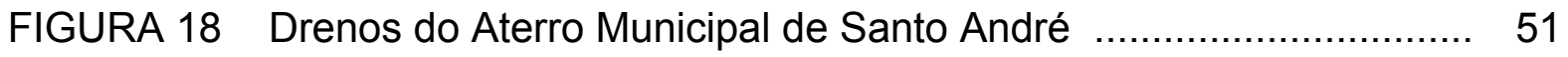

FIGURA 19 Estimativa das emissões de GEE do aterro sanitário de Santo André através da destruição do metano 


\section{INTRODUÇÃO}

No contexto de algumas conquistas do desenvolvimento tecnológico que se realiza no espaço global, a humanidade, com o advento da revolução industrial e nos séculos seguintes, a revolução das telecomunicações e da informática, atinge um estágio que quase conseguiu dobrar sua expectativa de vida, fez viagens espaciais tripuladas, conseguiu decodificar a maior parte de seu próprio genoma e vêm se realizando conferências virtuais com pessoas dos quatro cantos do mundo, discutindo simultaneamente. Esse desenvolvimento se encontra de modo extremamente descontínuo e não simultâneo nas diversas nações e regiões do mundo (ALTVATER, 1995). Quando se comparam os países pobres em desenvolvimento com os países industrializados, a expectativa de vida é $30 \%$ menor, a mortalidade infantil é de mais de 60 mortes por mil nascimentos, comparada com menos de 20 , nos países industrializados. O analfabetismo é superior a $40 \%$ nos países em desenvolvimento (GOLDEMBERG et al., 2003). Cerca de $65 \%$ dos seres humanos nunca fizeram uma chamada telefônica. Inserido neste contexto, existem mais de dois bilhões de pessoas, ou um terço da população mundial, que não têm acesso à eletricidade (RIFKIN, 2003).

Outra faceta do desenvolvimento é o descaso com o meio ambiente, fazendo com que cada vez mais a biodiversidade sofra perdas irreparáveis, o desmatamento e a degradação do solo aumentam a cada ano e as mudanças climáticas antropogênicas se agravam.

A vulnerabilidade a panes da infra-estrutura elétrica (usinas de força e linhas de transmissão) fica cada vez mais evidente por todo mundo. Isso se dá porque mesmo com as matrizes energéticas dos países sendo bem diferenciadas, o modelo de geração de energia elétrica é basicamente o mesmo, grandes usinas de força gerando energia para vastas áreas, por meio de quilômetros e quilômetros de linhas de transmissão. Os grandes conglomerados humanos, que são as áreas que mais utilizam energia elétrica, estão geralmente afastados das usinas de força.

A maior parte da energia elétrica no Brasil provém de usinas hidrelétricas, isso desde a década de 50; e, foram elas que deram sustentação ao forte impulso 
do país rumo à industrialização. Atualmente, as centrais hidrelétricas correspondem a cerca de $85,4 \%$ do total de energia elétrica (MME, 2005).

No ano de 2001, o Brasil viveu a pior crise no setor energético de sua história, e não foi muito de surpresa, pois já em meados dos anos 90 , os técnicos governamentais alertavam sobre o suprimento de energia elétrica atingindo níveis extremamente críticos nas regiões sudeste, centro-oeste e nordeste. O motivo mais determinante dessa crise foi uma sucessão de alguns anos de baixa precipitação pluviométrica, o que levou ao progressivo esvaziamento dos reservatórios das usinas hidrelétricas.

Como contraponto ao paradigma atual do setor energético, a utilização de células a combustível para geração de energia distribuída pode ser o alicerce de uma possível revolução não apenas energética, mas também sócio-ambiental.

As células a combustível são dispositivos que convertem diretamente energia química, presente em combustíveis como o hidrogênio, em energia elétrica, térmica e água. Particularmente, células a combustível do tipo óxido sólido (solid oxide fuel cells - SOFC), vêm sendo desenvolvidas no Brasil. Tanto as SOFC quanto outros tipos de células a combustível são vistos atualmente como uma das mais promissoras alternativas energéticas para anos vindouros. A SOFC é um dos dois tipos de células a combustível em desenvolvimento no Ipen. Esse tipo de célula a combustível possibilita a co-geração de calor e energia elétrica, e a reforma do combustível pode ser feita internamente na célula.

O Programa Célula a Combustível - PROCEL do Ipen que está de acordo com o ProH2 - Programa de Ciência, Tecnologia e Inovação para a Economia do Hidrogênio, ambos têm como foco a geração de energia elétrica para aplicação estacionária (geração distribuída), e prevê estudos de impacto social, ambiental, financeiro e tecnológico na matriz energética nacional (MCT, 2005). 


\section{OBJETIVOS}

Em face das considerações anteriores, o objetivo do presente trabalho será o de contribuir para o panorama energético alternativo, analisando a possibilidade de uma atividade de projeto de Mecanismo de Desenvolvimento Limpo (MDL) a partir do aproveitamento energético do gás gerado em aterros sanitários, particularmente do aterro sanitário municipal de Santo André - estudo de caso, utilizando a tecnologia de SOFC.

O objetivo específico é o de avaliar a possibilidade de obtenção de reduções certificadas de emissão (RCEs). Bem como a quantificação da potencial receita advinda da venda dessas RCEs. 


\section{FUNDAMENTAÇÃO TEÓRICA}

\subsection{Células a Combustível}

As células a combustível são dispositivos que convertem diretamente e continuadamente energia química, presente em combustíveis como o hidrogênio, em energia elétrica, térmica e água. Esta conversão ocorre por meio de reações de redução do $\mathrm{O}_{2}$ no catodo e oxidação do combustível no anodo. Ao contrário dos motores de combustão interna, não estão limitadas pelo ciclo de Carnot, conseqüentemente, as células a combustível não necessitam da produção intermediária de energia térmica (WENDT et al., 2000).

A descoberta das células a combustível antecede a do motor de combustão interna, sendo que o primeiro relato de uma operação de uma célula a combustível foi feito em 1839 por William Grove. A descoberta foi baseada na reversibilidade termodinâmica da eletrólise da água, cuja reação é:

$$
\mathrm{H}_{2} \mathrm{O}+\text { eletricidade } \leftrightarrow \mathrm{H}_{2}+1 / 2 \mathrm{O}_{2}
$$

Grove teve sucesso em detectar corrente elétrica fluindo pelos condutores de uma célula eletrolítica ao desligar a eletrólise por um curto intervalo de tempo, suprindo seus eletrodos com hidrogênio e oxigênio (RIFKIN, 2003).

Seu principio de funcionamento é basicamente o de uma bateria de operação contínua, que produz uma corrente contínua pela combustão eletroquímica a frio de um combustível gasoso, geralmente o hidrogênio $\left(\mathrm{H}_{2}\right)$.

Existem mais de dez tipos de células a combustível, sendo os principais: Célula a Combustível de Ácido Fosfórico (Phosphoric Acid Fuel Cell - PAFC), Célula a Combustível de Membrana Trocadora de Prótons (Proton Exchange Membrane Fuel Cell - PEMFC), Célula a Combustível de Carbonatos Fundidos (Molten Carbonate Fuel Cell - MCFC), Célula a Combustível Alcalina (Alkaline Fuel Cell AFC), Células a Combustível Regenerativas, Células a Combustível Zinco-Ar (Zinc Air Fual Cell - ZAFC) e Célula a Combustível de Óxido Sólido (Solid Oxide Fuel Cell - SOFC). A TAB. 1 apresenta características dos principais tipos de Células a Combustível em desenvolvimento. 
TABELA 1 - Principais tipos de Células a Combustível

\begin{tabular}{|c|c|c|c|c|c|}
\hline Tipo & $\begin{array}{c}\text { Eletrólito } \\
\text { (espécie } \\
\text { transportada) }\end{array}$ & $\begin{array}{c}\text { Faixa de } \\
\text { Temperatura } \\
\left({ }^{\circ} \mathrm{C}\right)\end{array}$ & Vantagens & Desvantagens & Aplicações \\
\hline AFC & $\begin{array}{l}\mathrm{KOH} \\
(\mathrm{OH})\end{array}$ & $60-90$ & $\begin{array}{l}\text { - Alta eficiência } \\
\text { (83\% teórica) }\end{array}$ & $\begin{array}{l}\text { - Sensível a } \mathrm{CO}_{2} \\
\text { - Gases ultra } \\
\text { puros, sem } \\
\text { reforma do } \\
\text { combustível }\end{array}$ & $\begin{array}{l}\text { - Espaçonaves } \\
\text { - Aplicações } \\
\text { militares }\end{array}$ \\
\hline PEMFC & $\begin{array}{l}\text { Polímero: } \\
\text { Nafion }{ }^{\circledR} \\
\left(\mathrm{H}_{3} \mathrm{O}^{+}\right)\end{array}$ & $80-90$ & $\begin{array}{l}\text { - Altas densidade } \\
\text { de potência e } \\
\text { eficiência } \\
\text { - Operação } \\
\text { flexível }\end{array}$ & $\begin{array}{l}\text { - Custo da } \\
\text { membrana e } \\
\text { catalisador } \\
\text { - Contaminação } \\
\text { do catalisador } \\
\text { com CO }\end{array}$ & $\begin{array}{l}\text { - Veículos } \\
\text { automotores } \\
\text { - Espaçonaves } \\
\text { - Unidades } \\
\text { Estacionárias }\end{array}$ \\
\hline PAFC & $\begin{array}{l}\mathrm{H}_{3} \mathrm{PO}_{3} \\
\left(\mathrm{H}_{3} \mathrm{O}^{+}\right)\end{array}$ & $160-200$ & $\begin{array}{l}\text { - Maior } \\
\text { desenvolvimento } \\
\text { tecnológico }\end{array}$ & $\begin{array}{l}\text { - Controle da } \\
\text { porosidade do } \\
\text { eletrodo } \\
\text { - Sensibilidade a } \\
\text { CO } \\
\text { - Eficiência } \\
\text { limitada pela } \\
\text { corrosão }\end{array}$ & $\begin{array}{l}\text { - Unidades } \\
\text { Estacionárias } \\
(100 k W \text { a alguns } \\
\text { MW) } \\
\text { - Cogeração } \\
\text { eletricidade /calor }\end{array}$ \\
\hline MCFC & $\begin{array}{l}\text { Carbonatos } \\
\text { fundidos } \\
\left(\mathrm{CO}_{3}^{2-}\right)\end{array}$ & $650-700$ & $\begin{array}{l}\text { - Tolerância a } \\
\mathrm{CO} / \mathrm{CO}_{2} \\
\text { - Eletrodos à base } \\
\text { de } \mathrm{Ni}\end{array}$ & $\begin{array}{l}\text { - Problemas de } \\
\text { materiais } \\
\text { - Necessidade de } \\
\text { reciclagem de } \\
\mathrm{CO}_{2} \\
\text { - Interface trifásica } \\
\text { de difícil controle }\end{array}$ & $\begin{array}{l}\text { - Unidades } \\
\text { Estacionárias de } \\
\text { algumas centenas } \\
\text { de kW } \\
\text { - Cogeração } \\
\text { eletricidade /calor }\end{array}$ \\
\hline SOFC & $\begin{array}{l}\mathrm{ZrO}_{2} \\
\left(\mathrm{O}^{2-}\right)\end{array}$ & $800-1000$ & $\begin{array}{l}\text { - Alta eficiência } \\
\text { (cinética } \\
\text { favorável) } \\
\text { - A reforma do } \\
\text { combustível pode } \\
\text { ser feita na célula }\end{array}$ & $\begin{array}{l}\text { - Problemas de } \\
\text { materiais } \\
\text { - Expansão } \\
\text { térmica } \\
\text { - Necessidade de } \\
\text { pré-reforma }\end{array}$ & $\begin{array}{l}\text { - Unidades } \\
\text { Estacionárias de } \\
10 \text { a algumas } \\
\text { centenas de kW } \\
\text { - Cogeração } \\
\text { eletricidade /calor }\end{array}$ \\
\hline
\end{tabular}

Fonte - WENDT et al., 2000.

A potência gerada pela tecnologia de célula a combustível varia de alguns watts até $1 \mathrm{MW}$. Com isso, existem muitas aplicações para a tecnologia de célula a combustível, desde equipamentos eletrônicos portáteis como telefones celulares e laptops; aplicações no transporte, que já possuem protótipos em desenvolvimento ou em prova de companhias como: Honda, Toyota, DaimlerChrysler, GM, Ford, Hyundai e Volkswagen; e aplicações para geração de energia estacionária. Dos três tipos de aplicações (estacionárias, portáteis e veiculares) as estacionárias são as únicas atualmente comercializadas, mesmo que ainda principalmente para fins de pesquisa, mas têm grande potencial para serem utilizadas para sistemas de back up em hospitais, bancos e outros estabelecimentos, onde o fluxo ininterrupto de 
eletricidade é de suma importância, e posteriormente para a geração de energia distribuída. Apenas esse mercado de aplicação estacionária pode chegar a 12 bilhões de dólares até 2011 (PwC, 2002).

Avanços recentes na tecnologia de células a combustível aumentaram de forma significativa o interesse da comunidade internacional, nas circunstâncias adequadas, as células a combustível a hidrogênio podem prestar uma contribuição importante na segurança energética e mitigação da emissão de dióxido de carbono $\left(\mathrm{CO}_{2}\right)$. Políticas que visam a diversificação do suprimento de energia são importantes. Todavia, políticas que incentivam a segurança energética somente não são suficientes. Os governos devem adotar políticas que incentivam a redução de $\mathrm{CO}_{2}$ por meio da atribuição de valor para as emissões evitadas. $\mathrm{Na}$ falta de incentivos de redução de $\mathrm{CO}_{2}$, outras tecnologias e combustíveis (como o carvão) podem diversificar a geração energética a um custo menor (IEA, 2005). Existem atualmente mais de 400 projetos de demonstração por todo o mundo (IEA, 2005).

As células a combustível do tipo MCFC e SOFC são as melhores candidatas para as aplicações estacionárias. Elas são menos sensíveis a contaminantes que as do tipo PEMFC. Atualmente as MCFC são abastecidas com gás natural, enquanto as SOFC podem ser abastecidas com qualquer hidrocarboneto ou hidrogênio puro. As duas operam em alta temperatura e não necessitam de reforma externa do combustível. Suas eficiência elétrica é maior que a da PEMFC. Entretanto, elas não são apropriadas para automóveis, por conta de suas altas temperaturas de operação e por conseqüência partidas demoradas. MCFC abastecidas com gás natural e SOFC podem co-existir, mas próximas décadas, mas SOFC tem vantagens em um cenário futuro onde as reduções de emissão de $\mathrm{CO}_{2}$ são obrigatórias.

No Brasil, em março de 2001 foi realizada na Universidade Estadual de Campinas - UNICAMP, na cidade de Campinas, SP, a $1^{\text {a }}$ reunião do Comitê Diretor do Centro Nacional de Referência em Energia do Hidrogênio - CENEH, que marcou o início oficial das atividades deste centro de referência no país, coroando um processo de dois anos de preparação.

De fato, este processo iniciou-se durante o IV Encontro do Fórum Permanente de Energias Renováveis, realizado de 06 a 09 de outubro de 1998 em Recife - PE, que congregou os cinco centros nacionais de referência em energias renováveis existentes até então: Centro Brasileiro de Energia Eólica, localizado na Universidade Federal de Pernambuco - UFPE, Centro Brasileiro para o Desenvolvimento de 
Energia Solar Térmica - GREEN SOLAR, instalado na Pontifícia Universidade Católica de Minas Gerais - PUC-MG, Centro Nacional de Referência de Pequenas Centrais Hidroenergéticas - CERPCH, localizado na Escola Federal de Engenharia de Itajubá (MG) - EFEI, o Centro de Pesquisas de Energia Elétrica - CEPEL e o Centro de Referência em Biomassa - CENBIO, instalado na Universidade de São Paulo - USP. Durante este encontro realizou-se também o I Workshop de Energia do Hidrogênio, que propôs ao Fórum a criação de um centro nacional de referência em hidrogênio, o que foi aprovado na plenária final do encontro (CENEH, 2006).

\subsubsection{Célula a Combustível de Óxido Sólido}

A FIG. 1 mostra o principio de funcionamento de uma célula a combustível do tipo SOFC, que é um dos tipos de células a combustível que o Ipen estuda e desenvolve desde 1998.

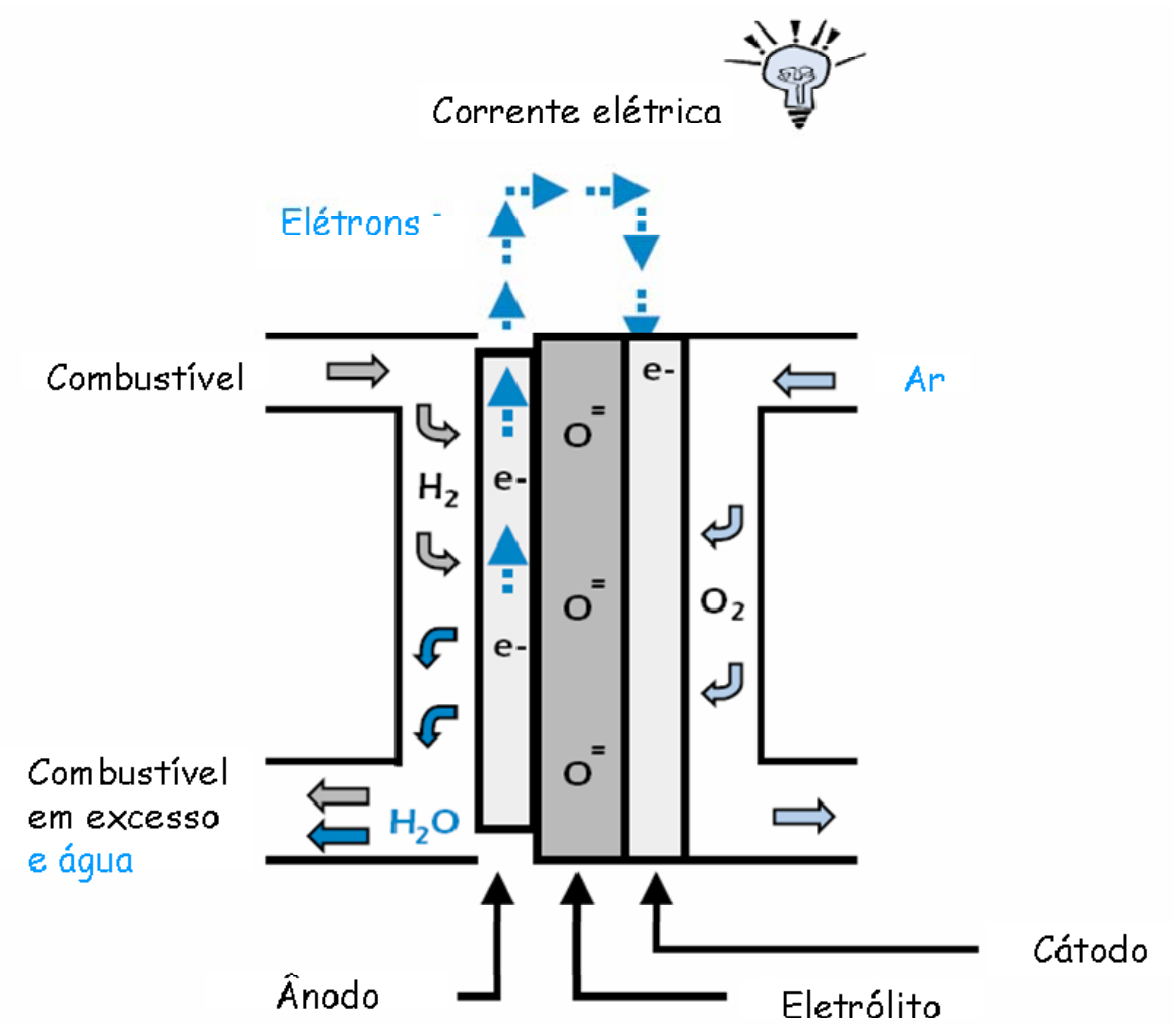

FIGURA 1 - Esquema simplificado de uma célula a combustível tipo SOFC Fonte - IEA, 2005

A característica básica da tecnologia SOFC é a utilização de um eletrólito cerâmico não-poroso condutor iônico, o estado da arte para esse material é a utilização de zircônia estabilizada com a ítria. Opera em alta temperatura (800 $1000^{\circ}$ C) o que favorece bastante a cinética das reações e possibilita a reforma interna do combustível. Também não necessita de metais nobres como 
eletrocatalizadores. Quando combinadas com uma turbina, as SOFCs tem uma eficiência elétrica esperada de 60 - 70\%, e uma eficiência geral de 80 - 85\% por conta da cogeração. Relativo ao combustível utilizado em SOFC, o monóxido de carbono (CO) pode ser adicionado ao $\mathrm{H}_{2}$.

Algumas desvantagens da SOFC são: baixo tempo de vida útil e demora na partida. A TAB. 2 apresenta informações das SOFCs testadas pela SiemensWestinghouse.

TABELA 2 - SOFCs testadas pela Siemens-Westinghouse

\begin{tabular}{cccccc}
\hline Ano & $\begin{array}{c}\text { Potência } \\
\text { (kWe) }\end{array}$ & $\begin{array}{c}\text { Tamanho } \\
(\mathbf{m m})\end{array}$ & $\begin{array}{c}\text { Número de } \\
\text { células no } \\
\text { stack }\end{array}$ & $\begin{array}{c}\text { Horas de } \\
\text { operação }\end{array}$ & Combustível \\
\hline 1986 & 0,4 & 300 & 24 & 1.760 & $\mathrm{H}_{2}+\mathrm{CO}$ \\
1987 & 3 & 360 & 144 & 3.012 & $\mathrm{H}_{2}+\mathrm{CO}$ \\
1987 & 3 & 360 & 144 & 3.683 & $\mathrm{H}_{2}+\mathrm{CO}$ \\
1987 & 3 & 360 & 144 & 4.882 & $\mathrm{H}_{2}+\mathrm{CO}$ \\
1992 & 20 & 500 & 576 & 817 & Gás Natural \\
1992 & 20 & 500 & 576 & 2.601 & Gás Natural \\
1992 & 20 & 500 & 576 & 1.579 & Gás Natural \\
1993 & 20 & 500 & 576 & 7.064 & Gás Natural \\
1994 & 20 & 500 & 576 & 6.015 & Gás Natural \\
1995 & 25 & 500 & 576 & 13.194 & Gás Natural \\
1997 & 27 & 500 & 576 & 3.394 & Gás Natural \\
1998 & 125 & 1.500 & 1.152 & 4.035 & Gás Natural \\
1999 & 125 & 1.500 & 1.152 & 12.577 & Gás Natural \\
2000 & 180 & 1.500 & 1.152 & 3.257 & Gás Natural \\
2001 & 125 & 1.500 & 1.152 & 3.872 & Gás Natural \\
2002 & 250 & 1.500 & 2.304 & $1.000+$ & Gás Natural \\
2005 & 125 & 1.500 & 1.128 & - & Gás Natural \\
2006 & 125 & 1.500 & 1.128 & - & Gás Natural \\
\hline
\end{tabular}

Fonte - Siemens-Westinghouse, 2005

Existem duas configurações geométricas básicas e mais estudadas para as SOFCs: planar e tubular. As empresas que estão desenvolvendo a configuração planar são Mitsubishi Heavy Industries, Honeywell, General Electric, Hexis e Siemens-Westinghouse. Essa configuração permite maiores densidades de corrente e mais fáceis de serem manufaturadas que as de configuração tubular (IEA, 2005). A FIG. 2 mostra exemplos dessa configuração geométrica para SOFC. 


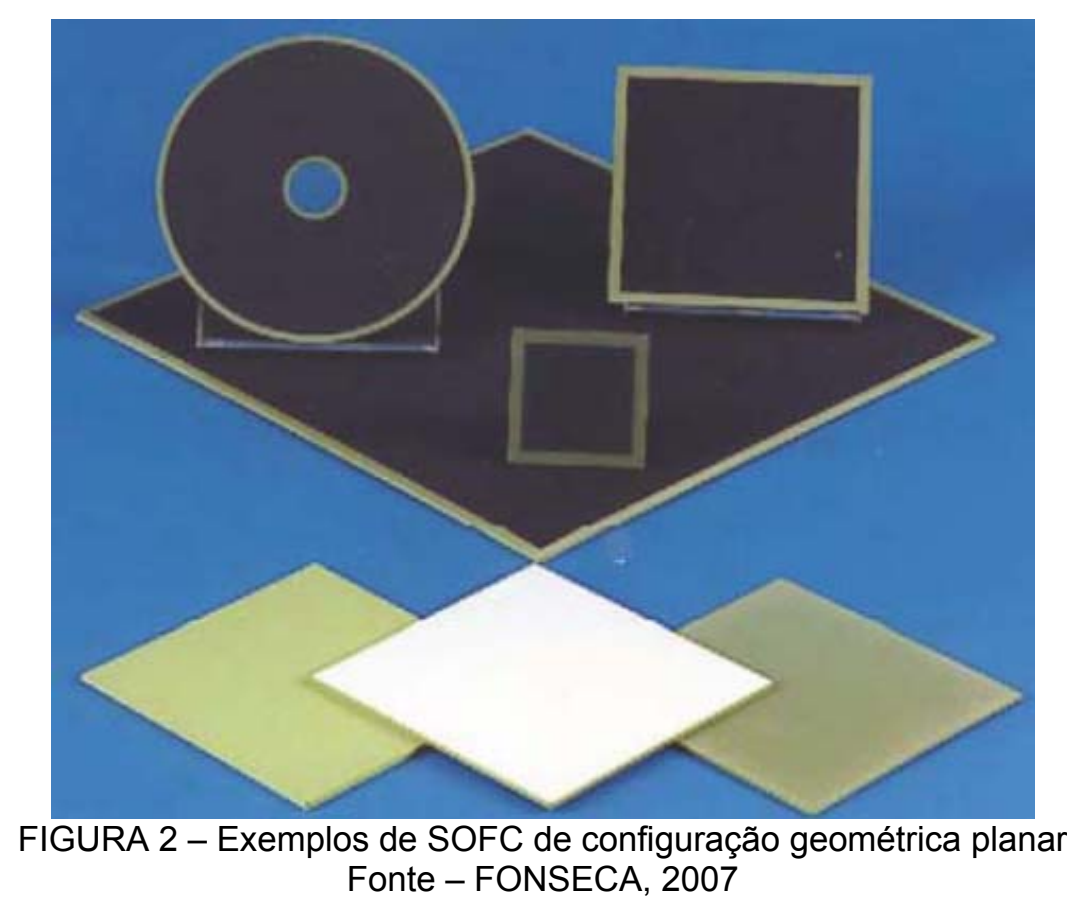

A configuração geométrica tubular tem sido desenvolvida pela SiemensWestinghouse e Mitsubishi Heavy Industries. As vantagens dessa configuração são uma melhor selagem e a utilização minimizada do interconector (IEA, 2005). A FIG. 3 apresenta os Protótipos de SOFC tubular da Siemens-Westinghouse.

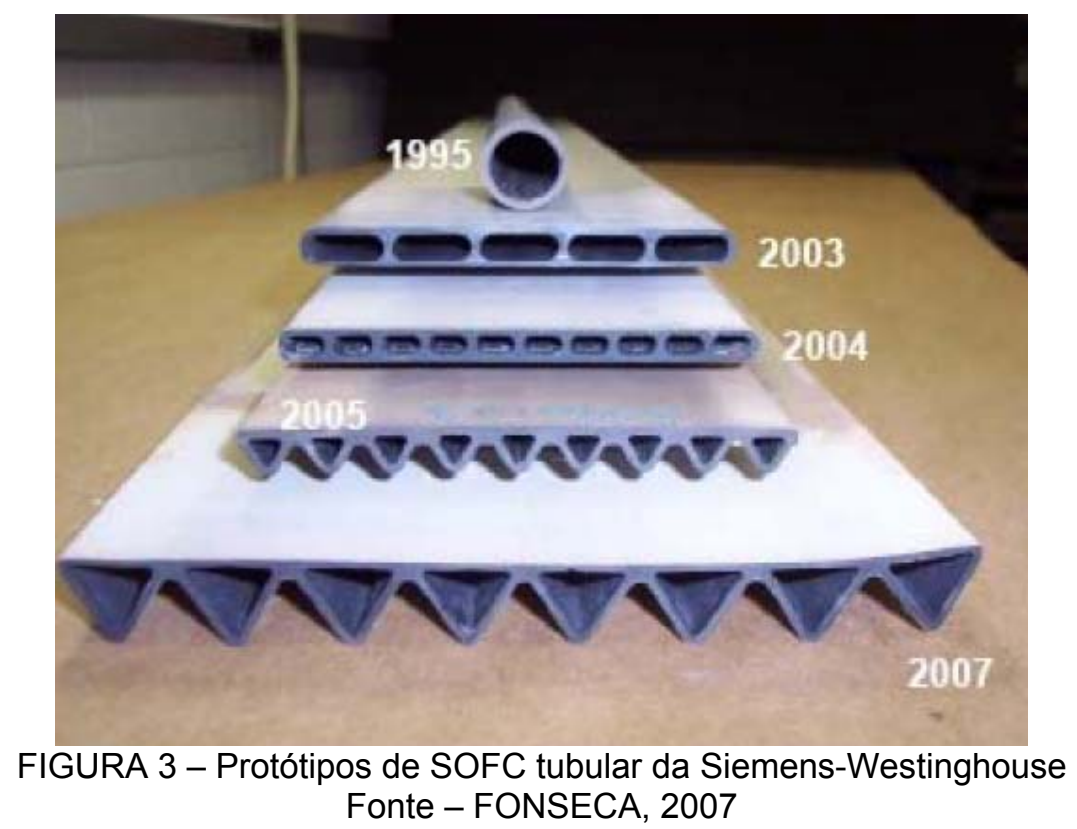

Um dos objetivos de pesquisa e desenvolvimento das SOFC, no contexto de utilização de biocombustíveis, é o aumento da tolerância ao enxofre (IEA, 2005). Ainda para ZHA (2007), apresenta as mudanças na densidade de corrente com uma 
camada de $\mathrm{Nb}_{2} \mathrm{O}_{5}$ sobre o anodo $\mathrm{Ni}$-YSZ utilizando 50ppm (partes por milhão) de $\mathrm{H}_{2} \mathrm{~S}$ em $\mathrm{H}_{2}$, à $700^{\circ} \mathrm{C}$ em uma célula a combustível de óxido sólido (FIG. 4). Esse experimento se mostrou estável por 12 horas.

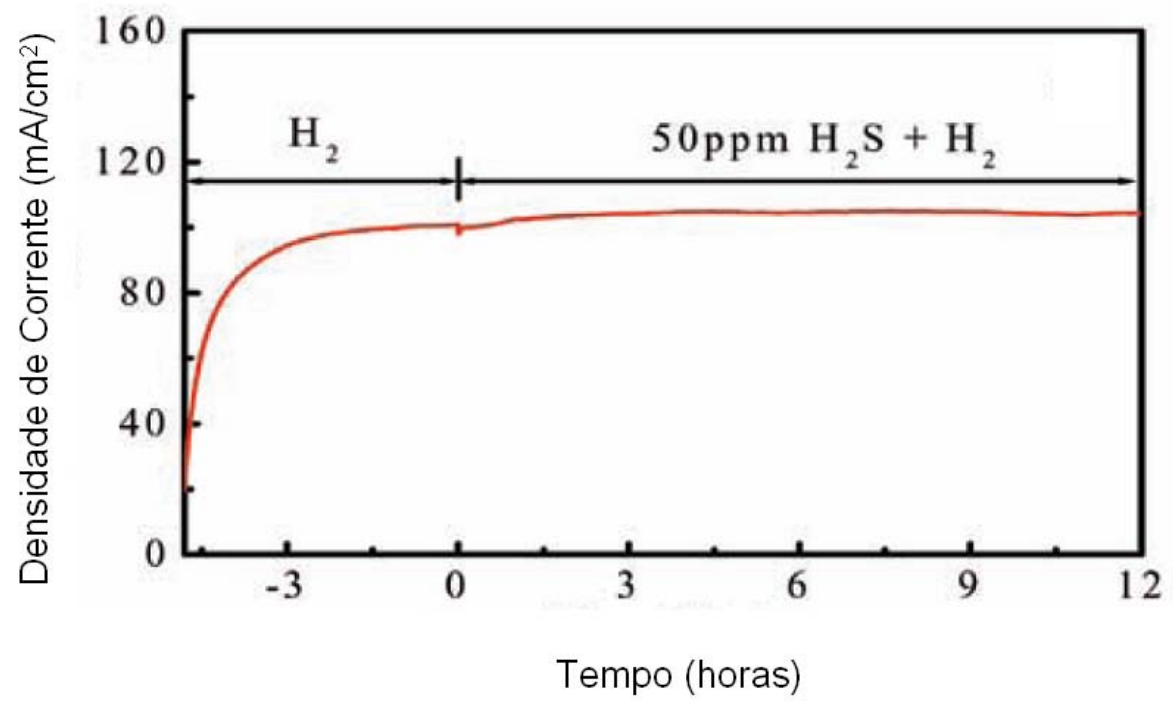

FIGURA 4 - Mudanças na densidade de corrente em uma SOFC com uma camada de $\mathrm{Nb}_{2} \mathrm{O}_{5}$ no anodo

Fonte - ZHA, 2007

\subsubsection{O Hidrogênio}

O hidrogênio foi descoberto pelo cientista britânico Henry Cavendish, no ano de 1776, num estudo apresentado à Real Sociedade de Londres em que ele descreveu uma experiência a qual produzira a partir da água, oxigênio e hidrogênio com o auxilio de uma centelha elétrica. Como os elementos ainda não haviam recebido seus respectivos nomes, ele chamou de "ar sustentador da vida" e o outro de "ar inflamável". O químico francês Antoine Laurent Lavoisier repetiu com êxito a experiência de Cavendish em 1785 e chamou o "ar sustentador da vida" de oxigênio e o "ar inflamável" de hidrogênio (RIFKIN, 2003).

Hoje se sabe que o hidrogênio é um dos elementos mais abundantes do universo, compondo $98 \%$ dele. A cada segundo, no sol, mais de 550 milhões de toneladas desse combustível se fundem para formar hélio. Na Terra, o hidrogênio existe quase que inteiramente sob a forma de compostos, sendo responsável por aproximadamente $70 \%$ da superfície terrestre.

No seu estado natural e sob condições ambientes de temperatura e pressão, o hidrogênio é um gás incolor, inodoro, insípido e muito mais leve que o ar. $O$ 
hidrogênio também pode estar em estado liquido, ocupando um espaço 700 vezes menor que se estivesse em forma de gás. Mas para isso, deve estar armazenado numa temperatura de $-253^{\circ} \mathrm{C}$, em sistemas criogênicos. Acima dessa temperatura, o hidrogênio não pode ser liquefeito, mas pode ser armazenado na forma de gás comprimido em cilindros de alta pressão (HOFFMANN, 2005).

Atualmente, são produzidos aproximadamente 40 milhões de toneladas de gás de hidrogênio por ano, o que corresponde a $5 \mathrm{EJ}$ equivalente a $1 \%$ da energia primária global. Mas a maior parte desse gás não é utilizada para fins de geração de energia, $40 \%$ é utilizado em processos da indústria química, $40 \%$ em refinarias e $20 \%$ em outros usos (ex., indústria alimentícia). A produção mundial de $\mathrm{H}_{2}$ é mostrada na FIG. 5 .

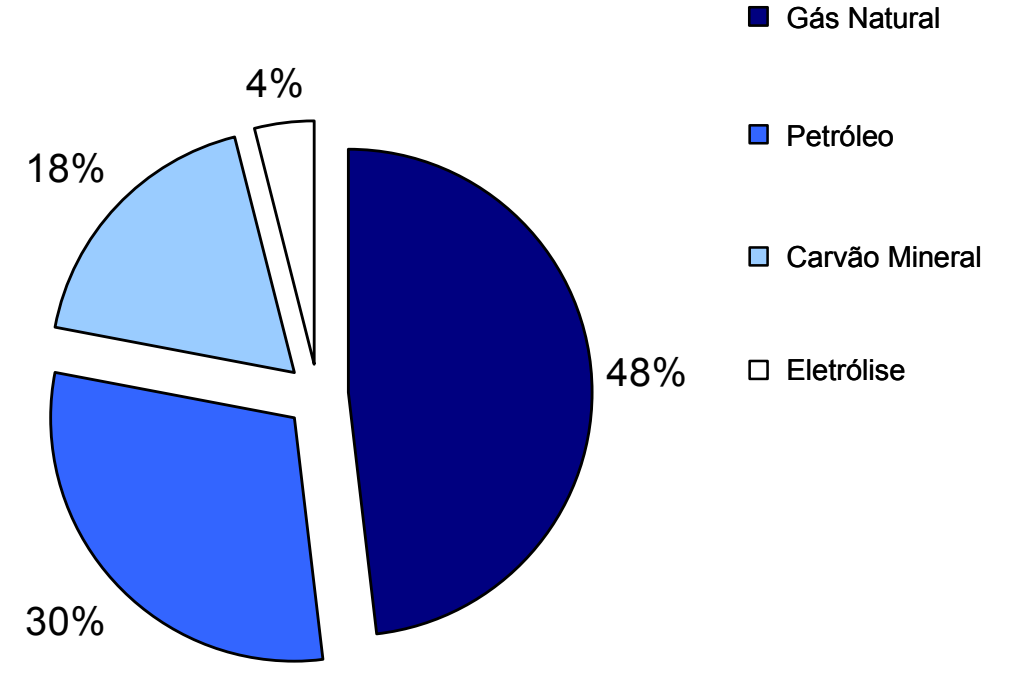

FIGURA 5 - Produção mundial de hidrogênio Fonte - Serra, 2006

O processo de produção do hidrogênio demanda a utilização de dois insumos básicos: o químico e o energético (TAB. 3). De forma geral, os compostos orgânicos considerados como insumos químicos nos processos de produção de hidrogênio são também utilizados como insumos energéticos, como é o caso do etanol, das biomassas e do gás natural. A água, por sua vez, requer a adição de energia para produzir hidrogênio, que pode ser gerada por fonte hidráulica, solar, eólica ou térmica (MME, 2005). 
TABELA 3 - Processos, insumos químicos e energéticos para produção de hidrogênio no Brasil.

\begin{tabular}{ccc}
\hline Processo & Insumo Químico & Insumo Energético \\
\hline Reforma do Gás Natural & Gás Natural & Gás Natural \\
Eletrólise & Água & Eletricidade \\
Reforma do Etanol & Etanol & Etanol \\
$\begin{array}{c}\text { Gaseificação de } \\
\text { biomassa }\end{array}$ & Biomassa & Biomassa \\
Biológico (biogás) & Biomassa & $\begin{array}{c}\text { Calor, eventualmente } \\
\text { Calor ou luz, } \\
\text { eventualmente }\end{array}$ \\
Alternativos & Água e biomassa &
\end{tabular}

Segundo FLANNERY (2007), a avaliação dos impactos climáticos de uma eventual economia do hidrogênio está apenas no começo. O hidrogênio molecular é um gás do qual se encontram traços na atmosfera, existindo em apenas meia parte por milhão (ppm), e com uma duração de apenas dois anos. Uma futura economia do hidrogênio exigirá o transporte anual de várias vezes a quantidade total de hidrogênio presente na atmosfera hoje, e o hidrogênio por suas características supracitadas é bastante suscetível a vazamentos. Ao substituir metade dos combustíveis fósseis atuais pelo hidrogênio, é possível que sua concentração atmosférica dobre.

Uma das propriedades mais indesejada do hidrogênio é sua capacidade de aumentar a abundância de metano em até $4 \%$. Além disso, o principal captador de nitrogênio molecular atmosférico são os microorganismos fixadores de nitrogênio no solo, e as conseqüências de um aumento do hidrogênio molecular sobre o nitrogênio molecular atmosférico ainda são desconhecidas. Existe ainda a possibilidade de que, se o hidrogênio for utilizado em grande escala pela humanidade, os vazamentos do $\mathrm{H}_{2}$ podem afetar $\mathrm{O}$ vapor de água estratosférico e o ozônio (FLANNERY, 2007).

O hidrogênio na estratosfera intensifica a concentração de vapor d'água o que interfere na concentração de ozônio. Na troposfera, seu efeito químico é similar ao CO (monóxido de carbono), levando a produção de ozônio e aumento de metano (PRATHER, 2003).

DERWENT et al. (2001) calcularam o Potencial de Aquecimento Global (Global Warming Potential - GWP) indireto do $\mathrm{H}_{2}$ no horizonte de tempo de 100 anos na troposfera de 5,8.

Neste sentido, sugere-se um aprofundamento de pesquisas nessa área visando a identificação dos impactos climáticos. 


\subsubsection{Geração de Energia Distribuída}

Geração de energia distribuída refere-se a pequenas usinas de geração de eletricidade, integradas ou individuais, localizadas próximas ou juntas ao usuário final. A energia distribuída poderá complementar nosso sistema atual de geração de energia que se encontra sobrecarregado em muitas partes do mundo.

Em muitas fábricas, escritórios comerciais, repartições públicas e lugares onde é essencial um fluxo contínuo de eletricidade, é extremamente necessário optar por geradores próprio de eletricidade. Atualmente, a maioria das microtecnologias energéticas são turbinas de combustão interna a diesel, gás natural ou recíprocos (FARRET, 1999).

Uma vantagem da geração de energia distribuída é o tempo de construção das pequenas usinas de energia. Em geral, a instalação é bem rápida, garantindo qualidade do suprimento de energia, especialmente em curto e médio prazos. As grandes usinas demoram de 4 a 10 anos para serem construídas, colocando em risco as necessidades de suprimento de energia em países como o Brasil, EUA e China. Outra vantagem é a maior facilidade na obtenção do licenciamento ambiental e do financiamento (HOFFMANN, 2005).

Com substituição dessas turbinas por células a combustível, uma maior difusão e uma integração em rede podem-se gerar energia elétrica com um menor risco de panes, pois a geração será próxima ao consumidor, e eventualmente até mais barata, pois isso diminuirá drasticamente os custos e perdas na transmissão (RIFKIN, 2003).

A FIG. 6 mostra uma comparação entre o sistema centralizado de geração de energia elétrica e a geração distribuída. A geração distribuída de energia estacionária por sistemas de células a combustíveis tem o potencial para ser um importante nicho para esta tecnologia, onde sua capacidade instalada acompanharia a curva da demanda. Para que isso ocorra será necessária a criação de uma infraestrutura para a geração do hidrogênio. 


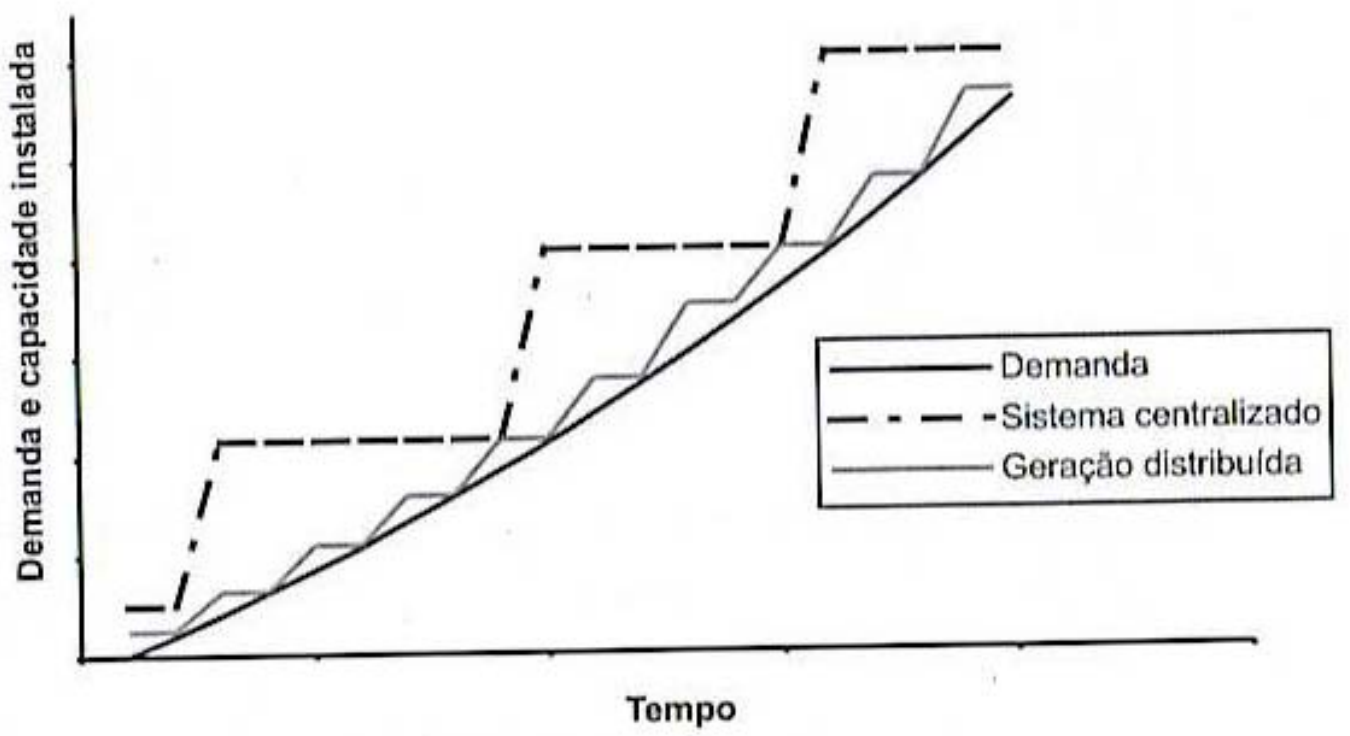

FIGURA 6 - Sistema centralizado e Geração distribuída Fonte: SERRA, 2006

O Artigo 14 do Decreto-Lei 5163/04, considera geração distribuída a produção de energia elétrica proveniente de empreendimentos de agentes concessionários, permissionários ou autorizados, conectada diretamente no sistema elétrico de distribuição do comprador, exceto aquela proveniente de empreendimento:

- Hidrelétrico, com capacidade instalada superior a $30 \mathrm{MW}$;

- Termelétrico, inclusive de co-geração, com eficiência energética inferior a $75 \%$, conforme regulação da ANEEL, estabelecida até dezembro de 2004. Os empreendimentos termelétricos que utilizem biomassa ou resíduos de processo como combustível não estão limitados a esse percentual de eficiência energética.

De acordo com o Ministério de Minas e Energia (2005) para a geração distribuída pode ser utilizado grupo gerador diesel, turbinas e motores a gás, células fotovoltáicas, turbinas eólicas e células a combustível. Esta última pode ser a fonte primária de energia ou entrar em operação quando outras fontes de eletricidade falharem. Atualmente esta demanda tem sido atendida basicamente por sistemas híbridos de geradores diesel e bancos de baterias. Estima-se que a produção anual de unidades de grupos geradores a diesel no país seja da ordem de 60.000 unidades/ano, metade desta quantidade para exportação.

A TAB. 4 apresenta projetos com células a combustível, em andamento ou concluídos no Brasil (MME, 2005). O número de concessionárias investindo em 
células a combustível e hidrogênio demonstra o interesse nessa aplicação. Porém, como também pode ser constatado não existem projetos de células a combustível a biocombustíveis no Brasil.

TABELA 4 - Projetos brasileiros com células a combustível para geração estacionária

\begin{tabular}{|c|c|c|}
\hline Descrição / Tecnologia & Participantes & $\begin{array}{c}\text { Potência } \\
\text { (kW) }\end{array}$ \\
\hline $\begin{array}{l}\text { Projeto de demonstração de } 3 \text { células a combustível, } \\
\text { tipo PAFC, alimentadas com gás natural, fabricada nos } \\
\text { EUA. }\end{array}$ & COPEL e LACTEC & 600 \\
\hline $\begin{array}{l}\text { Projeto de demonstração de tecnologias de geração } \\
\text { distribuída, envolvendo uma } 1 \text { célula a combustível, } \\
\text { tipo PAFC, alimentada a gás natural, fabricada nos } \\
\text { EUA. }\end{array}$ & CENPES & 200 \\
\hline $\begin{array}{l}\text { Projetos de desenvolvimento de células a combustível } \\
\text { de pequeno porte, tipo PEMFC. }\end{array}$ & $\begin{array}{l}\text { CEMIG, EESC/USP, } \\
\text { CLAMPLER e } \\
\text { UNITECH }\end{array}$ & 1,5 \\
\hline $\begin{array}{l}\text { Projeto de desenvolvimento de células a combustível, } \\
\text { tipo PEMFC, alimentada por hidrogênio eletrolisado. }\end{array}$ & $\begin{array}{l}\text { AES } \\
\text { ELETROPAULO e } \\
\text { ELECTROCELL }\end{array}$ & 50 \\
\hline $\begin{array}{l}\text { Projetos de demonstração de célula a combustível para } \\
\text { pequenas comunidades na Amazônia, tipo PEMFC. }\end{array}$ & $\begin{array}{l}\text { ELETRONORTE e } \\
\text { UFPA } \\
\text { UNICAMP e UFAM } \\
\text { UNICAMP e UFMT }\end{array}$ & 11 \\
\hline $\begin{array}{l}\text { Projeto de demonstração de célula a combustível, tipo } \\
\text { PEMFC, alimentada por gás natural, fabricada nos } \\
\text { EUA. }\end{array}$ & $\begin{array}{l}\text { CPFL, LACTEC e } \\
\text { UNICAMP }\end{array}$ & 6 \\
\hline $\begin{array}{l}\text { Projeto de demonstração de célula a combustível, tipo } \\
\text { PEMFC, fabricada no Brasil, alimentada com gás } \\
\text { natural do IPEN/INT. }\end{array}$ & $\begin{array}{l}\text { CEPEL, CHESF e } \\
\text { ELECTROCELL }\end{array}$ & 5 \\
\hline $\begin{array}{l}\text { Projeto de desenvolvimento de célula a combustível, } \\
\text { tipo PEMFC. }\end{array}$ & LIGHT e UNITECH & 10 \\
\hline
\end{tabular}

Fonte - MME, 2005

O engenheiro americano Geoffrey Ballard propõe uma economia baseada no hidrogênio bastante diferenciada da convencional. Seria a criação um estoque nacional de hidrogênio nos tanques de gasolina dos carros de todas as nações. Esse hidrogênio seria usado em células a combustível que movem os carros, mas ao mesmo tempo comporia um estoque nacional de energia (LOVELOCK, 2006).

As células a combustível podem ser reversíveis, ou seja, podem usar $\mathrm{o}_{2}$ para produzir eletricidade com eficiência, mas também podem ser fontes de $\mathrm{H}_{2}$ quando supridas de eletricidade. Ballard observa que a frota total de automóveis da maioria das nações tem uma capacidade geradora muitas vezes maior que as centrais termelétricas da nação. Basta que o carro, quando parado, seja conectado à rede nacional, o que pode acontecer em casa ou em estacionamentos (LOVELOCK, 2006). Os carros e caminhões seriam então depósitos de combustível e geradores 
do suprimento nacional de eletricidade, e capazes de extrair energia desse suprimento. A fonte primária de eletricidade seriam usinas de força não emissoras de gases de efeito estufa (GEE).

\subsubsection{Células a Combustível a biocombustíveis}

O programa do governo dos EUA “Northeast Regional Biomass" em parceria com a XENERGY Inc. realizou um estudo analisando a viabilidade da utilização de bio-combustíveis na tecnologia de células a combustível estacionárias. Os resultados demonstram que de uma perspectiva técnica, os biocombustíveis são capazes de prover um recurso energético renovável, limpo e de longo prazo. Estes resultados não são novidades, células a combustível já provaram ser bem sucedidas nestas aplicações, estando presente em mais de 150 aterros e em estações de tratamento de esgoto (ETE) nos EUA, gerando energia a partir do gás metano que produzem, e conseqüentemente reduzindo as emissões de gases poluidores.

Em 1992 uma bem sucedida demonstração no aterro Penrose em Sun Valley, Califórnia, EUA, pavimentou o caminho para a aplicação de células a combustível em aterros e ETEs. Desde 1996, o aterro Groton de Connecticut vem produzindo 600.000 kWh/ano de eletricidade, com uma célula combustível de geração de energia firme de $140 \mathrm{~kW}$.

Em 1997, a UTC Power (United Technologies Company) antiga IFC/ONSI, instalou um sistema de células a combustível na ETE da planta da Yonkers em Nova York, que produz, mas de 1,6 milhões de kWh/ano de eletricidade, liberando uma quantidade irrisória de emissões para o meio ambiente. A cidade de Portland, no Oregon, instalou uma célula a combustível para produzir energia utilizando gás digerido de forma anaeróbica proveniente de sua ETE e gerando 1,5 milhões de kWh/ano de eletricidade, desta forma reduzindo a conta de eletricidade da ETE em US\$ $102.000,00$ por ano. A UTC também vendeu 200 células a combustível PureCell ${ }^{\mathrm{TM}}$ para dois distritos da Califórnia para sua aplicação e oito usinas elétricas de células a combustível PC25TM para Autoridade de Energia Elétrica de Nova York. As 200 unidades de células a combustível 200-kilowat PureCell ${ }^{\mathrm{TM}}$ serão instaladas em quatro ETEs no Brooklyn, Staten Island, Bronx e Queens (XENERGY, 2002).

Fora dos EUA, a UTC instalou uma unidade da Célula a combustível PureCell ${ }^{\mathrm{TM}} 200$ na cidade chinesa de Guangzhou para gerar energia para 
equipamentos elétricos de uma fazenda de suínos, com o excedente exportado para os usuários externos da fazenda. Inicialmente a célula a combustível será abastecida por combustível fóssil liquefeito, mas eventualmente o próprio metano produzido pela decomposição dos dejetos suínos o substituirá como o gás que irá alimentar a célula.

Outra Companhia a FuelCell Energy, Inc. (FCE) foi selecionada para instalar e operar uma usina de energia Direct FuelCell ${ }^{\circledR}$ (DFC) de $1 \mathrm{MW}$ na ETE da King County em Renton, Washington. O projeto de demonstração de 2 anos tem o custo rateado igualmente entre a FuelCell Energy e a King County, através de uma cooperativa concedida a Counte pela EPA. O Valor total do contrato é de US\$18,8 milhões.

A FCE e o seu sócio/distribuidor Asiático, Marubeni Corporation, instalaram uma usina de energia SOFC em uma ETE municipal em Fukuoka, Japão. A instalação da unidade é parte do programa de dois anos para avaliar a célula a combustível, que irá operar no modo de co-geração, utilizando as emissões de metano provenientes do processamento dos efluentes municipais para gerar energia elétrica. Adicionalmente, um digestor anaeróbico para tratar os efluentes municipais usará a energia térmica da célula de combustível.

A FCE e a Marubeni também instalaram uma usina de energia SOFC na planta da cervejaria Kirin fora de Tokyo. A célula a combustível utiliza um gás digerido semelhante ao metano proveniente do efluente do processo da cervejaria. Também no Japão, a Toshiba instalou células a combustível que funcionam com gases residuais nas cervejarias Asahi e Sapparo e planeja expandir seus esforços para vender células a combustível que funcionam com gás proveniente de algas. $A$ Toshiba está iniciando esta operação na cidade de Yokohama, focando os sistemas para governos locais.

A TAB. 5 foi adaptada do estudo que analisa a viabilidade da utilização de biocombustíveis na tecnologia de células a combustível estacionárias elaborado pela XENERGY Inc.. 
TABELA 5 - Adequação das células a combustível para combustíveis de origem de biomassa

\begin{tabular}{|c|c|c|c|c|}
\hline \multirow{2}{*}{ Origem do combustível } & \multicolumn{4}{|c|}{ Tipo de célula a combustível } \\
\hline & PEMFC & PAFC & MCFC & SOFC \\
\hline Gaseificação de biomassa & $\boldsymbol{\nabla}$ & $\bullet$ & $\mathbf{x}$ & $\mathbf{x}$ \\
\hline Metano de gás de aterro sanitário & $\nabla$ & $\bullet$ & $\boldsymbol{*}$ & $\mathbf{x}$ \\
\hline Metano de biodigestores & $\boldsymbol{\nabla}$ & $\bullet$ & $\boldsymbol{x}$ & $\mathbf{x}$ \\
\hline Etanol & - & - & $\boldsymbol{x}$ & $\boldsymbol{*}$ \\
\hline Óleo de pirólise & $\square$ & $\square$ & $\square$ & $\square$ \\
\hline Biodiesel & $\square$ & $\square$ & $\square$ & $\square$ \\
\hline Ácido Levulínico & $\square$ & $\square$ & $\square$ & $\square$ \\
\hline Fonte - XENERGY, 2002 & & $\begin{array}{l}\boldsymbol{x}- \\
0-7 \\
\nabla- \\
\square-1\end{array}$ & $\begin{array}{l}\text { otencial } \\
\text { hte com } \\
\text { compa } \\
\text { de de } \mathrm{m}\end{array}$ & prazo \\
\hline
\end{tabular}

A TAB. 5 mostra um estudo comparativo das diferentes tecnologias de células a combustível com a utilização de biocombustíveis de algumas origens de combustível. Pode-se observar na TAB. 5 que a célula a combustível SOFC possui grande potencial no longo prazo para utilização do metano advindo do gás de aterro sanitário, gaseificação de biomassa e metano de biodigestores.

A TAB. 6 também adaptada do mesmo estudo mostra outro comparativo entre os tipos de células a combustível e a utilização de diferentes compostos gasosos comumente encontrados em biocombustíveis.

TABELA 6 - Impactos de compostos gasosos comuns nos quatro tipos de células a combustível

\begin{tabular}{|c|c|c|c|c|}
\hline Compostos gasosos & PEMFC & PAFC & MCFC & SOFC \\
\hline Hidrogênio & Combustível & Combustível & Combustível & Combustível \\
\hline Monóxido de carbono & Veneno & Veneno & Combustível & Combustível \\
\hline Metano & $\begin{array}{c}\text { Inerte, } \\
\text { combustível } \\
\text { se reformado }\end{array}$ & $\begin{array}{c}\text { Inerte, } \\
\text { combustível } \\
\text { se reformado }\end{array}$ & $\begin{array}{c}\text { Combustível } \\
\text { pode ser } \\
\text { reformado } \\
\text { internamente } \\
\text { ou } \\
\text { externamente }\end{array}$ & $\begin{array}{c}\text { Combustível } \\
\text { pode ser } \\
\text { reformado } \\
\text { internamente } \\
\text { ou } \\
\text { externamente }\end{array}$ \\
\hline Dióxido de carbono e água & Diluente & Diluente & Re-circulado & Diluente \\
\hline $\begin{array}{l}\text { Enxofre (Sulfeto de Hidrogênio e } \\
\text { Sulfeto Carbonílico) }\end{array}$ & $\begin{array}{l}\text { Não há } \\
\text { dados }\end{array}$ & $\begin{array}{c}\text { Veneno } \\
<20 \mathrm{ppm} \mathrm{H}_{2} \mathrm{~S} \\
<50 \mathrm{ppm} \mathrm{H}_{2} \mathrm{~S} \\
+ \text { COS }\end{array}$ & $\begin{array}{c}\text { Veneno } \\
<10{\text { ppm } \mathrm{H}_{2} \mathrm{~S}}_{\text {no }} \\
\text { combustível }< \\
1 \text { ppm } \mathrm{SO}_{2} \text { no } \\
\text { oxidante < } \\
0.1-0.5 \text { ppm } \\
\mathrm{H}_{2} \mathrm{~S}\end{array}$ & $\begin{aligned} & \text { Veneno } \\
< & 1 \text { ppm } \mathrm{H}_{2} \mathrm{~S}\end{aligned}$ \\
\hline Halogênios (HCl) & $\begin{array}{l}\text { Não há } \\
\text { dados }\end{array}$ & $\begin{array}{l}\text { Veneno } \\
4 \mathrm{ppm}\end{array}$ & $\begin{array}{c}\text { Veneno } \\
<0.1-1.0 \mathrm{ppm}\end{array}$ & $\begin{array}{l}\text { Veneno } \\
<1 \mathrm{ppm}\end{array}$ \\
\hline
\end{tabular}

Fonte - XENERGY, 2002 
Conforme apresentado na TAB. 6, as SOFCs possuem as maiores tolerâncias a gases que prejudicam a sua operação. A seguir, a Tabela 7 resume os principais pontos de atenção nos diferentes tipos de células a combustível.

Segundo a TAB. 7, células a combustível do tipo SOFC apresentam os melhores potenciais para a aplicação estacionária utilizando biogás proveniente de aterros sanitários, e outros combustíveis derivados de biomassa. Além disso, a geração de energia estacionária em SOFC é um dos pilares do Programa de Ciência, Tecnologia e Inovação para a Economia do Hidrogênio (ProH2).

TABELA 7 - Pontos de atenção nos diferentes tipos de células a combustível

\begin{tabular}{ccccc}
\hline Pontos de atenção & PEMFC & PAFC & MCFC & SOFC \\
\hline Tolerância com contaminantes & Intolerante & $\begin{array}{c}\text { Tolerância } \\
\text { moderada }\end{array}$ & Tolerante & $\begin{array}{c}\text { Maior } \\
\text { tolerância }\end{array}$ \\
\hline Calor residual & $\begin{array}{c}\text { Não } \\
\text { utilizável }\end{array}$ & Utilizável & Utilizável & Utilizável \\
\hline Eficiência do sistema & Menor & Moderada & Moderada & Maior \\
\hline Outros pontos & $\begin{array}{c}\text { Baixa } \\
\text { temperatura }\end{array}$ & $\begin{array}{c}\text { Problemas de } \\
\text { eficiência }\end{array}$ & Corrosividade & $\begin{array}{c}\text { Custos } \\
\text { elevados }\end{array}$ \\
\hline
\end{tabular}

Fonte - XENERGY, 2002 


\subsection{MUDANÇAS CLIMÁTICAS}

O termo mudança do clima usado pelo Painel Intergovernamental sobre Mudança do Clima (IPCC - Intergovernmental Panel on Climate Change) refere-se a qualquer mudança no clima ocorrida ao longo do tempo, quer se deva à variabilidade natural, ou seja, decorrente da atividade humana. Esse uso difere do da Convenção-Quadro das Nações Unidas sobre Mudança do Clima (CQNUMC), em que o termo mudança do clima se refere a: "mudança no clima que seja atribuída direta ou indiretamente à atividade humana, alterando a composição da atmosfera global, e seja adicional à variabilidade natural do clima observada ao longo de períodos comparáveis de tempo" (MCT, 1992). Para fins da presente dissertação foi adotada a definição da CQNUMC para o termo mudança do clima.

O efeito estufa é um fenômeno físico-químico atmosférico que acontece naturalmente, portanto, a vida na Terra somente é possível por causa desse efeito. Para se ter uma idéia da importância do efeito estufa, basta comparar a Terra e a Lua. Enquanto a camada atmosférica que envolve o nosso planeta mantém sua temperatura entre extremos aproximados de $-10^{\circ} \mathrm{C}$ e $50^{\circ} \mathrm{C}$, a Lua, que até onde sabemos não possui seres vivos, apresenta extremos de $-150^{\circ} \mathrm{C}$ a $100^{\circ} \mathrm{C}$ na sua superfície. Estas diferenças existem a despeito do fato de ambos os corpos celestes se encontrarem praticamente a mesma distância do Sol, porque a Terra possui uma camada de gases capaz, em diferentes níveis, de absorver parte da radiação emitida pelo Sol. A energia absorvida faz com que as moléculas de certos gases vibrem, promovendo produção de calor que em parte é re-emitido para o espaço (FIG. 7), e em parte é responsável pela manutenção do clima adequado para os sistemas vivos na superfície terrestre (BUCKERIDGE et al., 2005). 


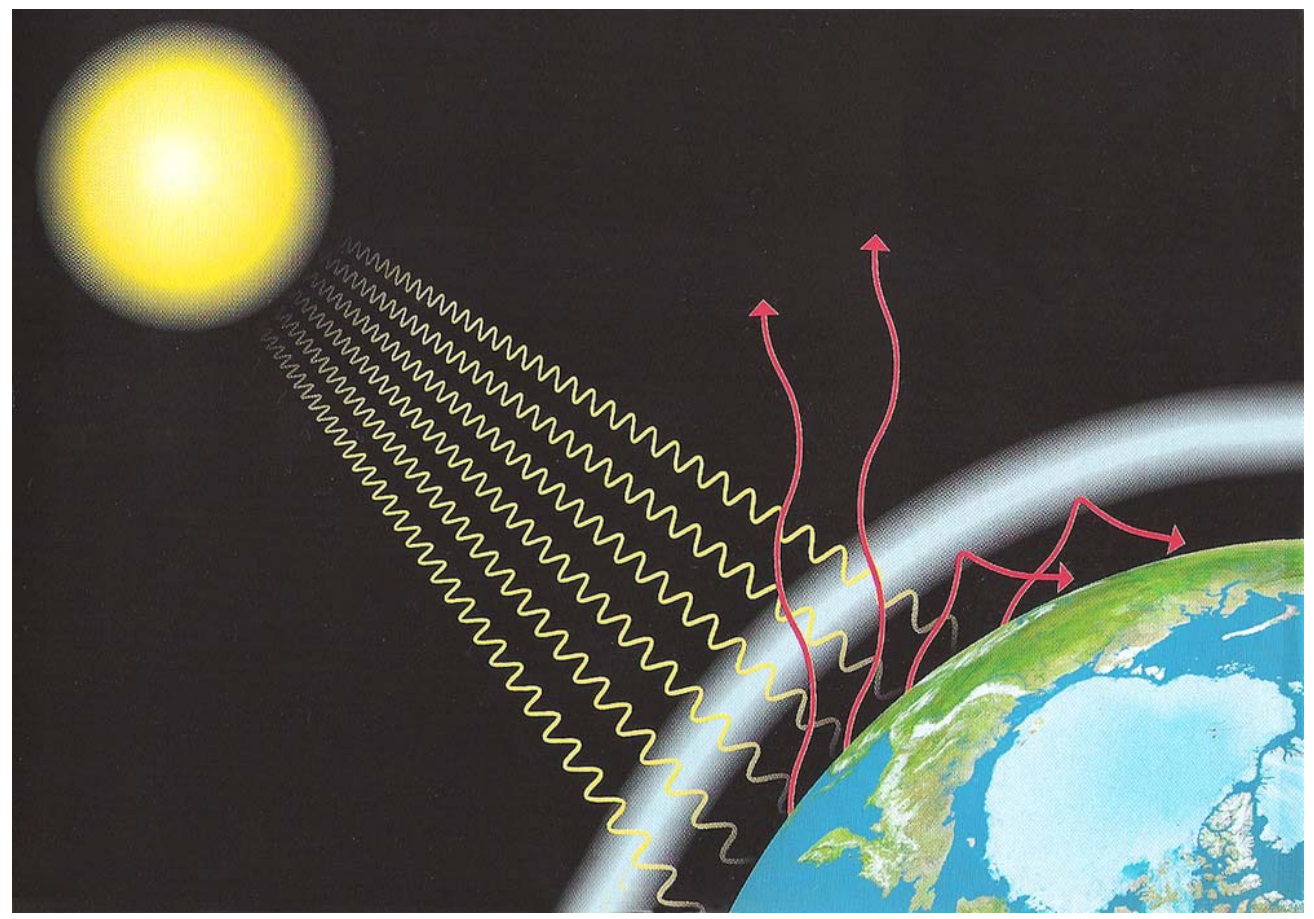

FIGURA 7 - Esquema simplificado do aquecimento global

Fonte - GORE, 2006

A pesquisa científica vem comprovando o contínuo aumento da temperatura média de forma desregulada sendo que grande parte dessa mudança climática tem origem antropogênica. Gylvan Meira Filho, ex-vice-Presidente do IPCC, relata a pesquisa em que foi possível isolar as causas naturais das antrópicas no aquecimento global, através do rastreamento da composição isotópica dos carbonos de diferentes origens, e confirma que o aumento de temperatura nos últimos 100 anos deve-se, em grande parte, à queima de combustíveis fósseis (PARIS, 2005).

O dióxido de carbono é o gás de efeito estufa antrópico mais importante. A concentração atmosférica global de dióxido de carbono aumentou de um valor préindustrial de cerca de 280 ppm para 379 ppm (partes por milhão) em 2005 (FIG.8). A concentração atmosférica de dióxido de carbono em 2005 ultrapassa em muito a faixa natural dos últimos 650.000 anos (180 a 300 ppm), como determinado a partir de testemunhos de gelo. A taxa de aumento da concentração anual de dióxido de carbono foi mais elevada durante os últimos 10 anos (média de 1995 a 2005: 1,9 ppm por ano) do que desde o início das medições atmosféricas diretas contínuas (média de 1960 a 2005: 1,4 ppm por ano), embora haja variações de um ano a outro nas taxas de aumento (IPCC, 2007). 

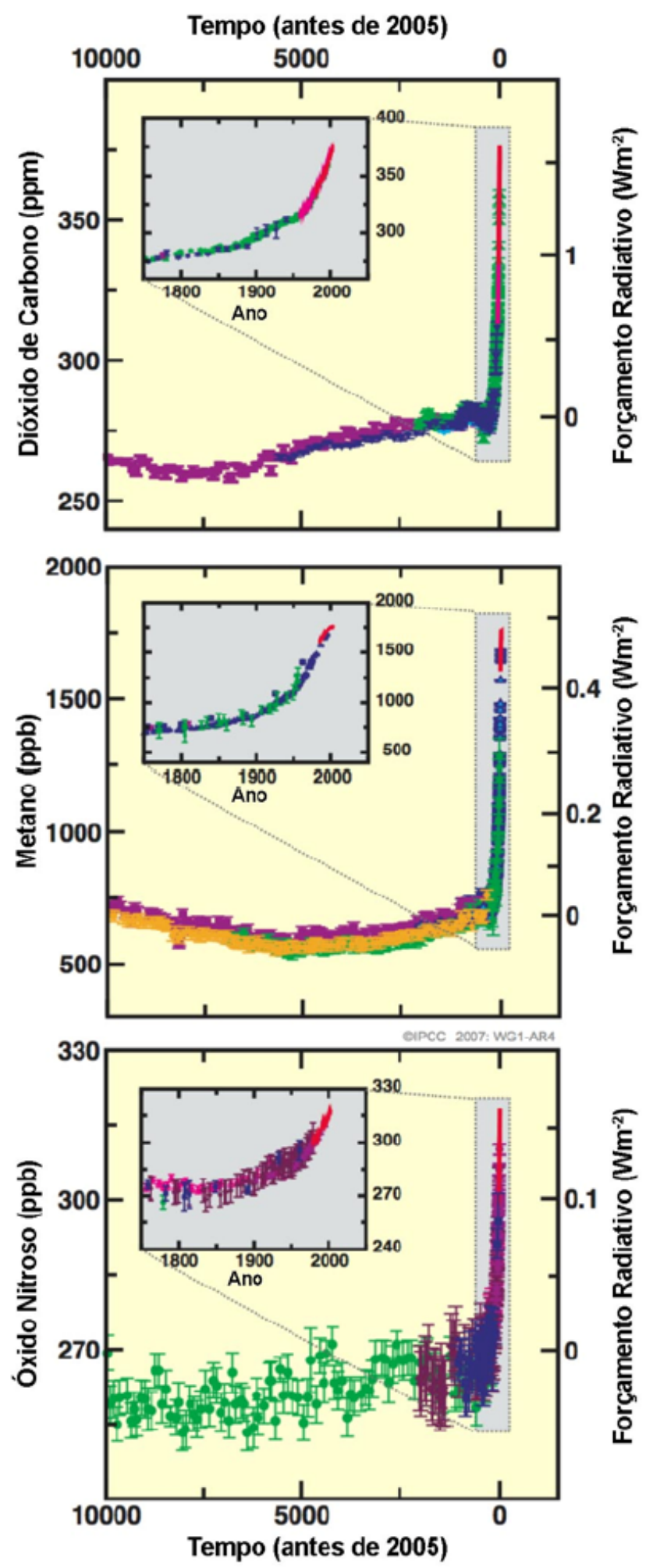

FIGURA 8 - Mudanças nos gases de efeito estufa a partir de dados de testemunho de gelo e dados modernos

Fonte - IPCC, 2007

A concentração atmosférica global de metano aumentou de um valor préindustrial de cerca de 715 ppb (partes por bilhão) para 1732 ppb no início da década 
de 90, sendo de 1.774 ppb em 2005 (FIG. 8). A concentração atmosférica de metano em 2005 ultrapassa em muito a faixa natural dos últimos 650.000 anos (320 a 790 $\mathrm{ppb}$ ), como determinado com base em testemunhos de gelo. As taxas de aumento diminuíram desde o início da década de 90, de forma condizente com o total de emissões (soma das fontes antrópicas e naturais), ficando aproximadamente constantes durante esse período (IPCC, 2007).

Sobre a origem antropogênica das mudanças climáticas Donald Kennedy, editor-chefe da revista Science, chegou a afirmar que um consenso tão forte como o que se formou em torno desse tópico é raro na ciência. Contudo, existe uma noção infundada de que a comunidade cientifica discorda quanto ao aquecimento global se ele é real, se a atividade humana é a causa principal, e se suas conseqüências são perigosas a ponto de exigir uma reação imediata. Não resta praticamente nenhuma divergência séria na comunidade cientifica mundial quanto a esses pontos centrais (GORE, 2006).

A corrente que não aceita a intervenção humana como fator de aquecimento global foi reforçada, em 2005, por várias entidades de representação empresarial. Lançou-se, também nos Estados Unidos, o livro de ficção State of Fear, de Michael Crichton, o mesmo autor do famoso bestseller Parque dos Dinossauros. Seu livro é um romance que apresenta gráficos e notas de rodapé baseados em artigos contrários às conclusões do IPCC.

Os gráficos apresentados pelo livro mostram lugares específicos do mundo onde as temperaturas estão ligeiramente diminuindo, ou permanecendo iguais. Esses gráficos apresentam dados reais, vindos de cientistas reais. Mas embora sejam fatos eles não bastam como argumentos, o aquecimento global se refere ao aumento de temperatura média de toda superfície da Terra. (GORE, 2006) A trama também identifica como agentes radicais os cientistas que acreditam que o ser humano interfere no clima global e todos os ambientalistas. Sabe-se que um romance como este, apoiado em maciça campanha de publicidade, conquistara infinitamente mais leitores do que um relatório da ONU. James Inhofe, que preside no Senado norte-americano a Comissão de Meio Ambiente, chegou a dizer que o romance era a "verdadeira história" das mudanças climáticas. (MARCOVITCH, 2006)

O ficcionista, com habilidade profissional, montou uma base de apoio com artigos escolhidos a dedo na literatura, omitindo evidências de que as mudanças climáticas anormais de nosso tempo derivam de ações antrópicas. Outra verdade 
desprezada foi a de que a concentração de gases na atmosfera, situada em 280 ppm (partes por milhão) de carbono antes da revolução industrial, é hoje, de 370 ppm. Infelizmente, o livro de Crichton tem tudo para ser um sucesso. E pode comprometer os esforços visando a atrair para causa ambiental o indispensável apoio da opinião pública. (MARCOVITCH, 2006)

É conhecido o principio da inexistência de $100 \%$ de certeza nas avaliações científicas. Outra peculiaridade, em ciência, é a contradição aparente entre estudos diversos que guardam, entretanto, harmonia essencial na busca da verdade. (MARCOVITCH, 2006)

Uma cientista da universidade da Califórnia, em San Diego, a $\mathrm{Dr}^{\mathrm{a}} \mathrm{Naomi}$ Oreskes, publicou na revista Science um volumoso estudo. Ela levantou todos os artigos sobre aquecimento global publicados nos 10 anos anteriores à pesquisa em revistas científicas, com revisão pelos pares. Ela e sua equipe escolheram uma grande amostra aleatória: 928 artigos, representado quase 10\% do total. Analisaram então cuidadosamente quantos desses artigos concordavam ou discordavam do consenso científico geral. Cerca de $1 / 4$ dos artigos da amostra não abordava os pontos centrais do consenso científico. Dos $3 / 4$ que tratavam desses pontos centrais $100 \%$ concordavam com o consenso.

A falsa noção de que existem sérias divergências entre os cientistas quanto ao aquecimento global é, na verdade, uma ilusão que vem sendo deliberadamente promovida por um grupo pequeno, mas de grande poder financeiro, representantes de interesses especiais, e que inclui a Exxon Mobil e algumas outras empresas de petróleo, carvão e eletricidade. Essas empresas estão decididas a barrar qualquer nova política capaz de interferir em seus planos de negócios, já que estes dependem da emissão, maciça e ilimitada, de poluentes causadores do aquecimento global, na atmosfera, a cada hora do dia, todos os dias (GORE, 2006).

Um memorando interno desse grupo, que orientava os funcionários contratados a divulgar informações errôneas, foi descoberto pelo repórter Ross Gelbspan, vencedor do Prêmio Pulitzer de jornalismo. Eis o objetivo do grupo, claramente enunciado: "Reposicionar o aquecimento global como uma teoria, e não um fato" (GORE, 2006).

Além do estudo de artigos em publicações científicas, descrito acima, foi realizado outro de significativa relevância. Este abordou todos os artigos sobre aquecimento global publicados nos 14 anos anteriores, nos quatro jornais 
considerados pelos estudiosos como os mais influentes dos EUA: New York Times, Washington Post, Los Angeles Times e Wall Street Journal.

Os pesquisadores escolheram uma amostra aleatória, com quase $18 \%$ dos artigos. Foi descoberto que mais da metade dava peso igual ao consenso científico e à opinião, sem qualquer validade científica, de que o ser humano não exerce nenhuma influencia no aquecimento global. Os estudiosos concluíram que a mídia americana estava, falsamente, "dando a impressão de que a comunidade científica está envolvida em um acalorado debate sobre o papel da contribuição humana para o aquecimento global" (GORE, 2006).

\subsubsection{Painel Intergovernamental sobre Mudança do Clima}

Em 1988 foi criado o Painel Intergovernamental sobre Mudança do Clima (IPCC - Intergovernmental Panel on Climate Change), pela Organização Mundial de Metereologia (WMO - World Meteorological Organization) e o Programa de Meio Ambiente das Nações Unidas (UNEP - United Nations Environment Programme) para se ter uma base científica para se entender como as mudanças climáticas irão se dar sobre o planeta e conseqüentemente como irão atingir os seres humanos. Hoje o IPCC possui o "banco de dados" das principais publicações mundiais sobre o tema de mudanças climáticas, de maior credibilidade em todo mundo.

O IPCC conduz avaliações periódicas do estado do conhecimento sobre a mudança do clima. O primeiro relatório de avaliação, de 1990, indicou que:

- a detecção inequívoca da mudança do clima levaria uma década ou mais;

- a estabilização da concentração atmosférica dos Gases de Efeito Estufa (GEE) exigiria uma redução das emissões globais líquidas (emissões menos seqüestro) antrópicas de, pelo menos, 60\% em relação aos níveis de 1990.

Em 5 de fevereiro de 2007 foi apresentado em Paris, o Sumário para Formuladores de Políticas que trata da contribuição do Grupo de Trabalho I (Base das Ciências Físicas da Mudança do Clima) para o Quarto Relatório de Avaliação do Painel Intergovernamental sobre Mudança do Clima (WGI-AR4), entre suas principais conclusões:

- a mudança do clima já foi detectada de forma inequívoca; 
- a estabilização da concentração atmosférica dos GEE exigirá uma redução das emissões globais de, pelo menos, $60 \%$ em relação aos níveis de 1990.

Durante o período de 1990 a 2007, o conhecimento sobre o ciclo de carbono (isto é, os fluxos naturais e antrópicos de entrada e saída de carbono na atmosfera) aumentou, mas, em termos gerais, a conclusão da necessidade de redução das emissões em, pelo menos, $60 \%$ foi mantida. As estimativas do quarto relatório de avaliação do IPCC, de 2007, são de que o fluxo de dióxido de carbono da atmosfera para os oceanos é de 2,2 $\pm .0,5$ gigatonelada de carbono (GtC/ano). As emissões fósseis globais em 1990 foram de 6,4 \pm 0,4 GtC/ano. Em conseqüência, a estabilização da concentração atmosférica de dióxido de carbono será obtida somente se as emissões globais de dióxido de carbono forem reduzidas de 6,4 para 2,2 GtC/ano, ou seja, uma redução de mais de 60\% em relação a 1990 (MEIRA, 2007).

É interessante notar que essa redução será necessária independentemente do nível da concentração atmosférica de dióxido de carbono que venha a ser considerado aceitável, ou não perigoso, nos termos da Convenção.

A TAB. 8 mostra as expressões utilizadas nos relatórios do IPCC juntamente com as probabilidades de ocorrência.

TABELA 8 - Expressões utilizadas para indicar a probabilidade avaliada, com base na opinião de especialistas, de uma conseqüência ou resultado, para os relatórios do IPCC.

\begin{tabular}{lc}
\hline Expressão utilizada & Probabilidade de ocorrer \\
\hline praticamente certo & $>99 \%$ \\
extremamente provável & $>95 \%$ \\
muito provável & $>90 \%$ \\
provável & $>66 \%$ \\
mais provável do que não & $>50 \%$ \\
improvável & $<33 \%$ \\
muito improvável & $<10 \%$ \\
extremamente improvável & $<5 \%$ \\
\hline
\end{tabular}

Com relação ao metano, ainda segundo o WGI-AR4 e de acordo com as expressões da TAB. 8, "é muito provável que o aumento observado da concentração de metano se deva às atividades antrópicas, predominantemente a agricultura e o uso de combustíveis fósseis, mas as contribuições relativas de diferentes tipos de fontes não estão bem determinadas." 
Ainda segundo WGI-AR4, é muito provável que os extremos de calor, ondas de calor e eventos de forte precipitação continuem sendo mais freqüentes.

Uma das mais conclusões mais contundentes é "que onze dos últimos doze anos (1995 a 2006) estão entre os 12 anos mais quentes do registro instrumental da temperatura da superfície global" (desde 1850).

Um dos principais gráficos do WGI-AR4 mostra a média de vários modelos e faixas avaliadas para o aquecimento da superfície, onde as linhas sólidas são médias globais do aquecimento da superfície produzidas por vários modelos (relativas a 1980-99) para os cenários de referência, mostradas como continuações das simulações do século XX (FIG. 9). O sombreamento denota a faixa de desvio padrão de mais/menos um das médias anuais individuais dos modelos. A linha alaranjada representa o experimento em que as concentrações foram mantidas constantes nos valores do ano 2000. As colunas cinzas à direita indicam a melhor estimativa (linha sólida dentro de cada coluna) e a faixa provável avaliada para os seis cenários.

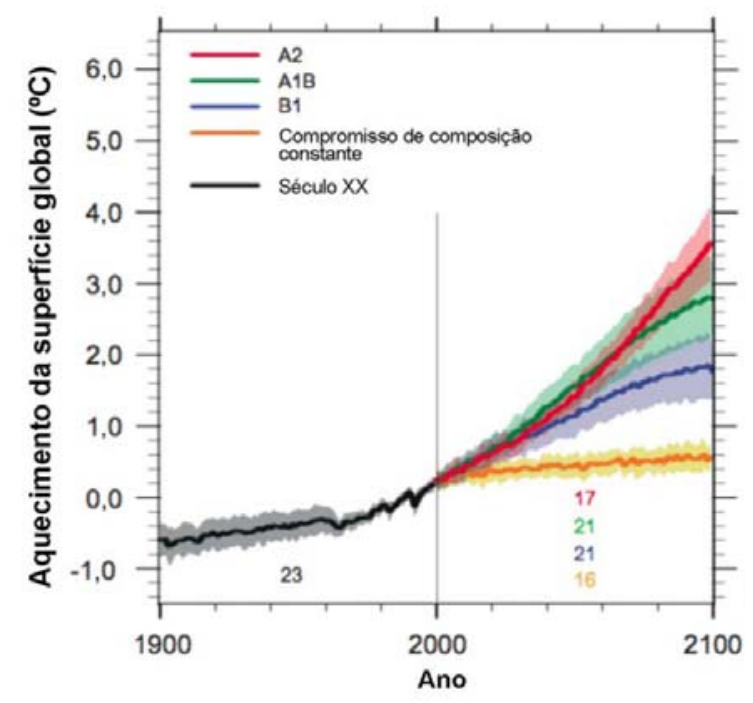

A1. - futuro de crescimento econômico muito rápido, com a população global atingindo um pico em meados do século e declinando em seguida e a rápida introdução de tecnologias novas e mais eficientes.

A2. - um mundo muito heterogêneo, o tema subjacente é a auto-suficiência e a preservação das identidades locais.

B1. - um mundo convergente com a mesma população global, que atinge o pico em meados do século e declina em seguida, como no enredo $A 1$, mas com uma mudança rápida nas estruturas econômicas em direção a uma economia de serviços e informação, com reduções da intensidade material e a introdução de tecnologias limpas e eficientes em relação ao uso dos recursos.

B2. - um mundo em que a ênfase está nas soluções locais para a sustentabilidade econômica, social e ambiental.

FIGURA 9 - Médias de vários modelos e faixas avaliadas para o aquecimento da superfície Fonte - IPCC, 2007

A TAB. 9 apresenta um resumo dos possíveis impactos decorrentes das mudanças climáticas. 
TABELA 9 - Possíveis impactos decorrentes das mudanças climáticas

\begin{tabular}{|c|c|}
\hline Região & Prováveis impactos \\
\hline \multirow[t]{5}{*}{ 1. África } & a. Diminuição da produção agrícola \\
\hline & $\begin{array}{l}\text { b. Diminuição da disponibilidade de água na região do Mediterrâneo e } \\
\text { em países o sul }\end{array}$ \\
\hline & c. Aumento dos vetores de diversas doenças \\
\hline & d. Aumento da desertificação \\
\hline & e. Extinção de animais e plantas \\
\hline \multirow[t]{3}{*}{ 2. Ásia } & a. Diminuição da produção agrícola \\
\hline & $\begin{array}{l}\text { b. Diminuição da disponibilidade de água nas regiões árida e semi- } \\
\text { árida }\end{array}$ \\
\hline & $\begin{array}{l}\text { c. Aumento do nível do mar deverá deslocar dezenas de milhões de } \\
\text { pessoas }\end{array}$ \\
\hline \multirow{2}{*}{$\begin{array}{l}\text { 3. Austrália e Nova } \\
\text { Zelândia }\end{array}$} & a. Diminuição da disponibilidade de água \\
\hline & b. Extinção de animais e plantas \\
\hline \multirow[t]{3}{*}{ 4. Europa } & a. Desaparecimento de geleiras nos Alpes \\
\hline & b. Aumento na produção agrícola em algumas regiões \\
\hline & c. Impactos no turismo \\
\hline \multirow[t]{3}{*}{ 5. América Latina } & a. Diminuição da produção agrícola \\
\hline & b. Aumento dos vetores de diversas doenças \\
\hline & c. Extinção de animais e plantas \\
\hline \multirow[t]{2}{*}{ 6. América do Norte } & a. Aumento na produção agrícola em algumas regiões \\
\hline & b. Aumento dos vetores de diversas doenças \\
\hline \multirow[t]{2}{*}{ 7. Polar } & a. Diminuição da calota polar \\
\hline & b. Extinção de animais e plantas \\
\hline \multirow[t]{4}{*}{ 8. Pequenas ilhas } & $\begin{array}{l}\text { a. Aumento do nível do mar deverá deslocar dezenas de milhões de } \\
\text { pessoas }\end{array}$ \\
\hline & b. Diminuição da disponibilidade de água \\
\hline & c. Diminuição da atividade pesqueira \\
\hline & d. Diminuição no turismo \\
\hline
\end{tabular}

O forçamento radiativo (FR) é uma medida da influência de um fator na alteração do equilíbrio da energia que entra e sai do sistema Terra-atmosfera e é um índice da importância do fator como possível mecanismo de mudança do clima. O forçamento positivo tende a aquecer a superfície, enquanto o forçamento negativo tende a esfriá-la. Os valores do forçamento radiativo na FIG. 10 são para 2005, relativos às condições pré-industriais definidas em 1750, e são expressos em watts por metro quadrado $\left(\mathrm{Wm}^{-2}\right)$.

Estimativas da média global do FR e faixas em 2005 para o dióxido de carbono $\left(\mathrm{CO}_{2}\right)$, o metano $\left(\mathrm{CH}_{4}\right)$, o óxido nitroso $\left(\mathrm{N}_{2} \mathrm{O}\right)$ antrópicos e outros agentes e mecanismos importantes, juntamente com a extensão geográfica típica (escala 
espacial) do forçamento e o nível avaliado de compreensão científica (NCC). O forçamento radiativo antrópico líquido e sua faixa também são mostrados na FIG.10.

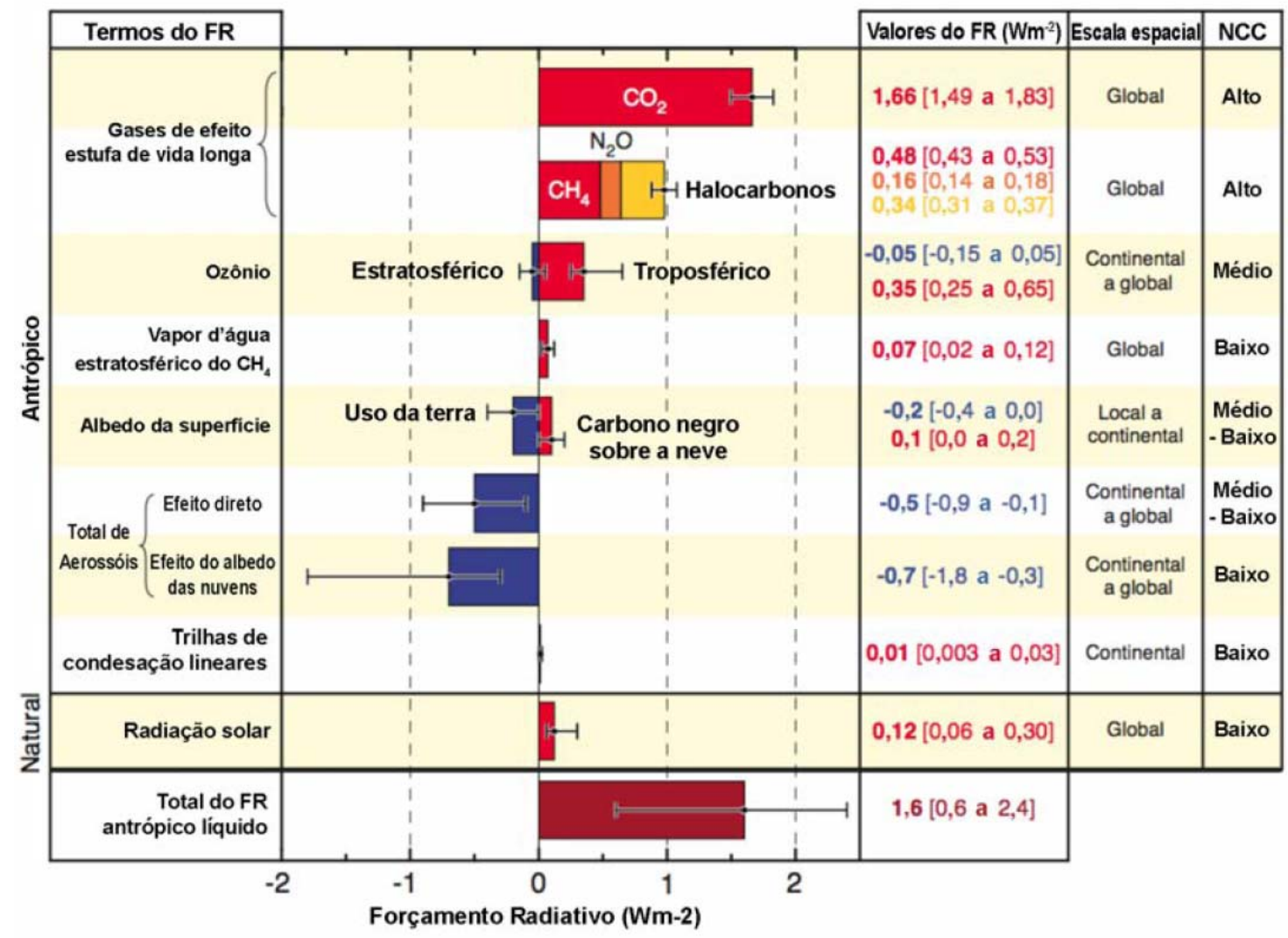

FIGURA 10 - Componentes do Forçamento Radiativo Fonte - IPCC, 2007

Isso requer a soma das estimativas assimétricas da incerteza dos termos componentes e não pode ser obtido por simples adição. Considera-se que outros fatores do forçamento não apresentados aqui tenham um NCC muito baixo (IPCC, 2007).

Foi instituído ao dióxido de carbono um potencial de aquecimento global (Global Warming Potential - GWP) igual a 1, a partir dessa premissa calculou-se os demais potencias dos outros cincos grupos gasosos listados no Anexo A do Protocolo de Quioto. A TAB. 10 mostra esses valores. 
TABELA 10 - Global Warming Potential - GWP, no horizonte de tempo de 100 anos

\begin{tabular}{lll}
\hline Gás de efeito estufa & & GWP \\
\hline Dióxido de Carbono & $\mathrm{CO}_{2}$ & 1 \\
\hline Metano & $\mathrm{CH}_{4}$ & 25 \\
\hline Óxido nitroso & $\mathrm{N}_{2} \mathrm{O}$ & 298 \\
\hline & $\mathrm{HFC}-23$ & 14.800 \\
& $\mathrm{HFC}-125$ & 3.500 \\
& $\mathrm{HFC}-134 \mathrm{a}$ & 1.430 \\
Hidrofluorcarbonos & $\mathrm{HFC}-143 \mathrm{a}$ & 4.470 \\
& $\mathrm{HFC}-152 \mathrm{a}$ & 124 \\
& $\mathrm{HFC}-227 \mathrm{ea}$ & 3.220 \\
& $\mathrm{HFC}-236 \mathrm{fa}$ & 9.810 \\
& $\mathrm{HFC}-43-10 \mathrm{mee}$ & 1.640 \\
\hline & $\mathrm{CF}_{4}$ & 7.390 \\
Perfluorcarbonos & $\mathrm{C}_{2} \mathrm{~F}_{6}$ & 12.200 \\
& $\mathrm{C}_{4} \mathrm{~F}_{10}$ & 8.860 \\
& $\mathrm{C}_{6} \mathrm{~F}_{14}$ & 9.300 \\
\hline Hexafluoreto de enxofre & $\mathrm{SF}_{6}$ & 22.800 \\
\hline
\end{tabular}

Fonte - IPCC, 2007

Para o primeiro período de compromisso (2008-2012) é recomendado pelo Painel de Metodologias (Meth Panel) e pelo Conselho Executivo da CQNUMC, para o metano um valor de GWP de 21, de acordo com as Diretrizes Revisadas do IPCC de 1996 para Inventários Nacionais de Gases de Efeito Estufa. Portanto, para o estudo de caso da presente dissertação o valor do GWP do metano aplicado será de 21.

De fato o GWP é uma medida simples e direta para ser utilizada por tomadores de decisões e agentes do mercado de carbono para classificar os diferentes gases de efeito estufa, mas não é tão obvia a obtenção dessa "equivalência" entre essas diferentes espécies gasosas (FUGLESTVEDT et al., 2003).

SHINE et al. (2005), propuseram o potencial de temperatura global (Global Temperature Potential - GTP) como uma nova métrica de emissões relativa. O GTP é definido como a razão entre a mudança de temperatura da superfície global num horizonte de tempo (TH) pela emissão de um componente $x$ relativo a um gás de referencia $r\left(\right.$ e.x., $\left.\mathrm{CO}_{2}\right)$. 


$$
G T P_{x}^{T H}=\frac{\Delta T_{x}^{H}}{\Delta T_{r}^{H}}
$$

Onde $\boldsymbol{\Delta} \boldsymbol{T}^{H}{ }_{x}$ significa a mudança na temperatura da superfície depois de $H$ anos pela emissão do componente $x$. O GWP utiliza uma quantidade definida dentro de um horizonte de tempo (i.e., a contribuição da RF sendo a mesmo do começo ao fim do horizonte de tempo), o GTP utiliza a mudança de temperatura no tempo $H$ (i.e., como RF é fechado para o tempo $H$ sua contribuição é relativamente maior). A métrica GTP requere o conhecimento dos mesmos parâmetros da GWP (RF, eficiência e tempo de vida), mas adicionalmente, o tempo de resposta do sistema climática deve ser conhecido, particularmente o tempo de vida do componente $x$ é bastante diferente do tempo de vida do gás de referencia $r$.

A utilização da métrica GTP ao invés do GWP possui a vantagem de ser diretamente relacionada com a mudança na temperatura da superfície (SHINE et al. 2005).

\subsubsection{Convenção-Quadro das Nações Unidas sobre Mudança do Clima} (CQNUMC)

A CQNUMC - Convenção-Quadro das Nações Unidas sobre Mudança do Clima (UNFCCC - United Nations Framework Convention on Climate Change) é o tratado internacional em vigor, de caráter universal na medida em que foi firmado e ratificado essencialmente por todos os países-membros da ONU, que estabelece o regime internacional para enfrentar o problema da mudança do clima.

No ano de 1994, foi homologada a CQNUMC que tem como base dois princípios. O primeiro é o princípio da precaução que institui para a Convenção que a falta de plena certeza científica não deve ser usada como razão para que os países posterguem a adoção de medidas para prever, evitar ou minimizar as causas da mudança do clima e mitigar seus efeitos negativos. O segundo é o princípio da responsabilidade comum, porém diferenciada, explicitando que a mudança do clima da Terra e seus efeitos negativos são preocupações comuns da humanidade. A maior parcela das emissões globais, históricas e atuais, de gases de efeito estufa é originária dos países desenvolvidos. As emissões per capita dos países em 
desenvolvimento ainda são relativamente baixas e a parcela de emissões globais originárias dos países em desenvolvimento prevê-se que crescerá para que eles possam satisfazer suas necessidades sociais e de desenvolvimento. (PARIS, 2005).

O principal objetivo dessa Convenção é de prevenir uma interferência antrópica "perigosa" no sistema climático da Terra. Porém, Convenção não estabelece qual o limiar de concentração atmosférica de gases de efeito estufa com base no fato de a interferência humana sobre o sistema climático ser considerada perigosa. Não existe um consenso sobre até que ponto essas interferências devem ser consideradas perigosas. As mudanças climáticas atingem os países e regiões de maneiras diferentes. Algumas regiões de certos países podem até se beneficiar com o aumento das temperaturas e dos índices pluviométricos, ao mesmo tempo em que o aumento do nível dos oceanos coloca em risco a própria existência de várias ilhas. Nos dois casos existem conceitos diferentes de interferência antrópica "perigosa". Com isso, qualquer definição de risco em nível global será uma decisão política (DUTSCHKE, 2005).

As nações desenvolvidas estão listadas no anexo $\mathrm{I}^{1}$, são as nações que pertencem à Organização para a Cooperação e o Desenvolvimento Econômico (OECD) mais as 12 economias de transição.

A CQNUMC instituiu que todos os anos os países signatários, na convenção eles são chamados de Partes, devem se reunir nas Conferências da Partes (Conference of the Parties - COP), para discutirem uma agenda para o atendimento dos objetivos da convenção. A partir de 2005 com entrada em vigor do Protocolo de Quioto as Conferências das Partes funcionaram agora como Reunião das Partes (Conference of the Parties serving as the Meeting of the Parties to the Kyoto Protocol - MOP) - Conferência das Partes na qualidade de Reunião das Partes do Protocolo de Quioto.

A TAB. 11 apresenta a lista de COPs e MOPs realizadas até a presente data e suas respectivas localizações, assim como, a próxima COP/MOP prevista para dezembro desse ano.

\footnotetext{
${ }^{1}$ Alemanha, Austrália, Áustria, Belarus, Bélgica, Bulgária, Canadá, Comunidade Européia, Croácia, Dinamarca, Eslováquia, Eslovênia, Espanha, Estados Unidos da América, Estônia, Federação Russa, Finlândia, França, Grécia, Hungria, Irlanda, Islândia, Itália, Japão, Letônia, Liechtenstein, Lituânia, Luxemburgo, Mônaco, Noruega, Nova Zelândia, Países Baixos, Polônia, Portugal, Reino Unido da Grã-Bretanha e Irlanda do Norte, República Tcheca, Romênia, Suécia, Suíça, Turquia e Ucrânia
} 
TABELA 11 - Lista das COPs e MOPs

\begin{tabular}{llll}
\hline Ano & Encontro & Cidade & País \\
\hline 1995 & COP 1 & Berlim & Alemanha \\
1996 & COP 2 & Genebra & Suíça \\
1997 & COP 3 & Quioto & Japão \\
1998 & COP 4 & Buenos Aires & Argentina \\
1999 & COP 5 & Bonn & Alemanha \\
2000 & COP 6 & Haia & Holanda \\
2001 & COP 6,5 & Bonn & Alemanha \\
2001 & COP 7 & Marrakeshi & Marrocos \\
2002 & COP 8 & Nova Deli & India \\
2003 & COP 9 & Milão & Itália \\
2004 & COP 10 & Buenos Aires & Argentina \\
2005 & COP 11 MOP 1 & Montreal & Canadá \\
2006 & COP 12 MOP 2 & Nairobi & Quênia \\
2007 & COP 13 MOP 3 & Bali & Indonésia \\
\hline
\end{tabular}

No debate internacional sobre o futuro da implementação da Convenção, foram mencionados, por vezes, os níveis de concentração de dióxido de carbono (por exemplo, 550 partes por milhão em volume - ppmv). Na última reunião do G8 (grupo formado por Alemanha, Canadá, Estados Unidos, França, Itália, Japão, Reino Unido e Rússia) em junho de 2007, foi proposta uma limitação do aumento da temperatura média da superfície em $2{ }^{\circ} \mathrm{C}$. As duas formas - limite de temperatura e de concentração - são equivalentes, na medida em que a adoção de um limite para o aumento da temperatura média global pode ser expressa com bastante segurança em termos de um limite para a concentração atmosférica de dióxido de carbono, que, no caso, é da ordem de 550 ppm. Essas propostas estabelecem que a redução de emissões globais para manter o aumento de temperatura ou a concentração de acordo com limites seja obtida até 2050.

\subsubsection{Protocolo de Quioto}

Segundo FRANGETTO e GAZANI (2002), advogados especialistas em direito ambiental, a convenção do clima é um ato geral e protocolo, um ato específico, ou seja, uma complementação a um ato geral.

$\mathrm{Na}$ terceira COP celebrou-se o Protocolo de Quioto que se propõe reduzir $5,2 \%$ o nível de emissões de gases de efeito estufa dos países desenvolvidos (que estão listados no anexo I da CQNUMC) tomando como base o ano 1990, no primeiro período de compromisso entre 2008 a 2012. Como o próprio nome indica que, em princípio, esse primeiro período seria seguido de um segundo de compromissos, e 
assim sucessivamente. Para isso esses países podem reduzir suas emissões domésticas ou através dos mecanismos de flexibilização, com o objetivo de reduzir o custo marginal da redução das emissões das partes listadas no Anexo I, os mecanismos de flexibilização são:

- Comércio de Emissões (ET - Emissions Trading): permite que partes do Anexo I que conseguirem reduzir suas emissões de Gases de Efeito Estufa (GEE) além da meta estabelecida pelo Protocolo, podem comercializar esse excedente com outras partes do Anexo I;

- Implementação Conjunta (JI - Joint Implementation): permite que partes do Anexo I participem em projetos de redução de emissões de GEE em outras partes do Anexo I. As reduções resultantes desses projetos podem ser divididas entre essas partes e utilizadas para atingir suas metas; e

- Mecanismo de Desenvolvimento Limpo (MDL) (CDM - Clean Development Mechanism): permite que partes do Anexo I invistam em projetos de redução de emissões ou comprem as reduções de emissões de projetos desenvolvidos em partes não listadas no Anexo I. Essas partes do Anexo I podem utilizar essas reduções de emissões para atingir suas metas. Portanto, esse é o único mecanismo de flexibilização do Protocolo que se aplica ao Brasil, que não é uma parte listada no Anexo I. Os procedimentos desse mecanismo foram estabelecidos nos Acordos de Marraquesh, em novembro de 2001, na Sétima Conferência das Partes - COP 7.

\subsubsection{Mecanismo de Desenvolvimento Limpo (MDL)}

O propósito do MDL é prestar assistência às Partes não-Anexo I da CQNUMC para que viabilizem o desenvolvimento sustentável através da implementação de atividades de projeto e contribuam para o objetivo final da convenção e, por outro lado, prestar assistência às Partes Anexo I para que cumpram seus compromissos quantificados de limitação e redução de emissões de gases de efeito estufa (LOPES, 2002). Podem participar de uma atividade de projeto do MDL as chamadas Partes Anexo I, Partes não-Anexo I ou entidades públicas e privadas dessas Partes, 
desde que por elas devidamente autorizadas. Atividades de projeto do MDL podem ser implementadas por meio de parcerias com o setor público ou privado.

O setor privado tem grande oportunidade de participação, pois o potencial para reduzir emissões nesse setor é significativo. Além disso, é receptor de fluxos crescentes de investimentos que podem ser destinados a atividades de projeto do MDL, que é um mecanismo de mercado concebido para ter sua ativa participação. Para que sejam consideradas elegíveis no âmbito do MDL, as atividades de projeto devem contribuir para o objetivo primordial da convenção e observar alguns critérios fundamentais, entre os quais o da adicionalidade, pelo qual uma atividade de projeto deve, comprovadamente, resultar na redução de emissões de gases de efeito estufa e/ou remoção de $\mathrm{CO}_{2}$, adicional ao que ocorreria na ausência da atividade de projeto do MDL.

Uma unidade de Redução Certificada de Emissão (RCE) é igual a uma tonelada métrica de dióxido de carbono equivalente, calculada de acordo com o Potencial de Aquecimento Global (GWP), índice divulgado pelo IPCC e utilizado para uniformizar as quantidades dos diversos gases de efeito estufa em termos de dióxido de carbono equivalente, possibilitando que reduções de diferentes gases sejam somadas. O GWP que deve ser utilizado para o primeiro período de compromisso (2008-2012) é o publicado no Segundo Relatório de Avaliação do IPCC.

As RCEs representam créditos que podem ser utilizados pelas Partes Anexo I - que tenham ratificado o Protocolo de Quioto - como forma de cumprimento parcial de suas metas de redução de emissão de gases de efeito estufa. As vantagens para o participante estrangeiro traduzem-se na possibilidade de cumprimento parcial de suas metas de redução a um custo marginal relativamente mais baixo.

As atividades de projeto do MDL, bem como as reduções de emissões de gases de efeito estufa e/ou aumento de remoção de $\mathrm{CO}_{2}$ a estas atribuídas deverão ser submetidas a um processo de aferição e verificação por meio de instituições e procedimentos estabelecidos na COP 7. Dentre as instituições relacionadas ao MDL destacam-se aquelas a seguir indicadas:

Conselho Executivo do MDL - Supervisiona o funcionamento do MDL. Entre suas responsabilidades destacam-se: (i) o credenciamento das Entidades Operacionais Designadas; (ii) registro das atividades de projeto do MDL; (iii) emissão das RCEs; (iv) desenvolvimento e operação do Registro do MDL; (v) 
estabelecimento e aperfeiçoamento de metodologias para definição da linha de base, monitoramento e fugas.

Autoridade Nacional Designada - Governos de países participantes de uma atividade de projeto do MDL devem designar junto à CQNUMC uma Autoridade Nacional para o MDL. A Autoridade Nacional Designada (AND) atesta que a participação dos países é voluntária e, no caso do país onde são implementadas as atividades de projeto, que ditas atividades contribuem para o desenvolvimento sustentável do país, a quem cabe decidir, de forma soberana, se este objetivo do MDL está sendo cumprido. As atividades de projetos do MDL devem ser aprovadas pela AND.

A Comissão Interministerial de Mudança Global do Clima, representa a AND brasileira, foi criado pelo Decreto Presidencial de 7 de julho de 1999, que constitui uma comissão originalmente composta por representantes de oito ministérios foi alterada em 10 de janeiro de 2006, sendo hoje representantes de onze ministérios, conforme apresentados na TAB. 12:

TABELA 12 - Comissão Interministerial de Mudança Global do Clima (CIMGC)

I. Ministério das Relações Exteriores;

II. Ministério da Agricultura, Pecuária e Abastecimento*;

III. Ministério dos Transportes;

IV. Ministério de Minas e Energia

V. Ministério do Planejamento, Orçamento e Gestão*;

VI. Ministério do Meio Ambiente;

VII. Ministério da Ciência e Tecnologia;

VIII. Ministério do Desenvolvimento, Indústria e Comércio Exterior*;

IX. Casa Civil da Presidência da República;

$X$. Ministério das Cidades*;

XI. Ministério da Fazenda*.

${ }^{*}$ Redação dada pelo Decreto de 10 de janeiro de 2006

Entidades Operacionais Designadas - São entidades nacionais ou internacionais credenciadas pelo Conselho Executivo e designadas pela COP/MOP, a qual ratificará ou não o credenciamento feito pelo Conselho Executivo. As responsabilidades das Entidades Operacionais Designadas - EODs consistem em: (i) Validar atividades de projetos do MDL de acordo com as decisões de Marraqueche; (ii) Verificar e certificar reduções de emissões de gases de efeito estufa e remoções de $\mathrm{CO}_{2}$; (iii) Manter uma lista pública de atividades de projetos do MDL; (iv) Enviar um relatório anual ao Conselho Executivo; (v) Manter disponíveis para o público as informações sobre as atividades de projeto do $M D L$, que não sejam consideradas confidenciais pelos participantes do projeto. 
Para que resultem em RCEs, as atividades de projeto do MDL devem, necessariamente, passar pelas etapas do Ciclo do Projeto, quais sejam:

(1) Elaboração do Documento de Concepção do Projeto - DCP;

(2) Validação/Aprovação;

(3) Registro;

(4) Monitoramento;

(5) Verificação/Certificação;

(6) Emissão das RCEs.

\subsubsection{Projetos de MDL em aterros sanitários}

Atualmente, o Brasil ocupa o $3^{\circ}$ lugar em número de atividades de projeto de MDL, com 221 projetos (12\%), sendo que em primeiro lugar encontra-se a Índia com 623 e, em segundo, a China com 446 projetos (MCT, 2007).

A primeira atividade de projeto registrada no Conselho Executivo do MDL foi o projeto NovaGerar de conversão de gás de aterro em energia, no município de Nova Iguaçu, Rio de Janeiro, Brasil. A TAB. 13 mostra as atividades de projetos no Brasil por tipo de projeto. Foram destacados os projetos de aterros sanitários que representam a segunda categoria em número de projetos e a maior redução em volume de emissões.

Para que uma atividade de projeto de MDL seja validada, esta necessariamente deve estar associada a metodologias de linha de base e monitoramento aprovadas pelo painel de metodologia (Meth Panel) da CQNUMC. Quando existem diversas metodologias aprovadas correlatas ou para projetos do mesmo escopo setorial essas metodologias são condensadas em uma metodologia consolidada aprovada.

Cita-se a ACM0001 "Metodologia consolidada aprovada de linha de base para atividades de projetos com gás de aterro" se aplica às atividades de projetos de captação de gás de aterro (LFG) em que o cenário da linha de base é a emissão parcial ou total do gás para a atmosfera e as atividades do projeto compreendem situações como:

a) O gás captado é queimado; ou

b) O gás captado é usado para produzir energia (por exemplo, eletricidade/energia térmica), mas não se reivindica nenhuma redução de emissões por se deslocar ou evitar o uso de energia de outras fontes; ou 
c) O gás captado é usado para produzir energia (por exemplo, eletricidade/energia térmica) e reduções de emissões são reivindicadas por se deslocar ou evitar a geração de energia a partir de outras fontes. Nesse caso, devese fornecer uma metodologia de linha de base para a eletricidade e/ou energia térmica deslocada ou usar uma já aprovada, inclusive a ACM0002 "Metodologia consolidada aprovada para a geração de energia elétrica Conectada à rede a partir de fontes renováveis". Se a capacidade de eletricidade gerada for inferior a $15 \mathrm{MW}$, e/ou a energia térmica deslocada for inferior a 54 TJ (15 GWh), podem ser usadas as metodologias de pequena escala.

TABELA 13 - Distribuição das atividades de projeto no Brasil por tipo de projeto

\begin{tabular}{|c|c|c|c|c|c|c|}
\hline $\begin{array}{l}\text { Projetos em } \\
\text { Validação/Aprovação }\end{array}$ & $\begin{array}{l}\text { Número } \\
\text { de } \\
\text { projetos }\end{array}$ & $\begin{array}{l}\text { Redução } \\
\text { anual de } \\
\text { emissão }\end{array}$ & $\begin{array}{l}\text { Redução de } \\
\text { emissão no } \\
1^{\circ} \text { período de } \\
\text { obtenção de } \\
\text { crédito }\end{array}$ & $\begin{array}{l}\text { Número } \\
\text { de } \\
\text { projetos }\end{array}$ & $\begin{array}{l}\text { Redução } \\
\text { anual de } \\
\text { emissão }\end{array}$ & $\begin{array}{l}\text { Redução } \\
\text { de emissão } \\
\text { no } 1^{\circ} \\
\text { período de } \\
\text { obtenção } \\
\text { de crédito }\end{array}$ \\
\hline Biomassa & 69 & 3.506 .997 & 25.631 .897 & $32 \%$ & $14 \%$ & $13 \%$ \\
\hline Aterro Sanitário & 26 & 9.437 .121 & 70.583 .306 & $12 \%$ & $37 \%$ & $36 \%$ \\
\hline $\mathrm{PCH}$ & 25 & 1.703 .427 & 13.428 .145 & $12 \%$ & $7 \%$ & $7 \%$ \\
\hline $\begin{array}{l}\text { Manejo e Tratamento } \\
\text { de Resíduos }\end{array}$ & 22 & 1.749 .102 & 17.176 .585 & $10 \%$ & $7 \%$ & $9 \%$ \\
\hline $\begin{array}{l}\text { Recuperação de } \\
\text { Metano }\end{array}$ & 20 & 592.472 & 5.428 .676 & $9 \%$ & $2 \%$ & $3 \%$ \\
\hline $\begin{array}{l}\text { Substituição de } \\
\text { Combustíveis }\end{array}$ & 15 & 1.227 .259 & 8.958 .891 & $7 \%$ & $5 \%$ & $5 \%$ \\
\hline Eficiência Energética & 9 & 48.440 & 406.496 & $4 \%$ & $0 \%$ & $0 \%$ \\
\hline Eólica & 6 & 367.033 & 2.141 .291 & $3 \%$ & $1 \%$ & $1 \%$ \\
\hline Hidro & 12 & 625.810 & 4.632 .931 & $6 \%$ & $2 \%$ & $2 \%$ \\
\hline Indústria Manufatureira & 3 & 430.788 & 3.075 .625 & $1 \%$ & $2 \%$ & $2 \%$ \\
\hline $\mathrm{N}_{2} \mathrm{O}$ & 2 & 6.041 .274 & 42.288 .918 & $1 \%$ & $23 \%$ & $22 \%$ \\
\hline Energia mecânica & 2 & 9.893 & 69.248 & $1 \%$ & $0 \%$ & $0 \%$ \\
\hline Distribuição energia & 1 & 53.327 & 533.270 & $0 \%$ & $0 \%$ & $0 \%$ \\
\hline Emissão fugitiva & 1 & 34.685 & 242.795 & $0 \%$ & $0 \%$ & $0 \%$ \\
\hline Indústria Química & 1 & 17.137 & 119.960 & $0 \%$ & $0 \%$ & $0 \%$ \\
\hline Total & 214 & 25.844 .765 & 194.718 .034 & $100 \%$ & $100 \%$ & $100 \%$ \\
\hline
\end{tabular}

A redução de emissões de gases de efeito estufa obtida pela atividade do projeto durante um determinado ano "y" $\left(E r_{y}\right)$ corresponde à diferença entre a quantidade de metano realmente destruída/queimada durante o ano $\left(M D_{\text {project,y }}\right)$ e a quantidade de metano que teria sido destruída/queimada durante o ano na ausência da atividade do projeto $\left(M D_{\text {reg,y }}\right)$, vezes o valor aprovado do Potencial de 
Aquecimento Global para o metano $\left(G W P_{\mathrm{CH}_{4}}\right)$, mais a quantidade líquida de eletricidade deslocada durante o ano $\left(E G_{y}\right)$, multiplicada pela intensidade de emissões de $\mathrm{CO}_{2}$ da eletricidade deslocada $\left(C E F_{\text {electricity,y }}\right)$, mais a quantidade de energia térmica deslocada durante o ano $\left(E T_{y}\right)$ multiplicada pela intensidade de emissões de $\mathrm{CO}_{2}$ da energia térmica deslocada ( $\left.C E F_{\text {thermal,y}}\right)$.

$$
E R_{y}=\left(M D_{\text {project }, y}-M D_{\text {reg }, y}\right) * G W P_{C H 4}+E L_{y} \cdot C E F_{\text {electricity } y}+E T_{y} * C E F_{\text {thermal }, y}
$$

Onde,

\begin{tabular}{|c|c|}
\hline$R_{y}$ & $\begin{array}{l}\text { a redução de emissões, em toneladas de equivalentes de } \mathrm{CO}_{2} \\
\left.\mathrm{CO}_{2} \mathrm{e}\right) ;\end{array}$ \\
\hline$D_{\text {project,y }}$ & $\begin{array}{l}\text { é a quantidade de metano que teria sido destruída/queimada } \\
\text { durante o ano, em toneladas de metano }\left(\mathrm{tCH}_{4}\right) ;\end{array}$ \\
\hline$D_{\text {reg,y3 }}$ & $\begin{array}{l}\text { é a quantidade de metano que teria sido destruída/queimada } \\
\text { durante o ano, na ausência do projeto, em toneladas de metano } \\
\left(\mathrm{tCH}_{4}\right) \text {; }\end{array}$ \\
\hline$G W P_{C H 4}$ & $\begin{array}{l}\text { é o valor do Potencial de Aquecimento Global para o metano no } \\
\text { primeiro período de compromisso, que é } 21 \mathrm{tCO}_{2} \mathrm{e} / \mathrm{tCH}_{4} ;\end{array}$ \\
\hline$E$ & $\begin{array}{l}\text { é a quantidade líquida de eletricidade exportada durante o ano y, } \\
\text { em megawatt horas (MWh); }\end{array}$ \\
\hline$C E F_{\text {electricity }, y}$ & $\begin{array}{l}\text { é a intensidade em emissões de } \mathrm{CO}_{2} \text { da eletricidade substituída, } \\
\text { em } \mathrm{tCO}_{2} \mathrm{e} / \mathrm{MWh} \text {. Pode ser estimada com o uso da ACM0002 ou }\end{array}$ \\
\hline & $\begin{array}{l}\text { AMS I.D, se a capacidade estiver dentro dos valores do patamar } \\
\text { de pequena escala, quando a eletricidade da rede for usada ou } \\
\text { substituída, ou AMS I.A se a energia cativa for usada ou } \\
\text { substituída; }\end{array}$ \\
\hline$E T$ & $\begin{array}{l}\text { é o aumento da quantidade de combustíveis fósseis, definido } \\
\text { como a diferença entre o combustível fóssil usado na linha de } \\
\text { base e o combustível fóssil usado no projeto, para atender as } \\
\text { necessidades de energia da atividade do projeto no local, durante } \\
\text { o ano y, em TJ; }\end{array}$ \\
\hline ermal,y & $\begin{array}{l}\text { é a intensidade em emissões de } \mathrm{CO}_{2} \text { do combustível usado pa } \\
\text { gerar energia térmica/mecânica, em } \mathrm{tCO}_{2} \mathrm{e} / \mathrm{TJ} \text {. }\end{array}$ \\
\hline
\end{tabular}

A metodologia de monitoramento ACM0001 é baseada na medição direta da quantidade de gás de aterro captada e destruída na plataforma de queima e na(s) unidade(s) geradora(s) de eletricidade/energia térmica a fim de determinar as quantidades conforme mostrado na FIG. 11. O plano de monitoramento prevê a medição contínua da quantidade e da qualidade do gás de aterro queimado. As 
variáveis principais que precisam ser determinadas são a quantidade de metano realmente captada $\left(M D_{\text {project,y }}\right)$, a quantidade de metano queimada $\left(M D_{\text {flared,y }}\right)$ e a quantidade de metano usada para gerar eletricidade $\left(M D_{\text {electricty,y }}\right) /$ energia térmica $\left(M D_{\text {thermal,y }}\right)$.

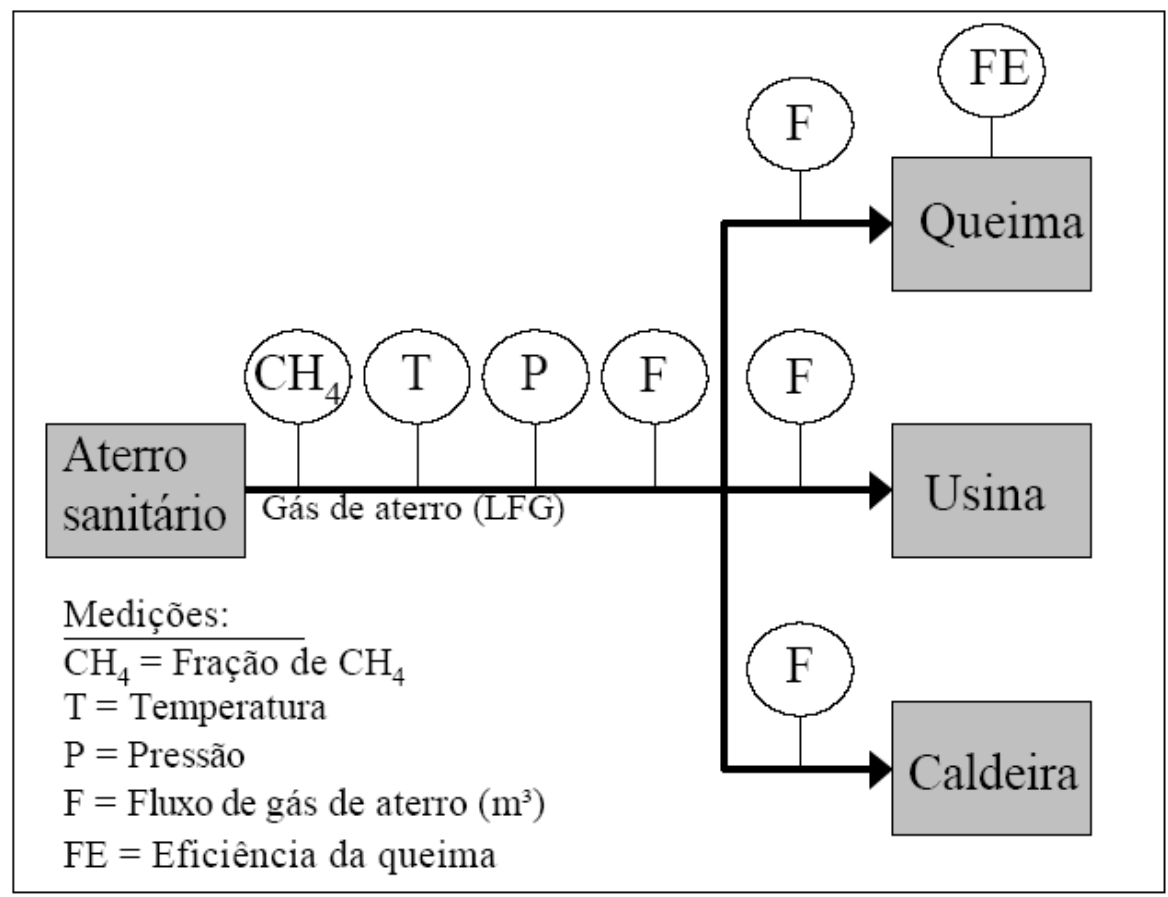

FIGURA 11 - Plano de Monitoramento da ACM0001

Segundo MÖLLERT e GRÖNKVIST (2007), existem erros nessa metodologia. O principal apontado é a exclusão da contabilização do $\mathrm{CO}_{2}$ advindo da oxidação do $\mathrm{CH}_{4}$ na ACM0001. A conseqüência dessa inconsistência são que as reduções dos projetos que se utilizam dessa metodologia, segundo esses autores, estão superestimadas em aproximadamente $13 \%$. Os autores enfatizam que todo $\mathrm{CO}_{2}$ é igual na atmosfera. $\mathrm{O} \mathrm{CO}_{2}$ de origem da queima combustíveis fósseis e o advindo da biomassa na atmosfera causam o mesmo impacto no balanço radiativo do planeta.

A ACM0002 se aplica às atividades de projetos de geração de energia renovável conectada à rede sob as seguintes condições:

- usinas hidrelétricas a fio de água; projetos de energia hidrelétrica com reservatórios existentes em que o volume do reservatório não aumente;

- novos projetos de energia hidrelétrica com reservatórios cujas densidades de energia (capacidade instalada de geração elétrica dividida pela área da superfície no nível máximo do reservatório) sejam superiores a $4 \mathrm{~W} / \mathrm{m}^{2}$;

- fontes de energia eólica; 
- fontes de energia geotérmica;

- fontes de energia solar;

- fontes de energia de ondas e marés.

- esta metodologia não se aplica às atividades de projetos que envolvam a mudança de combustíveis fósseis para energia renovável na área da atividade do projeto, uma vez que, nesse caso, a linha de base pode ser a continuação do uso de combustíveis fósseis no local;

- os limites geográficos e do sistema da rede elétrica pertinente possam ser claramente identificados e existam informações sobre as características da rede; e

- aplique-se à geração de eletricidade conectada à rede a partir da captação de gás de aterro, em conjunto com a ACM0001 "metodologia consolidada aprovada de linha de base para atividades de projetos com gás de aterro".

A geração de energia a partir da tecnologia de células a combustível não é mencionada por esta metodologia.

Todavia, a presente dissertação utilizou a ACM0001 como metodologia para os cálculos de redução de emissões de GEE. Caso a atividade de projeto de MDL venha a ser implementada, necessariamente uma revisão metodológica deve ser apresentada a CQNUMC, com a inclusão da tecnologia de células a combustível nesse contexto. 


\subsection{Resíduos Sólidos}

A palavra resíduo deriva do latim residuu, significando aquilo que resta de qualquer substância. Posteriormente foi adjetivada de "sólido" para diferenciar dos resíduos líquidos lançados nos esgotos domésticos e das emissões gasosas das chaminés à atmosfera (CADAVID, 2004). A caracterização do resíduo deve ser efetuada em função da composição de sua massa bruta, através de ensaios de laboratório ou catálogos técnicos, além da verificação de uma possível contaminação de outros materiais após sua disposição. A classificação é feita de acordo com as normas NBR 10.004, 10.005, 10.006 e 10.007, da Associação Brasileira de Normas Técnicas (ABNT).

Segundo ABNT NBR 10.004:2004 resíduos sólidos são resíduos no estado sólido e semi-sólido, que resultam de atividades de origem industrial, doméstica, hospitalar, comercial, agrícola, de serviços e de varrição. Ficam incluídos nesta definição os lodos provenientes de tratamentos de águas, aqueles gerados em equipamentos e instalações de controle de poluição, bem como determinados líquidos cujas particularidades tornem inviável o seu lançamento na rede pública de esgotos ou copos de água, ou exijam para isso soluções técnicas e economicamente inviáveis em face da melhor tecnologia disponível.

1. Classe I-perigosos

2. Classe II - não perigosos

3. Classe III A - não inertes

4. Classe III B - inertes

\subsubsection{Disposição de resíduos sólidos no Brasil}

De acordo com as estatísticas oficiais relativas a resíduos sólidos no Brasil (Pesquisa Nacional de Saneamento Básico 2000 - PNSB 2000) o país produz 228.413 toneladas diárias de resíduos, o que corresponde a aproximadamente 1,35 $\mathrm{Kg} / \mathrm{habitante} / \mathrm{dia}$. Ainda que exista uma tendência mundial para reduzir, reutilizar e reciclar os resíduos (diminuindo, assim, a quantidade de resíduos dispostos em aterros sanitários), a situação no Brasil é peculiar. A maior parte do resíduo produzido é disposto em aterros comuns, ou seja, lixões a céu aberto áreas sem nenhuma infra-estrutura para evitar danos ambientais. A FIG. 12 ilustra a destinação final dos resíduos por município. 


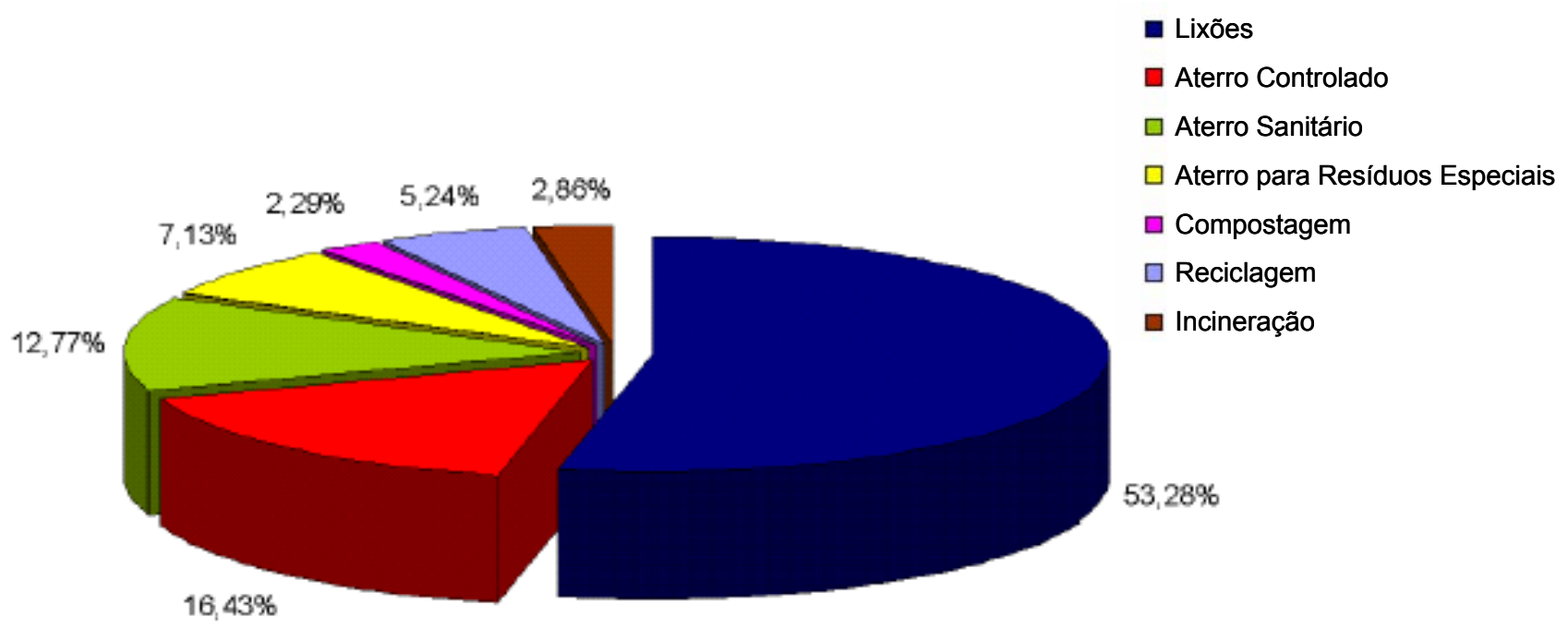

FIGURA 12 - Disposição final de resíduos por municípios no Brasil Fonte - PNSB, 2000

Somente um pequeno número de aterros existentes no Brasil conta com um sistema de coleta e queima instalado. A maior parte dos aterros opera com e emissão natural de metano para a atmosfera, através de drenos de concreto.

\subsubsection{Aterros Sanitários}

De acordo com a disposição dos resíduos os aterros podem ser classificados como:

Aterros comuns: mais conhecidos como lixões, lixeiras ou vazadouros, onde foi determinada uma área para depositar resíduos sem nenhum tipo de planejamento e controle. Este sistema é indesejável sob aspectos sanitários e ambientais, porem é o mais usual no Brasil.

Aterros controlados: diferenciam-se dos anteriores pelo fato de serem cobertos diariamente por uma camada de material inerte.

Aterros sanitários: são sistemas desejáveis sob aspectos sanitários e ambientais, porém envolvem altos custos de operação. Os Aterros sanitários são definidos como: "a técnica de disposição de resíduos sólidos urbanos no solo, sem causar danos ou riscos à saúde pública e à sua segurança, minimizando os impactos ambientais. Método este que utiliza princípios da engenharia para confinar os resíduos sólidos à menor área possível, reduzi-los ao menor volume permissível, cobrindo-os com uma camada de terra na conclusão de cada jornada de trabalho ou a intervalos menores se for necessário" (CADAVID, 2004). 


\subsubsection{Gás de Aterro Sanitário}

Quando os resíduos são depositados nos aterros sanitários, acontece uma decomposição anaeróbia que produz o gás de aterro sanitário, também conhecido como biogás, gás de lixo ou em inglês, landfill gas (LFG). Em alguns aterros, o gás gerado contém aproximadamente $50 \%$ de $\mathrm{CH}_{4}$, que pode ser usado para propósitos energéticos com tecnologias convencionais. Conforme SCOTT (1995), o gás de aterro pode ser definido como um composto de todos os gases e vapores gerados como resultado da decomposição de resíduos em um aterro sanitário.

O biogás também pode ser gerado em Estações de Tratamento de Esgoto (ETEs) e em áreas rurais com a decomposição de dejetos de animais, porém, 80\% de todo biogás gerado no mundo é proveniente de aterros sanitários (VAN HERLE et al., 2004).

\subsubsection{Produção de Energia Elétrica e Térmica}

As SOFCs podem ser uma das tecnologias apropriadas para a conversão do biogás em energia elétrica e térmica, pois é potencialmente a única tecnologia capaz de converter diretamente biogás de baixa qualidade, ou seja, com baixa concentração de metano. Testes de laboratório demonstram que é possível a conversão de biogás em energia em uma SOFC a níveis de baixíssimos de metano, até $5 \%$. Outro teste demonstrou que o desempenho se reduziu em apenas $5 \%$ quando a mistura foi alterada de $70-30 \% \mathrm{CH}_{4}-\mathrm{CO}_{2}$ para $30-70 \% \mathrm{CH}_{4}-\mathrm{CO}_{2}$ (VAN HERLE et al., 2004).

Tecnologias convencionais param de operar em baixas concentrações de metano. Em alguns casos combustíveis fósseis são utilizados de forma auxiliar para evitar a não-queima de fuga do metano.

Um desafio na utilização do gás gerado em aterros sanitários é que sua composição química apresenta uma significativa variação dependendo do local. Isso ocorre pois em condições anaeróbicas certas bactérias metabolizam material orgânico produzindo metano e dióxido de carbono como os principais subprodutos. As reações de metanogeneses são complexas e envolvem diferentes bactérias. Por causas desses diferentes tipos de populações de bactérias, a mistura final gasosa resultante da digestão anaeróbica é extremamente variável, podendo ser entre 2:1 à 
1:1 proporção metano - dióxido de carbono, com também grande variação na quantidade de impurezas voláteis.

A FIG. 13 mostra as diferentes performances em SOFC de pequeno porte e de configuração tubular (STANIFORTH et al., 1998).

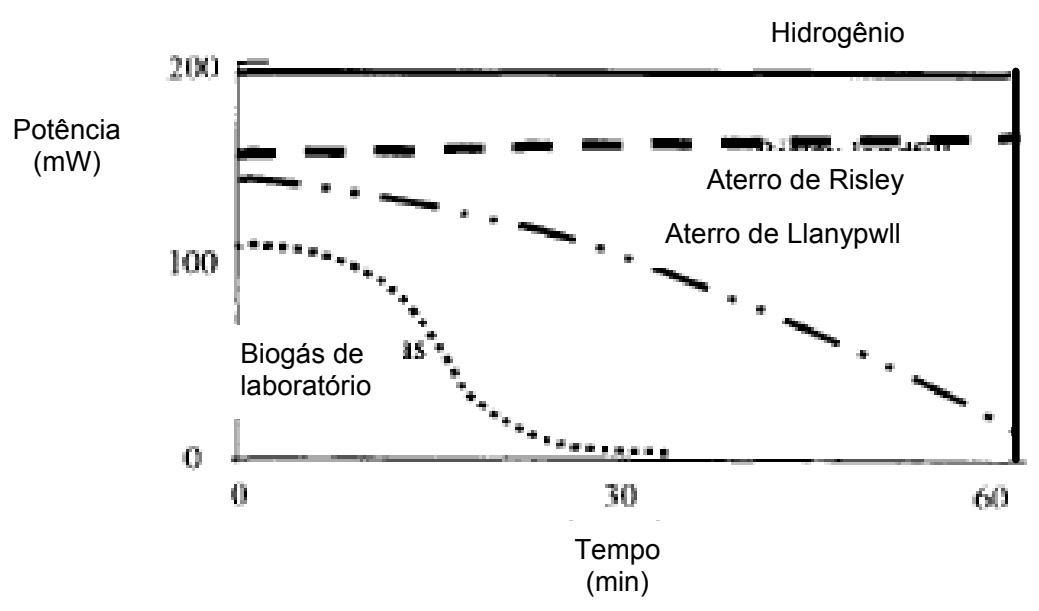

FIGURA 13 - Produção de energia a partir de amostras de biogás à $30 \mathrm{ml} / \mathrm{min}$ Fonte - STANIFORTH et al., 1998

Pode-se observar na FIG. 13, que existe grande variação segundo os tipos de biogás e entre diferentes aterros o que influência de maneira significativa na desempenho da SOFC.

A mesma SOFC foi testada com diferentes combustíveis: hidrogênio, gás natural e metano/dióxido de carbono mistura realizada para simular o biogás, os resultados são mostrados nas FIG. 14 e 15. 


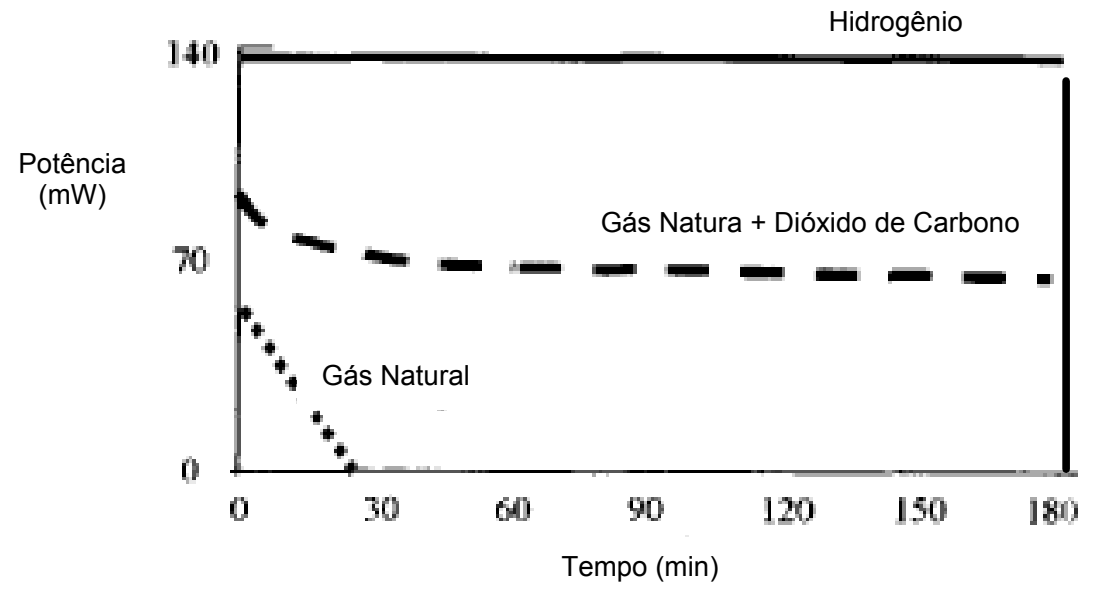

FIGURA 14 - Produção de energia em SOFC utilizando diferentes gases Fonte - STANIFORTH et al., 1998

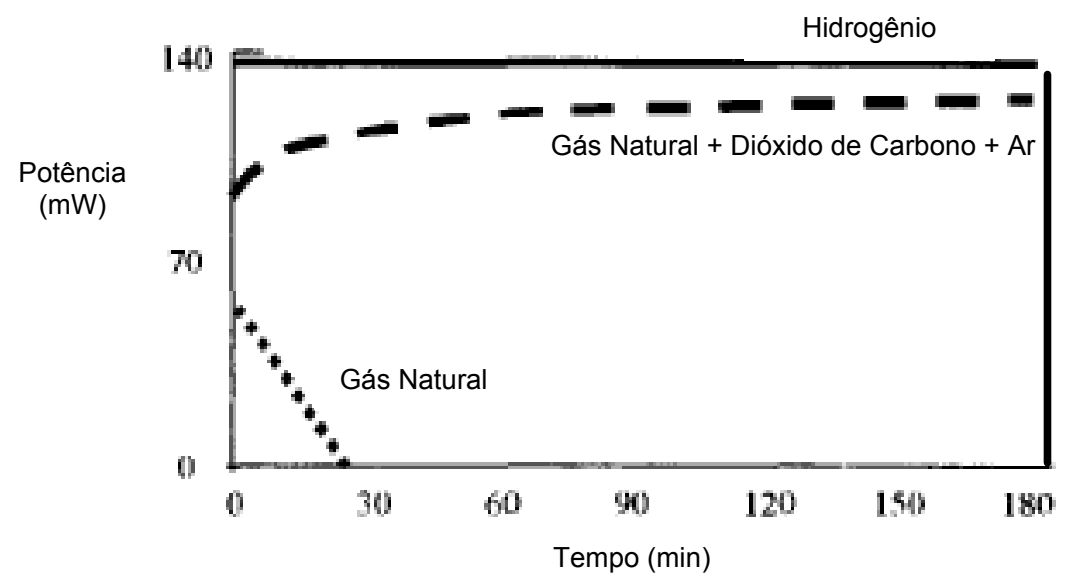

FIGURA 15 - Produção de energia em SOFC utilizando diferentes gases, com melhoria na performance ao se acrescentar ar Fonte - STANIFORTH et al, 1998

Comparando os resultados apresentados nas FIG. 14 e 15, verifica-se que o desempenho da SOFC aumentou significativamente com adição do ar na mistura de gás natural e dióxido de carbono. Portanto, a potência de uma SOFC depende do tipo de combustível alimentado.

Tendo em vista que um dos principais fatores limitantes para a utilização do biogás em uma tecnologia convencional é a grande variabilidade em sua composição química, não só de diferentes locais, mas também ao longo do tempo. Tecnologias convencionais não operam com concentrações de metano abaixo de $50 \%$. Todavia, é possível operar uma SOFC utilizando biogás, mesmo com níveis muito baixos de metano. 
A maioria das SOFCs que operam hoje utilizam vapor adicionado em excesso ao gás natural, convertendo-o em gás de síntese (syn gas) via reforma a vapor realizada no interior da SOFC se utilizando o níquel do anodo como catalisador ou a reforma é indireta realizada externamente (STANIFORTH et al., 2003), segundo a equação (4) sendo:

$$
\mathrm{H}_{2} \mathrm{O}+\mathrm{CH}_{4} \rightarrow \mathrm{CO}+3 \mathrm{H}_{2}
$$

Outra opção seria reforma do metano interna utilizando dióxido de carbono (seco) que pode ser atrativa se utilizado um catalisador adequado para a reação (5). Através dessa rota de reforma o deposito de carbono na SOFC é o maior problema em potencial que pode limitar a operação da célula se não for tomada a devida atenção (STANIFORTH et al., 2003).

$$
\mathrm{CO}_{2}+\mathrm{CH}_{4} \rightarrow 2 \mathrm{CO}+2 \mathrm{H}_{2}
$$




\section{METODOLOGIA}

A metodologia do trabalho consistiu-se em três etapas:

Etapa 1: uma pesquisa bibliográfica sobre os temas abordados no estudo;

Etapa 2: visitas ao Aterro Sanitário Municipal de Santo André, objeto do estudo de caso. Durante as visitas foram coletadas as informações sobre o aterro através de entrevistas (não estruturada) e relatórios da SEMASA;

Etapa 3: desenvolvimento de cálculos das RCEs aplicando-se as metodologias ACM0001, ACM0002 e a ferramenta metodológica "Tool to determine methane emissions avoided from dumping waste at a solid waste disposal site". Com relação a quantificação da potencial receita advinda da venda das RCEs foi realizada com os dados divulgados no mercado.

Para essa etapa serão elaborados cinco cenários de diferentes potências para uma SOFC. Os cenários de SOFC de 250 kW, 500 kW, 1.000 kW e 5.000 kW, 10.000 kW.de potência instalada. Para os cenários propostos os cálculos foram realizados de acordo com as duas modulações de cálculo da ACM0002, sendo ex ante e ex post.

\subsection{Sobre o município de Santo André - região delimitada para o estudo de}

caso

O município de Santo André está localizado na região metropolitana de São Paulo, mais especificamente no Grande $A B C$, que é o quarto pólo consumidor do país. Cerca de $54 \%$ do seu território do município está na Área de Proteção e Recuperação aos Mananciais - APRM e o restante encontra-se densamente urbanizado, o que acarreta na carência de sítios alternativos para a disposição dos resíduos sólidos. Santo André é o único município da região do Grande $A B C$, dotado de um Aterro Sanitário público e que para ele são destinados os resíduos sólidos urbanos aqui gerados.

O município de Santo André foi um dos 30 contemplados por meio do edital "Seleção de Municípios para elaboração de Estudos de Viabilidade de Projetos em MDL, baseados no Aproveitamento de Gases Gerados em locais de Destinação Final de Resíduos", realizado pelo Ministério do Meio Ambiente e Ministério das Cidades a desenvolver no aterro sanitário em operação o "Projeto para Aplicação do 
Mecanismo de desenvolvimento Limpo (MDL), na Redução de Emissões em Aterros de Resíduos Sólidos". Os projetos serão elaborados por empresas de consultoria nacionais e/ou internacionais a serem contratadas pelo Ministério das Cidades, por intermédio do Programa de Melhoramento do Setor de Saneamento - PMSS, e financiados pelo Banco Mundial por meio do fundo PHRD (Policy and Human Resources Development Fund).

Os Estudos de Viabilidade de Projetos em MDL no Aterro Sanitário de Santo André já se iniciaram, mas ainda não é possível ter acesso a esses estudos. Para o presente trabalho serão utilizados os dados disponibilizados pela SEMASA, órgão responsável pela gestão do Aterro Sanitário Municipal.

\subsection{Aterro Sanitário Municipal - objeto do estudo de caso}

O projeto do Aterro Sanitário de Santo André foi concebido em meados da década de 80 a partir de um convênio entre a EMPLASA e a Prefeitura Municipal de Santo André. Na ocasião visava atender a disposição dos resíduos gerados pelos municípios de Santo André, São Bernardo do Campo e São Caetano do Sul. No entanto, a proposta inicial não se concretizou e o aterro desde o início de sua operação, em meados de 1986, vem recebendo somente os resíduos gerados pela população de Santo André.

O Aterro Sanitário Municipal de Santo André ocupa uma área de $217.683 \mathrm{~m}^{2}$, e esta próximo de atingir sua capacidade máxima prevista. A FIG. 16 é uma foto de satélite da região do estudo de caso, ilustrando sua localização, a FIG. 17 foi extraída do software Google Earth e abrange toda a área do aterro municipal de Santo André. A FIG. 18 apresenta uma visão lateral do aterro mostrando os drenos de biogás, que o queimam em flare aberto de baixa eficiência, aproximadamente $10 \%$.

A gestão do Aterro Sanitário Municipal tem sua eficiência reconhecida pela CETESB cuja avaliação, o Índice de Qualidade de Aterro de Resíduos (IQR), entre 2001 e 2004 vem se mantendo em 9,3 - o mais alto da RMSP. 


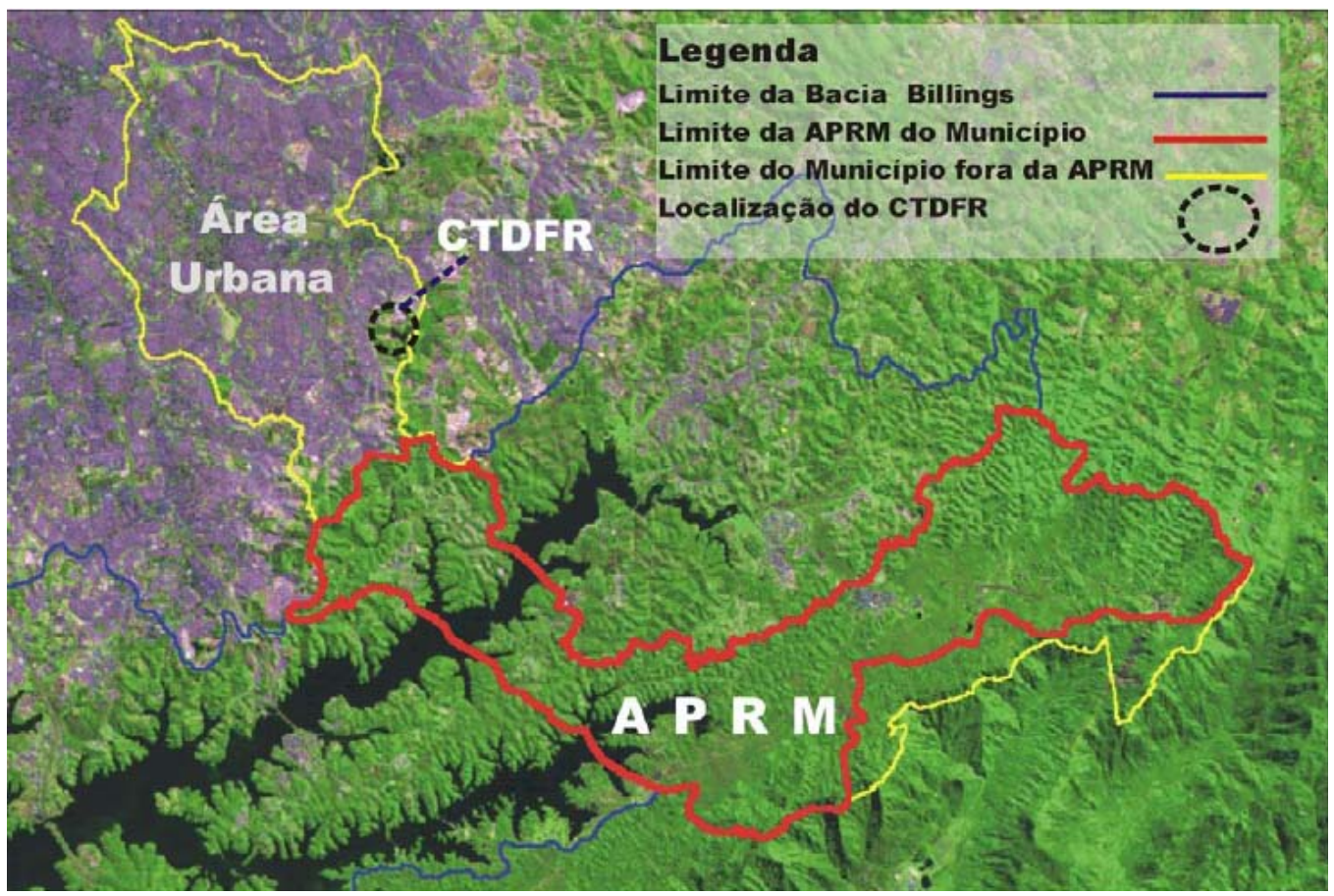

FIGURA 16 - Localização da Central de Tratamento e Destinação Final de Resíduos Sólidos CTDFR - Município de Santo André, SP

Fonte - SEMASA, 2006

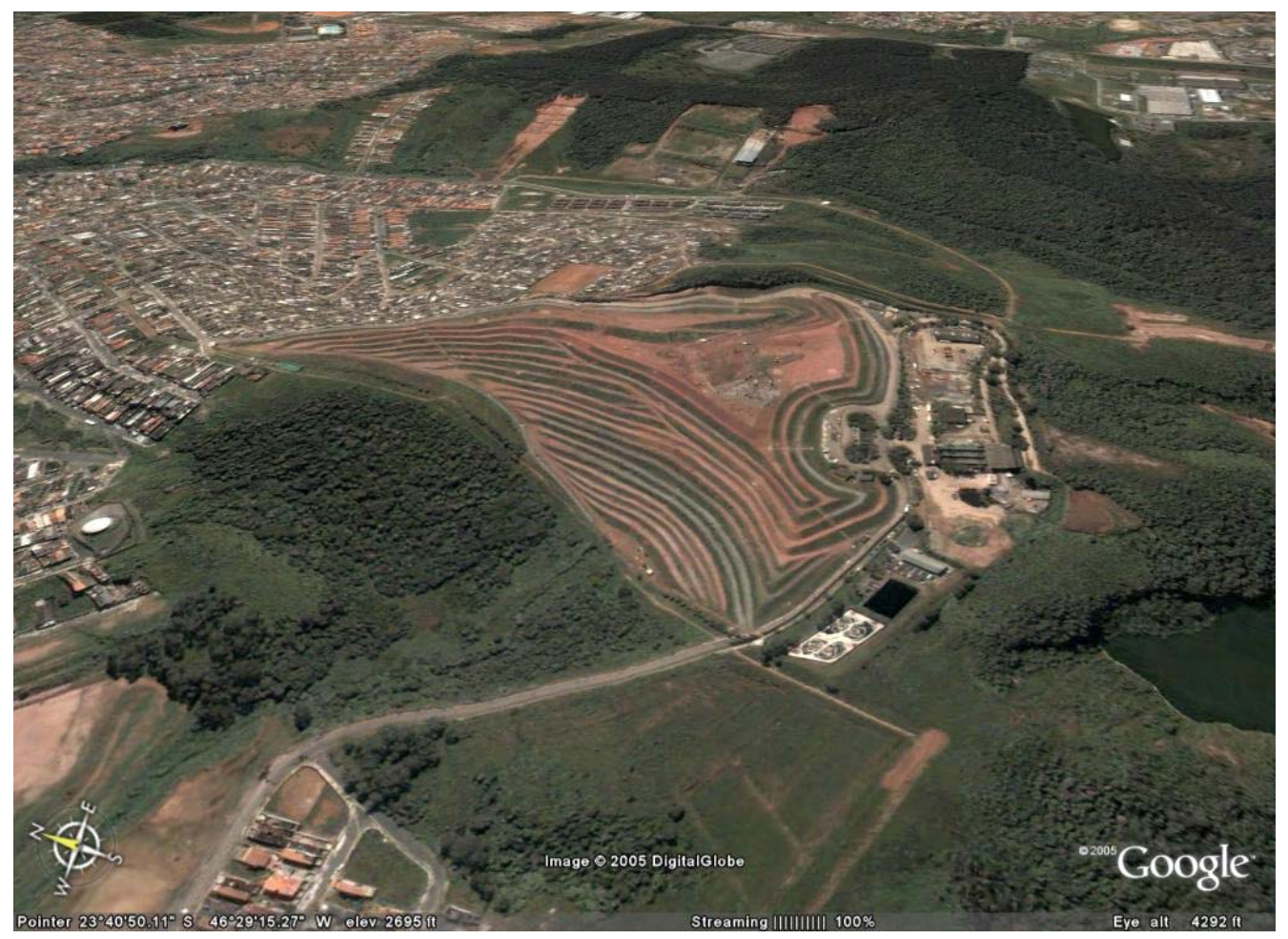

FIGURA 17 - Aterro Sanitário de Santo André 


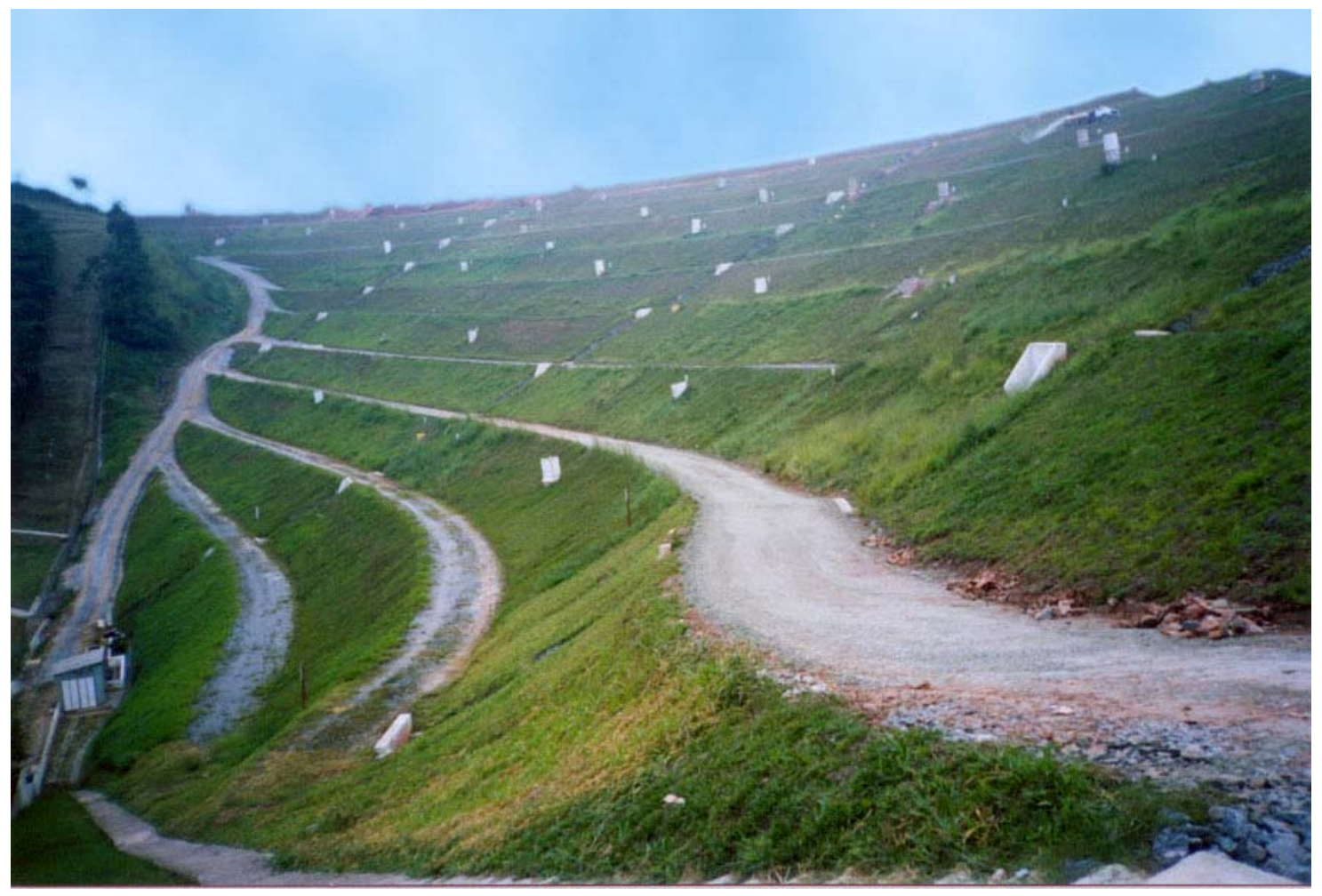

FIGURA 18 - Drenos do Aterro Municipal de Santo André

Atualmente, o aterro recebe cerca de 650 toneladas de resíduos sólidos urbanos por dia com a seguinte composição média em porcentagem em massa, segundo "Estudo de Caracterização" (SEMASA, 2005):

- Matéria orgânica - 44,48\%

- Papéis - 18,60\%

- Plásticos - 21,48\%

- Alumínio - 0,52\%

- Materiais ferrosos $-2,26 \%$

- Vidros $-2,92 \%$

- Outros - 9,74\%

Os levantamentos efetuados entre dezembro de 2003 e abril de 2006 indicam que a densidade média dos resíduos é de $0,978 \mathrm{t} / \mathrm{m}^{3}$.

Foi definido pela Sétima Conferência das Partes - COP 7 "Os Acordos de Marraqueche", no Anexo - Modalities and procedures for a clean development mechanism, G.Validation and registration, parágrafo 49, que os participantes do projeto devem escolher entre os seguintes períodos de creditação: 
- Máximo de sete anos, com a possibilidade de duas renovações, sendo que para cada renovação a entidade operacional designada (EOD) informa ao EB se a linha de base da atividade de projeto se ainda é valida ou deve ser atualizada; ou

- Dez anos sem a opção de renovação.

Para o desenvolvimento desta dissertação apresentar-se-á para os cenários escolhidos, a quantificação dos dois períodos de creditação, portanto, sendo os valores para 7, 10 e 21 anos. O período de creditação de 21 anos corresponde às duas renovações.

\subsection{ACM0001 - Metodologia consolidada de linha de base e monitoramento para atividades de projetos com gás de aterro}

Para o desenvolvimento de uma atividade de projeto de MDL, essa deve estar associada a uma metodologia de linha de base e monitoramento aprovada. Essas metodologias passam por revisões periódicas, e com isso alterações de sua versão.

As atividades de projetos devem utilizar necessariamente a versão vigente da metodologia aplicada. A TAB. 14 lista todas as alterações metodológicas da ACM0001. A ACM0001 versão 07 é apresentada no ANEXO A.

TABELA 14 - Histórico da metodologia ACM0001

\begin{tabular}{cc}
\hline ACM0001: "Metodologia consolidada de linha de base e \\
monitoramento para atividades de projetos com gás de aterro" \\
\hline Versão 07 & Válida a partir de 02 Nov 2007 \\
Versão 06 & Válida de 06 Jul 2007 a 01 Nov 2007 \\
Versão 05 & Válida de 22 Dez 2006 a 05 Jul 2007 \\
Versão 04 & Válida de 28 Jul 2006 a 21 Dez 2006 \\
Versão 03 & Válida de 19 Mai 2006 a 27 Jul 2006 \\
Versão 02 & Válida de 30 Set 2005 a 18 Mai 2006 \\
Versão 01 & Válida de 03 Set 2004 a 12 Out 2005 \\
\hline
\end{tabular}

O Conselho Executivo (Executive Board - EB) aprovou em sua $26^{\mathrm{a}}$ reunião, a ferramenta de auxílio metodológico que se aplicam às atividades de projeto em aterros sanitários:

- $\quad$ Tool to determine methane emissions avoided from dumping waste at a solid waste disposal site - Annex 14 de 26 de setembro de 2006 (ANEXO B) 
As constantes alterações metodológicas exigem que os desenvolvedores de projetos de MDL estejam permanentemente, durante a execução do projeto, realizando um acompanhamento das ações do EB e o Painel de Metodologias (Meth Panel).

\subsection{ACM0002 - Metodologia consolidada de linha de base para a geração de eletricidade conectada à rede a partir de fontes renováveis}

A TAB. 15 lista todas as alterações metodológicas dessa metodologia.

TABELA 15 - Histórico da metodologia ACM0002

\begin{tabular}{cc}
$\begin{array}{c}\text { ACM0002: "Metodologia consolidada de linha de base para a geração de } \\
\text { eletricidade conectada à rede a partir de fontes renováveis" }\end{array}$ \\
\hline Versão 06 & Válida a partir de 19 de Mai 2006 \\
Versão 05 & Válida de 03 Mar 2006 a 18 Mai 2006 \\
Versão 04 & Válida de 29 Nov 2005 a 02 Mar 2006 \\
Versão 03 & Válida de 30 Set 2005 a 28 Nov 2005 \\
Versão 02 & Válida de 03 Dez 2004 a 12 Out 2005 \\
Versão 01 & Válida de 03 Set 2004 a 02 Dez 2004 \\
\hline
\end{tabular}

No ANEXO C é apresentada a metodologia ACM0002, no qual mostra que para o cálculo do fator de emissão da linha de base (FE) é baseada na média ponderada do fator de emissão da Margem Operacional (EF $F_{O M}$ ) e o fator de emissão da Margem de Construção $\left(E F_{B M}\right)$.

Desde julho de 2007 o valor do FE do Sistema Interligado Nacional (SIN) é disponibilizado pelo MCT e a divisão dos submercados é diferente da apresentada anteriormente por atividades de projeto de MDL, no qual os próprios desenvolvedores dos Documentos de Concepção do Projeto (DCP) calculavam o FE. Para o cálculo do FE, em DCPs anteriores a essa data, o SIN era dividido em dois submercado: Sul / Sudeste / Centro-Oeste e Norte / Nordeste.

A região Sul atualmente aparece como um único submercado, e a Sudeste e Centro-Oeste outro, isso fez com que o FE do Sul aumentasse, principalmente por conta das termelétricas a carvão e diesel, e com que o FE do Sudeste e Centro-Oeste diminuisse. A TAB. 16 apresenta os fatores de emissão por submercado referentes ao ano de 2006. 
TABELA 16 - Fatores de emissão do SIN por submercado

\begin{tabular}{lccc}
\hline Submercado & $\begin{array}{l}\text { Fator de Emissão do } \\
\mathrm{SIN}\left(\mathrm{tCO}_{2} / \mathrm{MWh}\right)\end{array}$ & Fonte \\
\hline Sul & 0,5659 & & \\
Sudeste / & 0,1043 & $\begin{array}{l}\text { Ministério de Ciência e } \\
\text { Tecnologia }\end{array}$ & 2006 \\
Centro-Oeste & 0,0605 & Nono & \\
Nordeste & 0,0169 & & \\
Norte & & & \\
\hline
\end{tabular}

A TAB. 17 apresenta os fatores de emissão da rede de outros países da América do Sul. Pode-se destacar o FE do Equador de 0,7194 tCO2/MWh com o maior identificado. Vale destacar que os demais países da América do Sul não possuem projetos registrados na CQNUMC.

TABELA 17 - Fatores de emissão de paises da América do Sul

\begin{tabular}{lcll}
\hline País & $\begin{array}{l}\text { Fator de Emissão da } \\
\text { rede }\left(\mathrm{tCO}_{2} / \mathrm{MWh}\right)\end{array}$ & Fonte (DCP registrado na CQNUMC) & $\begin{array}{l}\text { Data do } \\
\text { documento }\end{array}$ \\
\hline Argentina & 0,4402 & $\begin{array}{l}\text { Methane recovery and effective use of power } \\
\text { generation project Norte III-B Landfill. }\end{array}$ & $10 / 01 / 2007$ \\
Bolívia & 0,5815 & Rio Taquesi Hydroelectric Power Project & $15 / 09 / 2006$ \\
Chile & 0,4380 & Puclaro Hydroelectric Power Plant & $09 / 07 / 2007$ \\
Colômbia & 0,4128 & La Vuelta and La Herradura Hydroelectric Project & $06 / 09 / 2006$ \\
Equador & 0,7194 & Calope Hydroelectric Project & $24 / 08 / 2006$ \\
Peru & 0,5449 & Quitaracsa I & $22 / 12 / 2006$ \\
\hline
\end{tabular}

A metodologia ACM0002 apresenta duas modalidades de fatores de emissão:

- A média ponderada da geração (ex ante) nos três anos mais recentes para os quais haja dados disponíveis quando do envio do DCP ou

- $\quad \mathrm{O}$ ano em que a geração do projeto ocorra, se o $\mathrm{EF}_{\mathrm{OM}, \mathrm{y}}$ for atualizado com base no monitoramento ex post.

No submercado Sudeste / Centro-Oeste, para ex ante são apresentados na TAB.18. 
TABELA 18 - Fatores de emissão para a modulação ex ante

\begin{tabular}{llll}
\hline Margem Operacional & Ano & $\mathrm{FE}$ oM & Unidade \\
\hline Sudeste-Centro-Oeste & 2006 & 0,1407 & $\mathrm{tCO}_{2} / \mathrm{MWh}$ \\
Sul-Sudeste-Centro-Oeste & 2005 & 0,3938 & $\mathrm{tCO}_{2} / \mathrm{MWh}$ \\
Sul-Sudeste-Centro-Oeste & 2004 & 0,4531 & $\mathrm{tCO}_{2} / \mathrm{MWh}$ \\
Margem Operacional Média : & & 0,3292 & $\mathrm{tCO}_{2} / \mathrm{MWh}$ \\
\hline \multicolumn{1}{l}{} & & & \\
\hline Margem de Construção & $\mathrm{Ano}$ & $\mathrm{FE}$ & \\
\hline Sudeste-Centro-Oeste & 2006 & 0,0678 & Unidade \\
\hline
\end{tabular}

FE é composto por 0,5 da margem operacional somado a 0,5 da margem de construção. FE $(2004,2005,2006)$ é 0,1985 tCO $2 / M W h$. 


\section{RESULTADOS E DISCUSSÃO}

\subsection{Estimativas de Reduções Certificadas de Emissão (RCEs)}

Para os cálculos das estimativas de Reduções Certificadas de Emissão $(\mathrm{RCEs})^{2}$ utilizou-se a equação (6) simplificada, desconsiderado a geração térmica, as eventuais emissões advindas da queima de combustíveis fósseis. O cálculo de $\left(M D_{\text {project,y }}-M_{\text {reg,y }}\right)^{*} G W P_{C H 4}$ da equação (6) foi baseado na ferramenta metodológica "Tool to determine methane emissions avoided from dumping waste at a solid waste disposal site" (ANEXO B), conforme a equação (6):

$$
\mathrm{BE}_{\mathrm{CH} 4, \mathrm{SWDS}, \mathrm{y}}=\varphi \cdot(1-\mathrm{f}) \cdot \mathrm{GWP}_{\mathrm{CH} 4} \cdot(1-\mathrm{OX}) \cdot \frac{16}{12} \cdot \mathrm{F} \cdot \mathrm{DOC}_{\mathrm{f}} \cdot \mathrm{MCF} \cdot \sum_{\mathrm{x}=1}^{y} \sum_{\mathrm{j}} \mathrm{W}_{\mathrm{j}, \mathrm{x}} \cdot \mathrm{DOC}_{\mathrm{j}} \cdot \mathrm{e}^{-\mathrm{k}_{\mathrm{j}} \cdot(\mathrm{y}-\mathrm{x})} \cdot\left(1-\mathrm{e}^{\left.-\mathrm{k}_{\mathrm{j}}\right)}\right.
$$

Onde:

\begin{tabular}{|c|c|c|c|}
\hline $\mathrm{BE}_{\mathrm{CH} 4}$ & Emissões da Linha de Base & & \\
\hline$\Phi$ & Fator de correção & 0,9 & \\
\hline $\mathrm{F}$ & $\%$ de metano queimado & 0,1 & \\
\hline $\mathrm{GWP} \mathrm{CH}_{4}$ & Potencial de aquecimento global & 21 & \\
\hline$O X^{-}$ & Fator oxidante & 0 & \\
\hline $\mathrm{F}$ & $\%$ de metano no biogás & 0,50 & \\
\hline $\mathrm{DOC}_{f}$ & \% lixo orgânico & 0,44 & \\
\hline MCF & Fator de correção do metano & 1,0 & \\
\hline$W_{j, x}$ & Total de lixo & 237.250 & ton \\
\hline $\mathrm{DOC}_{\mathrm{j}}$ & $\begin{array}{l}\text { Fração de carbono orgânico } \\
\text { degradável }\end{array}$ & 0,4 & \\
\hline $\mathrm{k}_{\mathrm{j}}$ & $\begin{array}{l}\text { Taxa de decaimento por tipo de lixo } \\
\text { Densidade do metano }\end{array}$ & $\begin{array}{c}0,4 \\
0,0007168\end{array}$ & $\mathrm{tCH}_{4} / \mathrm{m}^{3} \mathrm{CH}_{4}$ \\
\hline
\end{tabular}

Os valores utilizados para o cálculo, supracitados, foram extraídos da ferramenta metodológica "Tool to determine methane emissions avoided from dumping waste at a solid waste disposal site" exceto os dados relativos ao total de lixo e o percentual de lixo orgânico. Estes dados foram fornecidos pelo aterro sanitário. Para o desenvolvimento dos cálculos de $\mathrm{BE}_{\mathrm{CH} 4 \text {, swDS,y }}$ durante toda a vida útil do aterro e um projeção e emissões após o encerramento de suas atividades de deposição de resíduos sólidos, utilizou-se o Guia para a recuperação e uso

\footnotetext{
${ }^{2}$ Uma RCE representa uma tonelada de $\mathrm{CO}_{2}$ equivalente.
} 
energético do biogás gerado por resíduos sólidos urbanos em aterros sanitários (CETESB, 2006) e o software Microsoft Excel.

As estimativas de emissões de $\mathrm{CH}_{4}$ que são representadas na TAB. 19. e FIG. 19.

TABELA 19 - Estimativa das emissões de GEE do Aterro Sanitário de Santo André

\begin{tabular}{|c|c|c|c|}
\hline Ano & $\mathrm{m}^{3} \mathrm{CH}_{4}$ /ano & $\mathrm{tCH}_{4}$ /ano & $\mathrm{tCO}_{2}$ /ano \\
\hline 1986 & $1.252 .493,39$ & 897 & 18.854 \\
\hline 1987 & $2.408 .690,52$ & 1.726 & 36.258 \\
\hline 1988 & $3.475 .994,99$ & 2.491 & 52.323 \\
\hline 1989 & $4.461 .241,18$ & 3.197 & 67.154 \\
\hline 1990 & $5.370 .738,06$ & 3.849 & 80.845 \\
\hline 1991 & $6.210 .309,49$ & 4.451 & 93.483 \\
\hline 1992 & $6.985 .331,60$ & 5.007 & 105.149 \\
\hline 1993 & $7.700 .767,18$ & 5.519 & 115.918 \\
\hline 1994 & $8.361 .197,45$ & 5.993 & 125.859 \\
\hline 1995 & $8.970 .851,44$ & 6.430 & 135.036 \\
\hline 1996 & $9.533 .633,00$ & 6.833 & 143.508 \\
\hline 1997 & $10.053 .145,85$ & 7.206 & 151.328 \\
\hline 1998 & $10.532 .716,66$ & 7.549 & 158.547 \\
\hline 1999 & $10.975 .416,32$ & 7.867 & 165.211 \\
\hline 2000 & $11.384 .079,61$ & 8.160 & 171.362 \\
\hline 2001 & $11.761 .323,37$ & 8.430 & 177.041 \\
\hline 2002 & $13.061 .458,23$ & 9.362 & 196.612 \\
\hline 2003 & $14.261 .633,97$ & 10.222 & 214.678 \\
\hline 2004 & $15.369 .535,82$ & 11.016 & 231.355 \\
\hline 2005 & $16.392 .258,12$ & 11.749 & 246.749 \\
\hline 2006 & $17.384 .846,34$ & 12.461 & 261.691 \\
\hline 2007 & $19.655 .416,81$ & 14.089 & 295.869 \\
\hline 2008 & $20.549 .023,87$ & 14.729 & 309.320 \\
\hline 2009 & $18.969 .139,84$ & 13.597 & 285.539 \\
\hline 2010 & $17.510 .723,06$ & 12.551 & 263.585 \\
\hline 2011 & $16.164 .434,70$ & 11.586 & 243.320 \\
\hline 2012 & $14.921 .653,90$ & 10.695 & 224.613 \\
\hline 2013 & $13.774 .422,63$ & 9.873 & 207.344 \\
\hline 2014 & $12.715 .394,69$ & 9.114 & 191.402 \\
\hline 2015 & $11.737 .788,69$ & 8.413 & 176.687 \\
\hline 2016 & $10.835 .344,61$ & 7.766 & 163.102 \\
\hline 2017 & $10.002 .283,73$ & 7.169 & 150.562 \\
\hline 2018 & $9.233 .271,61$ & 6.618 & 138.987 \\
\hline 2019 & $8.523 .383,95$ & 6.109 & 128.301 \\
\hline 2020 & $7.868 .075,05$ & 5.639 & 118.437 \\
\hline 2021 & $7.263 .148,70$ & 5.206 & 109.331 \\
\hline 2022 & $6.704 .731,29$ & 4.805 & 100.925 \\
\hline 2023 & $6.189 .247,05$ & 4.436 & 93.165 \\
\hline 2024 & $5.713 .395,12$ & 4.095 & 86.003 \\
\hline 2025 & $5.274 .128,43$ & 3.780 & 79.390 \\
\hline 2026 & $4.868 .634,17$ & 3.489 & 73.287 \\
\hline 2027 & $4.494 .315,79$ & 3.221 & 67.652 \\
\hline 2028 & $4.148 .776,37$ & 2.973 & 62.451 \\
\hline 2029 & $3.829 .803,28$ & 2.745 & 57.649 \\
\hline 2030 & $3.535 .354,01$ & 2.534 & 53.217 \\
\hline 2031 & $3.263 .543,08$ & 2.339 & 49.125 \\
\hline 2032 & $3.012 .629,96$ & 2.159 & 45.349 \\
\hline 2033 & $2.781 .007,97$ & 1.993 & 41.862 \\
\hline 2034 & $2.567 .193,91$ & 1.840 & 38.643 \\
\hline
\end{tabular}




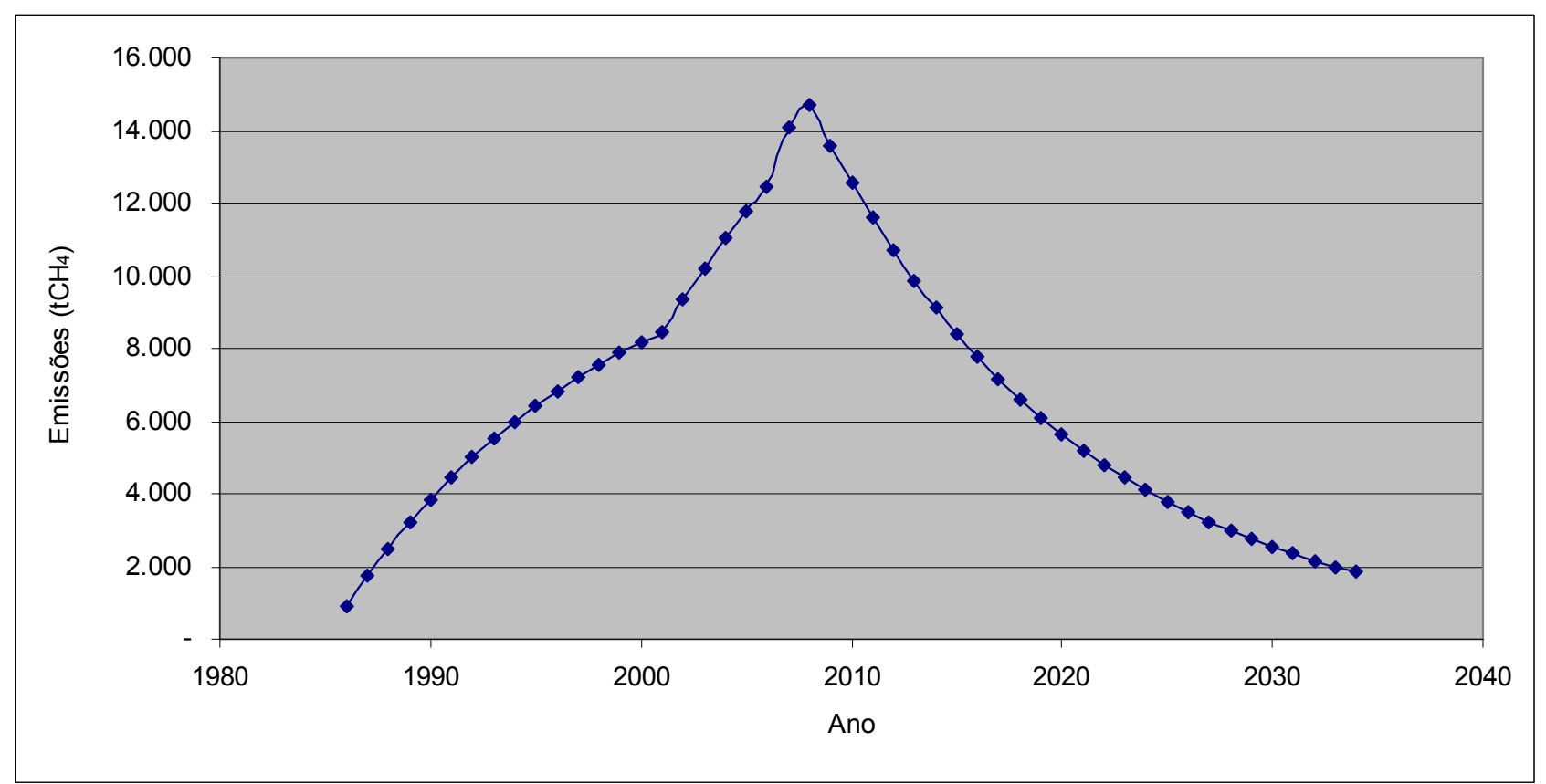

FIGURA 19 - Estimativa das emissões de $\mathrm{CH}_{4}$ do Aterro Sanitário de Santo André

Com relação a geração de energia para SOFC, foram adotadas para o desenvolvimento dessa dissertação, as capacidades instaladas de $250 \mathrm{~kW}, 500 \mathrm{~kW}$, $1.000 \mathrm{~kW}, 5.000 \mathrm{~kW}$ e $10.000 \mathrm{~kW}$, com um fator de capacidade de $70 \%$ e uma potência assegurada de $90 \%$, o que contabiliza as eventuais paradas para manutenção e falhas operacionais. As TAB. 20, 21, 22, 23, 24 e 25 apresentam os cenários.

As RCEs não têm valores fixos e são variáveis de acordo com diversos fatores, como por exemplo, a contribuição do projeto para o desenvolvimento sustentável, riscos de cumprir os compromissos e inovação tecnológica. O valor de US\$20,00 por RCE será utilizado apenas como referência monetária para fins do presente trabalho e representa um valor conservador (POINT CARBON, 2007). No APÊNDICE A são apresentadas planilhas com a memória de cálculo para os cinco cenários.

TABELA 20 - Reduções de emissão do Aterro Sanitário de Santo André pelo deslocamento do despacho no cenário de utilização de SOFC de $250 \mathrm{~kW}$

\begin{tabular}{lcc}
\hline Modalidades de FE & ex post & ex ante \\
\hline Emissões Reduzidas por ano $\left(\mathrm{tCO}_{2}\right)$ & 101 & 192 \\
Receita anual (US\$) & $2.014,64$ & $3.834,19$ \\
Receita 7 anos (US\$) & $14.102,47$ & $26.839,30$ \\
Receita 10 anos (US\$) & $20.146,38$ & $38.341,86$ \\
Receita 21 anos (US\$) & $42.307,40$ & $80.517,91$ \\
\hline
\end{tabular}


TABELA 21 - Reduções de emissão do Aterro Sanitário de Santo André pelo deslocamento do despacho no cenário de utilização de SOFC de $500 \mathrm{~kW}$

\begin{tabular}{lcc}
\hline Modalidades de FE & ex post & ex ante \\
\hline Emissões Reduzidas por ano $\left(\mathrm{tCO}_{2}\right)$ & 201 & 383 \\
Receita anual (US\$) & $4.029,28$ & $7.668,37$ \\
Receita 7 anos (US\$) & $28.204,93$ & $53.678,61$ \\
Receita 10 anos (US\$) & $40.292,76$ & $76.683,73$ \\
Receita 21 anos (US\$) & $84.614,79$ & $161.035,82$ \\
\hline
\end{tabular}

TABELA 22 - Reduções de emissão do Aterro Sanitário de Santo André pelo deslocamento do despacho no cenário de utilização de SOFC de $1.000 \mathrm{~kW}$

\begin{tabular}{lcc}
\hline Modalidades de FE & ex post & ex ante \\
\hline Emissões Reduzidas por ano $\left(\mathrm{tCO}_{2}\right)$ & 403 & 767 \\
Receita anual (US\$) & $8.058,55$ & $15.336,75$ \\
Receita 7 anos (US\$) & $56.409,86$ & $107.357,22$ \\
Receita 10 anos (US\$) & $80.585,52$ & $153.367,45$ \\
Receita 21 anos (US\$) & $169.229,59$ & $322.071,65$ \\
\hline
\end{tabular}

TABELA 23 - Reduções de emissão do Aterro Sanitário de Santo André pelo deslocamento do despacho no cenário de utilização de SOFC de $5.000 \mathrm{~kW}$

\begin{tabular}{lcc}
\hline Modalidades de FE & ex post & ex ante \\
\hline Emissões Reduzidas por ano $\left(\mathrm{tCO}_{2}\right)$ & 2.015 & 3.834 \\
Receita anual (US\$) & $40.292,76$ & $76.683,73$ \\
Receita 7 anos (US\$) & $282.049,31$ & $536.786,08$ \\
Receita 10 anos (US\$) & $402.927,59$ & $766.837,26$ \\
Receita 21 anos (US\$) & $846.147,93$ & $1.610 .358,25$ \\
\hline
\end{tabular}

TABELA 24 - Reduções de emissão do Aterro Sanitário de Santo André pelo deslocamento do despacho no cenário de utilização de SOFC de 10.000 kW

\begin{tabular}{lcc}
\hline Modalidades de FE & ex post & ex ante \\
\hline Emissões Reduzidas por ano $\left(\mathrm{tCO}_{2}\right)$ & 4.029 & 7.668 \\
Receita anual (US\$) & $80.585,52$ & $153.367,45$ \\
Receita 7 anos (US\$) & $564.098,62$ & $1.073 .572,16$ \\
Receita 10 anos (US\$) & $805.855,18$ & $1.533 .674,52$ \\
Receita 21 anos (US\$) & $1.692 .295,87$ & $3.220 .716,49$ \\
\hline
\end{tabular}

Vale enfatizar, que os valores das receitas foram estimados para 7, 10 e 21 anos conforme a metodologia anteriormente apresentada. Observa-se que para os cinco cenários há um aumento progressivo da receita total em função do aumento da potência instalada da SOFC.

Entretanto, para atividades de projetos de MDL existem custos associados para contratação de uma empresa de validação (EOD), que pode variar de US\$ 10.000,00 a US $\$ 50.000,00$, dependendo do tamanho e complexidade da atividade de projeto (PwC, 2007).

Para o registro do projeto na CQNUMC existe uma taxa cobrada de US $\$ 0,10$ por RCE até 15.000 RCEs, acima dessa quantidade será cobrado US\$ 0,20 por RCE. Além disso, $2 \%$ do total de RCEs das atividades de projeto devem ser 
destinados para um Fundo de Adaptação administrado pelo Conselho Executivo da CQNUMC (UNFCCC, 2007).

Segundo o Solid State Energy Conversion Alliance - SECA, um programa governamental dos Estados Unidos da América do U.S Department of Energy do Office of Fossil Energy, as metas para o custo de um SOFC é US $\$ 400,00 / \mathrm{kW}$ para o ano de 2010. Desta forma para os cinco cenários os custos da SOFC são apresentados na TAB. 25.

TABELA 25 - Custos da SOFC nos cenários desenvolvidos para o ano de 2010

\begin{tabular}{cc}
\hline $\begin{array}{c}\text { Potência da SOFC } \\
(\mathrm{kW})\end{array}$ & $\begin{array}{c}\text { Custo } \\
(\text { US } \$)\end{array}$ \\
\hline 250 & $100.000,00$ \\
500 & $200.000,00$ \\
1.000 & $400.000,00$ \\
5.000 & $2.000 .000,00$ \\
10.000 & $4.000 .000,00$ \\
\hline \multicolumn{2}{c}{ Fonte - SECA }
\end{tabular}

Comparando os custos para a instalação das potências estudadas com os cálculos de reduções de emissões, os custos se apresentam superiores, enquanto as reduções de emissões, que constituem uma potencial receita, além de inferiores estão distribuídas ao longo dos 7, 10 ou 21 anos da atividade de projeto.

Entretanto, outras receitas advindas da venda da energia e receitas da disposição dos resíduos sólidos devem ser levados em consideração na tomada de decisão de investimento em projetos dessa natureza.

Portanto, MDL tem o potencial para ser utilizado como parte importante da viabilização financeira da aplicação de SOFC para geração de energia a partir do biogás. 


\section{CONCLUSÕES}

Nos cinco cenários de potências instaladas em célula a combustível do tipo SOFC, o combustível utilizado para esta tecnologia, biogás, advindo do aterro sanitário de Santo André é uma possibilidade de insumo dentre outras alternativas já conhecidas na literatura. Esta opção se enquadra nos critérios do MDL.

Para aproveitamento energético do gás gerado em aterros sanitários utilizando SOFC existe a possibilidade de obtenção de RCEs, mesmo não havendo menção da tecnologia de células a combustível nas metodologias aprovadas e consolidadas utilizadas para os cálculos de reduções de emissões.

A quantificação das RCEs foi realizada com fatores de emissão calculados nas modalidades ex ante e ex post segundo a ACM0002. A opção ex ante apresentou valores superiores, todavia existe uma tendência de redução desse valor pela utilização dos fatores de emissão disponibilizados pelo Ministério de Ciência e Tecnologia.

A potencial receita advinda da venda das RCEs foi calculada e os valores, especialmente da parte do projeto relativa a destruição do metano do aterro sanitário de Santo André, que possui carga orgânica da ordem de 44,48\%, se mostraram significativos. Entretanto, a receita do projeto de MDL se constitui de um incentivo financeiro para investimento em tecnologias que reduza as emissões de gases de efeito estufa listados no Protocolo de Quioto, outros fatores devem ser levados em consideração para o investimento em projetos dessa natureza. 


\section{SUGESTÕES DE TRABALHOS FUTUROS}

Para trabalhos posteriores com temas correlatos é sugerido:

- Estudos sobre outros aspectos tecnológicos, operacionais e financeiros, de projetos de geração de energia a partir de SOFC e outras células a combustível utilizando o biogás e outros biocombustíveis;

- $\quad$ Estudos que visem aumentar a tolerância a contaminantes os materiais das SOFC para utilização do biogás;

- $\quad$ Estudos do impacto do $\mathrm{H}_{2}$ na atmosfera. 


\section{REFERÊNCIAS BIBLIOGRÁFICAS}

ALDABÓ, Ricardo. Célula Combustível a Hidrogênio: fonte de energia da nova era. São Paulo: Artliber Editora, 2004

ALTVATER, Elmar. O Preço da Riqueza: Pilhagem Ambiental e a Nova (Des) Ordem Mundial. São Paulo: Editora da Universidade Estadual Paulista, 1995

BUCKERIDGE, M. S.; AIDAR M. P. M. O Efeito Estufa e seu Impacto sobre a Biodiversidade. Seção de Fisiologia e Bioquímica de Plantas. Instituto de Botânica $<$ http://www.botanicasp.org.br/educacao/> Acessado em junho de 2005

CADAVID, Pablo César. Análise técnico-econômica para o aproveitamento energético do gás gerado em aterros sanitários utilizando pilhas a combustível "O caso do município de Campinas - S.P. - Brasil". Campinas: Dissertação (mestrado) - Universidade Estadual de Campinas, 2004

CARDOSO, Fátima. Efeito Estufa: porque a Terra morre de calor. São Paulo: Editora Terceiro Nome; Editora Mostarda Editora, 2006

CENTRO NACIONAL DE REFERÊNCIA EM ENERGIA DO HIDRGÊNIO (CENEH), Histórico, <http://www.ifi.unicamp.br/ceneh>, Acessado em dezembro de 2006

CLARK II, Woodrow W., RIFKIN, Jeremy. A green hydrogen economy. Energy Policy, 34, 2630-2630, 2006

CONTADINI, F., P\&D e o Estado-da-Arte de Células a Combustível na América do Norte , I Workshop Internacional de Células a Combustível, 2002 
DERWENT, R.G., W.J. COLLINS, C.E. JOHNSON, and D.S. STEVENSON, Transient behaviour of tropospheric ozone precursors in a global 3-D CTM and their indirect greenhouse effects. Clim. Change, 49, 463-487, 2001

DIÁRIO DO GRANDE ABC. Blecaute em Londres paralisa metrô e atinge 250 mil pessoas. 29 de agosto de 2003

DUTSCHKE, M. Forestry and the ultimate objective of the Climate Convention. Hamburg Climate + Papers. Hamburgo 2/2005

FAPESP. Comissão Européia Lança Programa para Estimular Pesquisas com Energias Sustentáveis, <http://www.ambientebrasil.com.br>, Acessado em janeiro de 2004

FARRET, Felix Alberto. Aproveitamento de pequenas fontes de energia elétrica. Santa Maria: Editora da UFSM, 1999

FLANNERY, Tim. Os Senhores do Clima: como o homem está alterando as condições climáticas e o que isso significa para o futuro do planeta. Rio de Janeiro: Editora Record, 2007

FOLHA DE SÃO PAULO. Megablecaute persiste 30 horas depois. 16 de agosto de 2003 . Eleito, Schwarzenegger se mantém vago. 9 de outubro de 2003 Blecaute deixa quase toda Itália sem luz. 29 de setembro de 2003

FONSECA, Fabio Coral, Desenvolvimento Células a Combustível de Óxido Sólido no IPEN, Brasil H2 Fuel Cell Expo / Seminar, Curitiba, setembro de 2007 
FRANGETTO, Flavia Witkowski e GAZANI, Flavio Rufino. Viabilização jurídica do Mecanismo de Desenvolvimento Limpo (MDL) no Brasil - O Protocolo de Kyoto e a cooperação internacional. São Paulo: Peirópolis; Brasília, DF: IIEB - Instituto Internacional de Educação do Brasil, 2002

FUGLESTVEDT, J.S., et al., Metrics of climate change: assessing radiative forcing and emission indices. Clim. Change, 58, 267-331, 2003

GELLER, Howard Steven. Revolução Energética: Políticas para um Futuro Sustentável. Rio de Janeiro: Relume Dumará: USAid, 2003

GOLDEMBERG, José e VILLANUEVA, Luz Dondero. Energia, Meio Ambiente e Desenvolvimento. São Paulo: Editora da Universidade de São Paulo, 2003

GORE, Albert. Uma verdade inconveniente - O que devemos saber (fazer) sobre o aquecimento global, Barueri, SP: Manole, 2006

HAWKEN, Paul, LOVINS, Amory e LOVINS, L. Hunter. Capitalismo Natural Criando a próxima revolução industrial. São Paulo: Editora Cultrix, 1999

HOFFMANN, Emilio Gomes Neto. Hidrogênio - Evoluir Sem Poluir - A era do hidrogênio, das energias renováveis e das células a combustível. Curitiba: BRASIL H2 FUEL CELL ENERGY, 2005

INTERNATIONAL ENERGY AGENCY, Prospects for Hydrogen and Fuel Cells, IEA/OCDE, Paris, 2005

IPCC - Intergovernmental Panel on Climate Change. Mudança do Clima 2007: a Base das Ciências Físicas, Sumário para os Formuladores de Políticas, Paris, 2007 
Contribution of Working Group I to the Third

Assessment Report of the Intergovernmental Panel on Climate Change. New York, 2001

. Land-Use, Land-Use Change and Forestry. Special

Report. New York, 2000

LOPES, Ignez Vidigal; O Mecanismo de Desenvolvimento Limpo - MDL: guia de orientação, Rio de Janeiro : Fundação Getulio Vargas, 2002.

LOVELOCK, James. A Vingança de Gaia, Rio de Janeiro: Editora Intrínseca, 2006

MARCOVITCH, Jacques. Para mudar o futuro: mudanças climáticas, políticas públicas e estratégias empresariais, São Paulo: Editora da Universidade de São Paulo: Editora Saraiva, 2006

MINISTÉRIO DA CIÊNCIA E TECNOLOGIA. Convenção - Quadro das Nações Unidas sobre Mudança do Clima, maio de 1992

Programa Brasileiro - Sistemas Célula a Combustível.

Brasília, novembro de 2002

MINISTÉRIO DE MINAS E ENERGIA, Roteiro para Estruturação da Economia do Hidrogênio no Brasil, <http://www.mme.gov.br>, Acessado em novembro de 2006

MÖLLERT, Kenneth, GRÖNKVIST, Stefan. All $\mathrm{CO}_{2}$ is equal in the atmosphere - $A$ comment on CDM GHG accounting standards for methane recovery and oxidation projects, Energy Policy, 35, 3675-3680, 2007

PARIS, Alexandre Gellert. A aurora da nova era. Revista Meio Ambiente Industrial. p. 98. Janeiro / Fevereiro, 2005 
Adicionalidade nos projetos de crédito de carbono.

Revista Meio Ambiente Industrial. p. 98. Julho / Agosto, 2005

POINT CARBON, <http://www.pointcarbon.com>, Acessado em novembro de 2007

PRATHER, M.J., Atmospheric science: an environmental experiment with $\mathrm{H}_{2}$.

Science, 302, 581-583, 2003

PRICEWATERHOUSECOOPERS, New Energy for World Markets: 2006 Fuel Cell Industry Survey - A Survey of 2005 Financial Results of Public Fuel Cell Companies, 2006

Fuel Cells: The Opportunity for Canada, Montreal,

2002

RIFKIN, Jeremy. A Economia do Hidrogênio. São Paulo: M.Books, 2003

ROCHA, Marcelo Theoto. Aquecimento global e o mercado de carbono: uma aplicação do modelo CERT. Piracicaba: Tese (doutorado) - Escola Superior de Agricultura Luiz de Queiroz, 2003

SECA. Solid State Energy Conversion Allience. Office of Fossil Energy Fuel Cell Program. FY 2007 Annual Report. Agosto, 2007

SEMASA, Diagnóstico Ambiental Preliminar da Área da Central de Tratamento e Destinação Final de Resíduos Sólidos de Santo André, SP, Outubro de 2006

SERRA, E. T., Células a Combustível: Uma Alternativa para Geração de Energia e sua Inserção no Mercado Brasileiro, Cepel, 2006 ., Células a Combustível: Fundamentos e Atividades do CEPEL, I Workshop Internacional de Células a Combustível, 2002 
SHINE, K.P., J.S. FUGLESTVEDT, K. HAILEMARIAM, and N. STUBER, Alternatives to the global warming potential for comparing climate impacts of emissions of greenhouse gases. Clim. Change, 68, 281-302, 2005

STANIFORTH, John, KENDALL, K. Biogas powering a small tubular solid oxide fuel cell. Journal of Power Sources, , 71, 275-277, 1998

STANIFORTH, John, ORMEROD, Mark. Running Solid Oxide Fuel Cells on Biogas. IONICS, 9, 336-341, 2003

TOLMASQUIM, Mauricio Tiomno. Alternativas energéticas sustentáveis no Brasil, Rio de Janeiro: Relume Dumará: COPPE: CENERGIA, 2004

U.S. Environmental Protection Agency, Landfill Methane Outreach Program (LMOP), <http://www.epa.gov//mop/>, Acessado em junho de 2006

VAN HERLE, Jan, MEMBREZ, Yves, BUCHELI, Oliver. Biogas as a fuel for SOFC co-generators. Journal of Power Sources, 127, 300 -312, 2004

XENERGY., Toward a Renewable Power Supply: The Use of Bio-based Fuels in Stationary Fuel Cells. Burlington, 2002

WENDT, Hartmut; GÖTZ Michael; LINARDI, Marcelo. Tecnologia de Células a Combustível. Química Nova, 23 (4) 538-546, 2000

ZHA, S., CHENG, Z. e LIU, M., "Sulfur Poisoning and Regeneration of Ni-based Anodes in Solid Oxide Fuel Cells", Journal of The Electrochemical Society, 154, b201, 2007. 


\section{APÊNDICE A - Memória de cálculo para as emissões reduzidas do aterro sanitário de Santo André através da destruição do metano}

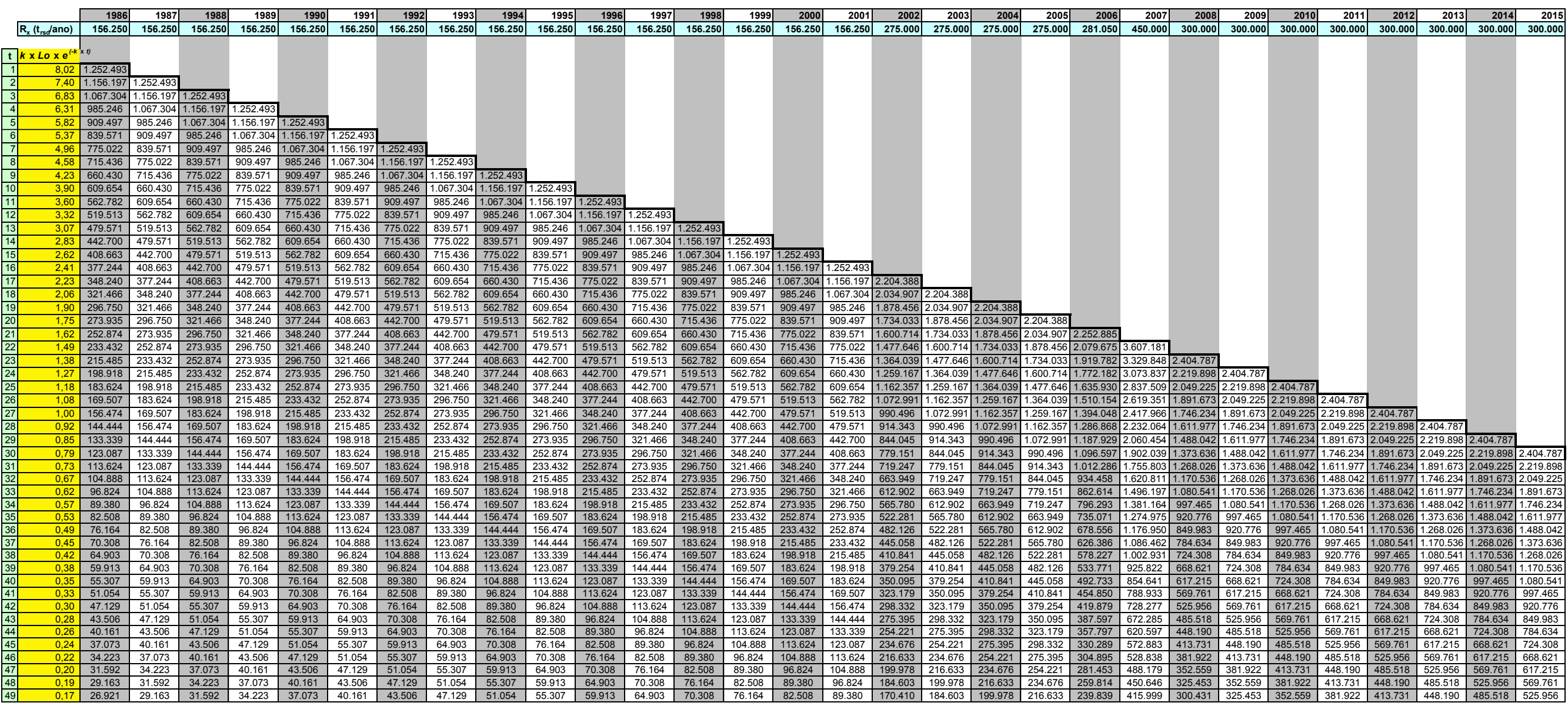




\section{Revision to the approved consolidated baseline methodology ACM0001}

\section{"Consolidated baseline methodology for landfill gas project activities"}

\section{Sources}

This methodology is based on elements from the following approved proposals for baseline methodologies:

- AM0002: Greenhouse Gas Emission Reductions through Landfill Gas Capture and Flaring where the Baseline is established by a Public Concession Contract (approved based on proposal NM0004 rev: Salvador da Bahia landfill gas project, whose project design document and baseline study, monitoring and verification plans were developed by ICF Consulting (version 03, June 2003));

- AM0003: Simplified financial analysis for landfill gas capture projects (approved based on proposal NM0005: Nova Gerar landfill gas to energy project, whose project design document and baseline study, monitoring and verification plans were developed by EcoSecurities Ltd. (version 14, July 2003) for the Carbon Finance Unit of the World Bank);

- AM0010: Landfill gas capture and electricity generation projects where landfill gas capture is not mandated by law (approved based on proposal NM0010 rev: Durban-landfill-gas-to-electricity project, whose project design document and baseline study, monitoring and verification plans were developed by Prototype Carbon Fund of the World Bank (April 2003));

- AM0011: Landfill gas recovery with electricity generation and no capture or destruction of methane in the baseline scenario (approved based on proposal NM0021: Cerupt methodology for landfill gas recovery, whose project design document and baseline study, monitoring and verification plans were developed by Onyx (July 2003)).

For more information regarding the proposals and its considerations by the Executive Board please refer to the cases on $<$ http://cdm.unfccc.int/methodologies/PAmethodologies/approved.html $>$

The methodology also refers to the latest version of the "Tool for the demonstration and assessment of additionality" and the latest version of the "Tool to determine project emissions from flaring gases containing Methane".

\section{Selected approach from paragraph 48 of the CDM modalities and procedures}

"Emissions from a technology that represents an economically attractive course of action, taking into account barriers to investment."

\section{Applicability}

This methodology is applicable to landfill gas capture project activities, where the baseline scenario is the partial or total atmospheric release of the gas and the project activities include situations such as:

a) The captured gas is flared; and/or

b) The captured gas is used to produce energy (e.g. electricity/thermal energy);

c) The captured gas is used to supply consumers through natural gas distribution network. If emissions reduction are claimed for displacing natural gas, project activities may use approved methodologies AM0053.

\footnotetext{
${ }^{1}$ Please refer to $<\underline{\text { http://cdm.unfccc.int/methodologies/PAmethodologies/approved.html }}>$ 
This baseline methodology shall be used in conjunction with the approved monitoring methodology ACM0001 ("Consolidated monitoring methodology for landfill gas project activities").

\section{BASELINE METHODOLOGY}

\section{Project Boundary}

The project boundary is the site of the project activity where the gas is captured and destroyed/used.

Possible $\mathrm{CO}_{2}$ emissions resulting from combustion of other fuels than the methane recovered should be accounted as project emissions. Such emissions may include fuel combustion due to pumping and collection of landfill gas or fuel combustion for transport of generated heat to the consumer locations. In addition, electricity required for the operation of the project activity, including transport of heat, should be accounted and monitored.

If the electricity for project activity is sourced from grid or electricity generated by the LFG captured would have been generated by power generation sources connected to the grid, the project boundary shall include all the power generation sources connected to the grid to which the project activity is connected.

If the electricity for project activity is from a captive generation source or electricity generated by the captured LFG would have been generated by a captive power plant, the captive power plant shall be included in the project boundary.

\section{Procedure for the selection of the most plausible baseline scenario}

\section{Step 1: identification of alternative scenarios.}

Project participants should use step 1 of the latest version of the "Tool for the demonstration and assessment of additionality", to identify all realistic and credible baseline alternatives. In doing so, relevant policies and regulations related to the management of landfill sites should be taken into account. Such policies or regulations may include mandatory landfill gas capture or destruction requirements because of safety issues or local environmental regulations. ${ }^{2}$ Other policies could include local policies promoting productive use of landfill gas such as those for the production of renewable energy, or those that promote the processing of organic waste. In addition, the assessment of alternative scenarios should take into account local economic and technological circumstances.

National and/or sectoral policies and circumstances must be taken into account in the following ways:

- In Sub-step 1b of the "Tool for the demonstration and assessment of additionality", the project developer must show that the project activity is not the only alternative that is in compliance with all regulations (e.g. because it is required by law);

- Via the adjustment factor $\mathrm{AF}$ in the baseline emissions project participants must take into account that some of the methane generated in the baseline may be captured and destroyed to comply with regulations or contractual requirements;

\footnotetext{
${ }^{2}$ The project developer must bear in mind the relevant clarifications on the treatment of national and/or sectoral policies and regulations in determining a baseline scenario as per Annex 3 to the Executive Board $22^{\text {nd }}$ meeting and any other forthcoming guidance from the Board on this subject.
} 
- The project participants must monitor all relevant policies and circumstances at the beginning of each crediting period and adjust the baseline accordingly.

Alternatives for the disposal/treatment of the waste in the absence of the project activity, i.e. the scenario relevant for estimating baseline methane emissions, to be analysed should include, inter alia:

LFG1. The project activity (i.e. capture of landfill gas and its flaring and/or its use) undertaken without being registered as a CDM project activity;

LFG2. Atmospheric release of the landfill gas or partial capture of landfill gas and destruction to comply with regulations or contractual requirements, or to address safety and odour concerns.

If energy is exported to a grid and/or to a nearby industry, or used on-site realistic and credible alternatives should also be separately determined for:

- Power generation in the absence of the project activity;

- Heat generation in the absence of the project activity.

For power generation, the realistic and credible alternative(s) may include, inter alia:

P1. Power generated from landfill gas undertaken without being registered as CDM project activity;

P2. Existing or Construction of a new on-site or off-site fossil fuel fired cogeneration plant;

P3. Existing or Construction of a new on-site or off-site renewable based cogeneration plant;

P4. Existing or Construction of a new on-site or off-site fossil fuel fired captive power plant;

P5. Existing or Construction of a new on-site or off-site renewable based captive power plant ;

P6. Existing and/or new grid-connected power plants.

For heat generation, the realistic and credible alternative(s) may include, inter alia:

H1. Heat generated from landfill gas undertaken without being registered as CDM project activity;

H2. Existing or Construction of a new on-site or off-site fossil fuel fired cogeneration plant;

H3. Existing or Construction of a new on-site or off-site renewable based cogeneration plant ;

H4. Existing or new construction of on-site or off-site fossil fuel based boilers;

H5. Existing or new construction of on-site or off-site renewable energy based boilers;

H6. Any other source such as district heat; and

H7. Other heat generation technologies (e.g. heat pumps or solar energy).

STEP 2: Identify the fuel for the baseline choice of energy source taking into account the national and/or sectoral policies as applicable.

Demonstrate that the identified baseline fuel is available in abundance in the host country and there is no supply constraint. In case of partial supply constraints (seasonal supply), the project participants may consider an alternative fuel that result in lowest baseline emissions during the period of partial supply. 
Detailed justification shall be provided for the selected baseline fuel. As a conservative approach, the lowest carbon intensive fuel such as natural gas through out the period may be used.

NOTE: Steps 3 and 4 shall be applied for each component of the baseline, i.e. baseline for waste treatment, electricity generation and heat generation.

STEP 3: Step 2 and/or step 3 of the latest approved version of the "Tool for demonstration and assessment of additionality" shall be used to assess which of these alternatives should be excluded from further consideration (e.g. alternatives facing prohibitive barriers or those clearly economically unattractive).

STEP 4: Where more than one credible and plausible alternative remains, project participants shall, as a conservative assumption, use the alternative baseline scenario that results in the lowest baseline emissions as the most likely baseline scenario. The least emission alternative will be identified for each component of the baseline scenario. In assessing these scenarios, any regulatory or contractual requirements should be taken into consideration.

NOTE: The methodology is only applicable if:

(a) the most plausible baseline scenario for the landfill gas is identified as either the atmospheric release of landfill gas or landfill gas is partially captured and subsequently flared (LFG2).

(b) the most plausible baseline scenario for the energy component of the baseline scenario is one of the following scenarios described in Table 1 below. 
Table 1: Combinations of baseline options and scenarios applicable to this methodology

\begin{tabular}{|l|l|l|l|l|}
\hline \multirow{2}{*}{ Scenario } & \multicolumn{2}{|c|}{ Baseline } & \multirow{2}{*}{ Description of situation } \\
\cline { 2 - 4 } & $\begin{array}{l}\text { landfill } \\
\text { gas }\end{array}$ & electricity & Heat & \\
\hline 1 & LFG2 & P4 or P6 & H4 & $\begin{array}{l}\text { The atmospheric release of landfill gas or landfill gas } \\
\text { is partially captured and subsequently flared . } \\
\text { The electricity is obtained from an existing/new fossil } \\
\text { based captive power plant or from the grid and heat } \\
\text { from an existing/new fossil fuel based boiler. }\end{array}$ \\
\hline
\end{tabular}

\section{Emission Reduction}

The greenhouse gas emission reduction achieved by the project activity during a given year " $\mathrm{y}$ " $\left(E R_{y}\right)$ are estimated as follows:

$$
\begin{aligned}
\mathrm{ER}_{\mathrm{y}}= & \left(\mathrm{MD}_{\text {project,y }}-\mathrm{MD}_{\text {reg,y }}\right) * \mathrm{GWP}_{\mathrm{CH} 4}+\mathrm{EL}_{\mathrm{LFG}, \mathrm{y}} \cdot \mathrm{CEF}_{\text {elec }, \mathrm{BL}, \mathrm{y}}-\mathrm{EL}_{\mathrm{PR}} \cdot \mathrm{CEF}_{\text {elec }, \mathrm{PR}, \mathrm{y}} \\
& +\mathrm{ET}_{\mathrm{LFG}, \mathrm{y}} * \mathrm{CEF}_{\text {ther, } \mathrm{BL}, \mathrm{y}}-\mathrm{ET}_{\mathrm{PR}, \mathrm{y}} * \mathrm{EF}_{\text {fuel,PR }, \mathrm{y}}
\end{aligned}
$$

\begin{tabular}{|c|c|}
\hline$E R_{y}$ & is emissions reduction, in tonnes of $\mathrm{CO}_{2}$ equivalents $\left(\mathrm{tCO}_{2} \mathrm{e}\right)$. \\
\hline$M D_{\text {project,y }}$ & $\begin{array}{l}\text { the amount of methane that would have been destroyed/combusted during the year, } \\
\text { in tonnes of methane }\left(\mathrm{tCH}_{4}\right)\end{array}$ \\
\hline$M D_{r e g, y}^{3}$ & $\begin{array}{l}\text { the amount of methane that would have been destroyed/combusted during the year in } \\
\text { the absence of the project, in tonnes of methane }\left(\mathrm{tCH}_{4}\right)\end{array}$ \\
\hline$G W P_{C H 4}$ & $\begin{array}{l}\text { Global Warming Potential value for methane for the first commitment period is } 21 \\
\mathrm{tCO}_{2} \mathrm{e} / \mathrm{tCH}_{4}\end{array}$ \\
\hline $\mathrm{EL}_{\mathrm{LFG}, \mathrm{y}}$ & $\begin{array}{l}\text { net quantity of electricity produced using LFG, expertedwhich in the absence of the } \\
\text { project activity would have been produced by power plants connected to the grid or } \\
\text { by an on-site/off-site fossil fuel based captive power generation, during year y, in } \\
\text { megawatt hours (MWh). }\end{array}$ \\
\hline$C E F_{\text {elecy, } B L, y}$ & $\begin{array}{l}\mathrm{CO}_{2} \text { emissions intensity of the baseline source of electricity displaced, in } \\
\mathrm{tCO}_{2} \mathrm{e} / \mathrm{MWh} \text {. This is estimated as per equation (6) below. }\end{array}$ \\
\hline$E T_{L F G, y}$ & $\begin{array}{l}\text { the quantity of thermal energy produced utilizing the landfill gas, which in the } \\
\text { absence of the project activity would have been produced from onsite/offsite fossil } \\
\text { fuel fired boiler, during the year y in TJ. }\end{array}$ \\
\hline$C E F_{\text {ther }, B L, y}$ & $\begin{array}{l}\mathrm{CO}_{2} \text { emissions intensity of the fuel used by boiler to generate thermalenergy which } \\
\text { is displaced by LFG based thermal energy generation, in } \mathrm{tCO}_{2} \mathrm{e} / \mathrm{TJ} \text {. This is estimated } \\
\text { as per equation ( } 7 \text { ) below. }\end{array}$ \\
\hline $\mathrm{EL}_{\mathrm{PR}, \mathrm{y}}$ & $\begin{array}{l}\text { is the amount of electricity generated in an on-site fossil fuel fired power plant or } \\
\text { imported from the grid as a result of the project activity, measured using an } \\
\text { electricity meter (MWh) }\end{array}$ \\
\hline$C E F_{\text {elec }, y, P R, y}$ & is the carbon emissions factor for electricity generation in the project activity \\
\hline
\end{tabular}

where:

\footnotetext{
${ }^{3} \mathrm{Reg}=$ regulatory and contractual requirements

${ }^{4}$ If in the baseline a part of LFG was captured then the electricity quantity used in calculation is electricity used in project activity net of that consumed in the baseline.
} 


\begin{tabular}{|l|l|}
\hline & (tCO2/MWh). This is estimated as per equation (8) below \\
\hline$E T_{P R, y}$ & is the fossil fuel consumption on site during project activity in year y (tonne) ${ }^{5}$ \\
\hline$E F_{f u l l, P R, y}$ & $\begin{array}{l}\mathrm{CO}_{2} \text { emissions factor of the fossil fuel used by boiler to generate thermal energy in } \\
\text { the project activity during year y. }\end{array}$ \\
\hline
\end{tabular}

In the case where the $M D_{\text {reg,y }}$ is given/defined as a quantity that quantity will be used.

In cases where regulatory or contractual requirements do not specify $M D_{\text {reg,y }}$ an "Adjustment Factor" (AF) shall be used and justified, taking into account the project context.

$M D_{\text {reg,y },}=M D_{\text {project }, y} * A F$

The following examples provide guidance on how to estimate $A F$ :

- In cases where a specific system for collection and destruction of methane is mandated by regulatory or contractual requirements, the ratio of the destruction efficiency of that system to the destruction efficiency of the system used in the project activity shall be used.

- In cases where a specific percentage of the "generated" amount of methane to be collected and destroyed is specified in the contract or mandated by regulations, this percentage divided by an assumed efficiency for the collection and destruction system used in the project activity shall be used.

Project proponents should provide an ex ante estimate of emissions reductions, by projecting the future GHG emissions of the landfill. In doing so, verifiable methods should be used. Ex ante emission estimates may have an influence on $M D_{\text {reg,y. }} . M D_{\text {project, } y}$ will be determined ex post by metering the actual quantity of methane captured and destroyed once the project activity is operational.

The methane destroyed by the project activity $\left(M D_{\text {project, } y}\right)$ during a year is determined by monitoring the quantity of methane actually flared and gas used to generate electricity and/or produce thermal energy, if applicable, and the total quantity of methane captured.

The sum of the quantities fed to the flare(s), to the power plant(s) and to the boiler(s) (estimated using equation (3)) must be compared annually with the total quantity of methane generated. The lowest value of the two must be adopted as $M D_{\text {project, } y \text {. }}$

The following procedure applies when the total quantity of methane generated is the highest. The working hours of the energy plant(s) and the boiler(s) should be monitored and no emission reduction could be claimed for methane destruction during non-operational hours of the energy plant or the boiler.

$$
M D_{\text {project }, y}=M D_{\text {flared }, y}+M D_{\text {electricity }, y}+M D_{\text {thermal }, y}
$$

Right Hand Side of the equation (3) is sum over all the points of captured methane use in case the methane is flared in more than one flare, and/or used in more than one electricity generation source, and/or more than one thermal energy generator. The supply to each point of methane destruction, through flaring or use for energy generation, shall be measured separately.

\footnotetext{
${ }^{5}$ If in the baseline part of a LFG was captured then the heat quantity used is calculation is fossil fuel used in project activity net of that consumed in the baseline.
} 
$M D_{\text {flared }, y}=\left\{L F G_{\text {flare }, y} * w_{C H 4, y} * D_{C H 4}\right)-\left(P E_{\text {flare }, y} / \mathrm{GWP}_{\mathrm{CH} 4}\right)$

Where $M D_{\text {flared, } y}$ is the quantity of methane destroyed by flaring, $L F G_{\text {flare, } y}$ is the quantity of landfill gas fed to the flare $(\mathrm{s})$ during the year measured in cubic meters $\left(\mathrm{m}^{3}\right), w_{C H 4, y}$ is the average methane fraction of the landfill gas as measured ${ }^{6}$ during the year and expressed as a fraction (in $\mathrm{m}^{3} \mathrm{CH}_{4} / \mathrm{m}^{3} \mathrm{LFG}$ ), $D_{\mathrm{CH} 4}$ is the methane density expressed in tonnes of methane per cubic meter of methane $\left(\mathrm{tCH}_{4} / \mathrm{m}^{3} \mathrm{CH}_{4}\right)^{7}$ and $\mathrm{PE}_{\text {flare, }}$ are the project emissions from flaring of the residual gas stream in year $\mathrm{y}$ $\left(\mathrm{tCO}_{2 \mathrm{e}}\right)$ determined following the procedure described in the "Tool to determine project emissions from flaring gases containing Methane". If methane is flared through more than one flare, the $\mathrm{PE}_{\text {flare, }}$ shall be determined for each flare using the tool.

$M D_{\text {electricity }, y}=L F G_{\text {electricity, } y} * w_{C H 4, y} * D_{C H 4}$

where $M D_{\text {electricity,y }}$ is the quantity of methane destroyed by generation of electricity and $L F G_{\text {electricity,y }}$ is the quantity of landfill gas fed into electricity generator.

where $M D_{\text {thermal } y}$ is the quantity of methane destroyed for the generation of thermal energy and $L F G_{\text {thermal, }}$ is the quantity of landfill gas fed into the boiler.

where $M D_{\text {total, } y}$ is the total quantity of methane generated and $L F G_{\text {total, } y}$ is the total quantity of landfill gas generated.

\section{Determination of $\mathrm{CEF}_{\text {elec,BL,y }}$}

In case the baseline is electricity generated by an on-site/off-site fossil fuel fired captive power plant in the baseline, project proponents may use a default value of $0.8 \mathrm{tCO} / \mathrm{MWh}$ or estimate the emission factor as follows:

$\mathrm{CEF}_{\text {elec,BL,y }}=\frac{\mathrm{EF}_{\text {fuel,BL }}}{\varepsilon_{\text {gen, BL }} \cdot \mathrm{NCV}_{\text {fuel,BL }}} * 3.6 \cdot$

Where:

$\mathrm{EF}_{\text {fuel,BL }} \quad$ is the emission factor of baseline fossil fuel used, as identified in the baseline scenario identification procedure, expressed in $\mathrm{tCO} 2 /$ mass of volume unit.

$\mathrm{NCV}_{\text {fuel,BL }} \quad$ Net calorific value of fuel, as identified through the baseline identification procedure, in GJ per unit of volume or mass

$\varepsilon_{\text {gen,BL }} \quad$ is the efficiency of baseline power generation plant.

3.6 equivalent of GJ energy in a MWh of electricity.

To estimate electricity generation efficiency, project participants may use the highest value among the

\footnotetext{
${ }^{6}$ Methane fraction of the landfill gas to be measured on wet basis.

${ }^{7}$ At standard temperature and pressure (0 degree Celsius and 1,013 bar) the density of methane is 0.0007168 $\mathrm{tCH}_{4} / \mathrm{m}^{3} \mathrm{CH}_{4}$.
} 
following three values as a conservative approach:

1. Measured efficiency prior to project implementation

2. Measured efficiency during monitoring

3. Data from manufacturer for efficiency at full load

4. Default efficiency of $60 \%$

In case the baseline is electricity generated by plants connected to the grid the emission factor should be calculated according to methodology ACM0002 ("Consolidated baseline methodology for gridconnected electricity generation from renewable sources"). If the thresholds for small-scale project activities apply, AMS-I.D may be used.

\section{Determination of $\mathrm{CEF}_{\text {ther,BL,y }}$}

$$
\mathrm{CEF}_{\text {therm,BL,y }}=\frac{\mathrm{EF}_{\text {fuel,BL }}}{\varepsilon_{\text {boiler }} \cdot \mathrm{NCV}_{\text {fuel,BL }}} .
$$

Where:

$\varepsilon_{\text {boiler }} \quad$ the energy efficiency of the boiler used in the absence of the project activity to generate the thermal energy

$\mathrm{NCV}_{\text {fuel,BL }} \quad$ Net calorific value of fuel, as identified through the baseline identification procedure, used in the boiler to generate the thermal energy in the absence of the project activity in TJ per unit of volume or mass

$\mathrm{EF}_{\text {fuel,BL}} \quad$ Emission factor of the fuel, as identified through the baseline identification procedure, used in the boiler to generate the thermal energy in the absence of the project activity in $\mathrm{tCO} 2$ / unit of volume or mass of the fuel.

To estimate boiler efficiency, project participants may choose between the following two options:

Option A

Use the highest value among the following three values as a conservative approach:

1. Measured efficiency prior to project implementation;

2. Measured efficiency during monitoring;

3. Manufacturer's information on the boiler efficiency.

Option B

Assume a boiler efficiency of $100 \%$ based on the net calorific values as a conservative approach.

In determining the $\mathrm{CO} 2$ emission factors $\left(\mathrm{EF}_{\text {fuel }}\right)$ of fuels, reliable local or national data should be used if available. Where such data is not available, IPCC default emission factors should be chosen in a conservative manner.

Determination of $C E F_{\text {elect, } P R, y}$

Project participants may use a default emission factor of $1.3 \mathrm{tCO}_{2} / \mathrm{MWh}$. 
In cases where electricity is generated in an on-site fossil fuel fired power plant, project participants may estimate the emission factor as follows:

$\mathrm{CEF}_{\text {elec,PR }, \mathrm{y}}=\frac{\mathrm{EF}_{\text {fuel,PR }}}{\varepsilon_{\text {gen,PR }} \cdot \mathrm{NCV}_{\text {fuel,PR }}} * 3.6 \cdot$

Where:

$\mathrm{EF}_{\text {fuel,PR }} \quad$ is the emission factor of fossil fuel used in captive power plant expressed in $\mathrm{tCO} 2 / \mathrm{unit}$ volume or mass unit

$\mathrm{NCV}_{\text {fuel,PR }} \quad$ is the net caloric value of the fossil fuel (TJ/ per unit volume of mass unit)

$\varepsilon_{\text {gen,PR }} \quad$ is the efficiency of captive power generation plant.

3.6 equivalent of GJ energy in a MWh of electricity.

In cases where electricity is purchased from the grid, the emission factor shall be calculated according to methodology ACM0002 ("Consolidated baseline methodology for grid-connected electricity generation from renewable sources"). If electricity consumption is less than small scale threshold (60 GWh per annum), AMS-I.D may be used.

\section{Additionality}

The additionality of the project activity shall be demonstrated and assessed using the latest version of the "Tool for the demonstration and assessment of additionality" agreed by the CDM Executive Board, which is available on the UNFCCC CDM web site.

\section{Leakage}

No leakage effects need to be accounted under this methodology.

\footnotetext{
${ }^{8}$ Please refer to: $<$ http://cdm.unfccc.int/methodologies/PAmethodologies/approved.html $>$
} 


\section{Revision to the approved consolidated monitoring methodology ACM0001}

\section{"Consolidated monitoring methodology for landfill gas project activities"}

\section{Sources}

This methodology is based on elements from the following approved proposals for monitoring methodologies:

- AM0002: Greenhouse Gas Emission Reductions through Landfill Gas Capture and Flaring where the Baseline is established by a Public Concession Contract (approved based on proposal NM0004 rev: Salvador da Bahia landfill gas project, whose project design document and baseline study, monitoring and verification plans were developed by ICF Consulting (version 03, June 2003));

- AM0003: Simplified financial analysis for landfill gas capture projects (approved based on proposal NM0005: Nova Gerar landfill gas to energy project, whose project design document and baseline study, monitoring and verification plans were developed by EcoSecurities Ltd. (version 14, July 2003) for the Carbon Finance Unit of the World Bank);

- AM0010: Landfill gas capture and electricity generation projects where landfill gas capture is not mandated by law (approved based on proposal NM0010 rev: Durban-landfill-gas-to-electricity project, whose project design document and baseline study, monitoring and verification plans were developed by Prototype Carbon Fund of the World Bank (April 2003));

- AM0011: Landfill gas recovery with electricity generation and no capture or destruction of methane in the baseline scenario (approved based on proposal NM0021: Cerupt methodology for landfill gas recovery, whose project design document and baseline study, monitoring and verification plans were developed by Onyx (July 2003)).

For more information regarding the proposals and its considerations by the Executive Board please refer to the cases on http://cdm.unfccc.int/methodologies/PAmethodologies/approved.html.

The methodology also refers to the latest version of the "Tool to determine project emissions from flaring gases containing Methane ${ }^{9, "}$

\section{Applicability}

This methodology is applicable to landfill gas capture project activities, where the baseline scenario is the partial or total atmospheric release of the gas and the project activities include situations such as:

a) The captured gas is flared; or

b) The captured gas is used to produce energy (e.g. electricity/thermal energy[.]

c)

This monitoring methodology shall be used in conjunction with the approved baseline methodology ACM0001 ("Consolidated baseline methodology for landfill gas project activities").

\section{Monitoring Methodology}

The monitoring methodology is based on direct measurement of the amount of landfill gas captured and destroyed at the flare platform(s) and the electricity generating/thermal energy unit(s) to determine the quantities as shown in Figure 1. The monitoring plan provides for continuous measurement of the

\footnotetext{
${ }^{9}$ Please refer to $<\underline{\text { http: } / / \text { cdm.unfccc.int/methodologies/PAmethodologies/approved.html }}>$ 
quantity and quality of LFG flared. The main variables that need to be determined are the quantity of

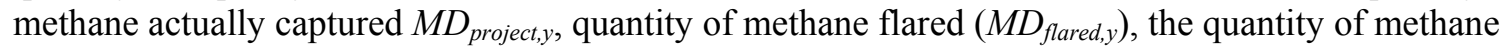
used to generate electricity $\left(M D_{\text {electricity,y }}\right)$ /thermal energy $\left(M D_{\text {thermal,y }}\right)$, and the quantity of methane generated $\left(M D_{\text {total,y }}\right)$. The methodology also measures the energy generated by use of LFG (EL $L_{L F G, y}$, $\mathrm{ET}_{\mathrm{LFG}, \mathrm{y}}$ ) and energy consumed by the project activity that is produced using fossil fuels.

\section{Figure 1: Monitoring Plan}

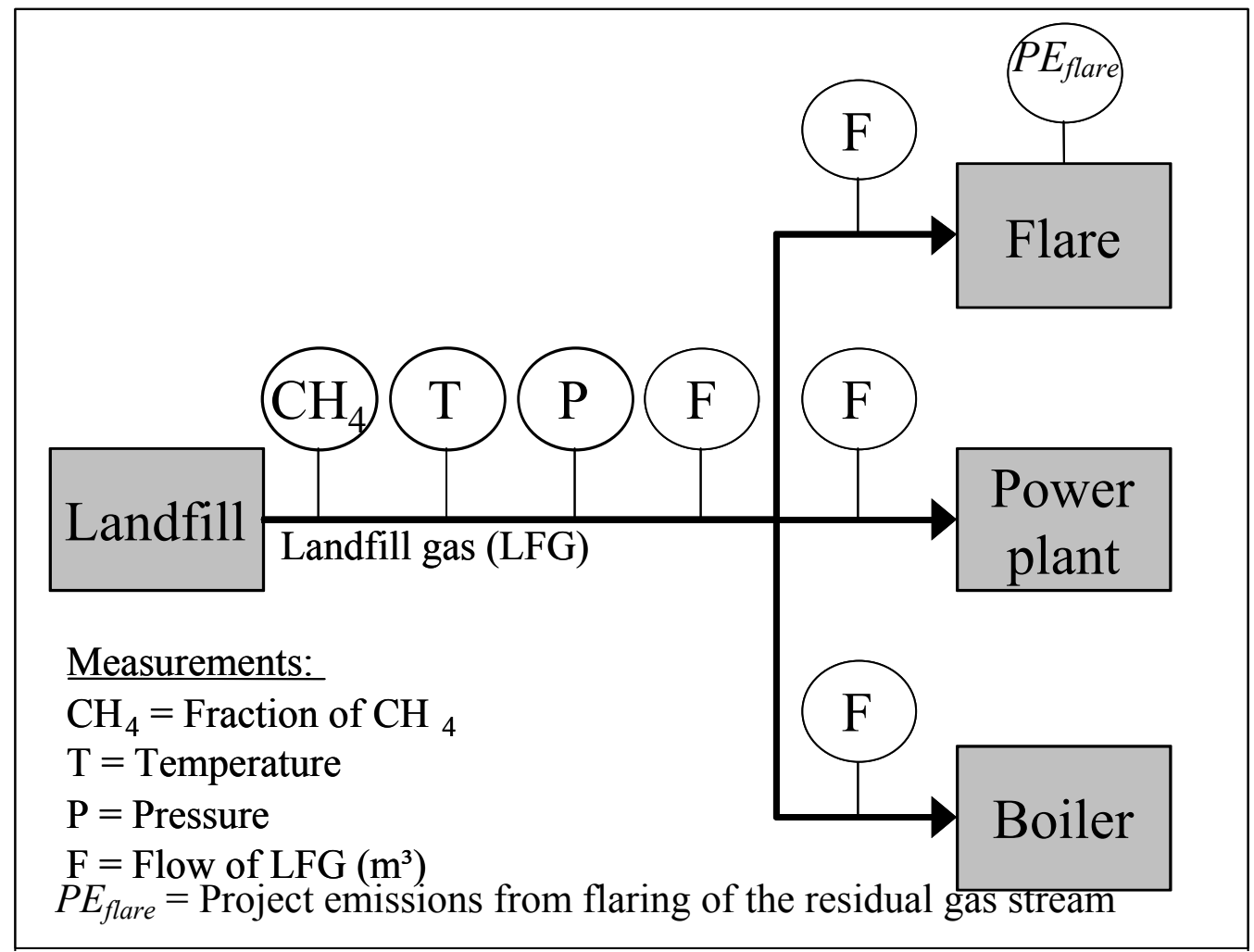

To determine these variables, the following parameters have to be monitored:

- The amount of landfill gas generated (in $\mathrm{m}^{3}$, using a continuous flow meter), where the total quantity $\left(L F G_{\text {total,y }}\right)$ as well as the quantities fed to the flare(s) $\left(L F G_{\text {flare }, y}\right)$, to the power plant(s) $\left(L F G_{\text {electricity } y}\right)$ and to the boiler(s) $\left(L F G_{\text {thermal,y }}\right)$ are measured continuously. In the case where LFG is just flared, one flow meter for each flare can be used provided that these meters used are calibrated periodically by an officially accredited entity.

- The fraction of methane in the landfill gas $\left(w_{C H 4, y}\right)$ should be measured with a continuous analyzer or, alternatively, with periodical measurements, at a 95\% confidence level, using calibrated portable gas meters and taking a statistically valid number of samples and accordingly the amount of land fill gas from $L F G_{\text {total, },}, L F G_{\text {flare, } y}, L F G_{\text {electricity, } y}$, and $L F G_{\text {thermal,y }}$ shall be monitored in the same frequency. The continuous methane analyser should be the preferred option because the methane content of landfill gas captured can vary by more than $20 \%$ during a single day due to gas capture network conditions (dilution with air at wellheads, leakage on pipes, etc.). Methane fraction of the landfill gas to be measured on wet basis. 
- The parameters used for determining the project emissions from flaring of the residual gas stream in year y $\left(\mathrm{PE}_{\text {flare,y }}\right)$ should be monitored as per the "Tool to determine project emissions from flaring gases containing Methane".

- Temperature $(T)$ and pressure $(p)$ of the landfill gas are required to determine the density of methane in the landfill gas.

- The quantities of fossil fuels required to operate the landfill gas project, including the pumping equipment for the collection system and energy required to transport heat, should be monitored. In projects where LFG gas is captured in the baseline to either meet the regulation or for safety reason, fossil fuel used in the baseline too should be recorded.

- The quantity of electricity imported, in the baseline and the project situation, to meet the requirements of the project activity, if any.

- The quantity of electricity exported out of the project boundary, generated from landfill gas, if any.

- Relevant regulations for LFG project activities shall be monitored and updated at renewal of each credit period. Changes to regulation should be converted to the amount of methane that would have been destroyed/combusted during the year in the absence of the project activity $\left(M D_{\text {reg,y }}\right)$. Project participants should explain how regulations are translated into that amount of gas.

- The operating hours of the energy plant(s) and the boiler(s).

The measurement equipment for gas quality (humidity, particulate, etc.) is sensitive, so a strong $\mathrm{QA} / \mathrm{QC}$ procedure for the calibration of this equipment is needed. 
Data to be collected or used to monitor emissions from the project activity, and how this data will be archived

\begin{tabular}{|c|c|c|c|c|c|c|c|c|}
\hline $\begin{array}{c}\text { ID } \\
\text { number }\end{array}$ & $\begin{array}{c}\text { Data } \\
\text { variable }\end{array}$ & $\begin{array}{l}\text { Data } \\
\text { unit }\end{array}$ & $\begin{array}{l}\text { Measured } \\
(\mathrm{m}) \\
\text { calculated (c) } \\
\text { estimated (e) }\end{array}$ & $\begin{array}{l}\text { Recording } \\
\text { frequency }\end{array}$ & $\begin{array}{l}\text { Proportion } \\
\text { of data } \\
\text { monitored }\end{array}$ & $\begin{array}{l}\text { How will data be } \\
\text { archived? } \\
\text { (electronic/ } \\
\text { paper) }\end{array}$ & $\begin{array}{c}\text { For how long is } \\
\text { archived data } \\
\text { kept? }\end{array}$ & Comment \\
\hline $\begin{array}{c}1 . \\
\mathrm{LFG}_{\text {total,y }}\end{array}$ & $\begin{array}{c}\text { Total } \\
\text { amount of } \\
\text { landfill gas } \\
\text { captured }\end{array}$ & $\mathrm{m}^{3}$ & $\mathrm{~m}$ & $\begin{array}{l}\text { Continuously/ } \\
\text { periodically }\end{array}$ & $100 \%$ & Electronic & $\begin{array}{c}\text { During the } \\
\text { crediting period } \\
\text { and two years } \\
\text { after }\end{array}$ & $\begin{array}{l}\text { Measured by a flow } \\
\text { meter. Data to be } \\
\text { aggregated monthly and } \\
\text { yearly. }\end{array}$ \\
\hline $\begin{array}{c}2 . \\
\mathrm{LFG}_{\text {flare,y }}\end{array}$ & $\begin{array}{l}\text { Amount of } \\
\text { landfill gas } \\
\text { flared }\end{array}$ & $\mathrm{m}^{3}$ & $\mathrm{~m}$ & $\begin{array}{l}\text { Continuously/ } \\
\text { periodically }\end{array}$ & $100 \%$ & Electronic & $\begin{array}{c}\text { During the } \\
\text { crediting period } \\
\text { and two years } \\
\text { after }\end{array}$ & $\begin{array}{l}\text { Measured by a flow } \\
\text { meter. Data to be } \\
\text { aggregated monthly and } \\
\text { yearly for each flare. }\end{array}$ \\
\hline $\begin{array}{c}3 . \\
\mathrm{LFG}_{\text {electric }} \\
\text { ity,y }\end{array}$ & $\begin{array}{l}\text { Amount of } \\
\text { landfill gas } \\
\text { combusted } \\
\text { in power } \\
\text { plant }\end{array}$ & $\mathrm{m}^{3}$ & $\mathrm{~m}$ & $\begin{array}{l}\text { Continuously/ } \\
\text { periodically }\end{array}$ & $100 \%$ & Electronic & $\begin{array}{l}\text { During the } \\
\text { crediting period } \\
\text { and two years } \\
\text { after }\end{array}$ & $\begin{array}{l}\text { Measured by a flow } \\
\text { meter. Data to be } \\
\text { aggregated monthly and } \\
\text { yearly for each power } \\
\text { plant. }\end{array}$ \\
\hline $\begin{array}{c}4 . \\
\mathrm{LFG}_{\text {thermal }} \\
, \mathrm{y}\end{array}$ & $\begin{array}{l}\text { Amount of } \\
\text { methane } \\
\text { combusted } \\
\text { in boiler }\end{array}$ & $\mathrm{m}^{3}$ & $\mathrm{~m}$ & $\begin{array}{l}\text { Continuously/ } \\
\text { periodically }\end{array}$ & $100 \%$ & Electronic & $\begin{array}{c}\text { During the } \\
\text { crediting period } \\
\text { and two years } \\
\text { after }\end{array}$ & $\begin{array}{l}\text { Measured by a flow } \\
\text { meter. Data to be } \\
\text { aggregated monthly and } \\
\text { yearly for each boiler. }\end{array}$ \\
\hline $\begin{array}{c}5 . \\
P_{\text {flare,y }}\end{array}$ & $\begin{array}{c}\text { Project } \\
\text { emissions } \\
\text { from flaring } \\
\text { of the } \\
\text { residual gas } \\
\text { stream in } \\
\text { year } y\end{array}$ & $\mathrm{tCO}_{2 \mathrm{e}}$ & $\mathrm{m} / \mathrm{c}$ & $\begin{array}{c}\text { See } \\
\text { comments }\end{array}$ & $\mathrm{n} / \mathrm{a}$ & Electronic & $\begin{array}{l}\text { During the } \\
\text { crediting period } \\
\text { and two years } \\
\text { after }\end{array}$ & $\begin{array}{l}\text { The parameters used for } \\
\text { determining the project } \\
\text { emissions from flaring } \\
\text { of the residual gas } \\
\text { stream in year y } \\
\left(\mathrm{PE}_{\mathrm{flare}, \mathrm{y}}\right) \text { should be } \\
\text { monitored as per the } \\
\text { "Tool to determine } \\
\text { project emissions from } \\
\text { flaring gases containing } \\
\text { Methane". }\end{array}$ \\
\hline
\end{tabular}




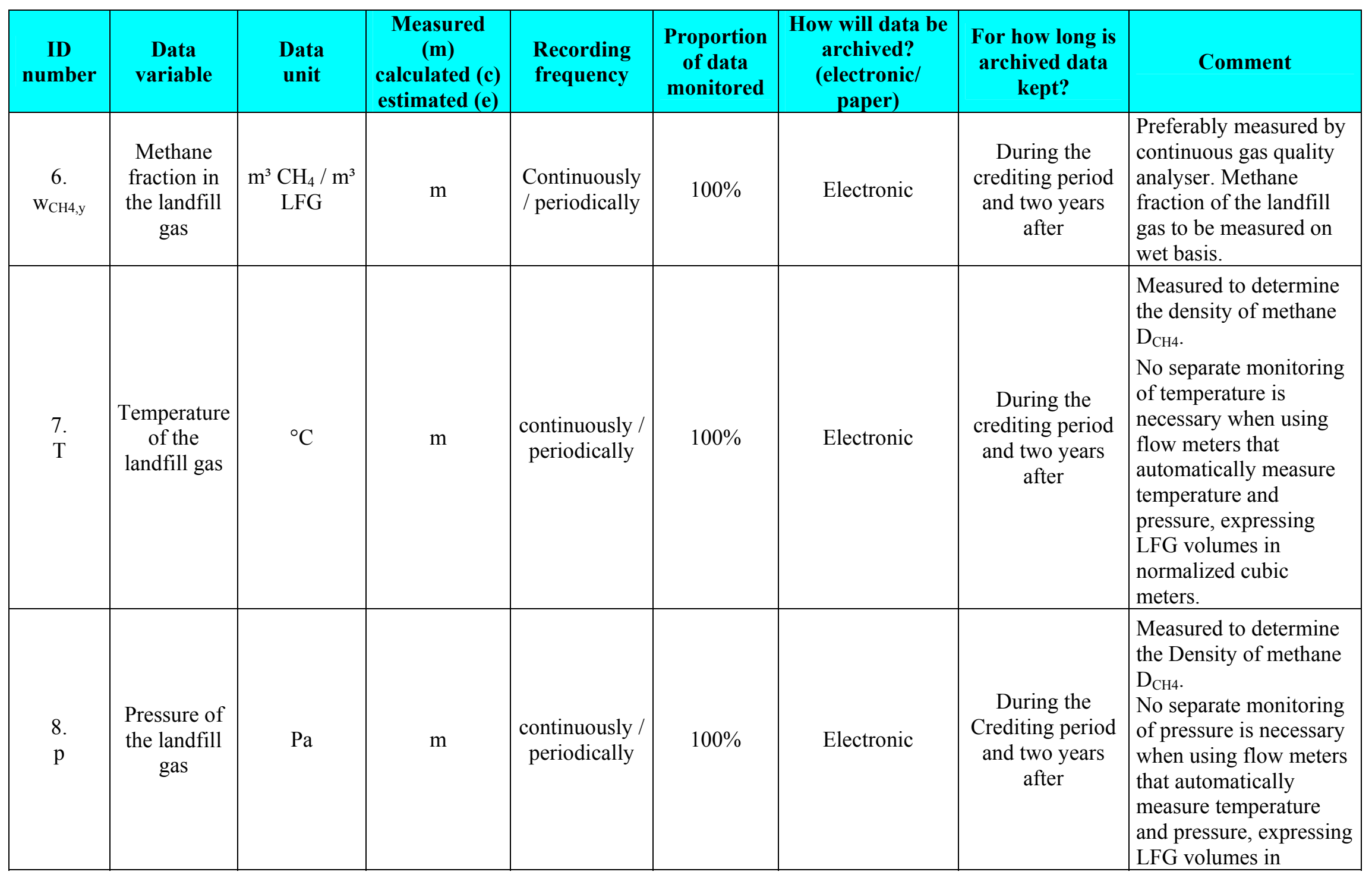




\begin{tabular}{|c|c|c|c|c|c|c|c|c|}
\hline $\begin{array}{c}\text { ID } \\
\text { number }\end{array}$ & $\begin{array}{c}\text { Data } \\
\text { variable }\end{array}$ & $\begin{array}{l}\text { Data } \\
\text { unit }\end{array}$ & $\begin{array}{l}\text { Measured } \\
(\mathrm{m}) \\
\text { calculated (c) } \\
\text { estimated (e) }\end{array}$ & $\begin{array}{l}\text { Recording } \\
\text { frequency }\end{array}$ & $\begin{array}{c}\text { Proportion } \\
\text { of data } \\
\text { monitored }\end{array}$ & $\begin{array}{c}\text { How will data be } \\
\text { archived? } \\
\text { (electronic/ } \\
\text { paper) }\end{array}$ & $\begin{array}{l}\text { For how long is } \\
\text { archived data } \\
\text { kept? }\end{array}$ & Comment \\
\hline & & & & & & & & $\begin{array}{l}\text { normalized cubic } \\
\text { meters. }\end{array}$ \\
\hline 9.EL $L_{\mathrm{LFG}}$ & $\begin{array}{l}\text { Net amount } \\
\text { of electricity } \\
\text { generated } \\
\text { using LFG. }\end{array}$ & MWh & $\mathrm{m}$ & continuously & $100 \%$ & Electronic & $\begin{array}{c}\text { During the } \\
\text { crediting period } \\
\text { and two years } \\
\text { after }\end{array}$ & $\begin{array}{l}\text { Required to estimate the } \\
\text { emission reductions } \\
\text { from electricity } \\
\text { generation from LFG, if } \\
\text { credits are claimed. } \\
\end{array}$ \\
\hline $\begin{array}{l}\text { 10. } P \\
\mathrm{EL}_{P R}\end{array}$ & $\begin{array}{c}\text { Total } \\
\text { amount of } \\
\text { electricity } \\
\text { required to } \\
\text { meet project } \\
\text { requirement }\end{array}$ & MWh & $\mathrm{m}$ & continuously & $100 \%$ & Electronic & $\begin{array}{c}\text { During the } \\
\text { crediting period } \\
\text { and two years } \\
\text { after }\end{array}$ & $\begin{array}{l}\text { Required to determine } \\
\mathrm{CO}_{2} \text { emissions from use } \\
\text { of electricity to operate } \\
\text { the project activity. } \\
\text { The records of any } \\
\text { electricity imported in } \\
\text { the baseline too should } \\
\text { be recorded at the start } \\
\text { of project. }\end{array}$ \\
\hline $\begin{array}{l}11 \\
\mathrm{ET}_{L F G}\end{array}$ & $\begin{array}{c}\text { Total } \\
\text { amount of } \\
\text { thermal } \\
\text { energy } \\
\text { generated } \\
\text { using LFG }\end{array}$ & $\mathrm{TJ}$ & $\mathrm{m}$ & continuously & $100 \%$ & Electronic & $\begin{array}{c}\text { During the } \\
\text { crediting period } \\
\text { and two years } \\
\text { after }\end{array}$ & $\begin{array}{l}\text { Required to estimate the } \\
\text { emission reductions } \\
\text { from thermal energy } \\
\text { generation from LFG, if } \\
\text { credits are claimed }\end{array}$ \\
\hline 12. $\mathrm{ET}_{P R}$ & $\begin{array}{c}\text { Total } \\
\text { amount of } \\
\text { fossil fuel } \\
\text { required to } \\
\text { meet project } \\
\text { requirement }\end{array}$ & tonne & $\mathrm{m}$ & continuously & $100 \%$ & Electronic & $\begin{array}{c}\text { During the } \\
\text { crediting period } \\
\text { and two years } \\
\text { after }\end{array}$ & $\begin{array}{l}\text { Required to determine } \\
\mathrm{CO}_{2} \text { emissions from use } \\
\text { of energy carriers to } \\
\text { operate the project } \\
\text { activity. }\end{array}$ \\
\hline $\begin{array}{c}13 . \\
C E F_{\text {elec }, B}\end{array}$ & $\begin{array}{l}\text { Carbon } \\
\text { emission }\end{array}$ & $\mathrm{tCO} 2 / \mathrm{MWh}$ & $\mathrm{c}$ & annually & $100 \%$ & Electronic & $\begin{array}{l}\text { During the } \\
\text { crediting period }\end{array}$ & $\begin{array}{l}\text { A default of } 0.8 \text { can be } \\
\text { used if electricity in the }\end{array}$ \\
\hline
\end{tabular}




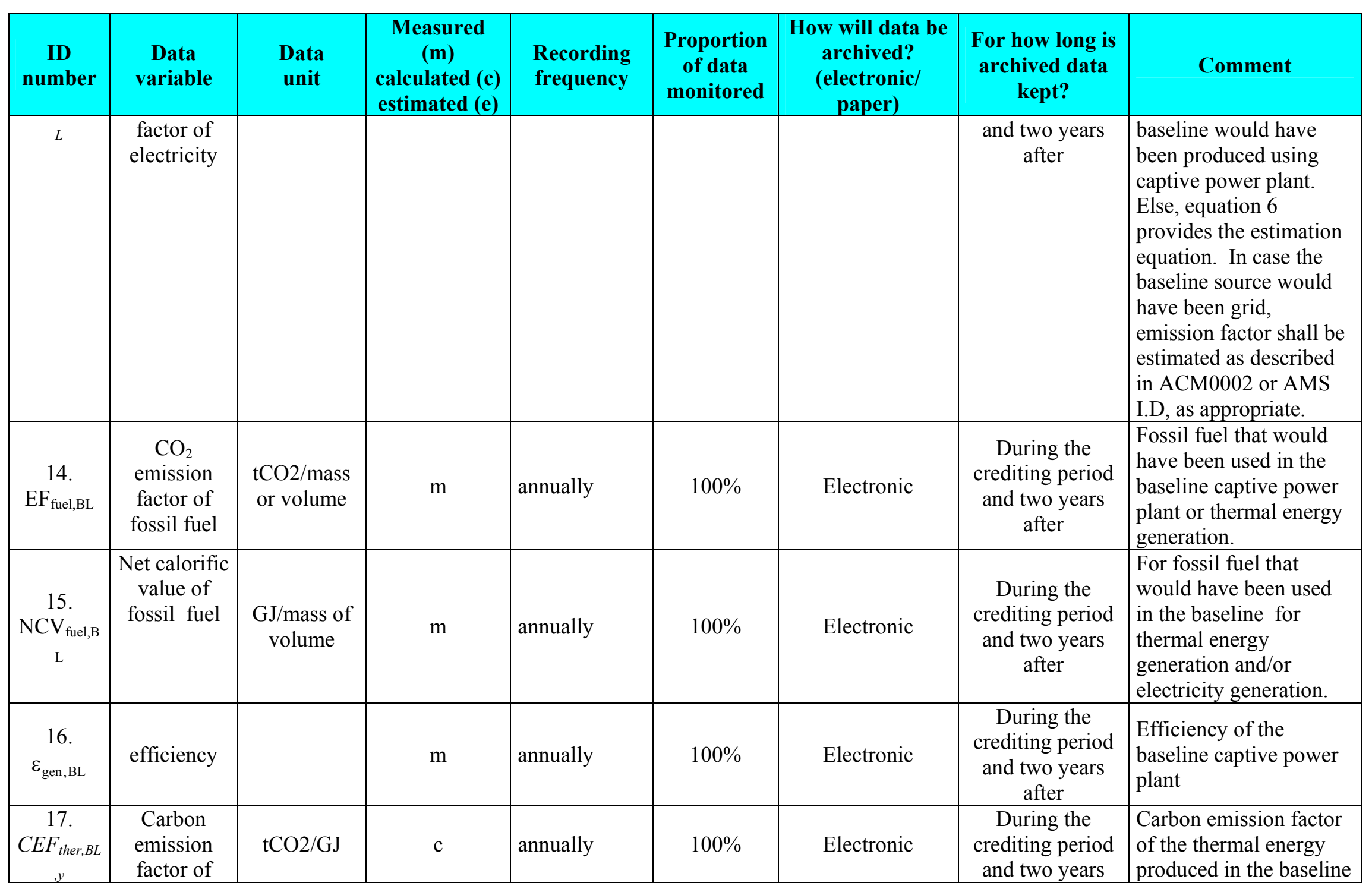




\begin{tabular}{|c|c|c|c|c|c|c|c|c|}
\hline $\begin{array}{c}\text { ID } \\
\text { number }\end{array}$ & $\begin{array}{c}\text { Data } \\
\text { variable }\end{array}$ & $\begin{array}{l}\text { Data } \\
\text { unit }\end{array}$ & $\begin{array}{l}\text { Measured } \\
(\mathrm{m}) \\
\text { calculated (c) } \\
\text { estimated (e) }\end{array}$ & $\begin{array}{l}\text { Recording } \\
\text { frequency }\end{array}$ & $\begin{array}{c}\text { Proportion } \\
\text { of data } \\
\text { monitored }\end{array}$ & $\begin{array}{c}\text { How will data be } \\
\text { archived? } \\
\text { (electronic/ } \\
\text { paper) }\end{array}$ & $\begin{array}{l}\text { For how long is } \\
\text { archived data } \\
\text { kept? }\end{array}$ & Comment \\
\hline & $\begin{array}{l}\text { thermal } \\
\text { energy }\end{array}$ & & & & & & after & (equation (7)) \\
\hline 18. $\varepsilon_{\text {boiler }}$ & efficiency & & $\mathrm{m}$ & annually & $100 \%$ & Electronic & $\begin{array}{c}\text { During the } \\
\text { crediting period } \\
\text { and two years } \\
\text { after }\end{array}$ & $\begin{array}{l}\text { Efficiency of the } \\
\text { baseline boiler for } \\
\text { producing thermal } \\
\text { energy. A default of } \\
100 \% \text { may be used in } \\
\text { absence of data. }\end{array}$ \\
\hline $\begin{array}{c}19 . \\
C E F_{\text {elec }, y}, \\
\quad R, y\end{array}$ & $\begin{array}{l}\text { Carbon } \\
\text { emission } \\
\text { factor of } \\
\text { electricity }\end{array}$ & $\mathrm{tCO} 2 / \mathrm{MWh}$ & $\mathrm{c}$ & annually & $100 \%$ & Electronic & $\begin{array}{c}\text { During the } \\
\text { crediting period } \\
\text { and two years } \\
\text { after }\end{array}$ & $\begin{array}{l}\text { Carbon emission factor } \\
\text { of electricity consumed } \\
\text { during project activity. }\end{array}$ \\
\hline $\begin{array}{c}21 . \\
\mathrm{EF}_{\text {fuel,PR }}\end{array}$ & $\begin{array}{l}\mathrm{CO}_{2} \\
\text { emission } \\
\text { factor of } \\
\text { fossil fuel }\end{array}$ & $\begin{array}{l}\mathrm{tCO} 2 / \mathrm{mass} \\
\text { or voulme }\end{array}$ & $\mathrm{m}$ & annually & $100 \%$ & Electronic & $\begin{array}{c}\text { During the } \\
\text { crediting period } \\
\text { and two years } \\
\text { after }\end{array}$ & $\begin{array}{l}\text { Fossil fuel that would } \\
\text { have been used in the } \\
\text { project captive power } \\
\text { plant or thermal energy } \\
\text { generation. }\end{array}$ \\
\hline $\begin{array}{l}22 . \\
\mathrm{NCV}_{\text {fuel,P }} \\
\mathrm{R}\end{array}$ & $\begin{array}{l}\text { Net calorific } \\
\text { value of } \\
\text { fossil fuel }\end{array}$ & $\begin{array}{c}\mathrm{GJ} / \text { mass of } \\
\text { volume }\end{array}$ & $\mathrm{m}$ & annually & $100 \%$ & Electronic & $\begin{array}{c}\text { During the } \\
\text { crediting period } \\
\text { and two years } \\
\text { after }\end{array}$ & $\begin{array}{l}\text { For fossil fuel that } \\
\text { would have been used } \\
\text { in the project scenario } \\
\text { for thermal energy } \\
\text { generation and/or } \\
\text { electricity generation. }\end{array}$ \\
\hline
\end{tabular}




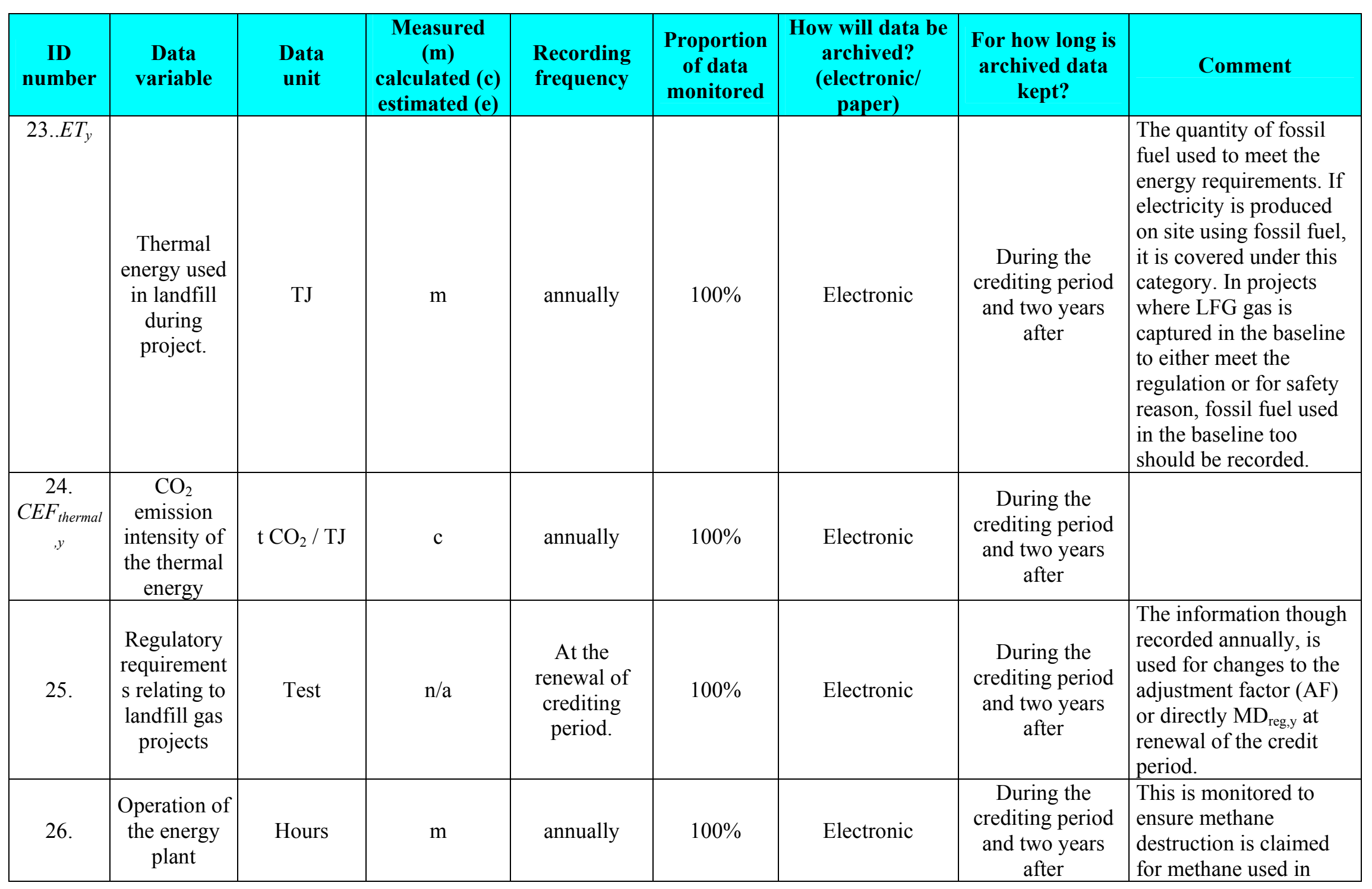




\begin{tabular}{|c|c|c|c|c|c|c|c|c|}
\hline $\begin{array}{c}\text { ID } \\
\text { number }\end{array}$ & $\begin{array}{c}\text { Data } \\
\text { variable }\end{array}$ & $\begin{array}{l}\text { Data } \\
\text { unit }\end{array}$ & $\begin{array}{l}\text { Measured } \\
(\mathrm{m}) \\
\text { calculated (c) } \\
\text { estimated (e) }\end{array}$ & $\begin{array}{l}\text { Recording } \\
\text { frequency }\end{array}$ & $\begin{array}{l}\text { Proportion } \\
\text { of data } \\
\text { monitored }\end{array}$ & $\begin{array}{l}\text { How will data be } \\
\text { archived? } \\
\text { (electronic/ } \\
\text { paper) }\end{array}$ & $\begin{array}{c}\text { For how long is } \\
\text { archived data } \\
\text { kept? }\end{array}$ & Comment \\
\hline 27. & $\begin{array}{l}\text { Operation of } \\
\text { the boiler }\end{array}$ & Hours & $\mathrm{m}$ & annually & $100 \%$ & Electronic & $\begin{array}{c}\text { During the } \\
\text { crediting period } \\
\text { and two years } \\
\text { after }\end{array}$ & $\begin{array}{l}\text { This is monitored to } \\
\text { ensure methane } \\
\text { destruction is claimed } \\
\text { for methane used in } \\
\text { boiler when it is } \\
\text { operational. }\end{array}$ \\
\hline
\end{tabular}

* Note: this can be calculated using the consolidated methodologies for grid-connected electricity generation from renewable sources (ACM0002) or AMS I.D, if the generation capacity meets the small scale definition.

\section{Quality control $(Q C)$ and quality assurance $(Q A)$ procedures to be undertaken for the items monitored. (see tables above)}

Appropriate quality control and quality assurance procedures are needed for the monitoring equipment and the data collected.

\begin{tabular}{|c|c|c|c|}
\hline Data & $\begin{array}{l}\text { Uncertainty level of data } \\
\text { (High/Medium/Low) }\end{array}$ & $\begin{array}{c}\text { Are } \mathrm{QA} / \mathrm{QC} \\
\text { procedures planned } \\
\text { for these data? }\end{array}$ & Outline explanation how QA/QC procedures are planned \\
\hline $\begin{array}{l}1 .-4 . \\
L_{F G}\end{array}$ & Low & Yes & $\begin{array}{l}\text { Flow meters should be subject to a regular maintenance and testing regime to } \\
\text { ensure accuracy. }\end{array}$ \\
\hline $\begin{array}{c}5 . \\
P_{\text {flare, }}\end{array}$ & & & $\begin{array}{l}\text { The parameters used for determining the project emissions from flaring of the } \\
\text { residual gas stream in year y }\left(\mathrm{PE}_{\text {flare, }}\right) \text { should use the } \mathrm{QA} / \mathrm{QC} \text { procedures as per } \\
\text { the "Tool to determine project emissions from flaring gases containing } \\
\text { Methane". }\end{array}$ \\
\hline $\begin{array}{c}6 . \\
\mathrm{w}_{\mathrm{CH} 4, \mathrm{y}}\end{array}$ & Low & Yes & $\begin{array}{l}\text { The gas analyser should be subject to a regular maintenance and testing regime } \\
\text { to ensure accuracy. }\end{array}$ \\
\hline
\end{tabular}




\section{Miscellaneous Parameters}

Factor Used for Converting Methane to Carbon Dioxide Equivalents ${ }^{1}$

\begin{tabular}{|l|l|l|}
\hline Factor used $\left(\mathbf{t C O}_{\mathbf{2}} \mathbf{e} / \mathbf{t} \mathbf{C H}_{4}\right)$ & Period Applicable & Source \\
\hline 21 & 1996-present & $\begin{array}{l}\text { Revised 1996 IPCC Guidelines for } \\
\text { National Greenhouse Gas Inventories }\end{array}$ \\
\hline
\end{tabular}

${ }^{1}$ This table is updated as reporting guidelines are modified.

Conversion Factors ${ }^{1}$

\begin{tabular}{|l|l|l|l|l|}
\hline & Factor & Unit & Period Applicable & Description/Source \\
\hline Methane Density & At standard & tonnes & Default & \\
& temperature and & $\mathrm{CH}_{4} / \mathrm{m}^{3} \mathrm{CH}_{4}$ & & \\
pressure $(0$ & & & \\
degree Celsius & & & \\
and 1,013 bar) & & & \\
the density of & & & \\
methane is & & & \\
& 0.0007168 & & & \\
& $\mathrm{tCH}_{4} / \mathrm{m}^{3} \mathrm{CH}_{4}$ & & & \\
\hline
\end{tabular}




\section{Revisão da metodologia consolidada aprovada de linha de base ACM0002}

\section{"Metodologia consolidada de linha de base para a geração de eletricidade conectada à rede a partir de fontes renováveis”}

\section{Fontes}

Esta metodologia consolidada de linha de base tem como fundamento elementos das seguintes novas metodologias propostas:

- NM0001-rev: Projeto da Vale do Rosário de Co-geração de Energia a partir do Bagaço da Cana-de-açúcar (VRBC), Brasil, cujo estudo da linha de base, plano de monitoramento e verificação e documento de concepção do projeto foram elaborados pela Econergy International Corporation;

- NM0012-rev: Projeto Wigton de Fazenda de Vento na Jamaica, cujo estudo da linha de base, plano de monitoramento e verificação e documento de concepção do projeto foram elaborados pela Ecosecurities Ltd;

- NM0023: Projeto Hidrelétrico de El Gallo, México, cujo estudo da linha de base, plano de monitoramento e verificação e documento de concepção do projeto foram elaborados pelo Prototype Carbon Fund (aprovado pelo Conselho Executivo do MDL em 14 de abril de 2004);

- NM0024-rev: Colômbia: Projeto de Usina Eólica de Jepirachi, cujo estudo da linha de base, plano de monitoramento e verificação e documento de concepção do projeto foram elaborados pelo Prototype Carbon Fund;

- NM0030-rev: Projeto de Co-Geração de Energia a partir de Bagaço da Haidergarh, Índia, cujo estudo da linha de base, plano de monitoramento e verificação e documento de concepção do projeto foram enviados pela Haidergarh Chini Mills, uma unidade da Balrampur Chini Mills Limited;

- NM0036: Projeto de Usina de Energia Eólica de Zafarana, República Árabe do Egito, cujo estudo da linha de base, plano de monitoramento e verificação e documento de concepção do projeto foram elaborados pela Mitsubishi Securities;

- NM0043: Projeto Hidrelétrico Bayano de Expansão e Modernização, Panamá, cujo estudo da linha de base, plano de monitoramento e verificação e documento de concepção do projeto foram elaborados pela Econergy International Corporation;

- NM0055: Projeto Geotérmico Unidade III de Darajat, Indonésia, cujo estudo da linha de base, plano de monitoramento e verificação e documento de concepção do projeto foram elaborados pela URS Corporation e Amoseas Indonesia Inc.

Mais informações sobre as propostas e sua análise pelo Conselho Executivo podem ser obtidas no endereço: http://cdm.unfccc.int/methodologies/PAmethodologies/approved.html.

\section{Aplicabilidade}

Esta metodologia se aplica às atividades de projetos de geração de energia renovável conectada à rede sob as seguintes condições: 
- Aplique-se aos acréscimos de capacidade de eletricidade de:

- Usinas hidrelétricas a fio de água; projetos de energia hidrelétrica com reservatórios existentes em que o volume do reservatório não aumente;

- Novos projetos de energia hidrelétrica com reservatórios cujas densidades de energia (capacidade instalada de geração elétrica dividida pela área da superfície no nível máximo do reservatório) sejam superiores a $4 \mathrm{~W} / \mathrm{m}^{2}{ }^{1}{ }^{1}$

- Fontes de energia eólica;

- Fontes de energia geotérmica;

- Fontes de energia solar;

- Fontes de energia de ondas e marés.

- Esta metodologia não se aplique às atividades de projetos que envolvam a mudança de combustíveis fósseis para energia renovável na área da atividade do projeto, uma vez que, nesse caso, a linha de base pode ser a continuação do uso de combustíveis fósseis no local;

- Os limites geográficos e do sistema da rede elétrica pertinente possam ser claramente identificados e existam informações sobre as características da rede; e

- Aplique-se à geração de eletricidade conectada à rede a partir da captação de gás de aterro, em conjunto com a "metodologia consolidada aprovada de linha de base para atividades de projetos com gás de aterro" (ACM0001).

Esta metodologia de linha de base deve ser usada em conjunto com a metodologia aprovada de monitoramento ACM0002 ("Metodologia consolidada de monitoramento para a geração de eletricidade conectada à rede a partir de fontes renováveis").

\section{Atividade do projeto}

A atividade do projeto é a geração de eletricidade conectada à rede a partir de fontes renováveis de energia. Há vários tamanhos e subtipos diferentes dessa atividade de projeto (usinas hidrelétricas a fio de água; projetos de energia hidrelétrica com reservatórios existentes em que o volume do reservatório não aumente, fontes de energia eólica, geotérmica, solar, marés e ondas).

\section{Abordagem}

"Emissões existentes, reais ou históricas, conforme o caso."

ou

"Emissões de uma tecnologia que represente um curso de ação economicamente atrativo, levando-se em conta as barreiras aos investimentos."

\footnotetext{
${ }^{1}$ A adoção desta orientação não impede que os participantes do projeto enviem novas metodologias para projetos hidrelétricos, a serem analisadas pelo Painel de Metodologias, especialmente quando os reservatórios não tiverem uma biomassa vegetativa significativa na área de captações.
} 


\section{Adicionalidade}

A adicionalidade da atividade do projeto deve ser demonstrada e avaliada com o uso da última versão da "Ferramenta para demonstrar e avaliar a adicionalidade", acordada pelo Conselho Executivo do MDL e disponível no web site da CQNUMC para $o M D L^{2}$.

\section{Limite do projeto}

1) Os participantes do projeto devem contabilizar somente as seguintes fontes de emissões para a atividade do projeto:

- Para as atividades de projetos geotérmicos, as emissões fugitivas de metano e dióxido de carbono provenientes de gases não-condensáveis contidos no vapor geotérmico e as emissões de dióxido de carbono provenientes da queima de combustíveis fósseis necessária para o funcionamento da usina de energia geotérmica;

- Para novos projetos hidrelétricos com reservatórios, o limite do projeto compreende a área física da usina, bem como a área do reservatório.

Para determinar a linha de base, os participantes do projeto devem contabilizar apenas as emissões de $\mathrm{CO}_{2}$ provenientes da geração de eletricidade, em usinas movidas a combustível fóssil, que for substituída em razão da atividade do projeto.

2) A extensão espacial do limite do projeto abrange a área do projeto e todas as usinas fisicamente conectadas ao sistema de eletricidade ao qual a usina do projeto no âmbito do MDL esteja conectada.

Para determinar o fator de emissão da margem de construção (BM) e da margem operacional (OM), conforme descrito a seguir, um sistema de eletricidade do projeto (regional) é definido pela extensão espacial das usinas que possam ser despachadas sem restrições significativas de transmissão. De forma similar, um sistema de eletricidade conectado, por exemplo, nacional ou internacional, é definido como um sistema de eletricidade (regional) conectado por linhas de transmissão ao sistema de eletricidade do projeto e no qual as usinas possam ser despachadas sem restrições significativas de transmissão. Na determinação do sistema de eletricidade do projeto, os participantes do projeto devem justificar suas suposições.

Quando não se obtiver, com a aplicação desta metodologia, um limite claro da rede, dadas as variações específicas do país nas políticas de gerenciamento de rede, deve-se:

(a) Usar a descrição dos limites da rede, conforme fornecida pela Autoridade Nacional Designada (DNA) do país anfitrião, se houver; ou

(b) Usar, quando não houver orientação da DNA, a seguinte definição de limite:

\footnotetext{
${ }^{2}$ No endereço: $\underline{\text { http://cdm.unfccc.int/methodologies/PAmethodologies/approved.html. }}$
} 
- Em países grandes, com sistemas de despacho por níveis (por exemplo, estadual/municipal/regional/nacional), deve-se usar a definição de rede regional. A definição de rede estadual/municipal pode, de fato, ser muito restrita em vários casos, dada a comercialização de energia significativa entre estados/municípios que pode ser afetada, direta ou indiretamente, por uma atividade de projeto no âmbito do MDL;

- Em outros países, a definição de rede nacional (ou outra mais ampla) deve ser usada como padrão.

As transferências de eletricidade dos sistemas de eletricidade conectados para o sistema de eletricidade do projeto são definidas como importações de energia e as transferências de eletricidade para os sistemas de eletricidade conectados são definidas como exportações de energia.

Para determinar o fator de emissão da Margem de Construção (BM), conforme descrito a seguir, a extensão espacial se limita ao sistema de eletricidade do projeto, exceto quando acréscimos recentes ou possíveis acréscimos futuros à capacidade de transmissão permitam aumentos significativos da eletricidade importada. Em tais casos, a capacidade de transmissão pode ser considerada uma fonte da margem de construção, com o fator de emissão determinado como para as importações da Margem Operacional abaixo.

Para determinar o fator de emissão da Margem Operacional (OM), conforme descrito a seguir, deve-se usar uma das seguintes opções para determinar o(s) fator(es) de emissão de $\mathrm{CO}_{2}$ para as importações líquidas de eletricidade da rede $\left(C O E F_{i, j, i m p o r t s}\right)$ a partir de um sistema de eletricidade conectado dentro do mesmo país anfitrião:

(a) $0 \mathrm{tCO}_{2} / \mathrm{MWh}$, ou

(b) o(s) fator(es) de emissão da(s) usina(s) de energia específica(s) da(s) qual(is) a eletricidade é importada, somente se as usinas específicas forem claramente conhecidas, ou

(c) a taxa média de emissão da rede de exportação, somente se as importações líquidas não excederem $20 \%$ da geração total do sistema de eletricidade do projeto, ou

(d) o fator de emissão da rede exportadora, determinado conforme descrito nas etapas 1,2 e 3 a seguir, se as importações líquidas excederem $20 \%$ da geração total do sistema de eletricidade do projeto.

Para as importações do sistema de eletricidade conectado localizado em outro país, o fator de emissão é 0 tonelada de $\mathrm{CO}_{2}$ por $\mathrm{MWh}$.

As exportações de energia não devem ser subtraídas dos dados de geração de eletricidade usados para calcular e monitorar a taxa de emissões da linha de base.

\section{Linha de base}

Para as atividades de projeto que não modifiquem ou façam retromodificação de uma usina existente de geração de eletricidade, o cenário da linha de base é o seguinte: 
A eletricidade fornecida à rede pelo projeto teria sido gerada, do contrário, por usinas de energia conectadas à rede e pelo acréscimo de novas fontes geradoras, conforme refletido nos cálculos da margem combinada (CM) descritos a seguir.

Para as atividades de projeto que modifiquem ou façam retromodificação de uma usina existente de geração de eletricidade, o cenário da linha de base é o seguinte:

$\mathrm{Na}$ ausência da atividade do projeto no âmbito do MDL, a usina existente continuaria a fornecer eletricidade à rede $\left(\mathrm{EG}_{\text {baseline, }} \mathrm{em} \mathrm{MWh} / \mathrm{ano}\right)$, em níveis médios históricos ( $\mathrm{EG}_{\text {historical, }}$ em $\left.\mathrm{MWh} / \mathrm{ano}\right)$, até o momento em que a usina provavelmente fosse substituída ou sofresse retromodificação na ausência da atividade do projeto no âmbito do MDL (DATE BaselineRetrofit $)$. Desse ponto em diante, supõe-se que o cenário da linha de base corresponda à atividade do projeto e que a produção de eletricidade na linha de base $\left(\mathrm{EG}_{\text {baseline }}\right)$ seja equivalente à produção de eletricidade do projeto $\left(\mathrm{EG}_{\mathrm{y}}\right.$, em $\left.\mathrm{MWh} / \mathrm{ano}\right)$, e supõe-se que não ocorram reduções de emissões.

$$
\begin{aligned}
& \mathrm{EG}_{\text {baseline }}=\mathrm{EG}_{\text {historical }} \quad \text { até } \mathrm{DATE}_{\text {BaselineRetrofit }} \\
& \mathrm{EG}_{\text {baseline }}=\mathrm{EG}_{\mathrm{y}} \quad \text { em/após DATE } \mathrm{BaselineRetrofit}
\end{aligned}
$$

Onde $\mathrm{EG}_{\text {historical }}$ é a média da eletricidade histórica fornecida pela usina existente à rede, cobrindo todos os dados disponíveis do ano (ou mês, semana ou outro período) mais recente até o momento em que a usina foi construída, sofreu retromodificação ou foi modificada de forma que afetasse significativamente a produção (ou seja, em $5 \%$ ou mais), expressa em MWh por ano. Um período mínimo de cinco anos (120 meses), excluindo-se os anos anormais, de dados da geração histórica é necessário no caso das hidrelétricas. Para outras usinas, dados de no mínimo três anos são necessários ${ }^{3}$. Caso não existam dados relativos a cinco anos (ou três anos no caso de atividades de projetos não-hidrelétricos), por exemplo, em razão de retromodificações recentes ou circunstâncias excepcionais, conforme descrito na nota de rodapé 2, deve ser proposta uma nova metodologia ou a revisão de uma metodologia.

Toda a geração de eletricidade do projeto acima dos níveis da linha de base $\left(\mathrm{EG}_{\text {baseline }}\right)$ teria sido de outra forma produzida por usinas conectadas à rede e pelo acréscimo de novas fontes geradoras, conforme refletido nos cálculos da margem combinada (CM) descritos a seguir.

Para estimar o momento em que o equipamento existente precisaria ser substituído na

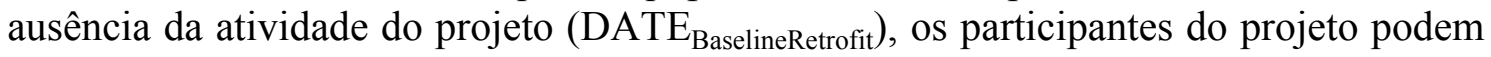
levar em conta as seguintes abordagens:

(a) A média típica do tempo de vida útil técnica do tipo de equipamento pode ser

\footnotetext{
${ }^{3}$ Dados relativos a períodos afetados por circunstâncias incomuns, como desastres naturais, conflitos, dificuldades de transmissão, devem ser excluídos.
} 
determinada e documentada, levando-se em conta as práticas comuns no setor e no país, como, por exemplo, com base em pesquisas do setor, estatísticas, publicações técnicas, etc.

(b) As práticas comuns da empresa responsável em relação a cronogramas de substituição podem ser avaliadas e documentadas, por exemplo, com base nos registros de substituições feitas no passado em equipamentos similares.

O momento em que o equipamento existente necessitaria de substituição na ausência da atividade do projeto deve ser escolhido de maneira conservadora, ou seja, se um intervalo de tempo for identificado, a data mais recente deve ser escolhida.

$\mathrm{O}$ fator de emissão da linha de base $\left(\mathrm{EF}_{\mathrm{y}}\right)$ é calculado como uma margem combinada $(\mathrm{CM})$, que consiste na combinação dos fatores da margem operacional (OM) e da margem de construção (BM), de acordo com as três etapas a seguir. Os cálculos para essa margem combinada devem basear-se em dados de uma fonte oficial (se houver) ${ }^{4} \mathrm{e}$ ser disponibilizados ao público.

Os acréscimos de capacidade das usinas elétricas registradas como atividades de projetos no âmbito do MDL devem ser excluídos de todos os cálculos abaixo (subgrupos j, m, n, abaixo).

ETAPA 1. Calcular o(s) fator(es) de emissão da Margem Operacional (EF OM,y $)$ com base em um dos quatro métodos abaixo:

(a) OM simples, ou

(b) OM simples ajustada, ou

(c) OM da análise dos dados de despacho, ou

(d) OM média.

Cada método será descrito a seguir.

\footnotetext{
${ }^{4}$ Os fatores de emissão da usina usados para calcular os fatores de emissão da margem operacional e da margem de construção devem ser obtidos de acordo com a seguinte prioridade:

1. Obtidos diretamente do centro de despacho ou produtores de energia, se houver; ou

2. Calculados, se os dados sobre o tipo de combustível, o fator de emissão do combustível, a entrada de combustível e a saída de energia puderem ser obtidos para cada usina; caso sejam usados dados confidenciais fornecidos pela autoridade da Parte anfitriã pertinente, o cálculo realizado pelos participantes do projeto deve ser verificado pela Entidade Operacional Designada (DOE) e o documento de concepção do projeto só poderá mostrar o fator de emissão de carbono resultante e a lista de usinas correspondente;

3. Calculados, conforme acima, mas com o uso de estimativas como:

Os valores padrão do IPCC contidos nas Diretrizes Revisadas do IPCC de 1996 e na Orientação de Boas Práticas do $I P C C$ para os poderes caloríficos líquidos e fatores de emissão de carbono para os combustíveis em vez de valores específicos das usinas (observe-se que a Orientação de Boas Práticas do IPCC contém algumas atualizações das Diretrizes Revisadas do IPCC de 1996);

Eficiência nominal da usina, conforme informado pelo provedor da tecnologia, ou a eficiência enérgica prevista e documentada em fontes oficiais (em vez de calculá-la a partir do consumo de combustível e a produção de energia). É provável que seja uma estimativa conservadora, pois nas condições reais de funcionamento, as usinas normalmente apresentam eficiências mais baixas e emissões mais altas do que o desempenho nominal poderia sugerir;

Estimativas conservadoras das eficiências da usina, com base em análises de especialistas em relação à tecnologia, $o$ tamanho e data da entrada em atividade da usina; ou

4. Calculados, para a OM simples e a OM média, com o uso de dados agregados de geração e consumo de combustível, nos casos em que não houver dados mais desagregados.
} 
A análise dos dados de despacho deve ser a primeira escolha metodológica. Quando essa opção não for selecionada, os participantes do projeto devem fornecer uma justificativa e usar a OM simples, a OM simples ajustada ou o método da taxa média de emissão, levando-se em conta disposições descritas a seguir.

O método da OM simples (a) só pode ser usado quando recursos de baixo custo/operação obrigatória ${ }^{5}$ constituírem menos de $50 \%$ da geração total da rede: 1) na média dos cinco anos mais recentes ou 2) com base em normais de longo prazo para a produção de hidroeletricidade.

O método da taxa média de emissão (d) só pode ser usado quando recursos de baixo custo/operação obrigatória constituírem mais de $50 \%$ da geração total da rede e não houver dados detalhados que permitam aplicar as opções (b) e (c) acima.

Os fatores de emissão da OM simples, da OM simples ajustada e da OM média podem ser calculados usando-se uma das duas validades dos dados a seguir para o(s) ano(s) $y$ :

- A média ponderada da geração (ex ante) nos três anos mais recentes para os quais haja dados disponíveis quando do envio do PDD ou

- $\mathrm{O}$ ano em que a geração do projeto ocorra, se o $\mathrm{EF}_{\mathrm{OM}, \mathrm{y}}$ for atualizado com base no monitoramento ex post.

A opção pela validade ex ante ou ex post deve ser especificada no PDD e não pode ser alterada durante o período de obtenção de créditos.

(a) OM simples. O fator de emissão da OM simples $\left(E F_{O M, \text { simple, } y}\right)$ é calculado como as emissões médias ponderadas da geração por unidade de eletricidade $\left(\mathrm{tCO}_{2} / \mathrm{MWh}\right)$ de todas as fontes geradoras que abastecem o sistema, não incluindo as usinas com baixo custo operacional e operação obrigatória:

$E F_{O M, y}=\frac{\sum_{i, j} F_{i, j, y} \cdot C O E F_{i, j}}{\sum_{j} G E N_{j, y}}$

Onde $F_{i, j, y}$ é a quantidade de combustível $i$ (em uma unidade de massa ou volume) consumido pelas fontes de energia pertinentes $j$ no(s) ano(s) $y$;

$j$ refere-se às fontes de energia que fornecem eletricidade à rede, não incluindo as usinas com baixo custo operacional e operação obrigatória, e incluindo as importações ${ }^{6}$ para a rede;

\footnotetext{
${ }^{5}$ Os recursos de baixo custo operacional e operação obrigatória normalmente abrangem a fontes de geração hidrelétrica, geotérmica, eólica, biomassa de baixo custo, nuclear e solar. Se o carvão mineral for obviamente usado como recurso de operação obrigatória, também deverá fazer parte dessa lista, ou seja, ser excluído do conjunto de usinas.

${ }^{6}$ Conforme descrito acima, uma importação de um sistema de eletricidade conectado deve ser considerada uma fonte de energia $j$.
} 
$C O E F_{i, j, y}$ é o coeficiente de emissão de $\mathrm{CO}_{2}$ do combustível $i\left(\mathrm{tCO}_{2} /\right.$ unidade de massa ou volume do combustível), levando-se em conta o teor de carbono dos combustíveis usados pelas fontes de energia pertinentes $j$ e o percentual de oxidação do combustível no(s) ano(s) $y$; e

$G E N_{j, y}$ é a eletricidade (MWh) fornecida à rede pela fonte $j$.

O coeficiente de emissão de $\mathrm{CO}_{2}, C O E F_{i}$, é obtido da seguinte forma:

$C O E F_{i}=N C V_{i} \cdot E F_{C O 2, i} \cdot O X I D_{i}$

Onde:

$N C V_{i}$ é o poder calorífico líquido (teor de energia) por unidade de massa ou volume de um combustível $i$;

$O X I D_{i}$ é o fator de oxidação do combustível (ver página 1.29 das Diretrizes Revisadas do IPCC de 1996 para obter os valores padrão);

$E F_{C O 2, i}$ é o fator de emissão de $\mathrm{CO}_{2}$ por unidade de energia do combustível $i$.

Quando disponíveis, os valores locais de $N C V_{i}$ e $E F_{C O 2, i}$ devem ser usados. Se não houver esses valores, os valores específicos do país (ver, por exemplo, a Orientação de Boas Práticas do IPCC) são preferíveis aos valores padrão mundiais do IPCC.

O fator de emissão da OM simples pode ser calculado com o uso de qualquer uma das duas validades de dados a seguir para o(s) ano(s) $y$ :

Média de três anos, com base nas estatísticas mais recentes disponíveis na época do envio do documento de concepção do projeto, ou

$\mathrm{O}$ ano em que a geração do projeto ocorreu, se $\mathrm{EF}_{\mathrm{OM}, \mathrm{y}}$ for atualizado com base no monitoramento ex post.

(b) OM simples ajustada. Esse fator de emissão ( $\left.E F_{O M, \text { simple adjusted,y }}\right)$ é uma variação do método anterior, em que as fontes de energia (inclusive as importações) são separadas em fontes de baixo custo/operação obrigatória $(k)$ e outras fontes de energia $(j)$ :

$$
E F_{\text {OM,simple_adjusted }, y}=\left(1-\lambda_{y}\right) \cdot \frac{\sum_{i, j} F_{i, j, y} \cdot C O E F_{i, j}}{\sum_{j} G E N_{i, j}}+\lambda_{y} \cdot \frac{\sum_{i, k} F_{i, k, y} \cdot C O E F_{i, k}}{\sum_{k} G E N_{k, y}}
$$

Onde $F_{i, k, y}, C O E F_{i, k}$ e $G E N_{k}$ são análogas às variáveis descritas para o método da $\mathrm{OM}$ simples, acima, para as usinas $k$; o(s) ano(s) y podem refletir qualquer uma das duas validades observadas para a OM simples, acima, e 
$\lambda_{y}(\%)=\frac{\text { Número de horas por ano em que as fontes de baixo custo / operação obrigatória ficam na marg em }}{8760 \text { horas por ano }}$

Onde lambda (ly) deve ser calculada como segue (ver figura abaixo):

Etapa i) Traçar uma Curva de Duração da Carga. Coletar dados cronológicos da carga (normalmente em MW) para cada hora do ano e classificar os dados da carga do nível mais alto ao mais baixo. Representar os MW em relação às 8760 horas no ano, em ordem decrescente.

Etapa ii) Organizar os Dados por Fontes Geradoras. Coletar os dados e calcular a geração anual total (em MWh) dos recursos de baixo custo/operação obrigatória (isto é, $\Sigma k G E N k, y$ ).

Etapa iii) Preencher a Curva de Duração da Carga. Representar uma linha horizontal cruzando a curva de duração da carga, de modo que a área abaixo da curva (MW vezes horas) seja igual à geração total (em $\mathrm{MWh}$ ) a partir dos recursos de baixo custo/operação obrigatória (isto é, $\Sigma k G E N k, y)$.

Etapa iv) Determinar o número de horas por ano em que as fontes de baixo custo/operação obrigatória ficam na margem. Primeiramente, localizar a interseção da linha horizontal traçada na etapa (iii) e a curva de duração da carga traçada na etapa (i). O número de horas (fora do total de 8760 horas) à direita da interseção é o número de horas em que as fontes de baixo custo/operação obrigatória ficam na margem. Se as linhas não se cruzarem, pode-se concluir que as fontes de baixo custo/operação obrigatória não ficam na margem, e $\lambda y$ é igual a zero. Lambda $(\lambda y)$ é o número calculado de horas dividido por 8760. 
Figura 1: Ilustração do Cálculo de Lambda para o Método da OM Simples Ajustada

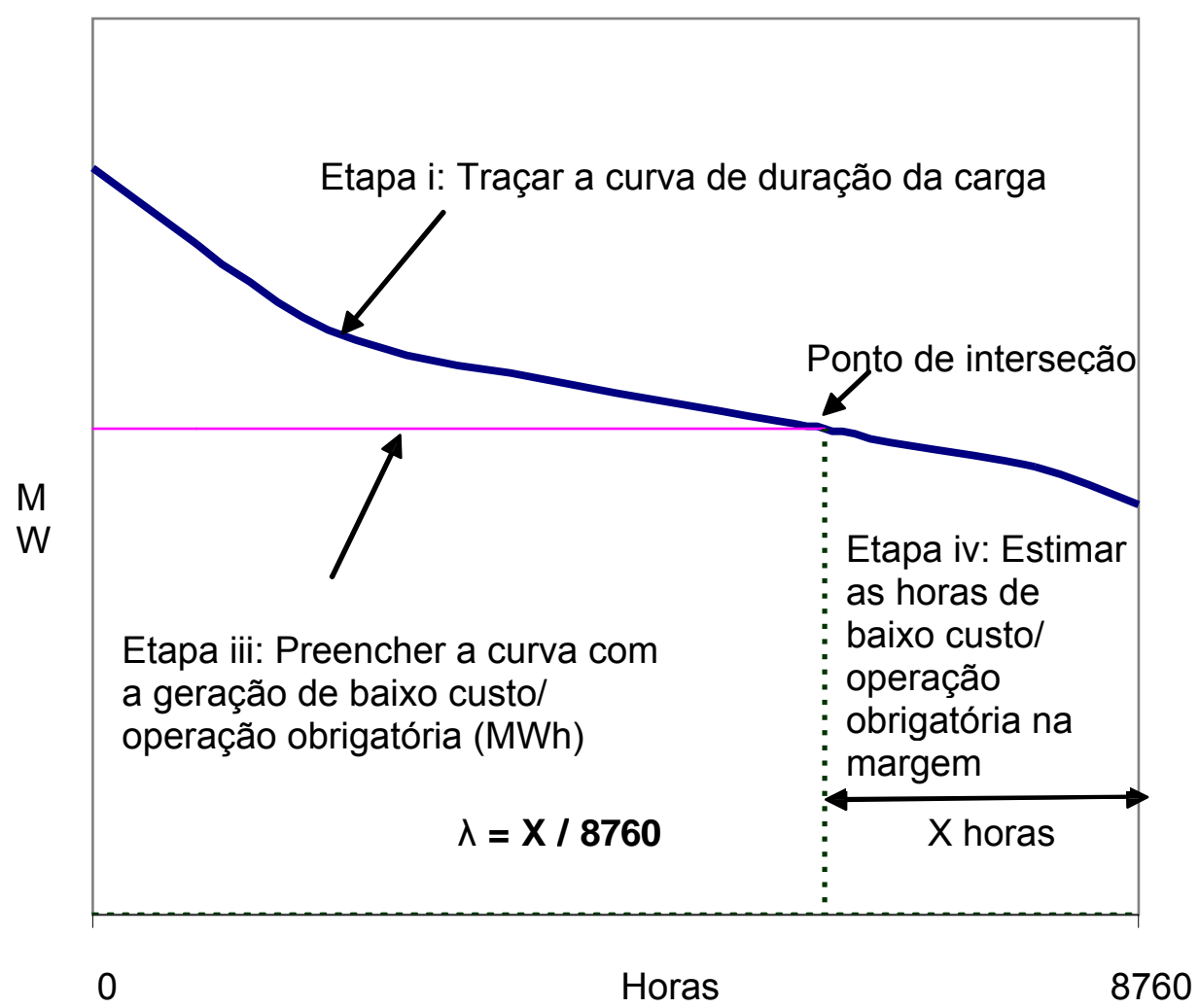


Observação: A etapa (ii) não aparece na figura, pois trata da organização dos dados por fonte.

(c) OM de Análise dos Dados de Despacho. O fator de emissão da OM dos dados de Despacho ( $\left.E F_{\text {OM,Dispatch Data,y }}\right)$ é sintetizado abaixo:

$$
E F_{O M, \text { Dispatch Data,y }}=\frac{E_{O M, y}}{E G_{y}}
$$

Onde $E G_{y}$ é a geração do projeto (em MWh) no ano $y$, e $E_{O M, y}$ são as emissões $\left(\mathrm{tCO}_{2}\right)$ associadas à margem operacional, calculadas como:

$$
E_{O M, y}=\sum_{h} E G_{h} \cdot E F_{D D, h}
$$

Onde $E G_{h}$ é a geração do projeto (em MWh) em cada hora $h$ e $E F_{D D, h}$ são as emissões médias ponderadas da geração a cada hora por unidade de eletricidade $\left(\mathrm{tCO}_{2} / \mathrm{MWh}\right)$ do grupo de usinas (n) nos primeiros $10 \%$ da ordem de despacho do sistema da rede durante a hora $h$ :

$$
E F_{D D, h}=\frac{\sum_{i, n} F_{i, n, h} \cdot C O E F_{i, n}}{\sum_{n} G E N_{n, h}}
$$

Onde $F, C O E F$ e $G E N$ são análogos às variáveis descritas para o método da OM simples, acima, mas calculados a cada hora para o conjunto das usinas $(n)$ nos primeiros $10 \%$ do sistema de despacho. Para determinar o conjunto de usinas $(n)$, deve-se obter de um centro nacional de despacho: a) a ordem de funcionamento do despacho do sistema da rede para cada usina do sistema e b) a quantidade de energia ( $\mathrm{MWh}$ ) despachada de todas as usinas no sistema durante cada hora em que a atividade do projeto esteja em funcionamento $\left(G E N_{h}\right)$. Em cada hora $h$, deve-se empilhar a geração de cada usina $\left(G E N_{h}\right)$ com o uso da ordem de mérito. O conjunto de usinas $(n)$ consiste nas usinas do topo da pilha (ou seja, as que têm menos mérito), cuja geração combinada ( $\Sigma G E N h$ ) compreenda $10 \%$ da geração total de todas as usinas durante aquela hora (inclusive as importações, à medida que são despachadas).

(d) OM Média. O fator de emissão médio da Margem Operacional (OM) (EF OM,average,y) é calculado como a taxa média de emissões de todas as usinas, com o uso da equação (1) acima, mas incluindo as usinas com baixo custo operacional e de operação obrigatória. Uma das duas validades dos dados descritas para a OM simples poderá ser usada.

ETAPA 2. Calcular o fator de emissão da Margem de Construção (EF BM,y $_{\text {) como o }}$ fator de emissão médio ponderado da geração $\left(\mathrm{tCO}_{2} / \mathrm{MWh}\right)$ de uma amostra de usinas $m$, conforme descrito a seguir: 
$E F_{B M, y}=\frac{\sum_{i, m} F_{i, m, y} \cdot C O E F_{i, m}}{\sum_{m} G E N_{m, y}}$

Onde $F_{i, m, y}, C O E F_{i, m}$ e $G E N_{m, y}$ são análogos às variáveis descritas para o método da OM simples, acima, para as usinas $m$.

Os participantes do projeto devem escolher uma das duas opções seguintes. A escolha entre as duas opções deve ser especificada no PDD e não pode ser alterada durante o período de obtenção de créditos.

Opção 1. Calcular o fator de emissão da Margem de Construção, $E F_{B M, y}$, ex ante com base nas informações mais recentes disponíveis sobre as usinas já construídas, para o grupo de amostragem $m$, na época do envio do documento de concepção do projeto. $\mathrm{O}$ grupo de amostragem $m$ consiste nas cinco usinas construídas mais recentemente ou nos acréscimos de capacidade das usinas do sistema de eletricidade que compreendam $20 \%$ da geração do sistema (em MWh) e que tenham sido construídas mais recentemente ${ }^{7}$. Os participantes do projeto devem usar, dessas duas opções, o grupo de amostragem que contenha a maior geração anual.

Opção 2. Para o primeiro período de obtenção de créditos, o fator de emissão da Margem de Constituição $E F_{B M, y}$ deve ser atualizado anualmente e ex post para o ano em que a geração real do projeto e as reduções correspondentes de emissão ocorrerem. Para períodos de crédito subseqüentes, $E F_{B M, y}$ deve ser calculado ex-ante, conforme descrito na opção 1 acima. O grupo de amostragem $m$ consiste nas cinco usinas construídas mais recentemente ou nos acréscimos de capacidade das usinas do sistema de eletricidade que compreendam $20 \%$ da geração do sistema (em MWh) e que tenham sido construídas mais recentemente ${ }^{8}$. Os participantes do projeto devem usar, dessas duas opções, o grupo de amostragem que contenha a maior geração anual.

ETAPA 3. Calcular o fator de emissão da linha de base, $\mathbf{E F}_{\mathbf{y}}$, como a média ponderada do fator de emissão da Margem Operacional $\left(E F_{O M, y}\right)$ e o fator de emissão da Margem de Construção $\left(E F_{B M, y}\right)$ :

$$
E F_{y}=w_{O M} \cdot E F_{O M, y}+w_{B M} \cdot E F_{B M, y}
$$

Onde os pesos $w_{O M}$ e $w_{B M}$, por padrão, são $50 \%$ (ou seja, $w_{O M}=w_{B M}=0,5$ ), e $E F_{O M, y}$ e $E F_{B M, y}$ são calculados conforme descrito nas Etapas 1 e 2 acima e expressos em $\mathrm{tCO}_{2} / \mathrm{MWh}$.

Para os projetos de energia eólica e solar, os pesos padrão são os seguintes: $\mathrm{w}_{\mathrm{OM}}=0,75$ e $\mathrm{w}_{\mathrm{BM}}=0,25$ (em razão da sua natureza intermitente e não-despachável).

\footnotetext{
${ }^{7}$ Se 20\% incidir sobre parte da capacidade de uma usina, essa usina será totalmente incluída no cálculo.

${ }^{8}$ Se $20 \%$ incidir sobre parte da capacidade de uma usina, essa usina será totalmente incluída no cálculo.
} 
Pesos alternativos podem ser usados desde que $w_{O M}+w_{B M}=1$ e que seja seguida a orientação prestada abaixo. Deve-se apresentar uma justificativa adequada, que será avaliada pelo Conselho Executivo.

A média ponderada empregada pelos participantes do projeto deve ser fixada para um período de obtenção de créditos e pode ser revista na renovação do período de obtenção de créditos.

\section{Orientação para a seleção de pesos alternativos}

A orientação a seguir fornece uma série de fatores específicos do projeto e específicos do contexto para o desenvolvimento de pesos alternativos da margem de operação e da margem de construção para os padrões acima. Não fornece, contudo, os algoritmos específicos para traduzir esses fatores em pesos quantificados nem trata de todos os fatores que possam afetar esses pesos. Nesse caso, sugere-se que os participantes do projeto proponham métodos de quantificação específicos com justificativas que sejam coerentes com a orientação fornecida abaixo. Como é improvável que um projeto afete a OM ou BM exclusivamente durante o primeiro período de obtenção de créditos, sugerese que nenhum dos pesos ultrapasse $75 \%$ durante o primeiro período de obtenção de créditos.

\begin{tabular}{|l|l|l|}
\hline Fator & Síntese - Efeito nos pesos & Outras explicações \\
\hline $\begin{array}{l}\text { Tamanho do projeto } \\
\text { (absoluto ou relativo ao } \\
\text { tamanho da rede do sistema } \\
\text { ou ao tamanho de outros } \\
\text { acréscimos de capacidade } \\
\text { no sistema) }\end{array}$ & $\begin{array}{l}\text { Nenhuma mudança no peso } \\
\text { com base apenas no } \\
\text { tamanho absoluto ou } \\
\text { relativo. }\end{array}$ & $\begin{array}{l}\text { Não parece haver } \\
\text { justificativa para pesos } \\
\text { alternativos com base } \\
\text { apenas no tamanho } \\
\text { absoluto ou relativo do } \\
\text { projeto. Ver o documento } \\
\text { elaborado pelo Sr. Bruce } \\
\text { Biewald para obter mais } \\
\text { informações a } \\
\text { explicaçóes. }\end{array}$ \\
\hline $\begin{array}{l}\text { O período da produção } \\
\text { do projeto }\end{array}$ & $\begin{array}{l}\text { Pode aumentar o peso da } \\
\text { OM para projetos } \\
\text { altamente fora de pico; } \\
\text { aumentar a BM para } \\
\text { projetos altamente no pico. }\end{array}$ & $\begin{array}{l}\text { Nos projetos em que a } \\
\text { produção for altamente } \\
\text { fora do pico, o peso da OM } \\
\text { pode ser maior (por } \\
\text { exemplo, projetos } \\
\text { fotovoltaicos de energia } \\
\text { solar em regiões de pico } \\
\text { durante a noite, geração } \\
\text { sazonal a partir da }\end{array}$ \\
\hline
\end{tabular}

\footnotetext{
${ }^{9}$ Consultar o endereço:

http://cdm.unfccc.int/Panels/meth/Meth17_repan12_BiewaldPaperOMBMMargins.pdf.
} 


\begin{tabular}{|c|c|c|}
\hline & & $\begin{array}{l}\text { biomassa durante as } \\
\text { estações fora do pico), } \\
\text { enquanto que nos projetos } \\
\text { com uma produção } \\
\text { desproporcionalmente alta } \\
\text { durante período de pico } \\
\text { (por exemplo, projetos de } \\
\text { eficiência no } \\
\text { condicionamento de ar em } \\
\text { algumas redes), o peso da } \\
\text { BM pode ser maior. }\end{array}$ \\
\hline $\begin{array}{ll}\text { Previsibilidade } & \text { da } \\
\text { produção do projeto } & \end{array}$ & $\begin{array}{l}\text { Pode aumentar a OM para } \\
\text { os recursos intermitentes } \\
\text { em alguns contextos. }\end{array}$ & $\begin{array}{l}\text { Os projetos com uma } \\
\text { produção de natureza } \\
\text { intermitente (por exemplo, } \\
\text { projetos de energia eólica } \\
\text { ou solar) podem ter um } \\
\text { valor de capacidade } \\
\text { limitado, dependendo da } \\
\text { natureza do recurso } \\
\text { (eólico/solar) e da rede em } \\
\text { questão, e à medida que o } \\
\text { valor de capacidade de um } \\
\text { projeto for mais baixo que } \\
\text { o de um recurso de rede } \\
\text { típico, o peso da BM pode } \\
\text { diminuir. Possíveis ajustes } \\
\text { na margem operacional/de } \\
\text { construção devem levar em } \\
\text { conta os métodos } \\
\text { existentes (na literatura } \\
\text { técnica) para estimar o } \\
\text { valor de capacidade. }\end{array}$ \\
\hline Demanda reprimida & $\begin{array}{l}\text { Pode aumentar o peso da } \\
\text { BM para o primeiro } \\
\text { período de obtenção de } \\
\text { créditos. }\end{array}$ & $\begin{array}{l}\text { Em condições de demanda } \\
\text { reprimida que devem } \\
\text { persistir ao longo de } \\
\text { metade do primeiro } \\
\text { período de obtenção de } \\
\text { créditos em um número } \\
\text { significativo de horas por } \\
\text { ano, é provável que as } \\
\text { usinas elétricas existentes } \\
\text { operem com capacidade } \\
\text { máxima apesar do projeto } \\
\text { no âmbito do MDL e, }\end{array}$ \\
\hline
\end{tabular}




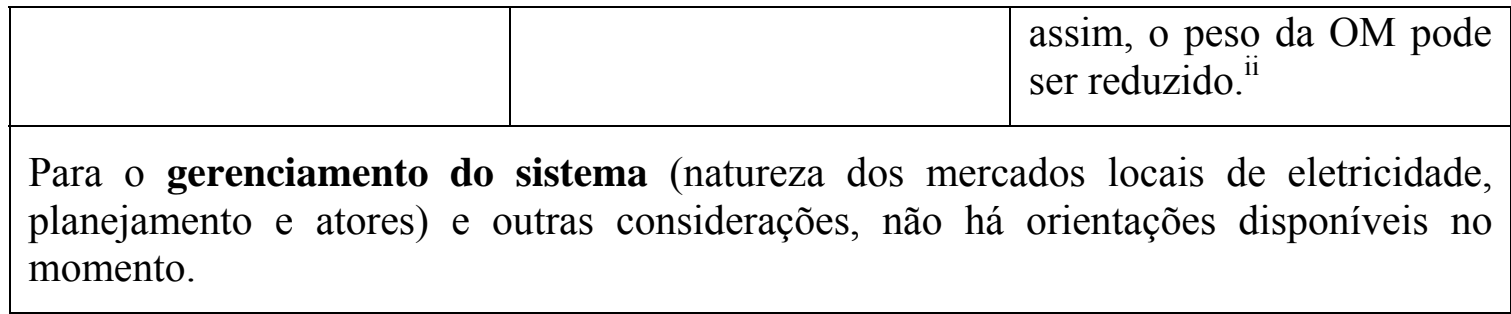

\section{Fugas}

As principais emissões com possibilidades de provocar fugas no contexto de projetos do setor elétrico são as emissões decorrentes de atividades como a construção de usinas, tratamento de combustível (extração, processamento e transporte) e inundação de terras (para projetos hidrelétricos - ver as condições de aplicabilidade acima). Os participantes do projeto não precisam considerar essas fontes de emissões como fugas na aplicação desta metodologia. As atividades de projetos que usarem esta metodologia de linha de base não devem solicitar créditos para o projeto por conta da redução dessas emissões para níveis inferiores ao do cenário da linha de base.

\section{Reduções de emissões}

A atividade do projeto reduz principalmente o dióxido de carbono por meio da substituição da geração de eletricidade da rede com usinas movidas a combustíveis fósseis, por eletricidade renovável. As reduções da emissões, $E R_{y}$, pela atividade do projeto durante um determinado ano y são a diferença entre as emissões da linha de base $\left(B E_{y}\right)$, as emissões do projeto $\left(P E_{y}\right)$ e as emissões decorrentes das fugas $\left(L_{y}\right)$, como segue:

$E R_{\mathrm{y}}=B E_{\mathrm{y}}-P E_{\mathrm{y}}-\mathrm{L}_{\mathrm{y}}$

Onde as emissões da linha de base $\left(B E_{y}\right.$ em $\left.\mathrm{tCO}_{2}\right)$ são o produto do fator de emissões na linha de base $\left(E F_{y}\right.$ em $\left.\mathrm{tCO}_{2} / \mathrm{MWh}\right)$, calculado na Etapa 3, vezes a eletricidade fornecida pela atividade do projeto à rede $\left(E G_{y}\right.$ em $\left.\mathrm{MWh}\right)$, menos a eletricidade da linha de base fornecida à rede no caso de instalações modificadas ou que sofreram retromodificação ( $E G_{\text {baseline }}$ em MWh), como segue:

$B E_{y}=\left(E G_{y}-E G_{\text {baseline }}\right) \cdot E F_{y}$

Para a maioria das atividades de projetos de energia renovável, $P E_{y}=0$. Entretanto, para as seguintes categorias de projetos, as emissões do projeto precisam ser estimadas:

(1) Atividades de projetos geotérmicos, os participantes do projeto devem contabilizar as seguintes fontes de emissões ${ }^{10}$, conforme o caso:

Emissões fugitivas de dióxido de carbono e metano decorrentes da emissão de gases não

${ }^{10}$ As emissões fugitivas de dióxido de carbono e metano decorrentes de testes e sangria de poços não são consideradas por serem insignificantes. 
condensáveis do vapor produzido; e

Emissões de dióxido de carbono resultantes da queima de combustíveis fósseis relacionada com o funcionamento da usina geotérmica.

Os dados a serem coletados estão listados na metodologia de monitoramento correspondente, ACM0002. As emissões do projeto devem ser calculadas como a seguir $^{11}$ :

a) Emissões fugitivas de dióxido de carbono e metano decorrentes da emissão de gases não-condensáveis do vapor produzido $\left(P E S_{y}\right)$

$$
P E S_{y}=\left(w_{\text {Main }, \mathrm{CO} 2}+w_{\text {Main }, \mathrm{CH} 4} \cdot G W P_{\mathrm{CH} 4}\right) \cdot M_{S, y}
$$

Onde $P E S_{y}$ são as emissões do projeto provenientes da emissão de dióxido de carbono e metano do vapor produzido durante o ano $y ; w_{\text {Main,CO2 }}$ e $w_{\text {Main,CH4 } 4}$ são as frações médias de massa de dióxido de carbono e metano no vapor produzido; $G W P_{C H 4}$ é o potencial de aquecimento global do metano; e $M_{S, y}$ é a quantidade de vapor produzida durante o ano $y$.

\section{b) Emissões de dióxido de carbono da queima de combustíveis fósseis (PEFFy)}

$$
\mathrm{PEFF}_{Y}=\sum F_{i, y} \cdot C O E F_{i}
$$

Onde $P E F F y$ são as emissões do projeto resultantes da queima de combustíveis fósseis relacionada com o funcionamento da usina geotérmica, em toneladas de $\mathrm{CO}_{2} ; F_{i, y}$ é o consumo do tipo de combustível $i$ durante o ano $y$; e $C O E F_{i}$ é o coeficiente do fator de emissão de $\mathrm{CO}_{2}$ do tipo de combustível $i$.

Portanto, para as atividades de projetos de energia geotérmica:

$P E_{y}=P E S_{y}+P E F F_{y}$

(II) Novos projetos de energia hidrelétrica com reservatórios, os proponentes do projeto devem contabilizar as emissões do projeto, estimadas do seguinte modo:

a) Se a densidade de energia do projeto for superior a $4 \mathrm{~W} / \mathrm{m}^{2}$ e inferior ou igual a $10 \mathrm{~W} / \mathrm{m}^{2}$ :

$P E_{y}=\frac{E F_{\text {Res }} * E G_{y}}{1000}$

Onde:

${ }^{11}$ No caso de projetos de retromodificação em usinas geotérmicas, esta metodologia não subtrai atualmente as emissões da linha de base dos componentes do vapor ou da queima de combustíveis fósseis. Os proponentes do projeto podem propor novas metodologias ou revisões nas metodologias para tratar dessas emissões da linha de base. 


\begin{tabular}{|l|l|}
\hline$P E_{y}$ & Emissão do reservatório, expressa como $\mathrm{tCO}_{2} \mathrm{e} / \mathrm{ano}$ \\
\hline$E S_{\text {Res }}$ & $\begin{array}{l}\text { É o fator de emissão padrão para as emissões dos reservatórios, e o valor } \\
\text { padrão conforme a EB23 é } 90 \mathrm{~kg} \mathrm{CO} \mathrm{CO}_{2} \mathrm{e} / \mathrm{MWh}\end{array}$ \\
\hline$E G_{y}$ & $\begin{array}{l}\text { Eletricidade produzida pelo projeto de energia hidrelétrica no ano y, em } \\
\text { MWh }\end{array}$ \\
\hline
\end{tabular}

b) Se a densidade de energia do projeto for superior a $10 \mathrm{~W} / \mathrm{m}^{2}$

$\mathrm{PE}_{\mathrm{y}}=0$

\section{Estimativa das Reduções de Emissões Antes da Validação}

Os participantes do projeto devem elaborar, como parte do documento de concepção do projeto, uma estimativa das reduções prováveis de emissões do projeto para o período de obtenção de créditos proposto. Essa estimativa deve, a princípio, empregar a mesma metodologia selecionada acima (ou seja, a opção de OM 1a, 1b, 1c ou 1d). Quando o fator de emissão $\left(E F_{y}\right)$ for determinado ex post durante o monitoramento, os participantes do projeto podem usar modelos e outras ferramentas para estimar as reduções de emissões antes da validação. 


\section{Revisão da metodologia consolidada aprovada de monitoramento ACM0002}

\section{"Metodologia consolidada de monitoramento para a geração de eletricidade conectada à rede a partir de fontes renováveis”}

\section{Fonte}

Esta metodologia de monitoramento baseia-se em elementos das seguintes novas metodologias propostas:

- NM0001-rev: Projeto da Vale do Rosário de Co-geração de Energia a partir do Bagaço da Cana-de-açúcar (VRBC), Brasil, cujo estudo da linha de base, plano de monitoramento e verificação e documento de concepção do projeto foram elaborados pela Econergy International Corporation;

- NM0012-rev: Projeto Wigton de Fazenda de Vento na Jamaica, cujo estudo da linha de base, plano de monitoramento e verificação e documento de concepção do projeto foram elaborados pela Ecosecurities Ltd;

- NM0023: Projeto Hidrelétrico de El Gallo, México, cujo estudo da linha de base, plano de monitoramento e verificação e documento de concepção do projeto foram elaborados pelo Prototype Carbon Fund (aprovado pelo Conselho Executivo do MDL em 14 de abril de 2004);

- NM0024-rev: Colômbia: Projeto de Usina Eólica de Jepirachi, cujo estudo da linha de base, plano de monitoramento e verificação e documento de concepção do projeto foram elaborados pelo Prototype Carbon Fund;

- NM0030-rev: Projeto de Co-Geração de Energia a partir de Bagaço da Haidergarh, Índia, cujo estudo da linha de base, plano de monitoramento e verificação e documento de concepção do projeto foram enviados pela Haidergarh Chini Mills, uma unidade da Balrampur Chini Mills Limited;

- NM0036: Projeto de Usina de Energia Eólica de Zafarana, República Árabe do Egito, cujo estudo da linha de base, plano de monitoramento e verificação e documento de concepção do projeto foram elaborados pela Mitsubishi Securities;

- NM0043: Projeto Hidrelétrico Bayano de Expansão e Modernização, Panamá, cujo estudo da linha de base, plano de monitoramento e verificação e documento de concepção do projeto foram elaborados pela Econergy International Corporation;

- NM0055: Projeto Geotérmico Unidade III de Darajat, Indonésia, cujo estudo da linha de base, plano de monitoramento e verificação e documento de concepção do projeto foram elaborados pela URS Corporation e Amoseas Indonesia Inc.

Mais informações sobre a proposta e sua análise pelo Conselho Executivo podem ser obtidas no endereço: http://cdm.unfccc.int/methodologies/PAmethodologies/approved.html. 


\section{Aplicabilidade}

Esta metodologia se aplica às atividades de projetos de geração de energia renovável conectada à rede sob as seguintes condições:

- Aplique-se aos acréscimos de capacidade de eletricidade de:

- Usinas hidrelétricas a fio de água; projetos de energia hidrelétrica com reservatórios existentes em que o volume do reservatório não aumente;

- Novos projetos de energia hidrelétrica com reservatórios cujas densidades de energia (capacidade instalada de geração elétrica dividida pela área da superfície no nível máximo do reservatório) sejam superiores a $4 \mathrm{~W} / \mathrm{m}^{2} ;{ }^{12}$

- Fontes de energia eólica;

- Fontes de energia geotérmica;

- Fontes de energia solar;

- Fontes de energia de ondas e marés.

- Esta metodologia não se aplique às atividades de projetos que envolvam a mudança de combustíveis fósseis para energia renovável na área da atividade do projeto, uma vez que, nesse caso, a linha de base pode ser a continuação do uso de combustíveis fósseis no local;

- Os limites geográficos e do sistema da rede elétrica pertinente possam ser claramente identificados e existam informações sobre as características da rede; e

- Aplique-se à geração de eletricidade conectada à rede a partir da captação de gás de aterro, em conjunto com a "metodologia consolidada aprovada de linha de base para atividades de projetos com gás de aterro" (ACM0001).

\section{Metodologia de Monitoramento}

A metodologia requer o monitoramento do seguinte:

- Geração de eletricidade da atividade de projeto proposta;

- Dados necessários para recalcular o fator de emissão da margem operacional, se necessário, com base na escolha do método para determinar a margem operacional (OM), de forma compatível com a "Metodologia consolidada de linha de base para a geração de eletricidade conectada à rede a partir de fontes renováveis" (ACM0002);

- Dados necessários para recalcular o fator de emissão da margem de construção, se necessário, de forma compatível com a "Metodologia consolidada de linha de base para a geração de eletricidade conectada à rede a partir de fontes renováveis" (ACM0002);

- Para projetos de energia geotérmica, os dados necessários para calcular as emissões fugitivas de dióxido de carbono e metano e as emissões de dióxido de carbono da queima de combustíveis fósseis necessária para o funcionamento da usina de energia geotérmica;

\footnotetext{
12 A adoção desta orientação não impede que os participantes do projeto enviem novas metodologias para projetos hidrelétricos, a serem analisadas pelo Painel de Metodologias, especialmente quando os reservatórios não tiverem uma biomassa vegetativa significativa na área de captações.
} 
- Para novos projetos de energia hidrelétrica, a área da superfície do reservatório no nível máximo de capacidade.

\section{Limite do projeto}

1) De acordo com a "Metodologia consolidada de linha de base para a geração de eletricidade conectada à rede a partir de fontes renováveis" (ACM0002), o limite do projeto abrange as seguintes fontes de emissões:

- Para as atividades de projetos geotérmicos, as emissões fugitivas de metano e dióxido de carbono provenientes de gases não-condensáveis contidos no vapor geotérmico e as emissões de dióxido de carbono provenientes da queima de combustíveis fósseis necessária para o funcionamento da usina de energia geotérmica;

- Para novos projetos hidrelétricos com reservatórios, o limite do projeto compreende a área física da usina, bem como a área do reservatório.

Para determinar a linha de base, os participantes do projeto devem contabilizar somente as emissões de $\mathrm{CO}_{2}$ provenientes da geração de eletricidade na usina movida a combustível fóssil que for substituída em razão da atividade do projeto.

2) A extensão espacial do limite do projeto abrange a área do projeto e todas as usinas fisicamente conectadas ao sistema de eletricidade ao qual a usina do projeto no âmbito do MDL esteja conectada. 


\section{Parâmetros das emissões da linha de base}

A sexta coluna indica quais elementos do monitoramento são necessários, dependendo do método usado para determinar a margem operacional (OM) na etapa 1 da "Metodologia consolidada de linha de base para a geração de eletricidade conectada à rede a partir de fontes renováveis" (ACM0002). A "OM simples" é definida na etapa Ia; a "OM simples ajustada", na 1b; a "OM dos dados de despacho", na 1c; e a "OM média", na etapa 1d. Os itens necessários para a "BM" referem-se à Margem de Construção definida na etapa 2. Observe-se que para a "OM simples", a "OM simples ajustada" e a "OM média”, bem como a "BM", quando os participantes do projeto escolherem, de forma compativel com a "Metodologia consolidada de linha de base para a geração de eletricidade conectada à rede a partir de fontes renováveis" (ACM0002), uma validade de dados com base no monitoramento ex ante, pelo menos a EG $G_{v}$ deve ser monitorada, e será necessário recalcular a margem combinada para todos os parâmetros em qualquer renovação de um período de obtenção de créditos, usando-se as etapas 1 a 3 da metodologia de linha de base.

\begin{tabular}{|c|c|c|c|c|c|c|c|c|c|c|}
\hline $\begin{array}{l}\text { Número de } \\
\text { identificação }\end{array}$ & $\begin{array}{c}\text { Tipo } \\
\text { dos dados }\end{array}$ & $\begin{array}{l}\text { Variável } \\
\text { dos dados }\end{array}$ & $\begin{array}{c}\text { Unidade } \\
\text { dos } \\
\text { dados }\end{array}$ & $\begin{array}{l}\text { Medidos } \\
\text { (m), } \\
\text { calculados } \\
\text { (c) ou } \\
\text { estimados } \\
\text { (e) }\end{array}$ & \begin{tabular}{|c|} 
Para qual \\
método da \\
linha de \\
base este \\
elemento \\
precisa ser \\
incluído
\end{tabular} & \begin{tabular}{|l|} 
Freqüência \\
do registro
\end{tabular} & \begin{tabular}{|} 
Parcela \\
dos dados \\
a ser \\
monito- \\
rada
\end{tabular} & $\begin{array}{c}\text { Como os } \\
\text { dados serão } \\
\text { arquivados? } \\
\text { (eletronica- } \\
\text { mente/em } \\
\text { papel) }\end{array}$ & $\begin{array}{c}\text { Por quanto } \\
\text { tempo os } \\
\text { dados } \\
\text { arquivados } \\
\text { serão } \\
\text { mantidos? }\end{array}$ & Comentários \\
\hline $\begin{array}{c}\text { 1. } \mathrm{EG}_{\mathrm{y}}\left(\mathrm{EG}_{\mathrm{h}}\right. \\
\text { se a OM dos } \\
\text { dados de } \\
\text { despacho for } \\
\text { usada) }\end{array}$ & $\begin{array}{l}\text { Quantidade } \\
\text { de } \\
\text { eletricidade }\end{array}$ & $\begin{array}{l}\text { Eletricidade } \\
\text { fornecida à } \\
\text { rede pelo } \\
\text { projeto }\end{array}$ & MWh & $\begin{array}{l}\text { Medida } \\
\text { direta- } \\
\text { mente }\end{array}$ & \begin{tabular}{|c|} 
OM \\
simples, \\
OM \\
simples \\
ajustada, \\
OM dos \\
dados de \\
despacho, \\
OM média, \\
BM
\end{tabular} & \begin{tabular}{|c|} 
\\
Medição \\
por hora e \\
registro por \\
mês
\end{tabular} & $100 \%$ & $\begin{array}{c}\text { Eletronica- } \\
\text { mente }\end{array}$ & \begin{tabular}{|} 
Durante o \\
período de \\
obtenção de \\
créditos e \\
nos dois \\
anos \\
seguintes
\end{tabular} & $\begin{array}{l}\text { Eletricidade fornecida } \\
\text { à rede pela atividade } \\
\text { do projeto. Checar } \\
\text { com as notas fiscais } \\
\text { das vendas. }\end{array}$ \\
\hline
\end{tabular}




\begin{tabular}{|c|c|c|c|c|c|c|c|c|c|c|}
\hline $\begin{array}{l}\text { Número de } \\
\text { identificação }\end{array}$ & $\begin{array}{c}\text { Tipo } \\
\text { dos dados }\end{array}$ & $\begin{array}{c}\text { Variável } \\
\text { dos dados }\end{array}$ & $\begin{array}{c}\text { Unidade } \\
\text { dos } \\
\text { dados }\end{array}$ & $\begin{array}{c}\text { Medidos } \\
\text { (m), } \\
\text { calculados } \\
\text { (c) ou } \\
\text { estimados } \\
\text { (e) }\end{array}$ & \begin{tabular}{|c|} 
Para qual \\
método da \\
linha de \\
base este \\
elemento \\
precisa ser \\
incluído \\
\end{tabular} & $\begin{array}{l}\text { Freqüência } \\
\text { do registro }\end{array}$ & $\begin{array}{c}\text { Parcela } \\
\text { dos dados } \\
\text { a ser } \\
\text { monito- } \\
\text { rada }\end{array}$ & $\begin{array}{c}\text { Como os } \\
\text { dados serão } \\
\text { arquivados? } \\
\text { (eletronica- } \\
\text { mente/em } \\
\text { papel) }\end{array}$ & $\begin{array}{l}\text { Por quanto } \\
\text { tempo os } \\
\text { dados } \\
\text { arquivados } \\
\text { serão } \\
\text { mantidos? }\end{array}$ & Comentários \\
\hline $\begin{array}{l}\text { 1b. } \mathrm{EG}_{\text {historical }} \\
\text { (somente } \\
\text { projetos de } \\
\text { retromo- } \\
\text { dificação) }\end{array}$ & $\begin{array}{l}\text { Quantidade } \\
\text { de } \\
\text { eletricidade }\end{array}$ & $\begin{array}{c}\text { Eletricidade } \\
\text { anual } \\
\text { fornecida à } \\
\text { rede antes da } \\
\text { retromo- } \\
\text { dificação }\end{array}$ & GWh & $\mathrm{c}$ & $\begin{array}{c}\text { OM } \\
\text { simples, } \\
\text { OM } \\
\text { simples } \\
\text { ajustada, } \\
\text { OM dos } \\
\text { dados de } \\
\text { despacho, } \\
\text { OM média, } \\
\text { BM }\end{array}$ & Uma vez & $100 \%$ & $\begin{array}{l}\text { Eletronica- } \\
\text { mente/em } \\
\text { papel }\end{array}$ & $\begin{array}{c}\text { Durante o } \\
\text { período de } \\
\text { obtenção de } \\
\text { créditos e } \\
\text { nos dois } \\
\text { anos } \\
\text { seguintes }\end{array}$ & $\begin{array}{l}\text { Conforme definido na } \\
\text { metodologia de linha } \\
\text { de base. }\end{array}$ \\
\hline 2. $\mathrm{EF}_{\mathrm{y}}$ & $\begin{array}{l}\text { Fator de } \\
\text { emissão }\end{array}$ & $\begin{array}{c}\text { Fator de } \\
\text { emissão de } \\
\mathrm{CO}_{2} \text { da rede }\end{array} \mid$ & $\begin{array}{c}\mathrm{tCO}_{2} \\
/ \mathrm{MWh}\end{array}$ & $\mathrm{c}$ & $\begin{array}{c}\text { OM } \\
\text { simples, } \\
\text { OM } \\
\text { simples } \\
\text { ajustada, } \\
\text { OM dos } \\
\text { dados de } \\
\text { despacho, } \\
\text { OM média, } \\
\text { BM }\end{array}$ & Anual & $100 \%$ & $\begin{array}{c}\text { Eletronica- } \\
\text { mente }\end{array}$ & $\begin{array}{c}\text { Durante o } \\
\text { período de } \\
\text { obtenção de } \\
\text { créditos e } \\
\text { nos dois } \\
\text { anos } \\
\text { seguintes }\end{array}$ & $\begin{array}{l}\frac{\text { Calculado como a }}{\text { soma ponderada dos }} \\
\text { fatores de emissão da } \\
\text { OM e da BM }\end{array}$ \\
\hline
\end{tabular}




\begin{tabular}{|c|c|c|c|c|c|c|c|c|c|c|}
\hline $\begin{array}{l}\text { Número de } \\
\text { identificação }\end{array}$ & $\begin{array}{c}\text { Tipo } \\
\text { dos dados }\end{array}$ & $\begin{array}{c}\text { Variável } \\
\text { dos dados }\end{array}$ & $\begin{array}{c}\text { Unidade } \\
\text { dos } \\
\text { dados }\end{array}$ & $\begin{array}{l}\text { Medidos } \\
\text { (m), } \\
\text { calculados } \\
\text { (c) ou } \\
\text { estimados } \\
\text { (e) }\end{array}$ & $\begin{array}{c}\text { Para qual } \\
\text { método da } \\
\text { linha de } \\
\text { base este } \\
\text { elemento } \\
\text { precisa ser } \\
\text { incluído } \\
\end{array}$ & $\begin{array}{l}\text { Freqüência } \\
\text { do registro }\end{array}$ & \begin{tabular}{|} 
Parcela \\
dos dados \\
a ser \\
monito- \\
rada
\end{tabular} & $\begin{array}{c}\text { Como os } \\
\text { dados serão } \\
\text { arquivados? } \\
\text { (eletronica- } \\
\text { mente/em } \\
\text { papel) }\end{array}$ & $\begin{array}{l}\text { Por quanto } \\
\text { tempo os } \\
\text { dados } \\
\text { arquivados } \\
\text { serão } \\
\text { mantidos? }\end{array}$ & Comentários \\
\hline 3. $\mathrm{EF}_{\mathrm{OM}, \mathrm{y}}$ & $\begin{array}{l}\text { Fator de } \\
\text { emissão }\end{array}$ & $\begin{array}{l}\text { Fator de } \\
\text { emissão de } \\
\mathrm{CO}_{2} \mathrm{da} \\
\text { margem } \\
\text { operacional } \\
\text { da rede }\end{array}$ & $\begin{array}{c}\mathrm{tCO}_{2} \\
/ \mathrm{MWh}\end{array}$ & $\mathrm{c}$ & $\begin{array}{c}\text { OM } \\
\text { simples, } \\
\text { OM } \\
\text { simples } \\
\text { ajustada, } \\
\text { OM dos } \\
\text { dados de } \\
\text { despacho, } \\
\text { OM média }\end{array}$ & Anual & $100 \%$ & $\begin{array}{c}\text { Eletronica- } \\
\text { mente }\end{array}$ & $\begin{array}{c}\text { Durante o } \\
\text { período de } \\
\text { obtenção de } \\
\text { créditos e } \\
\text { nos dois } \\
\text { anos } \\
\text { seguintes }\end{array}$ & $\begin{array}{l}\text { Calculado conforme } \\
\text { indicado no método de } \\
\text { linha de base da OM } \\
\text { pertinente, acima. }\end{array}$ \\
\hline 4. $\mathrm{EF}_{\mathrm{BM}, \mathrm{y}}$ & $\begin{array}{l}\text { Fator de } \\
\text { emissão }\end{array}$ & $\begin{array}{l}\text { Fator de } \\
\text { emissão de } \\
\mathrm{CO}_{2} \text { da } \\
\text { margem de } \\
\text { construção } \\
\text { da rede }\end{array}$ & $\begin{array}{c}\mathrm{tCO}_{2} \\
/ \mathrm{MWh}\end{array}$ & $\mathrm{c}$ & $\mathrm{BM}$ & Anual & $100 \%$ & $\begin{array}{c}\text { Eletronica- } \\
\text { mente }\end{array}$ & $\begin{array}{c}\text { Durante o } \\
\text { período de } \\
\text { obtenção de } \\
\text { créditos e } \\
\text { nos dois } \\
\text { anos } \\
\text { seguintes }\end{array}$ & $\begin{array}{l}\text { Calculado como }\left[\sum_{\mathrm{i}}\right. \\
\left.\mathrm{F}_{\mathrm{i}, \mathrm{y}}{ }^{*} \mathrm{COEF}_{\mathrm{i}}\right] /\left[\sum_{\mathrm{m}}\right. \\
\left.\mathrm{GEN}_{\mathrm{m}, \mathrm{y}}\right] \text { sobre as } \\
\text { usinas construídas } \\
\text { recentemente } \\
\text { conforme definido na } \\
\text { metodologia de linha } \\
\text { de base. }\end{array}$ \\
\hline
\end{tabular}




\begin{tabular}{|c|c|c|c|c|c|c|c|c|c|c|}
\hline $\begin{array}{l}\text { Número de } \\
\text { identificação }\end{array}$ & $\begin{array}{c}\text { Tipo } \\
\text { dos dados }\end{array}$ & $\begin{array}{c}\text { Variável } \\
\text { dos dados }\end{array}$ & $\begin{array}{c}\text { Unidade } \\
\text { dos } \\
\text { dados }\end{array}$ & $\begin{array}{l}\text { Medidos } \\
\text { (m), } \\
\text { calculados } \\
\text { (c) ou } \\
\text { estimados } \\
\text { (e) }\end{array}$ & \begin{tabular}{|c|} 
Para qual \\
método da \\
linha de \\
base este \\
elemento \\
precisa ser \\
incluído \\
\end{tabular} & \begin{tabular}{|l|} 
Freqüência \\
do registro
\end{tabular} & $\begin{array}{c}\text { Parcela } \\
\text { dos dados } \\
\text { a ser } \\
\text { monito- } \\
\text { rada }\end{array}$ & $\begin{array}{c}\text { Como os } \\
\text { dados serão } \\
\text { arquivados? } \\
\text { (eletronica- } \\
\text { mente/em } \\
\text { papel) }\end{array}$ & \begin{tabular}{|} 
Por quanto \\
tempo os \\
dados \\
arquivados \\
serão \\
mantidos?
\end{tabular} & Comentários \\
\hline 5. $\mathrm{F}_{\mathrm{i}, \mathrm{y}}$ & $\begin{array}{l}\text { Quantidade } \\
\text { de } \\
\text { combustível }\end{array}$ & $\begin{array}{c}\text { Quantidade } \\
\text { de cada } \\
\text { combustível } \\
\text { fóssil } \\
\text { consumido } \\
\text { por cada } \\
\text { fonte/usina } \\
\text { de energia }\end{array}$ & $\begin{array}{c}\text { Massa } \\
\text { ou } \\
\text { volume }\end{array}$ & $\mathrm{m}$ & \begin{tabular}{|c|} 
OM \\
simples, \\
OM \\
simples \\
ajustada, \\
OM dos \\
dados de \\
despacho, \\
OM média, \\
BM
\end{tabular} & Anual & $100 \%$ & $\begin{array}{l}\text { Eletronica- } \\
\text { mente }\end{array}$ & \begin{tabular}{|} 
Durante o \\
período de \\
obtenção de \\
créditos e \\
nos dois \\
anos \\
seguintes
\end{tabular} & $\begin{array}{l}\text { Obtida dos produtores } \\
\text { de energia, centros de } \\
\text { despacho ou } \\
\text { estatísticas locais mais } \\
\text { recentes. }\end{array}$ \\
\hline 6. $\mathrm{COEF}_{\mathrm{i}}$ & $\begin{array}{l}\text { Coeficiente } \\
\text { do fator de } \\
\text { emissão }\end{array}$ & $\begin{array}{c}\text { Coeficiente } \\
\text { da emissão } \\
\text { de } \mathrm{CO}_{2} \text { de } \\
\text { cada tipo de } \\
\text { combustível i }\end{array}$ & $\left|\begin{array}{c}\mathrm{tCO}_{2} / \\
\text { unidade } \\
\text { de massa } \\
\text { ou } \\
\text { volume }\end{array}\right|$ & $\mathrm{m}$ & \begin{tabular}{|c|} 
OM \\
simples, \\
OM \\
simples \\
ajustada, \\
OM dos \\
dados de \\
despacho, \\
OM média, \\
BM
\end{tabular} & Anual & $100 \%$ & $\begin{array}{l}\text { Eletronica- } \\
\text { mente }\end{array}$ & \begin{tabular}{|} 
Durante o \\
período de \\
obtenção de \\
créditos e \\
nos dois \\
anos \\
seguintes
\end{tabular} & $\begin{array}{l}\text { Valores específicos da } \\
\text { usina ou do país para } \\
\text { calcular o COEF são } \\
\text { preferíveis aos valores } \\
\text { padrão do IPCC. }\end{array}$ \\
\hline
\end{tabular}


Escopo setorial: 1

19 de maio de 2006

\begin{tabular}{|c|c|c|c|c|c|c|c|c|c|c|}
\hline $\begin{array}{l}\text { Número de } \\
\text { identificação }\end{array}$ & $\begin{array}{c}\text { Tipo } \\
\text { dos dados }\end{array}$ & $\begin{array}{c}\text { Variável } \\
\text { dos dados }\end{array}$ & $\begin{array}{c}\text { Unidade } \\
\text { dos } \\
\text { dados }\end{array}$ & $\begin{array}{l}\text { Medidos } \\
\text { (m), } \\
\text { calculados } \\
\text { (c) ou } \\
\text { estimados } \\
\text { (e) }\end{array}$ & \begin{tabular}{|c|} 
Para qual \\
método da \\
linha de \\
base este \\
elemento \\
precisa ser \\
incluído \\
\end{tabular} & $\begin{array}{l}\text { Freqüência } \\
\text { do registro }\end{array}$ & \begin{tabular}{|} 
Parcela \\
dos dados \\
a ser \\
monito- \\
rada
\end{tabular} & $\begin{array}{c}\text { Como os } \\
\text { dados serão } \\
\text { arquivados? } \\
\text { (eletronica- } \\
\text { mente/em } \\
\text { papel) }\end{array}$ & $\begin{array}{l}\text { Por quanto } \\
\text { tempo os } \\
\text { dados } \\
\text { arquivados } \\
\text { serão } \\
\text { mantidos? }\end{array}$ & Comentários \\
\hline 7. $\mathrm{GEN}_{\mathrm{j} / \mathrm{k} / \mathrm{n}, \mathrm{y}}$ & $\begin{array}{l}\text { Quantidade } \\
\text { de } \\
\text { eletricidade }\end{array}$ & $\begin{array}{c}\text { Geração de } \\
\text { eletricidade } \\
\text { de cada fonte } \\
\text { de energia/ } \\
\text { usina j, k ou } \\
n\end{array}$ & $\mathrm{MWh} / \mathrm{a}$ & $\mathrm{m}$ & $\begin{array}{c}\text { OM } \\
\text { simples, } \\
\text { OM } \\
\text { simples } \\
\text { ajustada, } \\
\text { OM dos } \\
\text { dados de } \\
\text { despacho, } \\
\text { OM média, } \\
\text { BM }\end{array}$ & Anual & $100 \%$ & $\begin{array}{l}\text { Eletronica- } \\
\text { mente }\end{array}$ & $\begin{array}{c}\text { Durante o } \\
\text { período de } \\
\text { obtenção de } \\
\text { créditos e } \\
\text { nos dois } \\
\text { anos } \\
\text { seguintes }\end{array}$ & $\begin{array}{l}\text { Obtida dos produtores } \\
\text { de energia, centros de } \\
\text { despacho ou } \\
\text { estatísticas locais mais } \\
\text { recentes. }\end{array}$ \\
\hline 8. & Área & \begin{tabular}{|c|} 
Área da \\
superfície no \\
nível \\
máximo de \\
capacidade \\
do \\
reservatório
\end{tabular} & $\mathrm{m}^{2}$ & $\mathrm{~m}$ & $\begin{array}{l}\text { Para novos } \\
\text { projetos } \\
\text { hidrelé- } \\
\text { tricos }\end{array}$ & $\begin{array}{l}\text { No início } \\
\text { do projeto }\end{array}$ & $100 \%$ & $\begin{array}{c}\text { Eletronica- } \\
\text { mente }\end{array}$ & $\begin{array}{l}\text { Durante o } \\
\text { período de } \\
\text { obtenção de } \\
\text { créditos }\end{array}$ & \\
\hline
\end{tabular}




\begin{tabular}{|c|c|c|c|c|c|c|c|c|c|c|}
\hline $\begin{array}{l}\text { Número de } \\
\text { identificação }\end{array}$ & $\begin{array}{c}\text { Tipo } \\
\text { dos dados }\end{array}$ & $\begin{array}{c}\text { Variável } \\
\text { dos dados }\end{array}$ & $\begin{array}{c}\text { Unidade } \\
\text { dos } \\
\text { dados }\end{array}$ & $\begin{array}{l}\text { Medidos } \\
\text { (m), } \\
\text { calculados } \\
\text { (c) ou } \\
\text { estimados } \\
\text { (e) }\end{array}$ & \begin{tabular}{|c|} 
Para qual \\
método da \\
linha de \\
base este \\
elemento \\
precisa ser \\
incluído \\
\end{tabular} & $\begin{array}{l}\text { Freqüência } \\
\text { do registro }\end{array}$ & $\begin{array}{c}\text { Parcela } \\
\text { dos dados } \\
\text { a ser } \\
\text { monito- } \\
\text { rada }\end{array}$ & $\begin{array}{c}\text { Como os } \\
\text { dados serão } \\
\text { arquivados? } \\
\text { (eletronica- } \\
\text { mente/em } \\
\text { papel) }\end{array}$ & \begin{tabular}{|} 
Por quanto \\
tempo os \\
dados \\
arquivados \\
serão \\
mantidos?
\end{tabular} & Comentários \\
\hline 9 & $\begin{array}{l}\text { Nome da } \\
\text { usina }\end{array}$ & \begin{tabular}{|} 
Identificação \\
da fonte de \\
energia/ \\
usina para a \\
OM
\end{tabular} & Texto & $\mathrm{e}$ & $\begin{array}{c}\text { OM } \\
\text { simples, } \\
\text { OM } \\
\text { simples } \\
\text { ajustada, } \\
\text { OM dos } \\
\text { dados de } \\
\text { despacho, } \\
\text { OM média }\end{array}$ & Anual & $\mid \begin{array}{c}100 \% \text { do } \\
\text { conjunto de } \\
\text { usinas }\end{array}$ & $\begin{array}{c}\text { Eletronica- } \\
\text { mente }\end{array}$ & $\begin{array}{c}\text { Durante o } \\
\text { período de } \\
\text { obtenção de } \\
\text { créditos e } \\
\text { nos dois } \\
\text { anos } \\
\text { seguintes }\end{array}$ & $\begin{array}{l}\text { Identificação das } \\
\text { usinas (j, k, ou n) para } \\
\text { calcular os fatores de } \\
\text { emissão da margem } \\
\text { operacional. }\end{array}$ \\
\hline 10 & $\begin{array}{l}\text { Nome da } \\
\text { usina }\end{array}$ & \begin{tabular}{|} 
Identificação \\
da fonte de \\
energia/ \\
usina para a \\
BM
\end{tabular} & Texto & e & $\mathrm{BM}$ & Anual & $\mid \begin{array}{c}100 \% \text { do } \\
\text { conjunto de } \\
\text { usinas }\end{array}$ & $\begin{array}{c}\text { Eletronica- } \\
\text { mente }\end{array}$ & $\begin{array}{c}\text { Durante o } \\
\text { período de } \\
\text { obtenção de } \\
\text { créditos e } \\
\text { nos dois } \\
\text { anos } \\
\text { seguintes }\end{array}$ & $\begin{array}{l}\text { Identificação das } \\
\text { usinas (m) para } \\
\text { calcular os fatores de } \\
\text { emissão da margem de } \\
\text { construção. }\end{array}$ \\
\hline
\end{tabular}




\begin{tabular}{|c|c|c|c|c|c|c|c|c|c|c|}
\hline $\begin{array}{l}\text { Número de } \\
\text { identificação }\end{array}$ & $\begin{array}{c}\text { Tipo } \\
\text { dos dados }\end{array}$ & $\begin{array}{l}\text { Variável } \\
\text { dos dados }\end{array}$ & $\begin{array}{c}\text { Unidade } \\
\text { dos } \\
\text { dados }\end{array}$ & $\begin{array}{l}\text { Medidos } \\
\text { (m), } \\
\text { calculados } \\
\text { (c) ou } \\
\text { estimados } \\
\text { (e) }\end{array}$ & \begin{tabular}{|c|} 
Para qual \\
método da \\
linha de \\
base este \\
elemento \\
precisa ser \\
incluído \\
\end{tabular} & $\begin{array}{l}\text { Freqüência } \\
\text { do registro }\end{array}$ & $\begin{array}{l}\text { Parcela } \\
\text { dos dados } \\
\text { a ser } \\
\text { monito- } \\
\text { rada }\end{array}$ & $\begin{array}{c}\text { Como os } \\
\text { dados serão } \\
\text { arquivados? } \\
\text { (eletronica- } \\
\text { mente/em } \\
\text { papel) }\end{array}$ & \begin{tabular}{|} 
Por quanto \\
tempo os \\
dados \\
arquivados \\
serão \\
mantidos?
\end{tabular} & Comentários \\
\hline 11. $\lambda_{\mathrm{y}}$ & Parâmetro & \begin{tabular}{|c} 
Fração de \\
tempo \\
durante a \\
qual as fontes \\
de baixo \\
custo/ \\
operação \\
obrigatória \\
ficam na \\
margem
\end{tabular} & Número & $\mathrm{c}$ & $\begin{array}{c}\text { OM } \\
\text { simples } \\
\text { ajustada }\end{array}$ & Anual & $100 \%$ & $\begin{array}{c}\text { Eletronica- } \\
\text { mente }\end{array}$ & $\begin{array}{l}\text { Durante o } \\
\text { período de } \\
\text { obtenção de } \\
\text { créditos e } \\
\text { nos dois } \\
\text { anos } \\
\text { seguintes }\end{array}$ & $\begin{array}{l}\text { Fator que contabilize } \\
\text { o número de horas por } \\
\text { ano durante as quais } \\
\text { as fontes de baixo } \\
\text { custo/operação } \\
\text { obrigatória ficam na } \\
\text { margem. }\end{array}$ \\
\hline 12. & $\begin{array}{l}\text { Ordem de } \\
\text { mérito }\end{array}$ & $\mid \begin{array}{c}\text { A ordem de } \\
\text { mérito em } \\
\text { que as usinas } \\
\text { são } \\
\text { despachadas, } \\
\text { segundo } \\
\text { evidência } \\
\text { documentada }\end{array}$ & Texto & $\mathrm{m}$ & $\begin{array}{l}\text { OM dos } \\
\text { dados de } \\
\text { despacho }\end{array}$ & Anual & $100 \%$ & $\begin{array}{c}\text { Em papel, os } \\
\text { documentos } \\
\text { originais; o } \\
\text { restante, } \\
\text { eletronica- } \\
\text { mente }\end{array}$ & $\begin{array}{l}\text { Durante o } \\
\text { período de } \\
\text { obtenção de } \\
\text { créditos e } \\
\text { nos dois } \\
\text { anos } \\
\text { seguintes }\end{array}$ & $\begin{array}{l}\text { Necessária para } \\
\text { empilhar as usinas na } \\
\text { análise dos dados de } \\
\text { despacho. }\end{array}$ \\
\hline
\end{tabular}




\begin{tabular}{|c|c|c|c|c|c|c|c|c|c|c|}
\hline $\begin{array}{l}\text { Número de } \\
\text { identificação }\end{array}$ & $\begin{array}{c}\text { Tipo } \\
\text { dos dados }\end{array}$ & $\begin{array}{c}\text { Variável } \\
\text { dos dados }\end{array}$ & $\begin{array}{c}\text { Unidade } \\
\text { dos } \\
\text { dados }\end{array}$ & $\begin{array}{l}\text { Medidos } \\
\text { (m), } \\
\text { calculados } \\
\text { (c) ou } \\
\text { estimados } \\
\text { (e) }\end{array}$ & \begin{tabular}{|c|} 
Para qual \\
método da \\
linha de \\
base este \\
elemento \\
precisa ser \\
incluído \\
\end{tabular} & $\begin{array}{l}\text { Freqüência } \\
\text { do registro }\end{array}$ & \begin{tabular}{|c|} 
Parcela \\
dos dados \\
a ser \\
monito- \\
rada
\end{tabular} & $\begin{array}{c}\text { Como os } \\
\text { dados serão } \\
\text { arquivados? } \\
\text { (eletronica- } \\
\text { mente/em } \\
\text { papel) }\end{array}$ & $\begin{array}{l}\text { Por quanto } \\
\text { tempo os } \\
\text { dados } \\
\text { arquivados } \\
\text { serão } \\
\text { mantidos? }\end{array}$ & Comentários \\
\hline $\begin{array}{c}12^{\mathrm{a}} \cdot \mathrm{GEN}_{j / k / l, y} \\
\text { IMPORTS }\end{array}$ & $\begin{array}{l}\text { Quantidade } \\
\text { de } \\
\text { eletricidade }\end{array}$ & \begin{tabular}{|} 
Importações \\
de \\
eletricidade \\
para o \\
sistema de \\
eletricidade \\
do projeto
\end{tabular} & $\mathrm{kWh}$ & $\mathrm{c}$ & $\begin{array}{c}\text { OM } \\
\text { simples, } \\
\text { OM } \\
\text { simples } \\
\text { ajustada, } \\
\text { OM dos } \\
\text { dados de } \\
\text { despacho, } \\
\text { OM média, } \\
\text { BM }\end{array}$ & Anual & $100 \%$ & $\begin{array}{c}\text { Eletronica- } \\
\text { mente }\end{array}$ & $\begin{array}{l}\text { Durante o } \\
\text { período de } \\
\text { obtenção de } \\
\text { créditos e } \\
\text { nos dois } \\
\text { anos } \\
\text { seguintes }\end{array}$ & $\begin{array}{l}\text { Obtida das estatísticas } \\
\text { locais mais recentes. } \\
\text { Se não houver } \\
\text { estatísticas locais, as } \\
\text { estatísticas da AIE } \\
\text { serão usadas para } \\
\text { determinar as } \\
\text { importações. }\end{array}$ \\
\hline $\begin{array}{c}\text { 12b. } \mathrm{COEF}_{i, j} \\
\text { y IMPORTS }\end{array}$ & $\begin{array}{l}\text { Coeficiente } \\
\text { do fator de } \\
\text { emissão }\end{array}$ & $\begin{array}{c}\text { Coeficiente } \\
\text { de emissão } \\
\text { de } \mathrm{CO}_{2} \text { dos } \\
\text { combustíveis } \\
\text { usados nos } \\
\text { sistemas de } \\
\text { eletricidade } \\
\text { conectados } \\
\text { (se ocorrer } \\
\text { importação) }\end{array}$ & $\mid \begin{array}{c}\mathrm{tCO}_{2} / \\
\text { unidade } \\
\text { de massa } \\
\text { ou } \\
\text { volume }\end{array}$ & $\mathrm{c}$ & $\begin{array}{c}\text { OM } \\
\text { simples, } \\
\text { OM } \\
\text { simples } \\
\text { ajustada, } \\
\text { OM dos } \\
\text { dados de } \\
\text { despacho, } \\
\text { OM média, } \\
\text { BM }\end{array}$ & Anual & $100 \%$ & $\begin{array}{c}\text { Eletronica- } \\
\text { mente }\end{array}$ & $\begin{array}{l}\text { Durante o } \\
\text { período de } \\
\text { obtenção de } \\
\text { créditos e } \\
\text { nos dois } \\
\text { anos } \\
\text { seguintes }\end{array}$ & $\begin{array}{l}\text { Obtido das estatísticas } \\
\text { locais mais recentes. } \\
\text { Se não houver } \\
\text { estatísticas locais, os } \\
\text { valores padrão do } \\
\text { IPCC serão utilizados } \\
\text { para calcular. }\end{array}$ \\
\hline
\end{tabular}




\section{Emissões do projeto (para projetos de energia geotérmica)}

\begin{tabular}{|c|c|c|c|c|c|c|c|c|c|}
\hline $\begin{array}{c}\text { Número de } \\
\text { identificação }\end{array}$ & $\begin{array}{c}\text { Tipo } \\
\text { dos dados }\end{array}$ & $\begin{array}{l}\text { Variável } \\
\text { dos dados }\end{array}$ & $\begin{array}{c}\text { Unidade } \\
\text { dos } \\
\text { dados }\end{array}$ & $\begin{array}{c}\text { Medidos } \\
\text { (m), } \\
\text { calculados } \\
\text { (c) ou } \\
\text { estimad } \\
\text { os } \\
\text { (e) } \\
\end{array}$ & $\begin{array}{c}\text { Freqüência } \\
\text { do registro }\end{array}$ & $\begin{array}{c}\text { Parcela } \\
\text { dos dados } \\
\text { a ser } \\
\text { monitorad } \\
\text { a }\end{array}$ & $\begin{array}{c}\text { Como os dados } \\
\text { serão arquivados? } \\
\text { (eletronicamente/ } \\
\text { em papel) }\end{array}$ & $\begin{array}{l}\text { Por quanto } \\
\text { tempo os } \\
\text { dados } \\
\text { arquivados } \\
\text { serão } \\
\text { mantidos? }\end{array}$ & Comentários \\
\hline 13. $\mathrm{M}_{\mathrm{S}, \mathrm{y}}$ & $\begin{array}{l}\text { Quantidade } \\
\text { de massa }\end{array}$ & $\begin{array}{l}\text { Quantidade } \\
\text { de vapor } \\
\text { produzida } \\
\text { durante o } \\
\text { ano y }\end{array}$ & $\mathrm{t}$ & $\mathrm{m}$ & Diária & $100 \%$ & Eletronicamente & \begin{tabular}{|} 
Durante o \\
período de \\
obtenção de \\
créditos e \\
nos dois \\
anos \\
seguintes \\
\end{tabular} & Ver observação 1. \\
\hline 14. $\mathrm{W}_{\text {Main, }, \mathrm{CO} 2}$ & $\begin{array}{l}\text { Fração de } \\
\text { massa }\end{array}$ & $\begin{array}{c}\text { Fração de } \\
\mathrm{CO}_{2} \text { no } \\
\text { vapor } \\
\text { produzido }\end{array}$ & $\begin{array}{l}\mathrm{tCO}_{2} / \mathrm{t} \\
\text { vapor }\end{array}$ & $\mathrm{m}$ & $\begin{array}{c}\text { A cada } \\
\text { quatro meses }\end{array}$ & $100 \%$ & Eletronicamente & $\begin{array}{c}\text { Durante o } \\
\text { período de } \\
\text { obtenção de } \\
\text { créditos e } \\
\text { nos dois } \\
\text { anos } \\
\text { seguintes } \\
\end{array}$ & Ver observação 2. \\
\hline 15. WMain,CH4 & $\begin{array}{c}\text { Fração de } \\
\text { massa }\end{array}$ & $\begin{array}{l}\text { Fração de } \\
\mathrm{CH}_{4} \text { no } \\
\text { vapor } \\
\text { produzido }\end{array}$ & $\begin{array}{l}\mathrm{tCH}_{4} / \mathrm{t} \\
\text { vapor }\end{array}$ & $\mathrm{m}$ & $\begin{array}{c}\text { A cada } \\
\text { quatro meses }\end{array}$ & $100 \%$ & Eletronicamente & \begin{tabular}{|} 
Durante o \\
período de \\
obtenção de \\
créditos e \\
nos dois \\
anos
\end{tabular} & Ver observação 2. \\
\hline
\end{tabular}




\begin{tabular}{|c|c|c|c|c|c|c|c|c|c|}
\hline $\begin{array}{l}\text { Número de } \\
\text { identificação }\end{array}$ & $\begin{array}{c}\text { Tipo } \\
\text { dos dados }\end{array}$ & $\begin{array}{l}\text { Variável } \\
\text { dos dados }\end{array}$ & \begin{tabular}{|c|} 
Unidade \\
dos \\
dados
\end{tabular} & $\begin{array}{c}\text { Medidos } \\
\text { (m), } \\
\text { calculados } \\
\text { (c) ou } \\
\text { estimad } \\
\text { os } \\
\text { (e) }\end{array}$ & $\begin{array}{l}\text { Freqüência } \\
\text { do registro }\end{array}$ & \begin{tabular}{|c|} 
Parcela \\
dos dados \\
a ser \\
monitorad \\
a
\end{tabular} & \begin{tabular}{|c|} 
Como os dados \\
serão arquivados? \\
(eletronicamente/ \\
em papel)
\end{tabular} & $\begin{array}{l}\text { Por quanto } \\
\text { tempo os } \\
\text { dados } \\
\text { arquivados } \\
\text { serão } \\
\text { mantidos? }\end{array}$ & Comentários \\
\hline & & & & & & & & seguintes & \\
\hline 16. $\mathrm{M}_{\mathrm{t}, \mathrm{y}}$ & $\begin{array}{c}\text { Quantidade } \\
\text { de massa }\end{array}$ & $\begin{array}{c}\text { Quantidade } \\
\text { de vapor } \\
\text { gerada } \\
\text { durante o } \\
\text { teste do } \\
\text { poço }\end{array}$ & $\mathrm{t}$ & $\mathrm{m}$ & Diária & $100 \%$ & Eletronicamente & $\begin{array}{c}\text { Durante o } \\
\text { período de } \\
\text { obtenção de } \\
\text { créditos e } \\
\text { nos dois } \\
\text { anos } \\
\text { seguintes }\end{array}$ & Ver observação 1. \\
\hline 17. $\mathrm{W}_{\mathrm{t}, \mathrm{CO} 2}$ & $\begin{array}{l}\text { Fração de } \\
\text { massa }\end{array}$ & $\begin{array}{c}\text { Fração de } \\
\mathrm{CO}_{2} \text { no } \\
\text { vapor } \\
\text { durante o } \\
\text { teste do } \\
\text { poço }\end{array}$ & $\begin{array}{l}\mathrm{tCO}_{2} / \mathrm{t} \\
\text { vapor }\end{array}$ & $\mathrm{m}$ & $\begin{array}{l}\text { Conforme } \\
\text { necessário }\end{array}$ & $100 \%$ & Eletronicamente & $\begin{array}{c}\text { Durante o } \\
\text { período de } \\
\text { obtenção de } \\
\text { créditos e } \\
\text { nos dois } \\
\text { anos } \\
\text { seguintes }\end{array}$ & Ver observação 2. \\
\hline 18. $\mathrm{w}_{\mathrm{t}, \mathrm{CH} 4}$ & $\begin{array}{c}\text { Fração de } \\
\text { massa }\end{array}$ & $\begin{array}{c}\text { Fração de } \\
\mathrm{CO}_{2} \text { no } \\
\text { vapor } \\
\text { durante o } \\
\text { teste do } \\
\text { poço }\end{array}$ & $\begin{array}{l}\mathrm{tCH}_{4} / \mathrm{t} \\
\text { vapor }\end{array}$ & $\mathrm{m}$ & $\begin{array}{l}\text { Conforme } \\
\text { necessário }\end{array}$ & $100 \%$ & Eletronicamente & $\begin{array}{c}\text { Durante o } \\
\text { período de } \\
\text { obtenção de } \\
\text { créditos e } \\
\text { nos dois } \\
\text { anos } \\
\text { seguintes }\end{array}$ & Ver observação 2 . \\
\hline
\end{tabular}




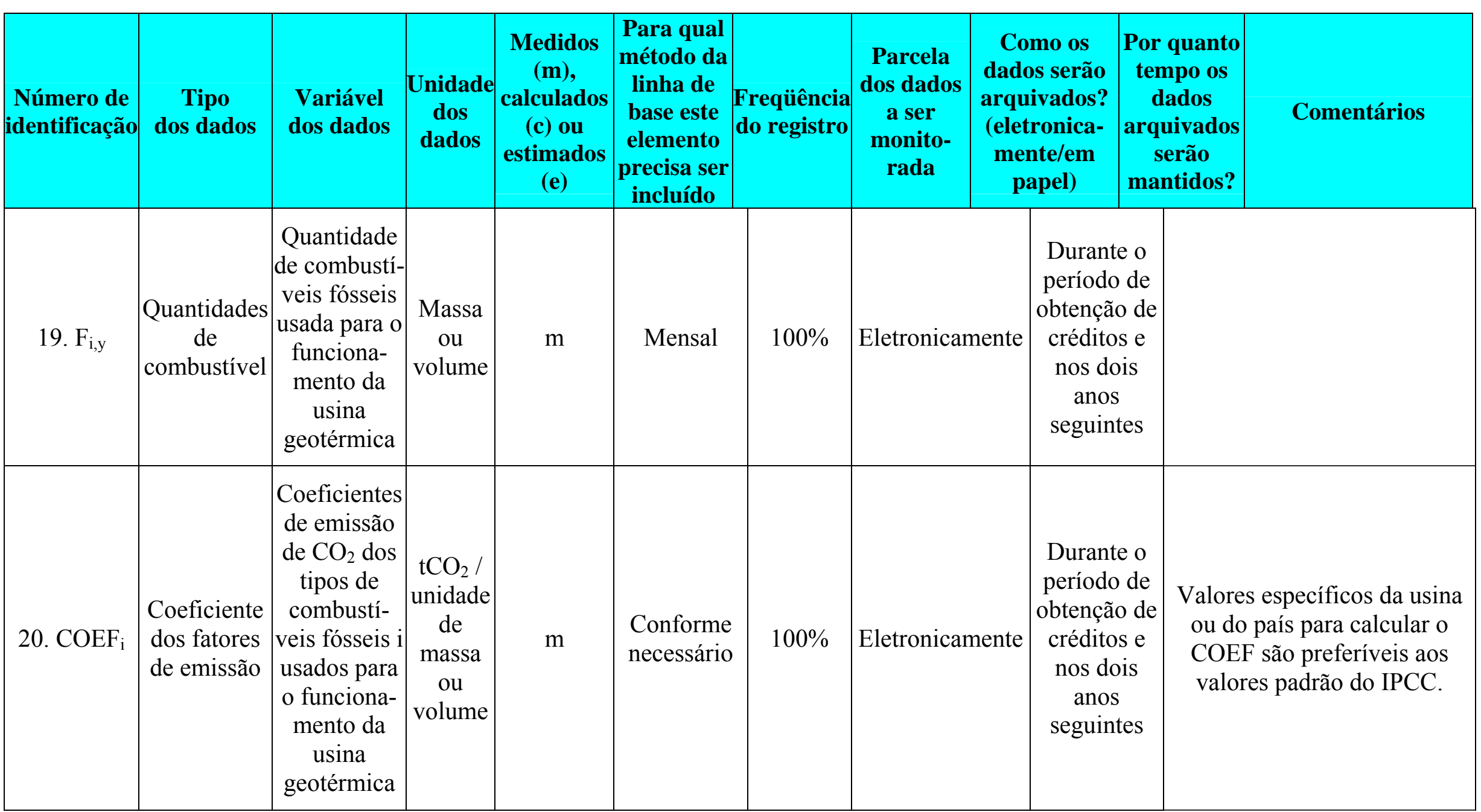




\section{Observação 1: Taxas de fluxo}

1a. Taxa de fluxo do vapor, usina

A quantidade de vapor descarregada dos poços geotérmicos deve ser medida com um medidor de Venturi (ou outro equipamento que tenha, pelo menos, a mesma precisão). É necessário medir a temperatura e a pressão dentro do medidor de Venturi para definir as propriedades do vapor. O cálculo das quantidades de vapor deve ser realizado continuamente e com base em padrões internacionais. Os resultados das medições devem ser sintetizados com transparência em relatórios periódicos de produção.

\section{Observação 2: Gases não-condensáveis no vapor geotérmico}

Em geral, os gases não-condensáveis (GNCs) nos reservatórios geotérmicos consistem principalmente em $\mathrm{CO}_{2}$ e $\mathrm{H}_{2} \mathrm{~S}$. Contêm também uma pequena quantidade de hidrocarbonetos, inclusive, predominantemente, o $\mathrm{CH}_{4}$. Nos projetos de energia geotérmica, os GNCs fluem com o vapor para dentro da usina. Uma pequena parcela de $\mathrm{CO}_{2}$ se converte em carbonato/bicarbonato no circuito da água de resfriamento. Além disso, partes dos GNCs são reinjetadas no reservatório geotérmico. Entretanto, por ser uma abordagem conservadora, esta metodologia supõe que todos os GNCs que entram na usina são descarregados na atmosfera por meio da torre de resfriamento. A amostragem dos GNCs deve ser realizada em poços de produção na interface campo de vapor-usina, com o uso da norma técnica da Sociedade Americana para Teste de Materiais ASTM E1675 - Standard Practice for Sampling Two-Phase Geothermal Fluid for Purposes of Chemical Analysis [Norma Técnica para a Amostragem de Fluido Geotérmico em Dois Níveis para Fins de Análise Química] (conforme aplicável à amostragem do vapor em apenas um nível). O procedimento de amostragem e análise de $\mathrm{CO}_{2}$ e $\mathrm{CH}_{4}$ consiste em coletar amostras de GNCs da principal linha de vapor com recipientes de vidro cheios de solução de hidróxido de sódio e outros produtos químicos, a fim de evitar a oxidação. $\mathrm{O}$ sulfeto de hidrogênio $\left(\mathrm{H}_{2} \mathrm{~S}\right)$ e o dióxido de carbono $\left(\mathrm{CO}_{2}\right)$ se dissolvem no solvente enquanto os compostos residuais permanecem na fase gasosa. A porção gasosa é, então, analisada com o uso da cromatografia gasosa para determinar o teor dos resíduos, inclusive o $\mathrm{CH}_{4}$. Todas as concentrações de alcanos são relatadas em relação ao metano. A amostragem e a análise dos GNCs devem ser realizadas pelo menos a cada três meses e com mais freqüência, se houver necessidade. 


\section{Procedimentos de Controle da Qualidade (CQ)e Garantia da Qualidade (GQ)}

Todas as variáveis, exceto uma relacionada com o transporte fora do local, usadas para calcular as emissões do projeto e da linha de base são medidas diretamente ou são dados oficiais disponíveis ao público. Para assegurar a qualidade dos dados, particularmente os que são medidos, os dados são comparados com dados comerciais. As medidas de controle da qualidade e garantia da qualidade planejadas para o projeto são descritas na tabela a seguir.

\begin{tabular}{|c|c|c|c|}
\hline Dados & $\begin{array}{c}\text { Nível de incerteza } \\
\text { dos dados } \\
\text { (Alto/Médio/Baixo) }\end{array}$ & $\begin{array}{c}\text { Procedimentos de GQ/CQ foram } \\
\text { planejados para esses dados? }\end{array}$ & $\begin{array}{c}\text { Explicação de como os procedimentos de GQ/CQ foram } \\
\text { planejados }\end{array}$ \\
\hline 1. & Baixo & Sim & $\begin{array}{l}\text { Esses dados serão usados diretamente para o cálculo das reduções } \\
\text { de emissões. O registro de vendas para a rede e outros registros } \\
\text { são usados para garantir a coerência. }\end{array}$ \\
\hline Outros & Baixo & Sim & $\begin{array}{l}\text { Dados padrão (para fatores de emissão) e estatísticas da AIE (para } \\
\text { dados de energia) são usados para checar os dados locais. }\end{array}$ \\
\hline
\end{tabular}




\section{Dados da linha de base}

Para os fatores de emissão padrão, as Diretrizes do IPCC de 1996 para Inventários de Gases de Efeito Estufa (Diretrizes Revisadas do IPPC de 1996 para Inventários Nacionais de Gases de Efeito Estufa, IPCC) e o Relatório de Orientação de Boas Práticas (Orientação de Boas Práticas e Gerenciamento de Incertezas nos Inventários Nacionais de Gases de Efeito Estufa, IPCC) devem ser consultados não apenas para obter valores padrão, mas também pela metodologia de monitoramento, assim como o gerenciamento de incertezas, para garantir a credibilidade dos dados. Esses documentos podem ser obtidos por download no endereço http://www.ipcc-nggip.iges.or.jp/. O segundo documento é uma publicação nova que complementa o primeiro.

Diretrizes de 1996

Vol. 2, Módulo 1 (Energia) para metodologia

Vol. 3, Módulo 1 (Energia) para aplicação (inclusive valores padrão)

Orientação de Boas Práticas nos Inventários de Gases de Efeito Estufa e Gerenciamento de Incertezas de 2000

Capítulo 2: Energia

Capítulo 6: Incertezas

AIE - Estatísticas Anuais

Emissões de $\mathrm{CO}_{2}$ da Queima de Combustíveis

Estatística de Energia de Países que não fazem parte da OCDE 


\section{Annex 14}

\section{Methodological tool}

\section{"Tool to determine methane emissions avoided from dumping waste at a solid waste disposal site"}

\section{SCOPE, APPLICABILITY AND PARAMETERS}

\section{Scope and applicability}

This tool calculates baseline emissions of methane from waste that would in the absence of the project activity be disposed at solid waste disposal sites (SWDS). Emission reductions are calculated with a first order decay model. The tool is applicable in cases where the solid waste disposal site where the waste would be dumped can be clearly identified. The tool is not applicable to hazardous wastes.

\section{Parameters}

This tool provides procedures to determine the following parameters:

\begin{tabular}{|l|c|l|}
\hline Parameter & SI Unit & Description \\
\hline $\mathrm{BE}_{\mathrm{CH} 4, \mathrm{SWDS}, \mathrm{y}}$ & $\mathrm{tCO}_{2} \mathrm{e}$ & $\begin{array}{l}\text { Methane emissions avoided during the year } y \text { from preventing waste } \\
\text { disposal at the solid waste disposal site during the period from the start of } \\
\text { the project activity to the end of the year y }\left(\mathrm{tCO}_{2} \mathrm{e}\right)\end{array}$ \\
\hline
\end{tabular}

\section{BASELINE METHODOLOGY PROCEDURE}

The amount of methane that would in the absence of the project activity be generated from disposal of waste at the solid waste disposal site $\left(B E_{C H 4, S W D S, y}\right)$ is calculated with a multi-phase model. The calculation is based on a first order decay (FOD) model. The model differentiates between the different types of waste $j$ with respectively different decay rates $k_{j}$ and different fractions of degradable organic carbon $\left(D O C_{j}\right)$. The model calculates the methane generation based on the actual waste streams $W_{j, x}$ disposed in each year $x$, starting with the first year after the start of the project activity until the until the end of the year $y$, for which baseline emissions are calculated (years $x$ with $\mathrm{x}=1$ to $\mathrm{x}=\mathrm{y}$ ).

In cases where at the SWDS methane is captured (e.g. due to safety regulations) and flared, combusted or used in another manner, the baseline emissions are adjusted for the fraction of methane captured at the SWDS.

The amount of methane produced in the year $y\left(B E_{C H 4, S W D S, y}\right)$ is calculated as follows:

$$
\mathrm{BE}_{\mathrm{CH} 4, \mathrm{SWDS}, \mathrm{y}}=\varphi \cdot(1-\mathrm{f}) \cdot \mathrm{GWP}_{\mathrm{CH} 4} \cdot(1-\mathrm{OX}) \cdot \frac{16}{12} \cdot \mathrm{F} \cdot \mathrm{DOC}_{\mathrm{f}} \cdot \mathrm{MCF} \cdot \sum_{\mathrm{x}=1}^{y} \sum_{\mathrm{j}} \mathrm{W}_{\mathrm{j}, \mathrm{x}} \cdot \mathrm{DOC}_{\mathrm{j}} \cdot \mathrm{e}^{-\mathrm{k}_{\mathrm{j}} \cdot(\mathrm{y}-\mathrm{x})} \cdot\left(1-\mathrm{e}^{-\mathrm{k}_{\mathrm{j}}}\right)
$$


Where:

$\mathrm{BE}_{\mathrm{CH} 4, \mathrm{SWDS}, \mathrm{y}}=$ Methane emissions avoided during the year $y$ from preventing waste disposal at the solid waste disposal site (SWDS) during the period from the start of the project activity to the end of the year y $\left(\mathrm{tCO}_{2} \mathrm{e}\right)$

$\varphi \quad=$ Model correction factor to account for model uncertainties (0.9)

$\mathrm{f}=\quad$ Fraction of methane captured at the SWDS and flared, combusted or used in another manner

$\mathrm{GWP}_{\mathrm{CH} 4}=$ Global Warming Potential (GWP) of methane, valid for the relevant commitment period

OX $=$ Oxidation factor (reflecting the amount of methane from SWDS that is oxidised in the soil or other material covering the waste)

$\mathrm{F} \quad=$ Fraction of methane in the SWDS gas (volume fraction) $(0.5)$

$\mathrm{DOC}_{\mathrm{f}} \quad=$ Fraction of degradable organic carbon (DOC) that can decompose

$\mathrm{MCF} \quad=$ Methane correction factor

$\mathrm{W}_{\mathrm{j}, \mathrm{x}} \quad=$ Amount of organic waste type $j$ prevented from disposal in the SWDS in the year $x$ (tons)

$\mathrm{DOC}_{\mathrm{j}}=$ Fraction of degradable organic carbon (by weight) in the waste type $j$

$\mathrm{k}_{\mathrm{j}} \quad=$ Decay rate for the waste type $j$

$\mathrm{j}=$ Waste type category (index)

$\mathrm{x} \quad=$ Year during the crediting period: $\mathrm{x}$ runs from the first year of the first crediting period $(\mathrm{x}=1)$ to the year $\mathrm{y}$ for which avoided emissions are calculated $(\mathrm{x}=\mathrm{y})$

$\mathrm{y} \quad=$ Year for which methane emissions are calculated

Where different waste types $j$ are prevented from disposal, determine the amount of different waste types $\left(\mathrm{W}_{\mathrm{j}, \mathrm{x}}\right)$ through sampling and calculate the mean from the samples, as follows:

$\mathrm{W}_{\mathrm{j}, \mathrm{x}}=\mathrm{W}_{\mathrm{x}} \cdot \frac{\sum_{\mathrm{n}=1}^{\mathrm{z}} \mathrm{p}_{\mathrm{n}, \mathrm{j}, \mathrm{x}}}{\mathrm{z}}$

Where:

$\mathrm{W}_{\mathrm{j}, \mathrm{x}} \quad=$ Amount of organic waste type $j$ prevented from disposal in the SWDS in the year $x$ (tons)

$\mathrm{W}_{\mathrm{x}} \quad=$ Total amount of organic waste prevented from disposal in year $x$ (tons)

$\mathrm{p}_{\mathrm{n}, \mathrm{j}, \mathrm{x}} \quad=$ Weight fraction of the waste type $j$ in the sample $n$ collected during the year $x$

$\mathrm{z} \quad=$ Number of samples collected during the year $x$

\section{Changes required for methodology implementation in $2^{\text {nd }}$ and $3^{\text {rd }}$ crediting periods}

At the renewal of the crediting period, the following data should be updated according to default values suggested in the most recently published IPCC Guidelines for National Greenhouse Gas Inventories:

- Oxidation factor $(O X)$;

- Fraction of methane in the SWDS gas $(F)$;

- Fraction of degradable organic carbon $(D O C)$ that can decompose $\left(D O C_{f}\right)$;

- Methane correction factor $(M C F)$;

- Fraction of degradable organic carbon (by weight) in each waste type $j(D O C j)$; 
- Decay rate for the waste type $j\left(k_{j}\right)$.

Respectively, if the most recent IPCC Guidelines suggest different categorization of waste types, solid waste disposal sites or climate conditions, these should be applied respectively.

\section{Data and parameters not monitored}

\begin{tabular}{|l|l|}
\hline Data / parameter: & $\boldsymbol{\varphi}$ \\
\hline Data unit: & - \\
\hline Description: & Model correction factor to account for model uncertainties \\
\hline $\begin{array}{l}\text { Value to be } \\
\text { applied: }\end{array}$ & 0.9 \\
\hline Any comment: & $\begin{array}{l}\text { Oonk et el. (1994) have validated several landfill gas models based on 17 realized } \\
\text { landfill gas projects. The mean relative error of multi-phase models was assessed to } \\
\text { be 18\%. Given the uncertainties associated with the model and in order to estimate } \\
\text { emission reductions in a conservative manner, a discount of } 10 \% \text { is applied to the } \\
\text { model results. }\end{array}$ \\
\hline
\end{tabular}

\begin{tabular}{|l|l|}
\hline Data / parameter: & OX \\
\hline Data unit: & - \\
\hline Description: & $\begin{array}{l}\text { Oxidation factor (reflecting the amount of methane from SWDS that is oxidized in } \\
\text { the soil or other material covering the waste) }\end{array}$ \\
\hline Source of data: & $\begin{array}{l}\text { Conduct a site visit at the solid waste disposal site in order to assess the type of cover } \\
\text { of the solid waste disposal site. Use the IPCC 2006 Guidelines for National } \\
\text { Greenhouse Gas Inventories for the choice of the value to be applied. }\end{array}$ \\
\hline $\begin{array}{l}\text { Value to be } \\
\text { applied: }\end{array}$ & $\begin{array}{l}\text { Use } 0.1 \text { for managed solid waste disposal sites that are covered with oxidizing } \\
\text { material such as soil or compost. Use } 0 \text { for other types of solid waste disposal sites. }\end{array}$ \\
\hline Any comment: & \\
\hline
\end{tabular}




\begin{tabular}{|l|l|}
\hline Data / parameter: & F \\
\hline Data unit: & - \\
\hline Description: & Fraction of methane in the SWDS gas (volume fraction) \\
\hline Source of data: & IPCC 2006 Guidelines for National Greenhouse Gas Inventories \\
\hline $\begin{array}{l}\text { Value to be } \\
\text { applied: }\end{array}$ & 0.5 \\
\hline Any comment: & $\begin{array}{l}\text { This factor reflects the fact that some degradable organic carbon does not degrade, or } \\
\text { degrades very slowly, under anaerobic conditions in the SWDS. A default value of } \\
0.5 \text { is recommended by IPCC. }\end{array}$ \\
\hline
\end{tabular}

\begin{tabular}{|l|l|}
\hline Data / parameter: & $\mathbf{D O C}$ \\
\hline Data unit: & - \\
\hline Description: & Fraction of degradable organic carbon (DOC) that can decompose \\
\hline Source of data: & IPCC 2006 Guidelines for National Greenhouse Gas Inventories \\
\hline $\begin{array}{l}\text { Value to be } \\
\text { applied: }\end{array}$ & 0.5 \\
\hline Any comment: & \\
\hline
\end{tabular}

\begin{tabular}{|l|l|}
\hline Data / parameter: & MCF \\
\hline Data unit: & - \\
\hline Description: & Methane correction factor \\
\hline Source of data: & IPCC 2006 Guidelines for National Greenhouse Gas Inventories \\
\hline Vapplied: & $\begin{array}{l}\text { Use the following values for MCF: } \\
\text { - } 1.0 \text { for anaerobic managed solid waste disposal sites. These must have } \\
\text { controlled placement of waste (i.e., waste directed to specific deposition areas, a } \\
\text { degree of control of scavenging and a degree of control of fires) and will include } \\
\text { at least one of the following: (i) cover material; (ii) mechanical compacting; or } \\
\text { (iii) leveling of the waste. }\end{array}$ \\
$\begin{array}{l}\text { 0.5 for semi-aerobic managed solid waste disposal sites. These must have } \\
\text { controlled placement of waste and will include all of the following structures for } \\
\text { introducing air to waste layer: (i) permeable cover material; (ii) leachate drainage } \\
\text { system; (iii) regulating pondage; and (iv) gas ventilation system. } \\
\text { 0.8 for unmanaged solid waste disposal sites - deep and/or with high water } \\
\text { table. This comprises all SWDS not meeting the criteria of managed SWDS and } \\
\text { which have depths of greater than or equal to 5 meters and/or high water table at } \\
\text { near ground level. Latter situation corresponds to filling inland water, such as } \\
\text { pond, river or wetland, by waste. } \\
\text { 0.4 for unmanaged-shallow solid waste disposal sites. This comprises all } \\
\text { SWDS not meeting the criteria of managed SWDS and which have depths of less } \\
\text { than 5 metres. }\end{array}$ \\
\hline $\begin{array}{l}\text { The methane correction factor (MCF) accounts for the fact that unmanaged SWDS } \\
\text { produce less methane from a given amount of waste than managed SWDS, because a } \\
\text { larger fraction of waste decomposes aerobically in the top layers of unmanaged }\end{array}$ \\
\hline Any comment:
\end{tabular}




\begin{tabular}{|c|c|c|c|}
\hline Data / parameter: & \multicolumn{3}{|l|}{ DOC $_{\mathrm{j}}$} \\
\hline Data unit: & \multicolumn{3}{|l|}{-} \\
\hline Description: & \multicolumn{3}{|c|}{ Fraction of degradable organic carbon (by weight) in the waste type $j$} \\
\hline Source of data: & \multicolumn{3}{|c|}{$\begin{array}{l}\text { IPCC } 2006 \text { Guidelines for National Greenhouse Gas Inventories (adapted from } \\
\text { Volume 5, Tables } 2.4 \text { and 2.5) }\end{array}$} \\
\hline \multirow{9}{*}{$\begin{array}{l}\text { Values to be } \\
\text { applied: }\end{array}$} & \multicolumn{3}{|c|}{ Apply the following values for the different waste types $j:$} \\
\hline & Waste type $j$ & $\begin{array}{c}\text { DOC }_{j} \\
(\% \text { wet waste })\end{array}$ & $\begin{array}{c}\mathrm{DOC}_{\mathrm{j}} \\
(\% \text { dry waste })\end{array}$ \\
\hline & Wood and wood products & 43 & 50 \\
\hline & Pulp, paper and cardboard (other than sludge) & 40 & 44 \\
\hline & $\begin{array}{l}\text { Food, food waste, beverages and tobacco } \\
\text { (other than sludge) }\end{array}$ & 15 & 38 \\
\hline & Textiles & 24 & 30 \\
\hline & Garden, yard and park waste & 20 & 49 \\
\hline & Glass, plastic, metal, other inert waste & 0 & 0 \\
\hline & \multicolumn{3}{|c|}{$\begin{array}{l}\text { If a waste type, prevented from disposal by the proposed CDM project activity, can } \\
\text { not clearly be attributed to one of the waste types in the table above, project } \\
\text { participants should choose among the waste types that have similar characteristics } \\
\text { that waste type where the values of } D O C_{j} \text { and } k_{j} \text { result in a conservative estimate } \\
\text { (lowest emissions), or request a revision of / deviation from this methodology. }\end{array}$} \\
\hline Any comment: & & & \\
\hline
\end{tabular}




\begin{tabular}{|c|c|c|c|c|c|c|}
\hline Data / parameter: & \multicolumn{6}{|l|}{$\mathbf{k}_{\mathbf{j}}$} \\
\hline Data unit: & \multicolumn{6}{|l|}{-} \\
\hline Description: & \multicolumn{6}{|c|}{ Decay rate for the waste type $j$} \\
\hline Source of data: & \multicolumn{6}{|c|}{$\begin{array}{l}\text { IPCC } 2006 \text { Guidelines for National Greenhouse Gas Inventories (adapted from } \\
\text { Volume 5, Table 3.3) }\end{array}$} \\
\hline \multirow{8}{*}{$\begin{array}{l}\text { Values to be } \\
\text { applied: }\end{array}$} & \multicolumn{6}{|c|}{ Apply the following default values for the different waste types $j$} \\
\hline & \multirow{2}{*}{\multicolumn{2}{|c|}{ Waste type $j$}} & \multicolumn{2}{|c|}{$\begin{array}{l}\text { Boreal and Temperate } \\
\left(\mathrm{MAT} \leq 20^{\circ} \mathrm{C}\right)\end{array}$} & \multicolumn{2}{|c|}{ Tropical $\left(\mathrm{MAT}>20^{\circ} \mathrm{C}\right)$} \\
\hline & & & $\begin{array}{c}\text { Dry } \\
(\mathrm{MAP} / \mathrm{PET} \\
<1) \\
\end{array}$ & $\begin{array}{c}\text { Wet } \\
(\mathrm{MAP} / \mathrm{PET} \\
>1)\end{array}$ & $\begin{array}{l}\text { Dry (MAP< } \\
1000 \mathrm{~mm})\end{array}$ & $\begin{array}{c}\text { Wet } \\
(\mathrm{MAP}> \\
1000 \mathrm{~mm})\end{array}$ \\
\hline & \multirow{2}{*}{ 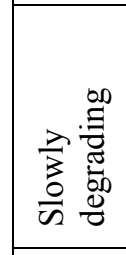 } & $\begin{array}{l}\text { Pulp, paper, } \\
\text { cardboard (other } \\
\text { than sludge), } \\
\text { textiles }\end{array}$ & 0.04 & 0.06 & 0.045 & 0.07 \\
\hline & & $\begin{array}{l}\text { Wood, wood } \\
\text { products and straw }\end{array}$ & 0.02 & 0.03 & 0.025 & 0.035 \\
\hline & 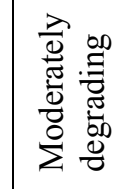 & $\begin{array}{l}\text { Other (non-food) } \\
\text { organic putrescible } \\
\text { garden and park } \\
\text { waste }\end{array}$ & 0.05 & 0.10 & 0.065 & 0.17 \\
\hline & 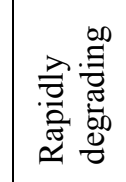 & $\begin{array}{l}\text { Food, food waste, } \\
\text { beverages and } \\
\text { tobacco } \\
\text { (other than sludge) }\end{array}$ & 0.06 & 0.185 & 0.085 & 0.40 \\
\hline & \multicolumn{6}{|c|}{$\begin{array}{l}\text { NB: MAT - mean annual temperature, MAP - Mean annual precipitation, PET - potential } \\
\text { evapotranspiration. MAP/PET is the ratio between the mean annual precipitation and the } \\
\text { potential evapotranspiration. } \\
\text { If a waste type, prevented from disposal by the proposed CDM project activity, can } \\
\text { not clearly be attributed to one of the waste types in the table above, project } \\
\text { participants should choose among the waste types that have similar characteristics } \\
\text { that waste type where the values of } D O C_{j} \text { and } k_{j} \text { result in a conservative estimate } \\
\text { (lowest emissions), or request a revision of / deviation from this methodology. }\end{array}$} \\
\hline Any comment: & \multicolumn{6}{|c|}{$\begin{array}{l}\text { Document in the CDM-PDD the climatic conditions at the SWDS site (temperature, } \\
\text { precipitation and, where applicable, evapotranspiration). Use long-term averages } \\
\text { based on statistical data, where available. Provide references. }\end{array}$} \\
\hline
\end{tabular}




\section{MONITORING METHODOLOGY PROCEDURE}

\section{Monitoring procedures}

Monitoring involves an annual assessment of the conditions at the solid waste disposal site (SWDS) where the waste would in the absence of the project activity be dumped. Methane emissions from preventing disposal of waste at the SWDS can only be claimed if there is no gas from the SWDS being captured and flared or combusted.

\section{Data and parameters monitored}

\begin{tabular}{|l|l|}
\hline Data / parameter: & f \\
\hline Data unit: & - \\
\hline Description: & $\begin{array}{l}\text { Fraction of methane captured at the SWDS and flared, combusted or used in } \\
\text { another manner }\end{array}$ \\
\hline Source of data: & $\begin{array}{l}\text { Written information from the operator of the solid waste disposal site and/or site } \\
\text { visits at the solid waste disposal site }\end{array}$ \\
\hline $\begin{array}{l}\text { Measurement } \\
\text { procedures (if any): }\end{array}$ & - \\
\hline Monitoring frequency: & Annually \\
\hline QA/QC procedures: & - \\
\hline Any comment: & \\
\hline
\end{tabular}

\begin{tabular}{|l|l|}
\hline Data / parameter: & $\mathbf{G W P}_{\mathbf{C H} 4}$ \\
\hline Data unit: & $\mathrm{tCO}_{2} \mathrm{e} / \mathrm{t} \mathrm{CH}_{4}$ \\
\hline Description: & $\begin{array}{l}\text { Global Warming Potential (GWP) of methane, valid for the relevant commitment } \\
\text { period }\end{array}$ \\
\hline Source of data: & $\begin{array}{l}\text { Decisions under UNFCCC and the Kyoto Protocol (a value of 21 is to be applied } \\
\text { for the first commitment period of the Kyoto Protocol) }\end{array}$ \\
\hline Monitoring frequency: & Annually \\
\hline Any comment: & \\
\hline
\end{tabular}

\begin{tabular}{|l|l|}
\hline Data / parameter: & $\mathbf{W}_{\mathbf{x}}$ \\
\hline Data unit: & tons \\
\hline Description: & Total amount of organic waste prevented from disposal in year $x$ (tons) \\
\hline Source of data: & Measurements by project participants \\
\hline $\begin{array}{l}\text { Measurement } \\
\text { procedures (if any): }\end{array}$ & \\
\hline Monitoring frequency: & Continuously, aggregated at least annually \\
\hline QA/QC procedures: & \\
\hline Any comment: & \\
\hline
\end{tabular}

\begin{tabular}{|l|l|}
\hline Data / parameter: & $\mathbf{p}_{\mathbf{n}, \mathbf{j}, \mathbf{x}}$ \\
\hline Data unit: & - \\
\hline Description: & Weight fraction of the waste type $j$ in the sample $n$ collected during the year $x$ \\
\hline
\end{tabular}




\begin{tabular}{|l|l|}
\hline Source of data: & Sample measurements by project participants \\
\hline $\begin{array}{l}\text { Measurement } \\
\text { procedures (if any): }\end{array}$ & $\begin{array}{l}\text { Sample the waste prevented from disposal, using the waste categories } j, \text { as } \\
\text { provided in the table for } D O C_{j} \text { and } k_{j} \text {, and weigh each waste fraction. }\end{array}$ \\
\hline Monitoring frequency: & $\begin{array}{l}\text { The size and frequency of sampling should be statistically significant with an } \\
\text { maximum uncertainty range of } 20 \% \text { at a } 95 \% \text { confidence level. As a minimum, } \\
\text { sampling should be undertaken four times per year. }\end{array}$ \\
\hline QA/QC procedures: & $\begin{array}{l}\text { This parameter only needs to be monitored if the waste prevented from disposal } \\
\text { includes several waste categories } j, \text { as categorized in the tables for } D O C_{j} \text { and } k_{j} .\end{array}$ \\
\hline Any comment:
\end{tabular}

\begin{tabular}{|l|l|}
\hline Data / parameter: & $\mathbf{Z}$ \\
\hline Data unit: & - \\
\hline Description: & Number of samples collected during the year $x$ \\
\hline Source of data: & Project participants \\
\hline Monitoring frequency: & Continuously, aggregated annually \\
\hline QA/QC procedures: & \\
\hline Any comment: & $\begin{array}{l}\text { This parameter only needs to be monitored if the waste prevented from disposal } \\
\text { includes several waste categories } j, \text { as categorized in the tables for } D O C_{j} \text { and } k_{j} .\end{array}$ \\
\hline
\end{tabular}

\section{References and any other information}

Oonk H., Weenk A., Coops O., Luning L. (1994) Validation of landfill gas formation models; EWAB 9427; NOVEM, Utrecht, The Netherlands. 


\section{APÊNDICE B - Memória de cálculo para as emissões reduzidas do aterro sanitário de Santo André pelo deslocamento do despacho}

\begin{tabular}{|c|c|c|c|c|c|c|c|c|c|c|c|c|}
\hline Analise de Emissões Reduzidas & & & & & & & & & & & & \\
\hline Potencia Instalada & 0,25 & $\mathrm{MW}$ & & & 0,5 & MW & & & 10 & MW & & \\
\hline Rendimento & $70 \%$ & & & & $70 \%$ & & & & $70 \%$ & & & \\
\hline Potencia Assegurada & $90 \%$ & & & & $90 \%$ & & & & $90 \%$ & & & \\
\hline Calculo Potencia de Geraç̃o & & & & & & & & & & & & \\
\hline Potencia Geração & 0,1575 & MW & & & 0,315 & MW & & & 6,3 & MW & & \\
\hline Energia Gerada Ano & & & & & & & & & & & & \\
\hline $\begin{array}{l}\text { Dias Ano } \\
\text { Dald Allo }\end{array}$ & 365 & d & & & 365 & d & & & 365 & d & & \\
\hline $\begin{array}{l}\text { Horas Ano } \\
\text { Hoso }\end{array}$ & 8760 & $\mathrm{~h}$ & & & 8760 & $\mathrm{~h}$ & & & 8760 & $\mathrm{~h}$ & & \\
\hline Energia Gerada & 6132 & MWh/ano & & & 6132 & MWh/ano & & & 6132 & MWh/ano & & \\
\hline Modalidades de FE & ex post & & ex ante & & ex post & & ex ante & & ex post & & ex ante & \\
\hline Fator de Emissão - SIN & 0,1043 & tCO2/MWh & 0,1985 & $\mathrm{tCO} / \mathrm{MWh}$ & 0,1043 & $\mathrm{tCO} / \mathrm{MWh}$ & 0,1985 & tCO2/MWh & 0,1043 & $\mathrm{tCO} / \mathrm{MWh}$ & 0,1985 & $\mathrm{tCO} / \mathrm{MWh}$ \\
\hline Emissões Reduzidas Ano & 101 & tCO2/ano & 192 & tCO2/ano & 201 & tCO2/ano & 383 & tCO2/ano & 4.029 & tCO2/ano & 7.668 & tCO2/ano \\
\hline Emissões Reduzidas 7 Anos & 705,12328 & 3 tCO2 & 1341,965205 & 5 tCO2 & 1410,246558 & $\mathrm{tCO} 2$ & 2683,93041 & $1 \mathrm{tCO} 2$ & 28204,93116 & $\mathrm{tCO} 2$ & 53678,6082 & tcO2 \\
\hline Emissōes Reduzidas 10 Anos & $1.007,32$ & $\mathrm{tCO} 2$ & $1.917,09$ & tCO2 & $2.014,64$ & tCO2 & $\begin{array}{c}2000,504,19 \\
3.834,19\end{array}$ & tCO2 & $40.292,76$ & tCO2 & $76.683,73$ & tCO2 \\
\hline Emissōes Reduzidas 21 Anos & 2115,3698 & 3 tCO2 & 4025,895615 & 5 tCO2 & 4230,739674 & tCO2 & 8051,79123 & 3 tCO2 & 84614,79348 & tCO2 & 161035,8246 & tCO2 \\
\hline Valor estimado por RCEs & 20 & US\$/tCO2 & & & 20 & US\$/tCO2 & & & 20 & US\$/tCO2 & & \\
\hline Receita anual & 2014,6379 & 9 US\$ & 3834,1863 & US\$ & 4029,27588 & US\$ & 7668,3726 & US\$ & 80585,5176 & US\$ & 153367,452 & US\$ \\
\hline Receita 7 Anos & $\begin{array}{l}20.102,47 \\
14.102\end{array}$ & US\$ & $\begin{array}{l}36.839,30 \\
26.30\end{array}$ & US\$ & $\begin{array}{c}40<9,204,93 \\
28.203\end{array}$ & US\$ & $53.678,61$ & US\$ & $564.098,62$ & US\$ & $\begin{array}{r}15300,452 \\
1.073 .572,16\end{array}$ & \\
\hline Receita 10 Anos & 20146,379 & US\$ & 38341,863 & US\$ & 40292,7588 & US\$ & 76683,726 & US\$ & 805855,176 & US\$ & 1533674,52 & USS \\
\hline Receita 21 Anos & $42.307,40$ & US\$ & $80.517,91$ & US\$ & $84.614,79$ & US\$ & $161.035,82$ & US\$ & 1.692.295,87 & US\$ & $3.220 .716,49$ & US\$ \\
\hline
\end{tabular}

Analise de Emissões Reduzidas

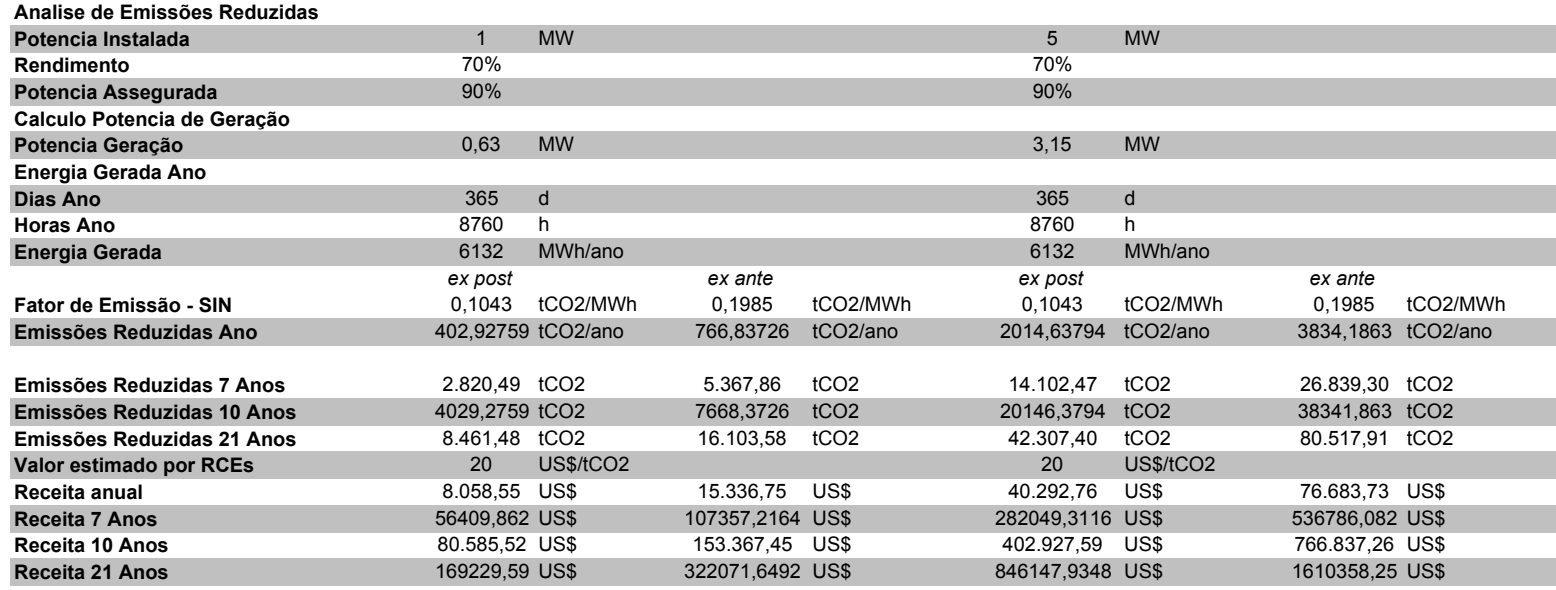

